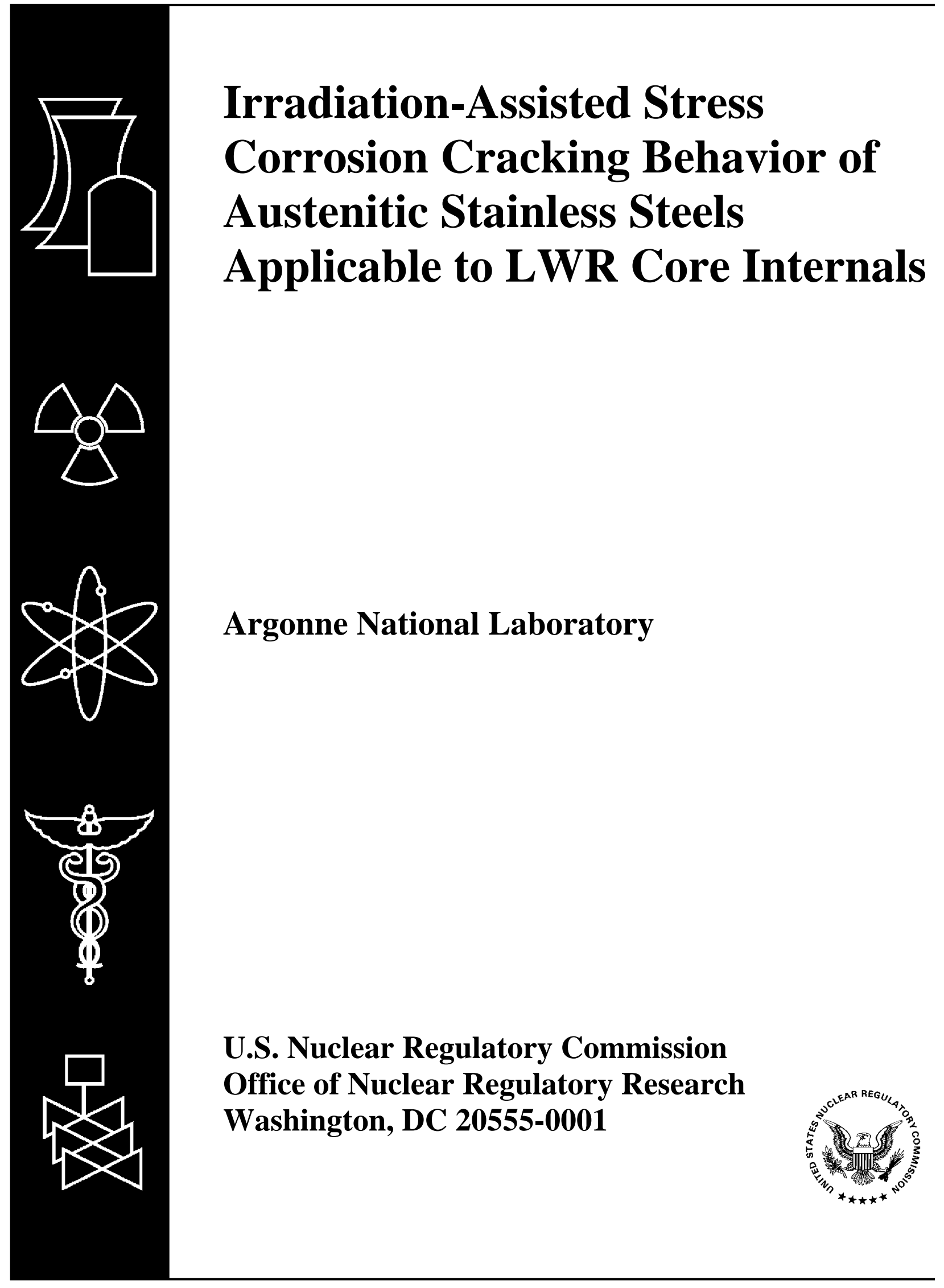




\section{Irradiation-Assisted Stress Corrosion Cracking Behavior of Austenitic Stainless Steels Applicable to LWR Core Internals}

Manuscript Completed: March 2005

Date Published: January 2006

Prepared by

H. M. Chung, W. J. Shack

Energy Technology Division

Argonne National Laboratory

9700 South Cass Avenue

Argonne, IL 60439

W. H. Cullen, Jr., NRC Project Manager

\section{Prepared for}

Division of Engineering Technology

Office of Nuclear Regulatory Research

U.S. Nuclear Regulatory Commission

Washington, DC 20555-0001

NRC Job Code Y6388

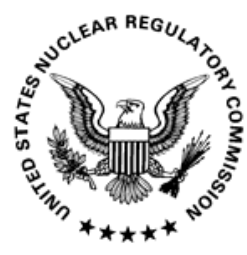


This page is intentionally blank. 


\title{
Irradiation-Assisted Stress Corrosion Cracking Behavior of Austenitic Stainless Steels Applicable to LWR Core Internals
}

\author{
by \\ H. M. Chung and W. J. Shack
}

\begin{abstract}
This report summarizes work performed at Argonne National Laboratory on irradiation-assisted stress corrosion cracking (IASCC) of austenitic stainless steels that were irradiated in the Halden reactor in simulation of irradiation-induced degradation of boiling water reactor (BWR) core internal components. Slow-strain-rate tensile tests in BWR-like oxidizing water were conducted on 27 austenitic stainless steel alloys that were irradiated at $288^{\circ} \mathrm{C}$ in helium to $0.4,1.3$, and $3.0 \mathrm{dpa}$. Fractographic analysis was conducted to determine the fracture surface morphology. Microchemical analysis by Auger electron spectroscopy was performed on BWR neutron absorber tubes to characterize grain-boundary segregation of important elements under BWR conditions. At 0.4 and $1.4 \mathrm{dpa}$, transgranular fracture was mixed with intergranular fracture. At $3 \mathrm{dpa}$, transgranular cracking was negligible, and fracture surface was either dominantly intergranular, as in field-cracked core internals, or dominantly ductile or mixed. This behavior indicates that percent intergranular stress corrosion cracking determined at $\approx 3 \mathrm{dpa}$ is a good measure of IASCC susceptibility. At $\approx 1.4 \mathrm{dpa}$, a beneficial effect of a high concentration of $\mathrm{Si}$ (0.8-1.5 wt.\%) was observed. At $\approx 3 \mathrm{dpa}$, however, such effect was obscured by a deleterious effect of S. Excellent resistance to IASCC was observed up to $\approx 3$ dpa for eight heats of Types 304,316 , and 348 steel that contain very low concentrations of S. Susceptibility of Types 304 and 316 steels that contain $>0.003$ wt. $\% \mathrm{~S}$ increased drastically. This indicates that a sulfurrelated critical phenomenon plays an important role in IASCC. A sulfur content of $<0.002 \mathrm{wt} . \%$ is the primary material factor necessary to ensure good resistance to IASCC. However, for Types 304L and 316L steel and their high-purity counterparts, a sulfur content of $<0.002 \mathrm{wt} . \%$ alone is not a sufficient condition to ensure good resistance to IASCC. This is in distinct contrast to the behavior of their high-C counterparts. At $\mathrm{S}$ concentrations $>0.002 \mathrm{wt} . \%$, the deleterious effect of $\mathrm{S}$ is so dominant that a high concentration of $\mathrm{C}$ is not an important factor. A two-dimensional map was developed in which susceptibility or resistance to IASCC is shown as a function of bulk concentrations of $\mathrm{S}$ and $\mathrm{C}$. Data reported in the literature are consistent with the map. The map is helpful to predict relative IASCC susceptibility of Types 304 and 316 steels. A similar but somewhat different map is helpful to predict IASCC behavior of Type 348 steels. Grain-boundary segregation of $\mathrm{S}$ was observed for BWR neutron absorber tubes irradiated to $\approx 3 \mathrm{dpa}$. On the basis of the results of the stress-corrosion-cracking tests and the microstructural characterization, a mechanistic IASCC model has been developed.
\end{abstract}


This page is intentionally blank. 


\section{Foreword}

This report examines the effects of simulated light-water reactor coolants, material chemistry, and irradiation damage on the susceptibility to stress corrosion cracking of a series of commercially available and laboratory-melted stainless steels. This report is one of a series dating back about 8 years, describing such results, which are required to support analysis of the structural integrity of reactor internal components, many of which are subject to irradiation-assisted stress corrosion cracking (IASCC). Earlier publications in this series include NUREG/CR-5608, "Irradiation-Assisted Stress Corrosion Cracking of Model Austenitic Stainless Steels Irradiated in the Halden Reactor"; NUREG/CR-6826, "Fracture Toughness and Crack Growth Rates of Irradiated Austenitic Stainless Steels"; and NUREG/CR-6687, "Irradiation-Assisted Stress Corrosion Cracking of Model Austenitic Stainless Steel Alloys."

This report and its sister report, which details crack growth rates in heat-affected zones adjacent to stainless steel weldments, comprise the final publications based on specimens irradiated in Phase I (of two) in the Halden test reactor. Phase I irradiations principally comprised stainless steels of wideranging chemistry (including commercial steels of typical chemistry) and conventional heat treatment and product form processing, while Phase II irradiations included a plurality of innovatively fabricated and engineered alloys designed to possibly be more resistant to IASCC. Irradiation levels in both phases ranged up to about $3 \mathrm{dpa}$, and the high-temperature water environment employed in these tests contained $200 \mathrm{ppb}$ to $8 \mathrm{ppm}$ dissolved oxygen. The materials tested included several commonly used stainless steels, such as Types 304, 316 (and their low-carbon counterparts), and 347, and several laboratory heats with the basic 300-series stainless steel materials chemistries, with additions of specific elements that were expected to have an impact on IASCC properties. Taken together, these materials and test conditions make these results most applicable to boiling-water reactor internals. Publications concerning test results from Phase II irradiations are expected in the $2006-2008$ time frame.

As in earlier reports, the deleterious effect of sulfur, which increases susceptibility to IASCC, was confirmed and further quantified. Reducing sulfur content to less than about $0.002 \mathrm{wt}$. \% provides protection against IASCC. By contrast, susceptibility increased dramatically with heats that contain $>0.003 \mathrm{wt} . \% \mathrm{~S}$. A sufficiently low concentration of sulfur is the primary material factor necessary to ensure good resistance to IASCC. However, a sulfur concentration of less than $0.002 \mathrm{wt.} \%$ alone is not a sufficient material condition to ensure resistance to IASCC. Rather, a moderately high ( $>0.03 \mathrm{wt}$. \%) level of carbon is also required in Type 304 and 316 steels. This is an important observation, given that many stainless steels (Type 304L or 316L) are decarburized to protect against thermal sensitization; too low a carbon level could render such steels susceptible to IASCC. Based on these results and related microstructural characteristics and data from electron microscopy studies, the authors have developed a model of grain boundary processes leading to IASCC. Such mechanistic understanding may shed light on the principles that might become the basis for a calculational model for use in predicting IASCC susceptibility.

Carl J. Paperiello, Director

Office of Nuclear Regulatory Research

U.S. Nuclear Regulatory Commission 
This page is intentionally blank. 


\section{Contents}

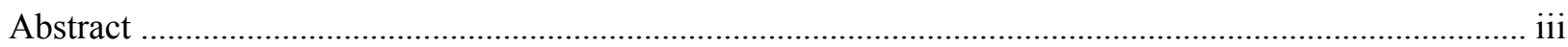

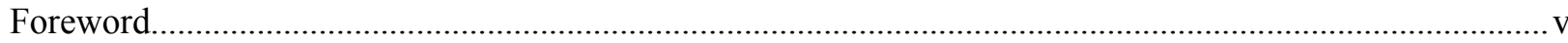

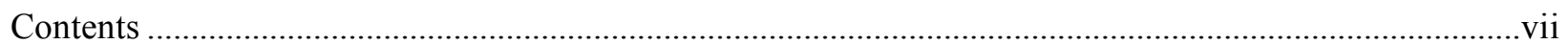

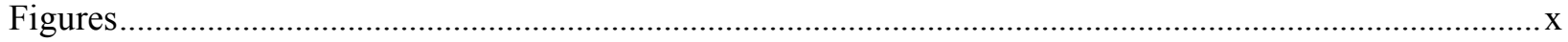

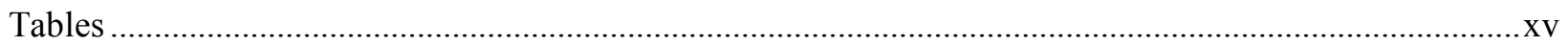

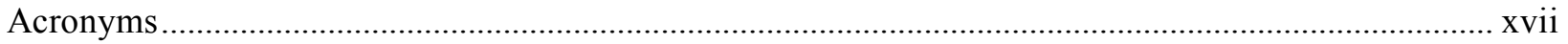

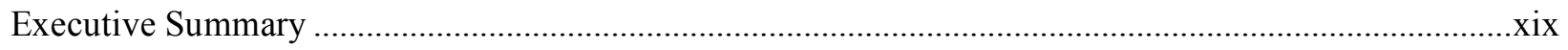

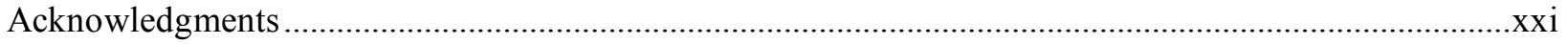

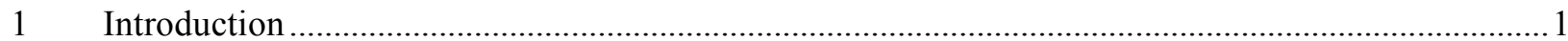

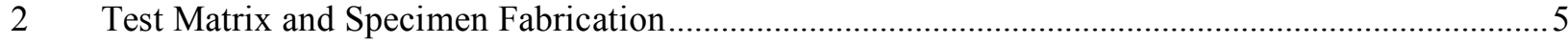

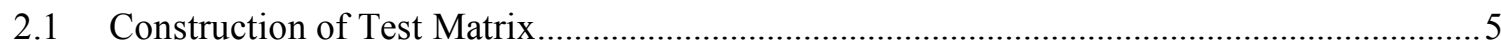

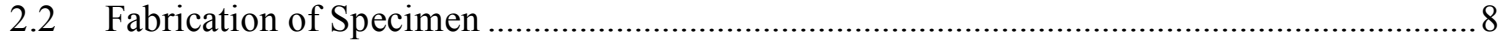

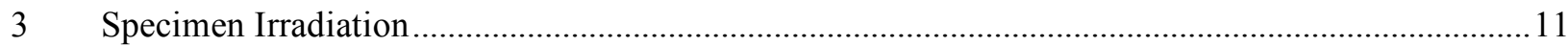

$4 \quad$ Postirradiation Testing and Posttest Characterization .................................................................... 13

$5 \quad$ SSRT SCC Test and Fractography on Unirradiated Specimens ……...........................................15

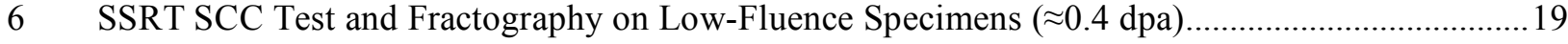

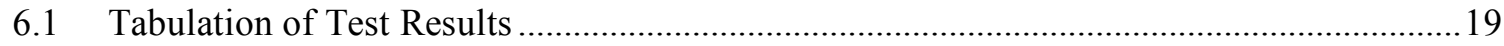

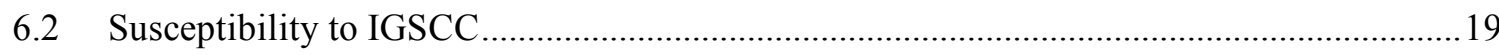

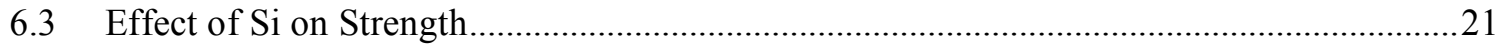

6.4 Correlation of S Content and Susceptibility to TGSCC of 304 and

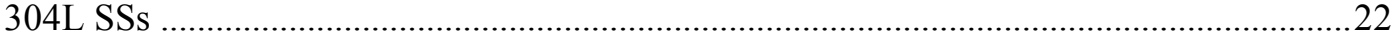

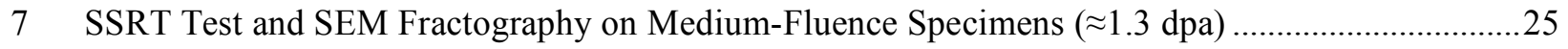




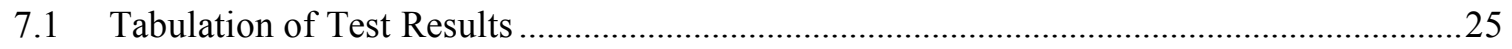

7.2 Heat-to-Heat Variations in Susceptibility to TGSCC and IGSCC ......................................25

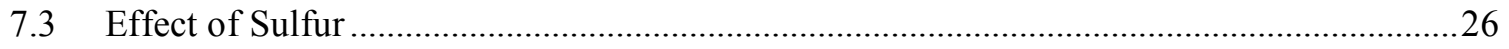

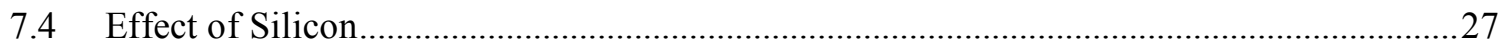

$8 \quad$ SSRT SCC Test and Fractography on High-Fluence Specimens (3.0 dpa) ........................................33

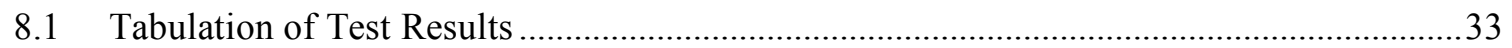

8.2 Correlation of Percent IGSCC with Elemental Composition .................................................34

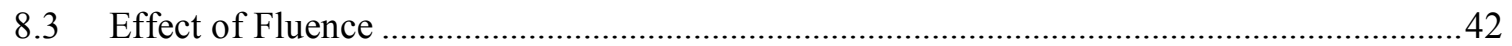

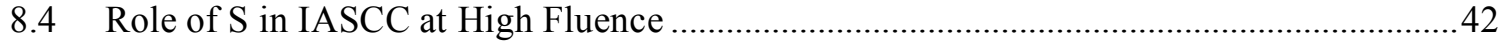

8.5 Effect of Carbon on Deleterious Role of Sulfur..................................................................4

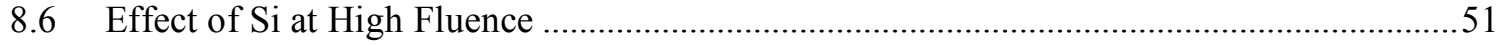

9 Representation of IASCC-Resistant or-Susceptible Behavior of 304- and 316-Type Steels in

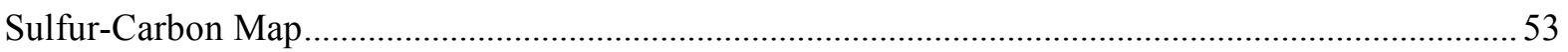

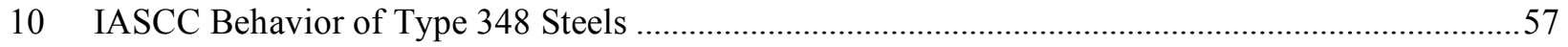

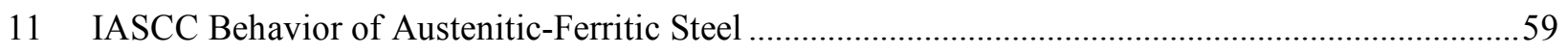

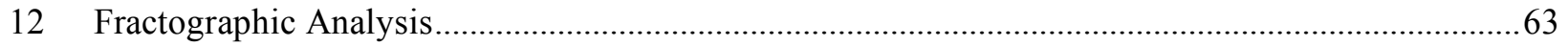

12.1 Fracture Surface Morphology of IASCC-Resistant Heats of 304, 316, and 348 Type

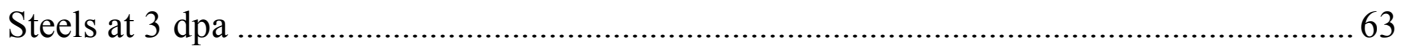

12.2 Fracture Surface Morphology of IASCC-Susceptible Heats of 304, 316, and 348 Type Steels at 3 dpa

13 Analysis of Grain-Boundary Microchemistry by Auger Electron Spectroscopy ...............................75

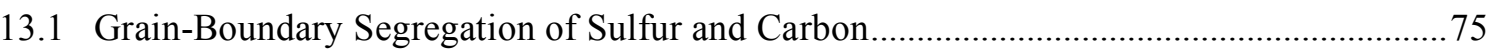

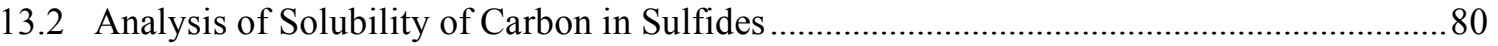

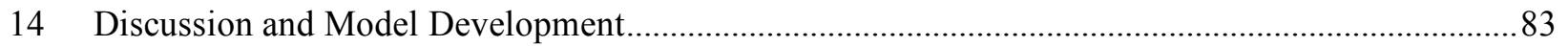

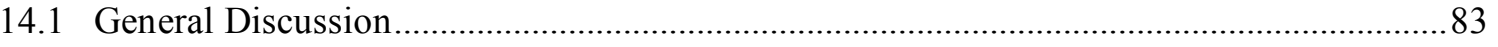




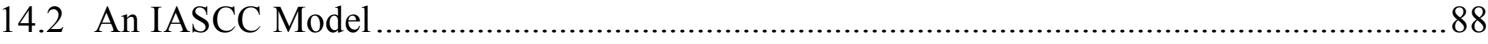

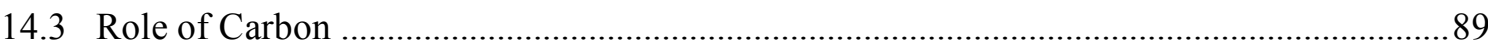

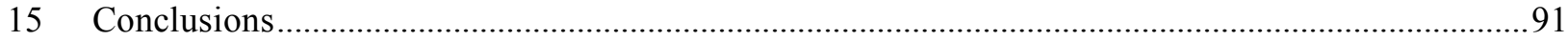

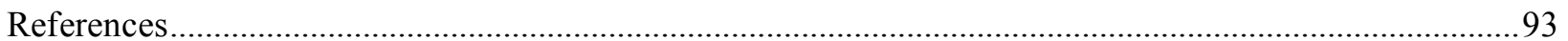




\section{Figures}

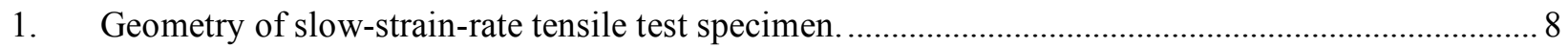

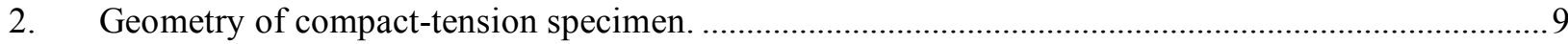

3. Yield strength of non-irradiated control specimens of model stainless steel alloys tested at $288^{\circ} \mathrm{C}$ in BWR-simulated water containing $\approx 8 \mathrm{ppm} \mathrm{DO}$.

4. Total elongation of non-irradiated control specimens of model stainless steel alloys tested at $288^{\circ} \mathrm{C}$ in BWR-simulated water containing $\approx 8 \mathrm{ppm}$ DO.

5. Load vs. elongation of non-irradiated Type 304 SS that contains unusually high concentrations of $\mathrm{O}$ and $\mathrm{S}$; tests at $289^{\circ} \mathrm{C}$ in air and $\mathrm{BWR}$-simulated water containing $\approx 8 \mathrm{ppm}$ DO.

6. Corrosion debris formed on non-ductile fracture surface of non-irradiated Type 304 SS Heat L7 that contains unusually high concentrations of $\mathrm{O}$ and S; SSRT test at $288^{\circ} \mathrm{C}$ in BWR-like water containing $\approx 8 \mathrm{ppm}$ DO.

7. Percent IGSCC of model SS alloys irradiated in He in the Halden reactor to fluence of $\approx 0.3 \times 10^{21} \mathrm{n} \cdot \mathrm{cm}^{-2}$ and tested at $289^{\circ} \mathrm{C}$ in BWR-like water.

8. Limited intergranular fracture surface surrounded by transgranular surface in 316L-like SS Heat L22 irradiated to $\approx 0.3 \times 10^{21} \mathrm{n} \cdot \mathrm{cm}^{-2}$ and tested at $289^{\circ} \mathrm{C}$ in BWR-like water.

9. Effects of Si concentration on yield and maximum strength of: unirradiated Types 304 and $304 \mathrm{~L} \mathrm{SS}$; Types 304 and 304L SS, fluence $\approx 0.3 \times 10^{21} \mathrm{n} \cdot \mathrm{cm}^{-2}$ and Type 304L SS, fluence $\approx 0.3 \times 10^{21} \mathrm{n} \cdot \mathrm{cm}^{-2}$

10. Effect of S content on the susceptibility to TGSCC of Type 304 or $304 \mathrm{~L}$ heats, irradiated to fluence of $\approx 0.3 \times 10^{21} \mathrm{n} \cdot \mathrm{cm}^{-2}$ and tested at $289^{\circ} \mathrm{C}$ in BWR-like water.

11. Effects of fluence and test environment on load elongation behavior of Type 304 SS commercial heat $\mathrm{C} 19$.

12. Effects of fluence on percent TGSCC measured in $289^{\circ} \mathrm{C}$ water containing $\approx 8 \mathrm{ppm}$ DO, 0.4 to $1.3 \mathrm{dpa}$.

13. Effects of fluence on percent IGSCC measured in $289^{\circ} \mathrm{C}$ water containing $\approx 8 \mathrm{ppm}$ DO, 0.4 and $1.3 \mathrm{dpa}$.

14. Effect of S on susceptibility to IGSCC of Type 304 and 304L steels irradiated to $\approx 0.9 \times 10^{21} \mathrm{n} \cdot \mathrm{cm}^{-2}$; one group of steels contains $<0.004 \mathrm{wt} . \% \mathrm{~S}$ and the other group contains $>0.005$ wt. $\% \mathrm{~S}$. 
15. Effect of $\mathrm{S}$ on uniform and total elongation of Type 304 and 304L steels irradiated to $\approx 0.9 \times 10^{21} \mathrm{n} \cdot \mathrm{cm}^{-2}$; one group of steels contains $<0.004 \mathrm{wt} . \% \mathrm{~S}$ and the other group contains $>0.005$ wt. $\% \mathrm{~S}$.

16. Effect of Si concentration on yield strength of Types 304 and $304 \mathrm{~L}$ steel measured in $289^{\circ} \mathrm{C}$ water before and after irradiation

17. Effect of Si on IGSCC of lab heats of Types 304 and 304L SS containing high concentrations of $\mathrm{S}$ and irradiated to $\approx 1.3 \mathrm{dpa}$; susceptible heats contain lower concentrations of $\mathrm{Si}$; resistant heats contain higher concentrations of $\mathrm{Si}$.

18. SSRT load-elongation behavior of Type 304 SS Heat C19: overall data; effect of damage level in $289^{\circ} \mathrm{C}$ water, $\mathrm{DO} \approx 8 \mathrm{ppm}$; effects of damage level and temperature in air; and behavior at $\approx 3 \mathrm{dpa}$ in $289^{\circ} \mathrm{C}$ water and $289-325^{\circ} \mathrm{C}$ air. 35

19. Percent IGSCC at $\approx 3$ dpa correlated with bulk $\mathrm{Cr}$ concentration, 304- and 316-type steels. .37

20. Percent IGSCC at $\approx 3$ dpa correlated with bulk Ni concentration, 304- and 316-type steels. .37

21. Percent IGSCC at $\approx 3$ dpa correlated with bulk Mn concentration, 304- and 316-type steels. ...........38

22. Percent IGSCC at $\approx 3$ dpa correlated with bulk Si concentration, 304- and 316-type steels..............38

23. Percent IGSCC at $\approx 3$ dpa correlated with bulk P concentration, 304- and 316-type steels..............39

24. Percent IGSCC at $\approx 3$ dpa correlated with bulk N concentration, 304- and 316-type steels. .............39

25. Percent IGSCC at $\approx 3$ dpa correlated with bulk O concentration, 304- and 316-type steels. .............40

26. Percent IGSCC at $\approx 3$ dpa correlated with bulk $\mathrm{C}$ concentration, 304- and 316-type steels. .............40

27. Percent IGSCC at $\approx 3$ dpa correlated with bulk $\mathrm{S}$ concentration, 304- and 316-type steels: all data at $\mathrm{S}<0.004 \mathrm{wt} . \%$ and expanded plot for $\mathrm{S}<0.01 \mathrm{wt} . \%$ showing details.

28. Effect of neutron damage on IASCC susceptibility of Type 304 or 316 steels that contain low concentrations of $\mathrm{S}$ and high concentrations of $\mathrm{C}$.

29. Effect of neutron damage on IASCC susceptibility of Type 304 or 316 steels that contain low $\mathrm{S}$ and low $\mathrm{C}$ concentrations, high $\mathrm{S}$ and high $\mathrm{C}$ concentrations, or high $\mathrm{S}$ and low $\mathrm{C}$ concentrations.

30. Effect of bulk S content on IASCC susceptibility of commercial heats of Types 304, 304L, 316 , and $316 \mathrm{~L}$ steels.

31. IASCC susceptibility of low-S and high-S heats of comparable chemical composition; Type 304 SS. 
32. IASCC susceptibility of high-purity heats of Type 304L SS doped with C or S, from Tsukada et al., Ref. 29.

33. IASCC susceptibility of low- and high-S heats of comparable composition, from

Kasahara et al., Ref. 28. 46

34. IASCC susceptibility of low- and high-S heats of comparable composition, from Jacobs et al., Ref. 21. 46

35. IASCC susceptibility of low- and high-S heats of comparable composition, from Garzarolli et al. Ref. 2.

36. Percent IGSCC from SSRT tests of low-S high-C and low-S low-C heats of Type 304 or 304L SSs.

37. Percent IGSCC from SSRT test of low-S high-C and low-S low-C heats of Type 316 or 316L SSs

38. Diametral strain at failure for low-S high-C and low-S low-C heats of Type $348 \mathrm{SSs}$ .50

39. Diametral strain at failure for low-S high-C and low-S low-C heats of Type $348 \mathrm{SSs}$ .50

40. Ductility and percent IGSCC of low- and high-S laboratory heats of Type 304 SSs that contain unusually high $\mathrm{Si}$ content.

41. Comparison of failure diametral strain for high- and low-Si heats of Type 316L SSs that contain low-S and low-C concentrations.

42. Range of bulk S and C contents in which Type 304 or 316 steels are resistant or susceptible to IASCC in BWR-like oxidizing water.

43. Expanded view of low-S portion of Fig. 42 showing data in detail.

44. Range of bulk S and C contents in which Type 304 or 316 steels are resistant or susceptible to IASCC, including four susceptible heats tested at $1.3 \mathrm{dpa}$ in this study.

45. Percent IGSCC of high- and low-sulfur laboratory heats of Type 348 SS after irradiation to 1.3 and 3 dpa, SSRT test in BWR-like water.

46. Range of bulk S and C contents in which Type 348 stainless steels are resistant or susceptible to IASCC.

47. Effect of neutron damage on percent IGSCC of austenitic-ferritic steel that contains $\approx 3$ vol.\% delta ferrite.

48. Optical metallograph of IASCC-resistant Alloy L5 that contains $\approx 3$ vol. $\%$ delta ferrite. .60 
49. Predominantly ductile fracture surface morphology of IASCC-resistant Alloy L5 that contains $\approx 3$ vol. $\%$ delta ferrite, 3 dpa.

50. Fe-rich side of Fe-S phase diagram; from Hansen, Ref. 47.

51. Dominantly ductile fracture surface morphology of IASCC-resistant Commercial Heat C1 of Type 304 SS; 3 dpa.

52. Dominantly ductile fracture surface morphology of IASCC-resistant Commercial Heat C10 of Type 304 SS; 3 dpa. 64

53. Dominantly ductile fracture surface morphology of IASCC-resistant Commercial Heat C12 of Type 304 SS; 3 dpa.

54. Fracture surface morphology of IASCC-resistant Laboratory Heat L14 of Type 304 SS, showing predominant ductile morphology and limited transgranular morphology; intergranular morphology is negligible.

55. Dominantly ductile fracture surface morphology of IASCC-resistant Commercial Heat C21 of Type $316 \mathrm{SS} ; 3$ dpa.

56. Fracture surface morphology of IASCC-resistant Laboratory Heat L24 of Type 348 SS; both low- and high-magnification images show that ductile morphology is dominant and intergranular morphology is negligible.

57. Fracture surface morphology of IASCC-resistant Laboratory Heat L26 of Type 304 SS, showing limited amount of transgranular morphology that surrounds insignificant amount of intergranular morphology and dominantly ductile morphology.

58. Ductile fracture morphology of IASCC-resistant Laboratory Heat L27; both low- and highmagnification images show that intergranular morphology is negligible.

59. Intergranular fracture surface morphology of IASCC-susceptible Heat C16.

60. Intergranular fracture surface morphology of IASCC-susceptible Heat C19. .68

61. Intergranular fracture surface morphology of IASCC-susceptible Heat L4.

62. Intergranular fracture surface morphology of IASCC-susceptible Heat C9. .69

63. Intergranular fracture surface morphology of IASCC-susceptible Heat L18. .70

64. Intergranular fracture surface morphology of IASCC-susceptible Heat C3. .70

65. Intergranular and ductile fracture surface morphologies of IASCC-susceptible Heat L25. .71 
66. Intergranular fracture surface morphology of IASCC-susceptible Heat L2 ..................................71

67. Intergranular fracture surface morphology of IASCC-susceptible Heat L7 .....................................72

68. Intergranular fracture surface morphology of IASCC-susceptible Heat L17 ..................................72

69. Intergranular and ductile fracture surface morphologies of IASCC-susceptible Heat L15..............73

70. Intergranular fracture surface morphology of IASCC-susceptible Heat L6 ...................................73

71. Intergranular fracture surface morphology of IASCC-susceptible Heat L23 ...................................74

72. High-magnification fractograph of H-charged BWR neutron absorber tube, $304 \mathrm{SS}$, Heat B, $\approx 3 \mathrm{dpa}$; fracture was produced at $23^{\circ} \mathrm{C}$ in ultra-high vacuum environment in a scanning Auger electron microscope. 76

73. Summary of AES analysis of grain-boundary segregation of S and C in BWR neutron absorber tube fabricated from Type 304 SS Heat A and irradiated to 3 dpa: S and C peak heights from ductile and IG fracture surfaces are compared. .77

74. Summary of AES analysis of grain-boundary segregation of $\mathrm{S}$ and $\mathrm{C}$ in BWR neutron absorber tube fabricated from Type 304 SS Heat B and irradiated to 3 dpa: S and C peak heights from ductile and IG fracture surfaces are compared. .78

75. Result of AES depth-profiling analysis of grain-boundary segregation of $\mathrm{S}$ and $\mathrm{C}$ in $\mathrm{BWR}$ neutron absorber tubes fabricated from Type 304 SS Heats A and B and irradiated to $\approx 3$ dpa........79

76. AES signal showing high concentrations of $\mathrm{Cu}, \mathrm{S}$, and $\mathrm{C}$ in $\mathrm{CuS}$-type precipitate denoted with number "6" in Fig. 72.

77. AES signal showing a high concentration of $\mathrm{C}$ in CUS-type precipitate in BWR neutron absorber tube, $304 \mathrm{SS}$, Heat $\mathrm{B}, \approx 3 \mathrm{dpa}$.

78. AES signal showing a high concentration of $\mathrm{C}$ in CuS-type precipitate in BWR neutron absorber tube, $304 \mathrm{SS}$, Heat $\mathrm{B}, \approx 3 \mathrm{dpa}$. .82

79. Fracture surface morphology of high-S, low-Mn Type 304 SS Specimen L13-03B produced during bending in $23^{\circ} \mathrm{C}$ air without previous exposure to water or $\mathrm{H}$ charging. .85

80. Schematic illustration of an IASCC model .90 


\section{Tables}

1. Compositions assigned to medium, high, and low levels of alloying and impurity elements used to construct Taguchi's $\mathrm{L}_{18}$ array.

2. Basic test matrix optimized according to Taguchi's orthogonal array $\mathrm{L}^{18}$....................................... 6

3. Composition of six supplementary commercial- and high-purity heats of Types 304, 316, and 348 stainless steel.

4. Elemental composition of 27 commercial and laboratory model austenitic stainless steel alloys irradiated in Halden Reactor.

5. Specimen number per alloy, irradiation fluence level, and postirradiation test type.

6. Summary of discharge date and fluence of model austenitic stainless steel alloys irradiated in Halden heavy boiling water reactor.

7. Results of SSRT test and SEM fractography for nonirradiated control specimens of model austenitic stainless steel alloys.

8. Composition of nonirradiated control specimens of model austenitic stainless steels correlated with results of SSRT test and SEM fractography.

9. Results of SSRT tests in $289^{\circ} \mathrm{C}$ water and SEM fractography of steels irradiated to $\approx 0.3 \times 10^{21} \mathrm{n} \cdot \mathrm{cm}^{-2}$

10. Composition of steels irradiated to $\approx 0.3 \times 10^{21} \mathrm{n} \cdot \mathrm{cm}^{-2}$ correlated with results of SSRT tests and SEM fractography

11. Results of SSRT test and fractography for model austenitic stainless steels irradiated to $\approx 0.9 \times 10^{21} \mathrm{n} \cdot \mathrm{cm}^{-2}$

12. Composition of stainless steels irradiated to $\approx 0.9 \times 10^{21} \mathrm{n} \cdot \mathrm{cm}^{-2}$ correlated with results of SSRT test and fractography

13. Results of SSRT tests and SEM fractography for model austenitic stainless steels irradiated to $\approx 2.0 \times 10^{21} \mathrm{n} \cdot \mathrm{cm}^{-2}$

14. Composition of stainless steels irradiated to $\approx 2.0 \times 10^{21} \mathrm{n} \cdot \mathrm{cm}^{-2}$ correlated with results of SSRT test and SEM fractography. 
This page is intentionally blank. 


\section{Acronyms}

AAEM $=$ advanced analytical electron microscopy

$\mathrm{AES}=$ Auger electron spectroscopy

AISI $=$ American Iron and Steel Institute

ASTM $=$ American Society for Testing and Materials

$\mathrm{BWR}=$ boiling water reactor

$\mathrm{CGR}=$ crack growth rate

$\mathrm{CP}=$ commercial purity

$\mathrm{CT}=$ compact tension

$\mathrm{dpa}=$ displacement per atom

$\mathrm{DO}=$ dissolved oxygen

$\mathrm{ECP}=$ electrochemical potential

EDS $=$ energy dispersive spectroscopy

FEG-AAEM = field-emission-gun advanced analytical electron microscopy

HBWR = heavy boiling water reactor

$\mathrm{HP}=$ high purity

IASCC $=$ irradiation-induced stress corrosion cracking

$\mathrm{IG}=$ intergranular

$\mathrm{IGC}=$ intergranular cracking

IGSCC $=$ intergranular stress corrosion cracking

$\mathrm{JRR}=$ Japan Research Reactor

$\mathrm{LWR}=$ light water reactor

$\mathrm{PWR}=$ pressurized water reactor

$\mathrm{SAM}=$ scanning Auger electron microscope

SEM = scanning electron microscopy

$\mathrm{SS}=$ stainless steel 
SSRT $=$ slow-strain-rate tensile

$\mathrm{TE}=$ total elongation

$\mathrm{TEM}=$ transmission electron microscopy

$\mathrm{TG}=$ transgranular

TGSCC $=$ transgranular stress corrosion cracking

$\mathrm{UE}=$ uniform elongation

$\mathrm{UHP}=$ ultra high purity

$\mathrm{UTS}=$ ultimate tensile strength

YS = yield strength 


\section{Executive Summary}

This report summarizes experimental work performed at Argonne National Laboratory on irradiationassisted stress corrosion cracking (IASCC) of austenitic stainless steels that were irradiated in the Halden boiling heavy water reactor in order to simulate irradiation-induced degradation of boiling water reactor (BWR) core internal components. Slow-strain-rate tensile tests in BWR-like water were conducted on 27 austenitic stainless steel alloys that were irradiated at $288^{\circ} \mathrm{C}$ in helium to three fluence levels, i.e., $\approx 0.3 \times 10^{21}$ $\mathrm{n} \cdot \mathrm{cm}^{-2}, \approx 0.9 \times 10^{21} \mathrm{n} \cdot \mathrm{cm}^{-2}$, and $\approx 2.0 \times 10^{21} \mathrm{n} \cdot \mathrm{cm}^{-2}(\mathrm{E}>1 \mathrm{MeV}$ ) (neutron damage $\approx 0.4, \approx 1.3$, and $\approx 3.0$ displacement per atom [dpa]). Fractographic analysis by scanning electron microscopy was conducted to determine the susceptibility to IASCC as manifested by the degree of intergranular fracture surface morphology. Microchemical analysis by Auger electron spectroscopy was performed on BWR neutron absorber tubes to characterize the behavior of grain-boundary segregation of important elements under BWR operating conditions. On the basis of the results from the stress-corrosion-cracking tests and microstructural analyses, a mechanistic model for IASCC was developed.

At $\approx 0.3 \times 10^{21} \mathrm{n} \cdot \mathrm{cm}^{-2}(\mathrm{E}>1 \mathrm{MeV})(\approx 0.4 \mathrm{dpa})$, IASCC susceptibility was negligible for all tested heats, with the exception of a 316L-like high-purity model alloy that contained $0.003 \mathrm{wt} . \% \mathrm{C}$ and $0.004 \mathrm{wt} . \% \mathrm{~S}$. At $\approx 0.4$ and $\approx 1.3 \mathrm{dpa}$, significant transgranular fracture was mixed with intergranular fracture. At $\approx 3 \mathrm{dpa}$, susceptibility to transgranular stress corrosion cracking was negligible, and fracture surface morphology was either dominantly intergranular, as in field-cracked core internal components, or dominantly ductile or mixed. This behavior indicates that percent intergranular stress corrosion cracking determined at $\approx 3 \mathrm{dpa}$ is a good measure of IASCC susceptibility.

At $\approx 1.4$ dpa, a beneficial effect of a high concentration of Si (0.8-1.5 wt.\%) was observed. At $\approx 3$ dpa, however, such effect was obscured by a strongly deleterious effect of S. From the standpoint of BWR IASCC, which usually occurs at $>2.5 \mathrm{dpa}$, typical variation in Si concentration in the range of $0.4-1.1 \mathrm{wt} . \%$ in Types 304, 316, and 348 steel is, therefore, not an important factor.

Excellent resistance to IASCC was observed up to $\approx 3$ dpa for seven heats of Types 304 and 316 steel that contain very low $\mathrm{S}$ concentrations of $\leq 0.002 \mathrm{wt} . \%$ and for one heat of Type 348 steel that contains 0.005 wt. $\%$ S. Susceptibility of Types 304 and 316 steel that contain $>0.003$ wt. $\%$ S increased drastically. These observations indicate that a sulfur-related critical phenomenon plays an important role in IASCC. A sufficiently low concentration of S (i.e., $<0.002 \mathrm{wt} . \%$ ) is the primary material factor necessary to ensure good resistance to IASCC. For Types 304L and 316L steels and their high-purity counterparts that contain $<0.025 \mathrm{wt} . \% \mathrm{C}$, a sulfur concentration of $<0.002 \mathrm{wt} . \%$ alone is not a sufficient material condition to ensure good resistance to IASCC. This is in distinct contrast to the behavior of the high-C counterparts (i.e., Types 304 and 316 steel that contain $<0.002 \mathrm{wt} . \% \mathrm{~S}$ and $>0.03 \mathrm{wt} . \% \mathrm{C}$ ), which exhibit good resistance to IASCC. The contrasting behavior indicates that, at sufficiently low concentrations of $\mathrm{S}$, a high concentration of $\mathrm{C}$ is beneficial. However, at $\mathrm{S}$ concentrations $>0.003 \mathrm{wt} . \%$, the deleterious effect of $\mathrm{S}$ is so dominant that a high concentration of $\mathrm{C}$ is not an important factor.

A two-dimensional map was developed in which susceptibility or resistance to IASCC is shown as a function of bulk concentrations of S and C. Data reported in the literature are consistent with the map. The two-dimensional map is helpful to predict relative IASCC susceptibility of Types 304 and 316 steels. A similar map is helpful to predict IASCC behavior of Type 348 steels. 
At $\mathrm{S}$ concentrations $>0.003 \mathrm{wt} . \%$, IASCC susceptibility is thought to be influenced significantly by various material-related factors, such as the degree of $\mathrm{S}$ segregation to grain boundaries, annealing and cooling during fabrication, component thickness, presence of a small amount of delta ferrite, Mn content, precipitation of sulfides, solubility of sulfides in the crack-tip water, and the thickness and morphology of the Cr oxide on the crack-tip grain boundary, which controls oxygen permeation and diffusion along the grain boundary. A model alloy that contains $\approx 3$ vol. $\%$ globular-shaped delta ferrite and $\approx 21 \mathrm{wt} . \% \mathrm{Cr}$ exhibited excellent resistance to IASCC, despite the fact that it contained a very high S concentration of 0.028 wt. $\%$. The excellent resistance is attributed to the effect of delta ferrite, which traps $\mathrm{S}$ atoms, and the effect of a high concentration of $\mathrm{Cr}$, which forms $\mathrm{Cr}$ oxide and helps to block oxygen permeation and diffusion along the austenite grain boundary.

Grain-boundary segregation of S was observed for BWR neutron absorber tubes irradiated to $\approx 3 \mathrm{dpa}$. It is not clear, however, whether the $\mathrm{S}$ segregation occurred via a thermal process, an irradiation-induced process, or both. The $\mathrm{S}$ segregation behavior is consistent with the results of stress-corrosion-cracking tests that showed a predominantly deleterious effect of S on IASCC at high fluence. Based on the results of stresscorrosion-cracking tests and microstructural characterization, an IASCC model has been developed. The model is based on several key steps postulated to occur at the crack-tip grain boundary, i.e., grain-boundary segregation of $\mathrm{Ni}$ and $\mathrm{S}$, preferential oxidation of $\mathrm{Cr}$ and $\mathrm{Fe}$ atoms over $\mathrm{Ni}$ atoms by oxygen that diffuses along the grain boundary, formation of a $\mathrm{Cr}-\mathrm{Fe}$ spinel oxide ahead of the crack tip, formation of Ni- and $\mathrm{S}$ rich thin films and islands at the metal/spinel boundary, and melting or amorphization of the Ni-and S-rich thin films and islands. The model also predicts that the thickness and morphology of Cr oxide that covers the crack-tip grain boundary strongly influence the rate of oxygen permeation and diffusion along the grain boundary. 


\section{Acknowledgments}

The authors thank T. M. Karlsen, OECD Halden Reactor Project, Halden, Norway for many years of specimen irradiations in the Halden reactor; H. Valseth and J. R. McDade for transportation of the irradiated specimens; D. O. Pushis and D. McGann for specimen retrieval; W. E. Ruther, D. R. Perkins, R. W. Clark, and L. A. Knoblich for conducting slow-strain-rate-tensile tests; R. V. Strain, D. L. Perry, A. G. Hins, and J. Y. Park for fractographic examination by scanning electron microscopy; and J. E. Sanecki for grain-boundary analysis by Auger electron spectroscopy. The authors are grateful to C. Moyer and A. Lee for many helpful

discussions. The authors would like to express special thanks to W. H. Cullen, Jr. of U.S. Nuclear Regulatory Commission who managed this project. 
This page is intentionally blank. 


\section{Introduction}

In recent years, failures of reactor core internal components have increased after accumulating a fluence $>0.5 \times 10^{21} \mathrm{n} \cdot \mathrm{cm}^{-2}(\mathrm{E}>1 \mathrm{MeV})$, or $\approx 0.7 \mathrm{dpa}$, in boiling water reactors (BWRs), ${ }^{1}$ and at approximately one order of magnitude higher fluences in some pressurized water reactors (PWRs). ${ }^{2}$ The general pattern of the observed failures indicates that, as nuclear plants age and neutron fluence increases, various nonsensitized austenitic stainless steels (SSs) become susceptible to intergranular (IG) failure. Some components are known to have cracked under minimal applied stress. Although most failed components can be replaced, some safety-significant structural components (e.g., the BWR top guide, shroud, and core plate) would be very costly or impractical to replace. Therefore, the structural integrity of these components at high fluence or near the end of life (EOL) has been a subject of concern, and extensive research has been conducted to provide an understanding of this type of degradation, commonly known as irradiation-assisted stress corrosion cracking (IASCC).

Irradiation affects profoundly both local coolant-water chemistry and component microstructure. The primary effects of irradiation on materials include alteration of local microchemistry, microstructure, and mechanical properties of the core internal components, which are usually fabricated from American Iron and Steel Institute (AISI) Types 304, 316, or 348 SS. Irradiation produces defects and defect clusters in grain matrices, alters the dislocation and dislocation loop structures, and produces defect-impurity and defectcluster-impurity complexes, leading to radiation-induced hardening and, in many cases, flow localization via dislocation channeling. Irradiation also leads to changes in the stability of second-phase precipitates and the local alloy chemistry near grain boundaries, precipitates, and defect clusters. Grain-boundary microchemistry that significantly differs from bulk composition can be produced in association with not only radiationinduced segregation but also thermally driven segregation of alloying and impurity elements. ${ }^{1-3}$

For many years, irradiation-induced grain-boundary depletion of $\mathrm{Cr}$ has been considered the primary metallurgical process that causes IASCC. One of the most important factors that has been considered by many investigators to be a support for the $\mathrm{Cr}$-depletion mechanism is the similarity in dependence on water chemistry (i.e., oxidizing potential) of both intergranular stress corrosion cracking (IGSCC) of unirradiated, thermally sensitized material and IASCC of solution-annealed and quenched, BWR-irradiated material. 4,5,6 However, contrary to expectations based on the $\mathrm{Cr}$-depletion mechanism, cracking incidents of control rod cladding and baffle bolts have been reported in numerous PWRs (i.e., under nonoxidizing potential). Also, the susceptibility of PWR-irradiated components to IASCC has been shown clearly by expanding-mandrel, 2,7 slow-strain-rate tensile (SSRT) tests, $8,9,10$ and C-ring compression tests ${ }^{11}$ in PWR water ${ }^{2,7}$ or simulated PWR-like water, ${ }^{8-11}$ although PWR water chemistry falls well within the range of protective electrochemical potential (ECP). Also, it has been reported that crack propagation by intergranular separation occurs in highly irradiated compact-tension specimens even in hydrogen-water chemistry (HWC) in a simulated BWR

environment. ${ }^{12}$ These observations indicate that the phenomenon of IASCC cannot be explained well by the grain-boundary $\mathrm{Cr}$ depletion and slip dissolution mechanism.

Another important aspect of IASCC characteristics that does not support the grain-boundary Crdepletion mechanism is the effect of postirradiation annealing. Several investigators have reported that postirradiation annealing at $450-550^{\circ} \mathrm{C}$ for relatively short periods of time is sufficient to partially or fully mitigate the susceptibility to IASCC of austenitic SSs irradiated under BWR ${ }^{13-15}$ and PWR ${ }^{10,16}$ conditions. During short annealing at such low temperatures (e.g., 5-24 h at $475^{\circ} \mathrm{C}^{14}$ and $1 \mathrm{~h}$ at $550^{\circ} \mathrm{C}^{16}$ ), it is not possible for significant back diffusion of metallic elements $(\mathrm{Fe}, \mathrm{Cr}$, and $\mathrm{Ni}$ ) to occur from the grain boundary. 
It has been shown that, during postirradiation annealing, IASCC susceptibility becomes negligible long before grain-boundary $\mathrm{Cr}$ concentration begins to change from its level in as-irradiated state. ${ }^{16,17}$ These observations do not support the premise that grain-boundary $\mathrm{Cr}$ depletion is the direct cause of IASCC. The observations, however, suggest a possibility that a rapidly diffusing impurity element, segregated on the grain boundary during irradiation, plays an important role in annealing-induced restoration of the resistance to IASCC.

In general, IASCC is characterized by strong heat-to-heat variation in susceptibility, in addition to strong dependence on irradiation condition, material type, and grade, even among materials of virtually identical chemical composition. This behavior also indicates that the traditional interpretation based on the role of grain-boundary $\mathrm{Cr}$ depletion cannot explain well the mechanism of IASCC, because, for a given level of neutron fluence, heat-to-heat variation of $\mathrm{Cr}$ depletion is insignificant among a given type of solutionannealed and quenched steel.

Many investigators have implicated radiation-induced segregation of $\mathrm{Si}$ or $\mathrm{P}$ as the primary process that causes IASCC. ${ }^{1-3,7}$ The superior resistance of one heat of Type 348 SS that is especially low in C, Si, and P seemed to provide support for this process, ${ }^{2}$ and the same rationale was extended to Type 304 SS. However, in direct contradiction, several investigators reported that IASCC resistance of high-purity (HP) heats (low in $\mathrm{C}, \mathrm{Si}$, and P) of Type $304 \mathrm{SS}$ is no better than that of commercial-purity (CP) counterparts. ${ }^{7-9,12,16,23}$ Therefore, the role of grain-boundary segregation of $\mathrm{C}, \mathrm{Si}$, and $\mathrm{P}$ appeared poorly established.

Although $\mathrm{C}$ significantly increases the yield strength of irradiated stainless steels, higher $\mathrm{C}$ content ( $>0.06$ wt. \%) seems to be either benign or even conducive to lower susceptibility of irradiated austenitic SSs to IASCC. ${ }^{23,24}$

Deleterious effects of O on IGSCC of proton-irradiated steels have been reported by Cookson et al., who showed that oxides near the surface facilitate crack nucleation. ${ }^{25}$ High concentrations of $\mathrm{O}$ and internal oxide precipitates were also reported for grain boundaries in the heat-affected zones of unirradiated Types 304 and 304L SSs and field-cracked BWR core shroud welds that were fabricated by the shielded-metal-arc procedure. ${ }^{26,27}$ Yet, the exact role and the source of O on grain boundaries in IASCC of a solution-annealed material or intergranular failure of a BWR core internal weld remain poorly understood.

Indications of the deleterious effect of grain-boundary segregation of $\mathrm{N}$ have been reported for BWR neutron absorber tubes fabricated from high- and commercial-purity heats of Type $304 \mathrm{SS}^{23}$ Similar reports suggested that a high concentration of $\mathrm{N}$ (e.g., $>0.06 \mathrm{wt. \%}$ ) is deleterious, at least under BWR conditions. ${ }^{1,28-}$ 30 Indications of the deleterious role of $\mathrm{N}$ have also been reported for Types 304L and 316L SS that contain $<0.024 \mathrm{wt} . \% \mathrm{C}$ and have been irradiated in BWRs or test reactors at $240-300^{\circ} \mathrm{C} .{ }^{22}$ Kasahara et al. ${ }^{28}$ also reported that higher $\mathrm{N}$ in Type $316 \mathrm{~L}$ increased the susceptibility to IASCC, indicating that Type $316 \mathrm{LN}$ is a susceptible material. This observation appeared to be consistent with the behavior of $316 \mathrm{NG}$ SSs reported by Jacobs et al. ${ }^{1}$ and Jenssen and Ljungberg. ${ }^{30}$ In contrast to these observations, $316 \mathrm{NG} \mathrm{SSs} \mathrm{irradiated} \mathrm{at} \approx 50^{\circ} \mathrm{C}$ have been reported to be resistant to intergranular failure at $\approx 288^{\circ} \mathrm{C}$ in high-purity water that contained $\approx 32 \mathrm{ppm}$ dissolved oxygen (DO). ${ }^{22}$ Therefore, the role of $\mathrm{N}$ appears to be neither clear nor convincing.

The strong heat-to-heat variation in IASCC susceptibility has been customarily correlated with variations in irradiation-induced evolution of the microstructure and microchemistry of ordinary grain boundaries, i.e., grain boundaries not directly involved in crack-tip formation or crack propagation. This approach implicitly assumes that the crack tip, stress intensity, or the event of crack propagation itself does 
not influence the microstructure and microchemistry of the grain boundary in front of the advancing crack tip. However, contrary to this assumption, results from several crack-tip microstructural studies indicate that the microstructure and microchemistry of a crack-tip grain boundary differ significantly from those of an ordinary grain boundary. $31-34$

Although intergranular failure in irradiated fuel cladding fabricated from austenitic SSs has been observed since the 1960s, extensive research and investigations on core internals were not conducted until the late 1980s. In spite of the extensive investigations, IASCC is still only poorly understood, and its mechanism remains elusive, and in some respects, more perplexing. In the context of this somewhat unusual background, we have initiated a comprehensive program to systematically investigate the effects of alloying and impurity elements ( $\mathrm{Cr}, \mathrm{Ni}, \mathrm{Si}, \mathrm{P}, \mathrm{S}, \mathrm{Mn}, \mathrm{C}, \mathrm{O}$, and $\mathrm{N})$ on the susceptibility of austenitic SSs to IASCC at several fluence levels. Construction of the test matrix was based on the method of Taguchi, ${ }^{35}$ and susceptibility to IASCC was March 17, 2005 determined by well-controlled SSRT testing of the irradiated specimens in BWR-like water. Posttest fractographic examination was performed by scanning electron microscopy (SEM) and Auger electron spectroscopy (AES).

This report is the final topical report of the program; it summarizes the results obtained from 27 austenitic SS alloys that were irradiated in the Halden reactor at $288^{\circ} \mathrm{C}$ in helium to three fluence levels, i.e., $\approx 0.3 \times 10^{21} \mathrm{n} \cdot \mathrm{cm}^{-2}(\mathrm{E}>1 \mathrm{MeV})(\approx 0.4 \mathrm{dpa}), \approx 0.9 \times 10^{21} \mathrm{n} \cdot \mathrm{cm}^{-2}(\approx 1.3 \mathrm{dpa})$, and $\approx 2.0 \times 10^{21} \mathrm{n} \cdot \mathrm{cm}^{-2}(\approx 3.0$ dpa). Several reports have been issued previously to document the results obtained from specimens irradiated to the low, ${ }^{36,37}$ medium, ${ }^{38,39}$ and high ${ }^{40}$ fluence levels. 
This page is intentionally blank. 


\section{Test Matrix and Specimen Fabrication}

\subsection{Construction of Test Matrix}

The test matrix for irradiation and stress corrosion testing for this project was constructed according to the method of Taguchi, which is described in detail in Ref. 39. The base matrix followed Taguchi's standard orthogonal array $\mathrm{L}_{18}\left(2^{1} \times 3^{7}\right)$, which is an optimized matrix designed to systematically determine the effects of seven variables (i.e., bulk material concentrations of $\mathrm{Cr}, \mathrm{Si}, \mathrm{P}, \mathrm{S}, \mathrm{Mn}, \mathrm{C}$, and $\mathrm{N}$ ) at three concentration levels, and one variable (bulk Ni concentration) at two levels. A possible synergistic interaction was assumed only between $\mathrm{Ni}$ and $\mathrm{Si}$. Compositions assigned to the three levels of the seven alloying and impurity elements and two levels of $\mathrm{Ni}$ are given in Table 1. The basic test matrix, optimized on the basis of the orthogonal array $\mathrm{L}_{18}\left(2^{1} \times 3^{7}\right)$, is given in Table 2 .

Table 1. Compositions assigned to medium, high, and low levels of alloying and impurity elements used to construct Taguchi's $L_{18}$ $\left(2^{1} \times 3^{7}\right)$ array.

\begin{tabular}{ccrrr}
\hline & & \multicolumn{3}{c}{ COMPOSITION (IN WT.\%) } \\
FACTOR & ELEMENT & \multicolumn{3}{c}{ ASSIGNED TO LEVEL } \\
\cline { 3 - 5 } No. & ASSIGNED & \multicolumn{1}{c}{1} & \multicolumn{1}{c}{2} & 3 \\
\hline 1 & NI & 8.000 & 10.000 & - \\
2 & SI & 0.700 & 1.400 & 0.150 \\
3 & P & 0.040 & 0.090 & 0.020 \\
4 & S & 0.006 & 0.020 & 0.002 \\
5 & MN & 1.200 & 2.050 & 0.500 \\
6 & C & 0.040 & 0.090 & 0.010 \\
7 & N & 0.040 & 0.090 & 0.010 \\
8 & CR & 17.500 & 18.500 & 16.000 \\
\hline
\end{tabular}

In addition to the 18 statistically optimized heats given in Table 2, six supplementary heats of commercial- and high-purity grade Types 304, 316, and 348 SS were included in the test matrix. Compositions of the six supplementary heats are given in Table 3. Of the 24 heats given in Tables 2 and 3 , eight (i.e., Heats 1, 3, 9, 10, 12, 16, 19, and 21) were replaced by commercially purchased heats. Compositions of major impurities (i.e., Si, P, C, and N) of each of the eight commercial heats matched closely those of each corresponding heat given in Tables 2 and 3. The prefix " $\mathrm{C}$ " was added to the identification number of these eight commercial heats (see Table 4).

The remaining 16 heats in Tables 2 and 3 were fabricated in the laboratory (USDOE Materials Preparation Center, Ames Laboratory, Ames, Iowa). All of the laboratory-fabricated heats were designated with identification numbers that began with "L". To this matrix of 24 heats, three laboratory heats were added to test the effects of the fabrication procedure. Compositions of these three laboratory heats (i.e., Heats L25, L26, and L27 in Table 4) closely match those of the counterpart commercial heats (i.e., Heats C3, C19, 
and C21), respectively. Elemental composition of the complete test matrix, comprising 27 austenitic SSs, is given in Table 4.

Oxygen content, which is not specified in AISI Specifications for Types 304, 316, and 348 SS and their low-C counterparts, was not systematically controlled. However, oxygen content in the 27 heats ranged from 0.0037 wt.\% (L4) to $0.0274 \mathrm{wt} \%$ (L7) except for one heat: Heat L20 contained an unusually high concentration of O $(0.0940 \mathrm{wt} . \%)$ and exhibited an anomalous dendritic structure that is not characteristic of an austenitic SS.

Table 2. Basic test matrix optimized according to Taguchi's orthogonal array $L_{18}\left(2^{1} \times 3^{7}\right)$.

\begin{tabular}{|c|c|c|c|c|c|c|c|c|}
\hline \multirow{2}{*}{$\begin{array}{l}\text { HEAT } \\
\text { No. }\end{array}$} & \multicolumn{8}{|c|}{ COMPOSITION (IN WT.\%) } \\
\hline & NI & SI & $\mathbf{P}$ & $S$ & MN & C & $\mathbf{N}$ & $\mathbf{C R}$ \\
\hline 1 & 10.0 & 0.70 & 0.04 & 0.006 & 1.20 & 0.04 & 0.04 & 18.5 \\
\hline 2 & 10.0 & 0.70 & 0.09 & 0.020 & 2.05 & 0.09 & 0.09 & 17.5 \\
\hline 3 & 10.0 & 0.70 & 0.02 & 0.002 & 0.50 & 0.01 & 0.01 & 16.0 \\
\hline 4 & 10.0 & 1.40 & 0.04 & 0.006 & 2.05 & 0.09 & 0.01 & 16.0 \\
\hline 5 & 00 & 1.40 & 0.09 & 0.020 & 0.50 & 0.0 & & 18.5 \\
\hline 6 & 10.0 & 1.40 & 0.02 & 0.002 & 1.20 & 0.04 & 0.09 & 17.5 \\
\hline 7 & 10.0 & 0.15 & 0.04 & 0.020 & 1.20 & 0.01 & 0.09 & 16.0 \\
\hline 8 & 10.0 & 0.15 & 0.09 & 0.006 & 2.05 & 0.04 & 0.01 & 18.5 \\
\hline 9 & 10.0 & 0.15 & 0.02 & 0.002 & 0.50 & 0.09 & 0.04 & 17.5 \\
\hline 10 & 8.0 & 0.70 & 0.04 & 0.002 & 0.50 & 0.09 & 0.09 & 18.5 \\
\hline 11 & 8.0 & 0.70 & 0.09 & 0.006 & 1.20 & 0.01 & 0.01 & 17.5 \\
\hline 12 & 8.0 & 0.70 & 0.02 & 0.020 & 2.05 & 0.04 & 0.04 & 16.0 \\
\hline 13 & 8.0 & 1.40 & 0.04 & 0.020 & 0.50 & 0.04 & 0.01 & 17.5 \\
\hline 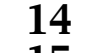 & 8. & 1.40 & 0.09 & 0.002 & 2.05 & 0.09 & 0.04 & 16.0 \\
\hline 15 & 8.0 & 1.40 & 0.02 & 0.006 & 1.20 & 0.01 & 0.09 & 18.5 \\
\hline 16 & 8. & 0.15 & 0.04 & 0.002 & 2.1 & 0.01 & 0.04 & 17.5 \\
\hline 17 & 8.0 & 0.15 & 0.09 & 0.006 & 0.50 & 0.04 & 0.09 & 16.0 \\
\hline 18 & 8.0 & 0.15 & 0.02 & 0.020 & 1.20 & 0.09 & 0.01 & 18.5 \\
\hline
\end{tabular}


Table 3. Composition (wt.\%) of six supplementary commercial- and high-purity heats of Types 304, 316, and 348 stainless steel.

\begin{tabular}{cccccccccccc}
\hline HEAT & SS TYPE & C & N & SI & P & S & MN & CR & NI & NB & MO \\
\hline 19 & CP 304 & 0.04 & 0.04 & 0.70 & 0.04 & 0.06 & 1.20 & 18.5 & 10.0 & - & - \\
20 & HP 304 & 0.01 & 0.01 & 0.15 & 0.02 & 0.02 & 0.50 & 18.5 & 10.0 & - & - \\
21 & CP 316 & 0.04 & 0.04 & 0.70 & 0.04 & 0.06 & 1.20 & 16.5 & 13.5 & - & 2.20 \\
22 & HP 316 & 0.01 & 0.01 & 0.15 & 0.02 & 0.02 & 0.50 & 16.5 & 13.5 & - & 2.20 \\
23 & CP 348 & 0.04 & 0.04 & 0.70 & 0.04 & 0.06 & 1.20 & 17.5 & 11.5 & 2.20 & - \\
24 & HP 348 & 0.01 & 0.01 & 0.15 & 0.02 & 0.02 & 0.50 & 17.5 & 11.5 & 2.20 & - \\
\hline
\end{tabular}

Table 4. Elemental composition of 27 commercial and laboratory model austenitic stainless steel alloys irradiated in Halden Reactor.

\begin{tabular}{|c|c|c|c|c|c|c|c|c|c|c|c|c|}
\hline \multirow{2}{*}{$\begin{array}{l}\text { ANL } \\
\mathrm{ID}^{\mathrm{a}} \\
\end{array}$} & \multirow{2}{*}{$\begin{array}{l}\text { Source } \\
\text { Heat ID }\end{array}$} & \multicolumn{11}{|c|}{ Elemental Composition (wt.\%) } \\
\hline & & $\mathrm{Ni}$ & $\mathrm{Si}$ & $\mathrm{P}$ & $\mathrm{S}$ & $\mathrm{Mn}$ & $\mathrm{C}$ & $\mathrm{N}$ & $\mathrm{Cr}$ & $\mathrm{O}$ & B & $\mathrm{Mo}, \mathrm{Nb}$ \\
\hline $\mathrm{C} 1$ & ASW-70378 & 8.12 & 0.50 & 0.038 & 0.0020 & 1.00 & 0.060 & 0.060 & 18.11 & 0.0102 & $<0.001$ & - \\
\hline L2 & BPC-4111 & 10.50 & 0.82 & 0.080 & 0.0345 & 1.58 & 0.074 & 0.102 & 17.02 & 0.0065 & $<0.001$ & - \\
\hline $\mathrm{C} 3$ & PNL-C1 & 8.91 & 0.46 & 0.019 & 0.0040 & 1.81 & 0.016 & 0.083 & 18.55 & - & $<0.001$ & - \\
\hline L4 & BPC-488 & 10.20 & 0.94 & 0.031 & 0.0100 & 1.75 & 0.110 & 0.002 & 15.80 & 0.0037 & $<0.001$ & - \\
\hline L5 & BPC-4104 & 9.66 & 0.90 & 0.113 & 0.0283 & 0.47 & 0.006 & 0.033 & 21.00 & 0.0068 & $<0.001$ & - \\
\hline L6 & BPC-4127 & 10.00 & 1.90 & 0.020 & 0.0051 & 1.13 & 0.096 & 0.087 & 17.10 & 0.0058 & $<0.001$ & - \\
\hline L7 & BPC-4112 & 10.60 & 0.18 & 0.040 & 0.0384 & 1.02 & 0.007 & 0.111 & 15.40 & 0.0274 & $<0.001$ & - \\
\hline L8 & BPC-491 & 10.20 & 0.15 & 0.093 & 0.0100 & 1.85 & 0.041 & 0.001 & 18.30 & 0.0059 & $<0.001$ & - \\
\hline C9 & PNL-C6 & 8.75 & 0.39 & 0.013 & 0.0130 & 1.72 & 0.062 & 0.065 & 18.48 & 0.0102 & $<0.001$ & - \\
\hline $\mathrm{C} 10$ & ASW-23381 & 8.13 & 0.55 & 0.033 & 0.0020 & 1.00 & 0.060 & 0.086 & 18.19 & 0.0074 & $<0.001$ & - \\
\hline L11 & ВPC-493 & 8.15 & 0.47 & 0.097 & 0.0094 & 1.02 & 0.014 & 0.004 & 17.40 & 0.0071 & $<0.001$ & - \\
\hline $\mathrm{C} 12$ & ASW-23805 & 8.23 & 0.47 & 0.018 & 0.0020 & 1.00 & 0.060 & 0.070 & 18.43 & - & $<0.001$ & - \\
\hline L13 & ВPC-496 & 8.18 & 1.18 & 0.027 & 0.0222 & 0.36 & 0.026 & 0.001 & 17.40 & 0.0042 & $<0.001$ & - \\
\hline L14 & BPC-4129 & 7.93 & 1.49 & 0.080 & 0.0023 & 1.76 & 0.107 & 0.028 & 15.00 & 0.0045 & $<0.001$ & - \\
\hline L15 & BPC-4126 & 8.00 & 1.82 & 0.010 & 0.0129 & 1.07 & 0.020 & 0.085 & 17.80 & 0.0110 & $<0.001$ & - \\
\hline $\mathrm{C} 16$ & PNL-SS14 & 12.90 & 0.38 & 0.014 & 0.0020 & 1.66 & 0.020 & 0.011 & 16.92 & 0.0157 & $<0.001$ & Mo 2.30 \\
\hline L17 & BPC-4128 & 8.00 & 0.66 & 0.090 & 0.0089 & 0.48 & 0.061 & 0.078 & 15.30 & 0.0090 & $<0.001$ & - \\
\hline L18 & BPC-498 & 8.13 & 0.14 & 0.016 & 0.0326 & 1.13 & 0.080 & 0.001 & 18.00 & 0.0055 & $<0.001$ & - \\
\hline C19 & ASW-74827 & 8.08 & 0.45 & 0.031 & 0.0030 & 0.99 & 0.060 & 0.070 & 18.21 & 0.0200 & $<0.001$ & - \\
\hline L20 & BPC-4101 & 8.91 & 0.017 & 0.010 & 0.0039 & 0.41 & 0.002 & 0.002 & 18.10 & 0.0940 & $<0.001$ & - \\
\hline $\mathrm{C} 21$ & ASW-12455 & 10.24 & 0.51 & 0.034 & 0.0010 & 1.19 & 0.060 & 0.020 & 16.28 & 0.0112 & $<0.001$ & Mo 2.08 \\
\hline L22 & BPC-4100 & 13.30 & 0.024 & 0.015 & 0.0036 & 0.40 & 0.003 & 0.001 & 16.10 & 0.0103 & $<0.001$ & Mo 2.04 \\
\hline L23 & BPC-4114 & 12.04 & 0.68 & 0.030 & 0.0475 & 0.96 & 0.043 & 0.092 & 17.30 & 0.0093 & $<0.001$ & $\mathrm{Nb} 1.06$ \\
\hline L24 & BPC-4105 & 12.30 & 0.03 & 0.007 & 0.0055 & 0.48 & 0.031 & 0.002 & 16.90 & 0.0129 & $<0.001$ & $\mathrm{Nb} 1.72$ \\
\hline L25 & BPC-4133 & 8.93 & 0.92 & 0.020 & 0.0082 & 1.54 & 0.019 & 0.095 & 17.20 & 0.0085 & 0.010 & - \\
\hline L26 & BPC-4131 & 8.09 & 0.79 & 0.004 & 0.0022 & 0.91 & 0.070 & 0.089 & 17.20 & 0.0080 & $<0.001$ & - \\
\hline L27 & BPC-4132 & 10.30 & 0.96 & 0.040 & 0.0018 & 0.97 & 0.057 & 0.019 & 15.30 & 0.0058 & 0.030 & Mo 2.01 \\
\hline
\end{tabular}

aThe first letter "C" or "L" denotes, respectively, a commercial or a laboratory-fabricated heat. 


\subsection{Fabrication of Specimen}

Slow-strain-rate tensile (SSRT) specimens were machined from solution-annealed and water-quenched plates, pipes, or sheets that were fabricated from the 27 model austenitic SS alloys. Thick plates or pipes of various thickness and diameter were obtained only for commercial heats, and the laboratory heats were in sheet form. The geometry of the SSRT specimens, $0.76 \mathrm{~mm}$ thick, $57.2 \mathrm{~mm}$ long, and $12.7 \mathrm{~mm}$ wide (gauge section $19.1 \mathrm{~mm}$ long and $3.1 \mathrm{~mm}$ wide), is shown in Fig. 1. Gauge length and plane of the specimen were parallel to the rolling direction and the plane of the sheet, respectively. Subsize compact-tension (1/4TCT) specimens were also fabricated and irradiated in tandem in the same capsules with the SSRT specimens to determine J-R fracture toughness properties and crack growth rate (CGR). The geometry of the CT specimen is shown in Fig. 2. Together, 96 SSRT and 24 CT specimens were prepared and irradiated in this study.

Before machining the specimens, the surface oxide layer was removed to minimize specimen-tospecimen variation in surface roughness and uncertainty in surface chemical composition. After the specimens were mechanically machined and polished, no additional heat treatment was applied to them. Electric discharge machining was not employed because of concern about potential contamination of the surface by $\mathrm{Cu}$ impurity. The machined specimens were degreased in acetone and cleaned ultrasonically in alcohol before they were encapsulated in clean Type 304 SS capsules. The capsules were filled with research-grade He for irradiation in the Halden HBWR located in Halden, Norway.

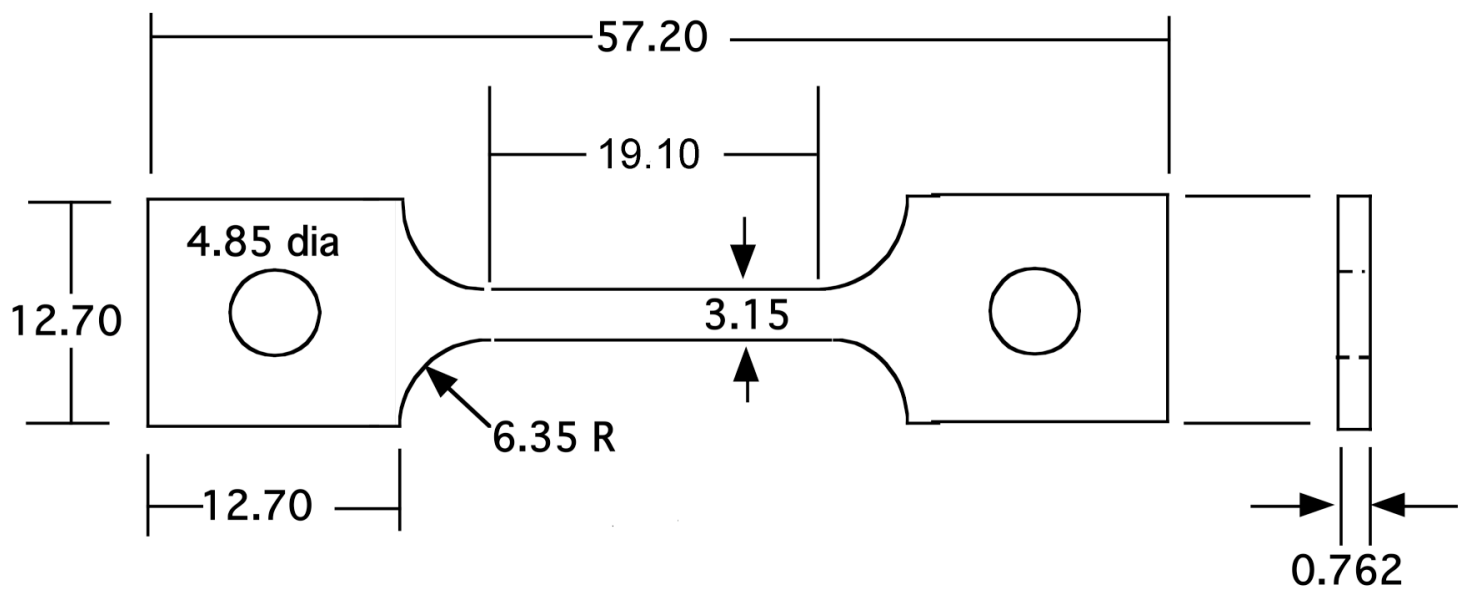

ALL DIMENSIONS IN MM

Figure 1. Geometry of slow-strain-rate tensile test specimen; all dimensions in $\mathrm{mm}$. 
The width of the SSRT specimens $(12.7 \mathrm{~mm}$, Fig. 1) was chosen similar to the width of the compacttension specimens (14.0 mm, Fig. 2) so that an optimum combination of the two types of specimens could be stacked in the irradiation capsule of the Halden reactor. In each capsule, four CT specimens were positioned at the bottom, and 16 SSRT specimens could be stacked vertically on top of the CT specimens. In this way, it was possible to make the best use of the irradiation space. For reference, the dimension of the compact tension specimens is given in Fig. 2, although the specimens were tested in a separate investigation.

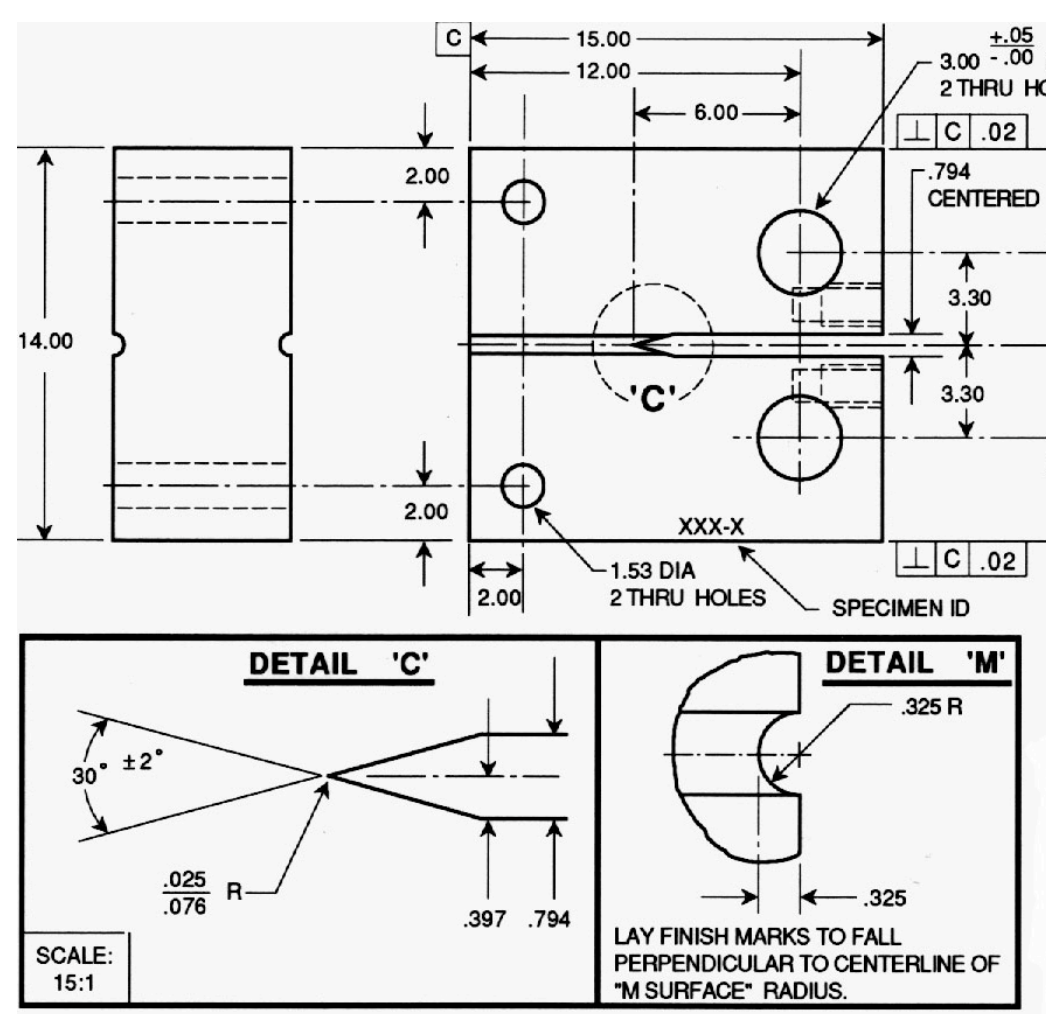

Figure 2. Geometry of compact-tension specimen. 
This page is intentionally blank. 


\section{Specimen Irradiation}

Ninety-six SSRT and 24 CT specimens were encapsulated in six capsules, each capsule containing 16 SSRT and 4 CT specimens. A fixed 0.5-mm gap, filled with He, was allowed between the inner wall of the Type 304 SS capsule and the specimen surface. The size of the gap was selected to maintain specimen temperature at $289^{\circ} \mathrm{C}$ during irradiation in He. To prevent capsule wall creepdown and possible changes in gap size, spacers in the form of Type $304 \mathrm{SS}$ wires $(0.5$ - $\mathrm{mm}$ diameter) were placed between the specimens and the capsule inner wall. Type $304 \mathrm{SS}$ filler bodies were inserted on both sides of the SSRT specimen stack to avoid overheating the thin gauge section. Table 5 shows the specimens categorized according to alloy, fluence level, and postirradiation test type. The six capsules were irradiated in the Halden HBWR starting on April 8, 1992. Fast neutron $(\mathrm{E}>1 \mathrm{MeV})$ flux during the various irradiation cycles ranged from $1.80 \times 10^{13}$ $\mathrm{n} \cdot \mathrm{cm}^{-2} \mathrm{~s}^{-1}$ to $3.31 \times 10^{13} \mathrm{n} \cdot \mathrm{cm}^{-2} \mathrm{~s}^{-1}$. The irradiation history of the six capsules is summarized in Table 6 . Specimen temperature during the irradiation, determined on the basis of the melting behavior of five to six types of low-melting alloys, was $288 \pm 2^{\circ} \mathrm{C}$.

Table 5. Specimen number per alloy, irradiation fluence level, and postirradiation test type.

\begin{tabular}{|c|c|c|c|c|c|c|c|c|c|}
\hline \multirow[t]{2}{*}{ Alloy ID } & \multicolumn{3}{|c|}{ SSRT Test } & \multicolumn{3}{|c|}{ Constant Load Test } & \multicolumn{3}{|c|}{ J-R, Crack Growth Rate Test } \\
\hline & high $^{\mathrm{a}}$ & medium $^{\mathrm{a}}$ & low ${ }^{\mathrm{a}}$ & high & & low & & & low \\
\hline $\mathrm{C} 1$ & 1 & 1 & 1 & & & & & & \\
\hline $\mathrm{L} 2$ & 1 & 1 & & & & & 1 & 1 & \\
\hline $\mathrm{C} 3$ & 1 & 1 & 1 & & & & 1 & 1 & 1 \\
\hline L4 & 1 & 1 & 1 & & & & & & \\
\hline L5 & 1 & 1 & 1 & & & & 1 & & \\
\hline L6 & 1 & 1 & & & & & & & \\
\hline L7 & 1 & 1 & & & & & & & \\
\hline L8 & 1 & 1 & 1 & & & & & & \\
\hline C9 & 1 & 1 & 1 & & & & & & \\
\hline $\mathrm{C} 10$ & 1 & 1 & 1 & & & & & & \\
\hline L11 & 1 & 1 & 1 & & & & & & \\
\hline $\mathrm{C} 12$ & 1 & 1 & 1 & & & & & & \\
\hline L13 & 1 & 1 & 1 & & & & & & \\
\hline L14 & 1 & 1 & & & & & 1 & & \\
\hline L15 & 1 & 1 & & & & & & & \\
\hline $\mathrm{C} 16$ & 1 & 1 & 1 & & & & 1 & 1 & \\
\hline L17 & 1 & 1 & & & & & & & \\
\hline L18 & 1 & 1 & 1 & & & & 1 & 1 & \\
\hline C19 & 5 & 1 & 1 & 4 & 4 & & 1 & 1 & 1 \\
\hline L20 & 5 & 1 & 1 & 4 & 4 & & 1 & 1 & 1 \\
\hline $\mathrm{C} 21$ & 1 & 1 & 1 & & & & 1 & 1 & 1 \\
\hline L22 & 1 & 1 & 1 & & & & 1 & 1 & \\
\hline L23 & 1 & 1 & & & & & 1 & & \\
\hline L24 & 1 & 1 & & & & & 1 & & \\
\hline L25 & 3 & & & & & & & & \\
\hline L26 & 3 & & & & & & & & \\
\hline L27 & 2 & & & & & & & & \\
\hline
\end{tabular}

a Target fluence level in units of $10^{21} \mathrm{n} \cdot \mathrm{cm}^{-2}, 0.3$ (low), 0.9 (medium), and 2.5 (high). 
Table 6. Summary of discharge date and fluence of model austenitic stainless steel alloys irradiated in Halden Heavy Boiling Water Reactor.

\begin{tabular}{|c|l|c|l|l|c|}
\hline Capsule ID & $\begin{array}{c}\text { Fluence } \\
\text { Level }\end{array}$ & $\begin{array}{c}\text { Target } \\
\text { Fluence }^{\mathrm{a}}\end{array}$ & \multicolumn{1}{|c|}{ Irradiation Cycles } & \multicolumn{1}{|c|}{$\begin{array}{c}\text { Discharge } \\
\text { Date }\end{array}$} & $\begin{array}{c}\text { Discharge } \\
\text { Fluence }^{\mathrm{a}}\end{array}$ \\
\hline 1 & Medium & 1.0 & IFA 530-3 to -6, D07-004-2 & Nov. 1996 & 0.9 \\
\hline 4 & Low & 0.4 & IFA 530-3 & Oct. 1992 & 0.3 \\
\hline 5 & High & 2.5 & IFA 530-4 to -6, D07-004-1 to -3 & Nov. 1999 & 2.0 \\
\hline 6 & High & 2.5 & IFA 530-4 to -6, D07-004-1 to -3 & Nov. 1999 & 2.0 \\
\hline 7 & Medium & 1.0 & IFA 530-4 and -6, D07-004-1 & May 1996 & 0.9 \\
\hline 8 & high & 2.5 & IFA 530-5 to -6, D07-004-1 to -3 & Nov. 1999 & 2.0 \\
\hline
\end{tabular}

an units of $10^{21} \mathrm{n} \cdot \mathrm{cm}^{-2}(\mathrm{E}>1 \mathrm{MeV})$. 


\section{Postirradiation Testing and Posttest Characterization}

After retrieval of the irradiated specimens from the capsules, slow-strain-rate tensile tests and fractographic characterization by scanning electron microscopy were performed for each specimen listed in Table 5. In addition to the irradiated specimens, unirradiated control specimens were also tested under the same conditions.

All SSRT tests were conducted at $289^{\circ} \mathrm{C}$ in simulated BWR-like water that contained $\approx 8$ ppm dissolved oxygen (DO). Conductivity and $\mathrm{pH}$ of the water at $23^{\circ} \mathrm{C}$ were kept at $\approx 0.07-0.10 \mu \mathrm{S} \mathrm{cm}^{-1}$ and $\approx 6.5$, respectively. Strain rate was held constant at $1.65 \times 10^{-7} \mathrm{~s}^{-1}$. Electrochemical potential (ECP) was measured at the effluent side at regular intervals.

A limited number of specimens were selected and tested in air either at $23^{\circ} \mathrm{C}$ or $289-325^{\circ} \mathrm{C}$ in asirradiated state by the SSRT technique at a strain rate of $1.65 \times 10^{-7} \mathrm{~s}^{-1}$. The objective of such testing was to determine the susceptibility of the selected heats to irradiation-assisted intergranular cracking in an inert environment at high fluence, and to compare the result with the susceptibility of the same heats to IASCC in $289^{\circ} \mathrm{C}$ water.

Some high-fluence specimens, irradiated to $2.0 \times 10^{21} \mathrm{n} \mathrm{cm}^{-2}(\approx 3 \mathrm{dpa})$ and SSRT-tested in BWR-like oxidizing water at $289^{\circ} \mathrm{C}$, were selected for rapid bending tests in $23^{\circ} \mathrm{C}$ air. Fracture in such a test was produced by simple bending of the gauge section near the specimen fracture tip that was produced during SSRT testing in $289^{\circ} \mathrm{C}$ water. Surprisingly, many high-fluence specimens were susceptible to intergranular cracking in $23^{\circ} \mathrm{C}$ air after $1-3$ times of repeated bending to $\approx 90^{\circ}$.

After SSRT testing in water or in air, fracture surface morphology was imaged in a shield scanning electron microscope (SEM). From the medium-magnification (100-150X) images, a composite fracture surface was constructed for each tested specimen. The type of fracture surface morphology (i.e., ductile, intergranular, and transgranular) was identified from the high-magnification fractographs, which varied from region to region on the fracture surface. From the composite of the whole fracture surface, fractions of intergranular (IG) and transgranular (TG) fracture morphology were measured. 
This page is intentionally blank. 


\section{SSRT SCC Test and Fractography on Unirradiated Specimens}

Yield strength and total elongation, measured on the non-irradiated control specimens in the 8-ppm-DO water at $288^{\circ} \mathrm{C}$, are plotted in Figs. 3 and 4, respectively. Yield strengths of the non-irradiated solutionannealed Type 304 SS heats were 170-240 MPa, whereas yield strengths of Type 316 and 348 SS heats were significantly higher, i.e., 280-300 MPa and 330-350 MPa, respectively. Total elongation measured in water on most non-irradiated specimens was $17-59 \%$ (see Fig. 4). However, heat-to-heat variation in ductility in BWR-like water was significant, even among the same type of steel. Of the 17 heats tested in $289^{\circ} \mathrm{C}$ water, five heats exhibited relatively low ductility. Compositional characteristics of these five heats are denoted in Fig. 4. Two Type 304 SS heats that contained unusually high concentrations of S exhibited unusually low ductility (5-8\%), i.e., Heat L7 (S 0.038 wt.\%) and Heat L2 (S 0.034 wt.\%). Tables 7 and 8 summarize the results obtained from non-irradiated specimens.
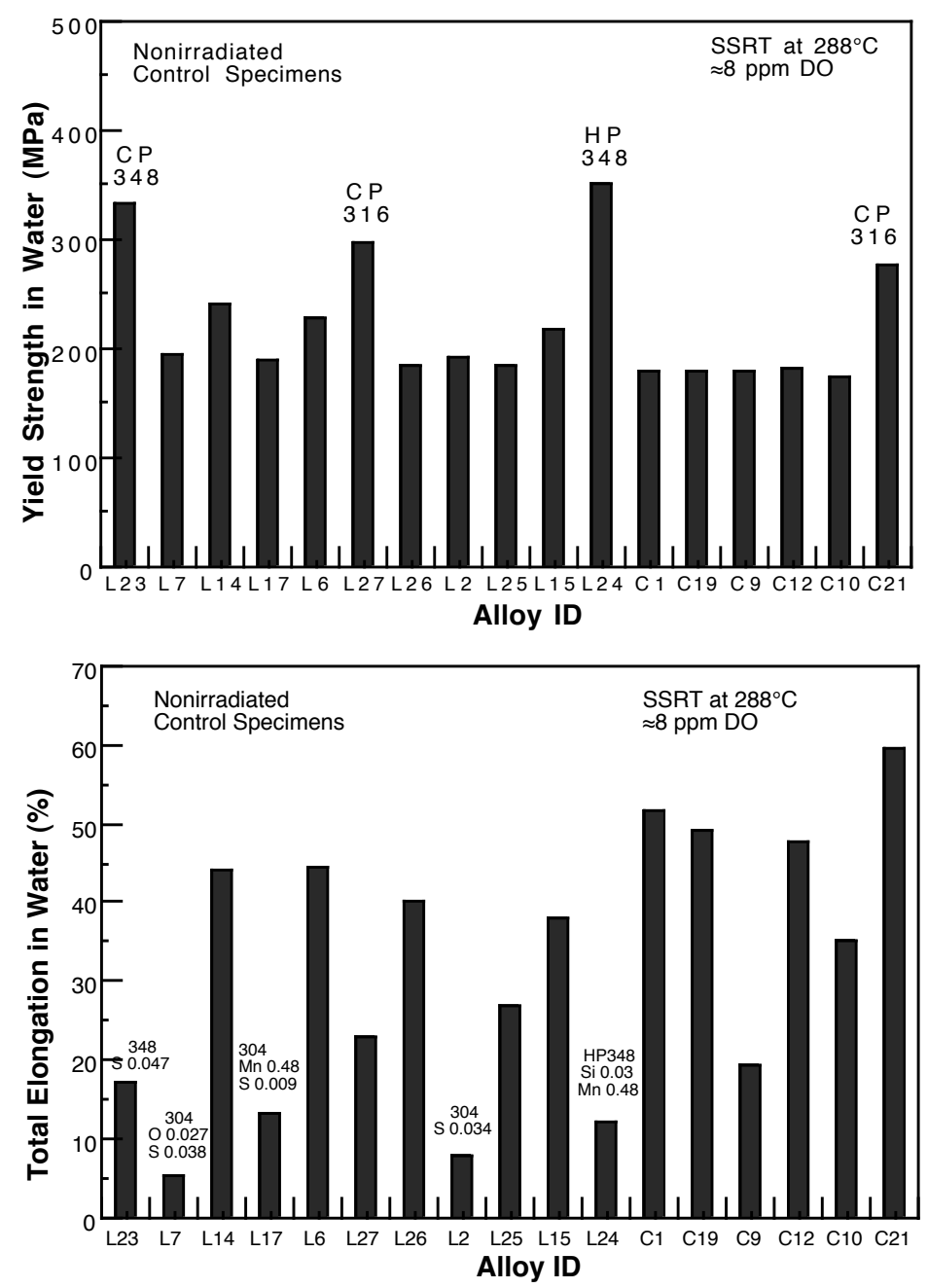

Figure 3.

Yield strength of non-irradiated control specimens of model stainless steel alloys tested at $288^{\circ} \mathrm{C}$ in BWR-simulated water containing $\approx 8$ ppm DO.
Figure 4.

Total elongation of nonirradiated control specimens of model stainless steel alloys tested at $288^{\circ} \mathrm{C}$ in BWRsimulated water containing $\approx 8 \mathrm{ppm} \mathrm{DO}$. 
Table 7. Results of SSRT test and SEM fractography for non-irradiated control specimens of model austenitic stainless steel alloys.

\begin{tabular}{|c|c|c|c|c|c|c|c|c|c|c|c|c|}
\hline \multirow{2}{*}{$\begin{array}{c}\text { ALLOY ANI } \\
\text { SPECIMEN } \\
\text { IDENT. } \\
\text { No. }\end{array}$} & \multirow[b]{2}{*}{$\begin{array}{c}\text { SSRT } \\
\text { No. }\end{array}$} & \multicolumn{4}{|c|}{ FEEDWATER CHEMISTRY } & \multicolumn{4}{|c|}{ SSRT PARAMETERS } & \multicolumn{3}{|c|}{ FRACTURE BEHAVIOR } \\
\hline & & $\begin{array}{l}\text { OXYGEN } \\
\text { CONC. } \\
\text { (PPM) }\end{array}$ & $\begin{array}{c}\text { AVERAGE } \\
\text { ECP } \\
\text { (MV SHE) }\end{array}$ & $\begin{array}{c}\text { COND. } \\
\text { AT } 25^{\circ} \mathrm{C} \\
\left(\mu \mathrm{S} \cdot \mathrm{CM}^{1}\right)\end{array}$ & $\begin{array}{c}\text { PH } \\
\text { AT } 25^{\circ} \mathrm{C}\end{array}$ & $\begin{array}{c}\text { YIELD } \\
\text { STRESS } \\
\text { (MPA) }\end{array}$ & $\begin{array}{c}\text { MAX. } \\
\text { STRESS } \\
\text { (MPA) }\end{array}$ & $\begin{array}{l}\text { UNIFORM } \\
\text { ELONG. } \\
\text { (\%) }\end{array}$ & $\begin{array}{l}\text { TOTAL } \\
\text { ELONG. } \\
\text { (\%) }\end{array}$ & $\begin{array}{c}\text { TGSCC } \\
\text { (\%) }\end{array}$ & $\begin{array}{l}\text { IGSCC } \\
\text { (\%) }\end{array}$ & $\begin{array}{l}\text { TGSCC+ } \\
\text { IGSCC } \\
\text { (\%) }\end{array}$ \\
\hline L23-4 & CHR-1 & 8.6 & +228 & 0.07 & 6.65 & 332 & 480 & 15.6 & 17.0 & 15 & $\mathbf{0}$ & 15 \\
\hline L7-4 & CHR-2 & 8.0 & +217 & 0.07 & 7.37 & 195 & 370 & 2.5 & 5.2 & 20 & $\mathbf{0}$ & 20 \\
\hline L7-B1 & CHR-7 & \multicolumn{4}{|c|}{ TESTED IN AIR } & 282 & 676 & 42.3 & 43.9 & $\mathbf{0}$ & $\mathbf{0}$ & $\mathbf{0}$ \\
\hline L14-4 & CHR-3 & 8.6 & +208 & 0.07 & 7.37 & 240 & 474 & 41.8 & 44.2 & 0 & $\mathbf{0}$ & $\mathbf{0}$ \\
\hline L17-4 & CHR-4 & 7.5 & +262 & 0.06 & 7.09 & 189 & 412 & 11.6 & 13.3 & 60 & $\mathbf{0}$ & 60 \\
\hline L17-B1 & CHR-19 & 7.8 & +166 & 0.08 & 6.71 & 184 & 447 & 30.1 & 31.2 & 8 & $\mathbf{0}$ & 8 \\
\hline L6-4 & CHR-5 & 7.9 & +256 & 0.08 & 6.85 & 227 & 545 & 43.0 & 44.5 & $\mathbf{0}$ & $\mathbf{0}$ & $\mathbf{0}$ \\
\hline L27-4 & CHR-6 & 9.3 & +247 & 0.08 & 6.96 & 298 & 483 & 20.6 & 22.9 & 0 & $\mathbf{0}$ & $\mathbf{0}$ \\
\hline L26-4 & CHR-8 & 9.4 & +223 & 0.07 & 6.65 & 184 & 596 & 38.2 & 40.2 & $\mathbf{0}$ & $\mathbf{0}$ & $\mathbf{0}$ \\
\hline L2-4 & CHR-9 & 8.6 & +292 & 0.06 & 6.55 & 193 & 348 & 6.6 & 7.8 & 57 & $\mathbf{0}$ & 57 \\
\hline L25-4 & CHR-10 & 8.2 & +239 & 0.06 & 6.42 & 184 & 458 & 25.5 & 27.0 & 0 & 0 & 0 \\
\hline L15-4 & CHR-11 & 8.2 & +195 & 0.06 & 6.32 & 218 & 512 & 36.7 & 37.9 & 0 & 0 & 0 \\
\hline L24-4 & CHR-12 & 8.4 & +200 & 0.07 & 6.20 & 352 & 461 & 10.4 & 12.3 & 10 & o & 10 \\
\hline C1-15 & CHR-13 & 8.1 & +187 & 0.07 & 6.33 & 179 & 498 & 49.4 & 51.7 & 0 & 0 & 0 \\
\hline C19-B1 & CHR-14 & 8.8 & +179 & 0.08 & 6.29 & 178 & 501 & 47.4 & 49.2 & 0 & o & 0 \\
\hline C9-B1 & CHR-15 & 8.5 & +166 & 0.07 & 6.83 & 178 & 408 & 17.4 & 19.4 & 32 & o & 32 \\
\hline C12-B1 & CHR-16 & 8.5 & +124 & 0.07 & 6.18 & 182 & 511 & 46.0 & 47.6 & 0 & o & 0 \\
\hline C10-B1 & CHR-17 & 9.2 & +145 & 0.07 & 6.26 & 174 & 478 & 30.6 & 35.1 & 0 & o & 0 \\
\hline C21-9 & CHR-18 & 9.2 & +187 & 0.07 & 6.41 & 277 & 455 & 48.9 & 59.5 & 0 & 0 & 0 \\
\hline
\end{tabular}

Table 8. Composition (wt.\%) of non-irradiated control specimens of model austenitic stainless steels correlated with results of SSRT test and SEM fractography.

\begin{tabular}{|c|c|c|c|c|c|c|c|c|c|c|c|c|c|c|c|c|}
\hline $\begin{array}{c}\text { Alloy } \\
\text { ID }\end{array}$ & $\mathrm{Ni}$ & $\mathrm{Si}$ & $\mathrm{P}$ & $\mathrm{S}$ & $\mathrm{Mn}$ & $\mathrm{C}$ & $\mathrm{N}$ & $\mathrm{Cr}$ & $\begin{array}{c}\text { Mo or } \\
\mathrm{Nb}\end{array}$ & $\begin{array}{c}\mathrm{O} \\
\text { wppm }\end{array}$ & $\begin{array}{c}\mathrm{YS} \\
(\mathrm{MPa})\end{array}$ & $\begin{array}{c}\text { UTS } \\
(\mathrm{MPa})\end{array}$ & $\begin{array}{l}\text { UE } \\
(\%)\end{array}$ & $\begin{array}{c}\mathrm{TE} \\
(\%)\end{array}$ & $\begin{array}{l}\text { TG } \\
(\%)\end{array}$ & $\begin{array}{l}\mathrm{IG} \\
(\%)\end{array}$ \\
\hline L23 & 12.04 & 0.68 & 0.030 & 0.047 & 0.96 & 0.043 & 0.092 & 17.30 & $\mathrm{Nb} 1.06$ & 93 & 332 & 480 & 15.6 & 17.0 & 15 & 0 \\
\hline L7 & 10.60 & 0.18 & 0.040 & 0.038 & 1.02 & 0.007 & 0.111 & 15.40 & - & 274 & 195 & 370 & 2.5 & 5.2 & 20 & 0 \\
\hline L14 & 7.93 & 1.49 & 0.080 & 0.002 & 1.76 & 0.107 & 0.028 & 15.00 & - & 45 & 240 & 474 & 41.8 & 44.2 & 0 & 0 \\
\hline L17 & 8.00 & 0.66 & 0.090 & 0.009 & 0.48 & 0.061 & 0.078 & 15.30 & - & 90 & 189 & 412 & 11.6 & 13.3 & 60 & 0 \\
\hline L6 & 10.00 & 1.90 & 0.020 & 0.005 & 1.13 & 0.096 & 0.087 & 17.10 & - & 58 & 227 & 515 & 43.0 & 44.5 & 0 & 0 \\
\hline $\mathrm{L} 27$ & 10.30 & 0.96 & 0.040 & 0.002 & 0.97 & 0.057 & 0.019 & 15.30 & Mo 2.01 & 58 & 298 & 483 & 20.6 & 22.9 & 0 & 0 \\
\hline L26 & 8.09 & 0.79 & 0.004 & 0.002 & 0.91 & 0.070 & 0.089 & 17.20 & - & 80 & 184 & 506 & 38.2 & 40.2 & 0 & 0 \\
\hline $\mathrm{L} 2$ & 10.50 & 0.82 & 0.080 & 0.034 & 1.58 & 0.074 & 0.102 & 17.02 & - & 66 & 193 & 348 & 6.6 & 7.8 & 57 & 0 \\
\hline L25 & 8.93 & 0.92 & 0.020 & 0.008 & 1.54 & 0.019 & 0.095 & 17.20 & - & 85 & 184 & 458 & 25.5 & 27.0 & 0 & 0 \\
\hline L15 & 8.00 & 1.82 & 0.010 & 0.013 & 1.07 & 0.020 & 0.085 & 17.80 & - & 110 & 218 & 512 & 36.7 & 37.9 & 10 & 0 \\
\hline L24 & 12.30 & 0.03 & 0.007 & 0.005 & 0.48 & 0.031 & 0.002 & 16.90 & $\mathrm{Nb} 1.72$ & 129 & 352 & 461 & 10.4 & 12.3 & 0 & 0 \\
\hline $\mathrm{C} 1$ & 8.12 & 0.50 & 0.038 & 0.002 & 1.00 & 0.060 & 0.060 & 18.11 & - & 102 & 179 & 498 & 49.4 & 51.7 & 0 & 0 \\
\hline C19 & 8.08 & 0.45 & 0.031 & 0.003 & 0.99 & 0.060 & 0.070 & 18.21 & - & 200 & 178 & 501 & 47.4 & 49.2 & 0 & 0 \\
\hline $\mathrm{C} 9$ & 8.75 & 0.39 & 0.013 & 0.013 & 1.72 & 0.062 & 0.065 & 18.48 & - & 102 & 178 & 408 & 17.4 & 19.4 & 32 & 0 \\
\hline $\mathrm{C} 12$ & 8.23 & 0.47 & 0.018 & 0.002 & 1.00 & 0.060 & 0.070 & 18.43 & - & - & 182 & 511 & 46.0 & 47.6 & 0 & 0 \\
\hline $\mathrm{C} 10$ & 8.13 & 0.55 & 0.033 & 0.002 & 1.00 & 0.060 & 0.086 & 18.19 & - & 74 & 174 & 478 & 30.6 & 35.1 & 0 & 0 \\
\hline $\mathrm{C} 21$ & 10.24 & 0.51 & 0.034 & 0.001 & 1.19 & 0.060 & 0.020 & 16.28 & Mo 2.08 & 112 & 277 & 455 & 48.9 & 59.5 & 0 & 0 \\
\hline
\end{tabular}


Load-elongation behavior of Type 304 SS Heat L7 exhibited significantly deleterious effects of water even in the nonirradiated state, as shown in Fig. 5. Approximately $20 \%$ of the fracture surface of the specimen was characterized by transgranular fracture morphology that was mostly covered with unidentified corrosion debris (Fig. 6). Although it was suspected that such corrosion debris contained a high concentration of S, positive identification of the debris could not be determined.

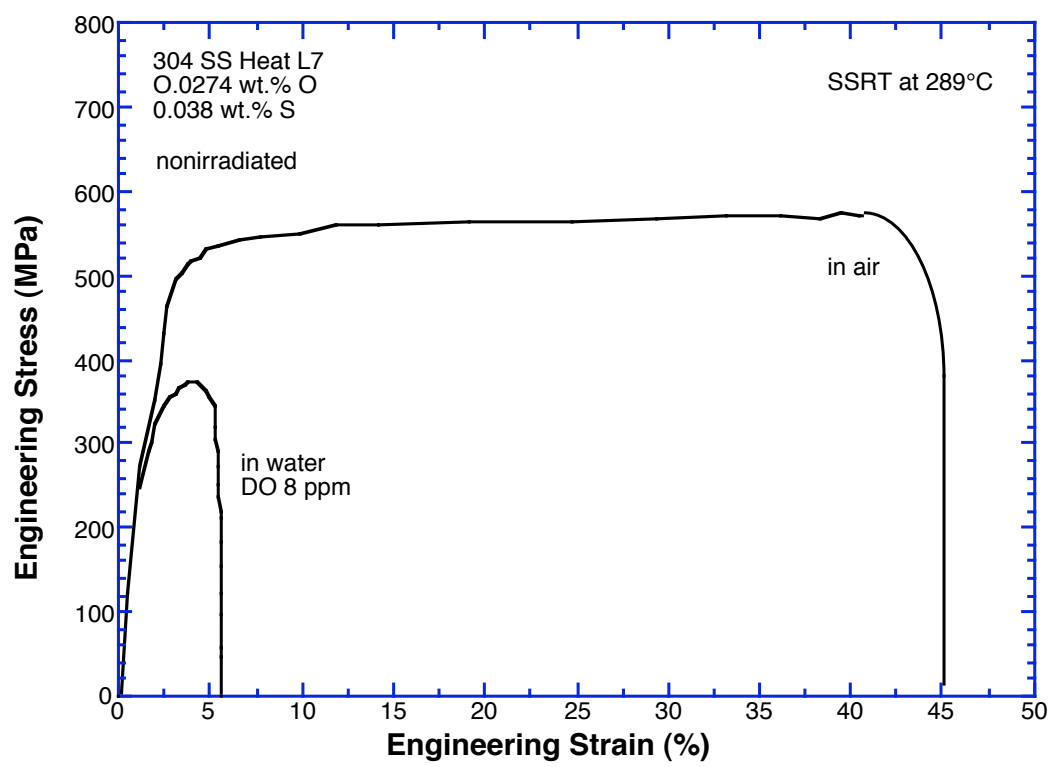

Figure 5.

Load vs. elongation of nonirradiated Type 304 SS that contains unusually high concentrations of $\mathrm{O}$ (0.0274 wt.\%) and S (0.038 wt. \%); tests at $289^{\circ} \mathrm{C}$ in air and BWR-simulated water containing $\approx 8 \mathrm{ppm}$ DO.

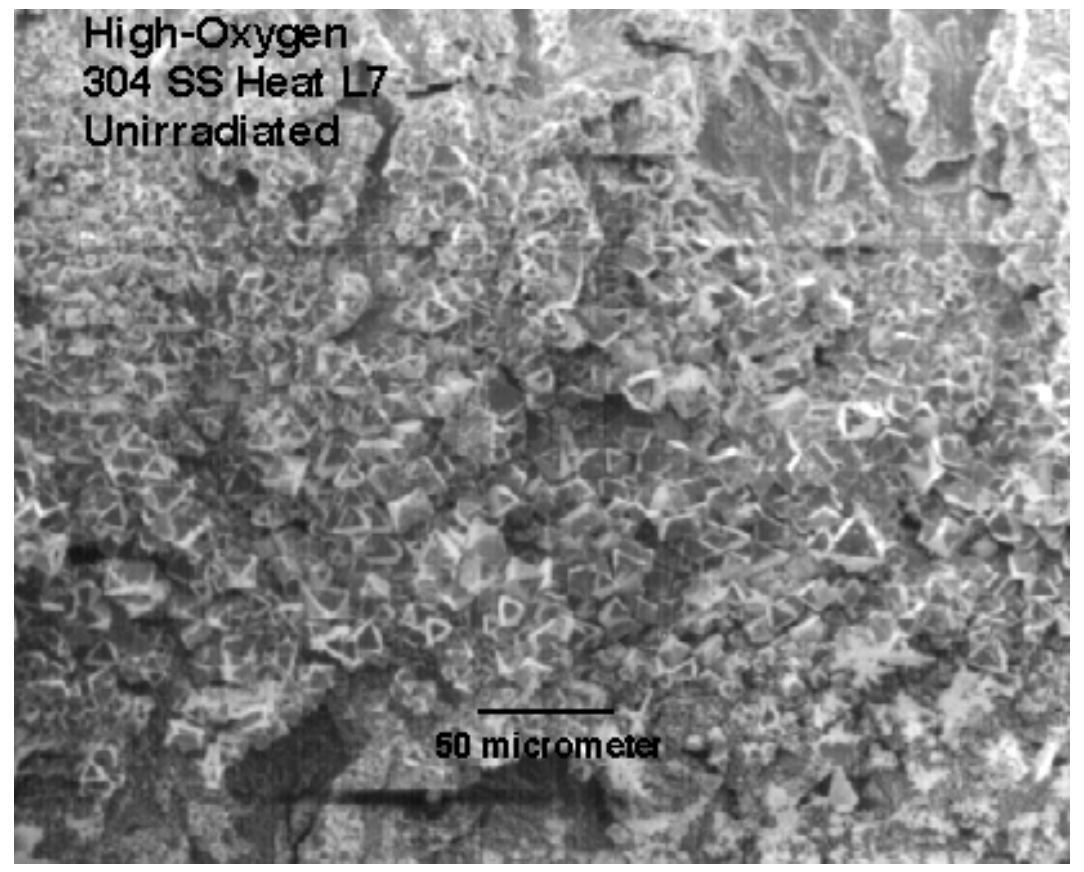

Figure 6.

Corrosion debris formed on non-ductile fracture surface of non-irradiated Type 304 SS Heat L7 that contains unusually high concentrations of $\mathrm{O}$ and $\mathrm{S}$; SSRT test at $288^{\circ} \mathrm{C}$ in BWRlike water containing $\approx 8 \mathrm{ppm}$ DO.

The five heats that exhibited relatively low ductility were characterized by relatively high susceptibility to TGSCC. Other heats were very ductile and exhibited predominantly ductile dimple fracture surface morphology. However, no evidence of susceptibility to IGSCC was observed in any of the 17 heats that were tested in the BWR-like water at $289^{\circ} \mathrm{C}$ in the nonirradiated state. 
This page is intentionally blank. 


\section{SSRT SCC Test and Fractography on Low-Fluence Specimens ( $\approx 0.4 \mathrm{dpa})$}

\subsection{Tabulation of Test Results}

Results of SSRT tests on specimens irradiated to $\approx 0.3 \times 10^{21} \mathrm{n} \cdot \mathrm{cm}^{-2}(\mathrm{E}>1 \mathrm{MeV})(\approx 0.4 \mathrm{dpa})$ are summarized in Tables 9 and 10. Feedwater chemistry (i.e., DO, ECP, conductivity, and pH) and SSRT behavior in water (i.e., $0.2 \%$-offset yield strength, maximum strength, uniform strain, and total strain) are given in Table 9. Also shown in these tables are results of SEM fractographic analysis of the failure mode (i.e., ductile, intergranular, and transgranular fracture surface morphology) of the specimens. In Table 10, the results of SSRT and SEM fractographic analysis (percent TGSCC and percent IGSCC) are correlated with the compositions of the low-fluence specimens.

Table 9. Results of SSRT tests in $289^{\circ} \mathrm{C}$ water $(\mathrm{DO} \approx 8 \mathrm{ppm})$ and SEM fractography of steels irradiated to $\approx 0.3 \times 10^{21} \mathrm{n} \cdot \mathrm{cm}^{-2}(\mathrm{E}>1 \mathrm{MeV})$.

\begin{tabular}{|c|c|c|c|c|c|c|c|c|c|c|c|}
\hline Specimen & & Oxygen & Average & Cond. & $\mathrm{pH}$ & Yield & Max. & Uniform & Total & \multicolumn{2}{|c|}{ Fracture } \\
\hline $\begin{array}{l}\text { Ident. } \\
\text { No. }\end{array}$ & $\begin{array}{l}\text { SSRT } \\
\text { No. }\end{array}$ & $\begin{array}{l}\text { Conc. } \\
\text { (ppm) }\end{array}$ & $\begin{array}{c}\text { ECP } \\
(\mathrm{mV} \mathrm{SHE})\end{array}$ & $\begin{array}{l}\text { at } 25^{\circ} \mathrm{C} \\
\left(\mu \mathrm{S} \mathrm{cm}^{-1}\right)\end{array}$ & $\begin{array}{c}\text { at } \\
25^{\circ} \mathrm{C}\end{array}$ & $\begin{array}{l}\text { Stress } \\
(\mathrm{MPa})\end{array}$ & $\begin{array}{l}\text { Stress } \\
(\mathrm{MPa})\end{array}$ & $\begin{array}{l}\text { Elong. } \\
(\%)\end{array}$ & $\begin{array}{c}\text { Elong. } \\
(\%)\end{array}$ & $\begin{array}{c}\text { TGSCC } \\
(\%)\end{array}$ & $\begin{array}{c}\text { IGSCC } \\
(\%)\end{array}$ \\
\hline C1-1 & HR-1 & 8.3 & +184 & 0.07 & 7.03 & 490 & 680 & 13.4 & 16.6 & 4 & 0 \\
\hline L5-1 & HR-2 & 9.7 & +208 & 0.07 & 6.89 & 413 & 539 & 29.5 & 32.7 & 2 & 2 \\
\hline L22-1 & HR-3 & 8.0 & +236 & 0.07 & 6.80 & 360 & 596 & 6.6 & 9.4 & 50 & 15 \\
\hline C3-1 & HR-4 & 8.7 & +161 & 0.07 & 6.68 & 338 & 491 & 27.7 & 31.6 & 5 & 0 \\
\hline C16-1 & HR-5 & 8.3 & +204 & 0.08 & 6.74 & 370 & 527 & 17.6 & 20.6 & 2 & 0 \\
\hline L4-1 & HR-6 & 9.0 & +202 & 0.08 & 6.70 & 367 & 542 & 19.7 & 22.3 & 46 & 0 \\
\hline L18-1 & HR-7 & 9.0 & +203 & 0.08 & 6.33 & 503 & 572 & 6.3 & 8.8 & 54 & 0 \\
\hline $\mathrm{C} 10-1$ & HR-8 & 8.2 & +174 & 0.07 & 6.35 & 523 & 640 & 17.4 & 18.9 & 6 & 0 \\
\hline C21-1 & HR-9 & 8.1 & +149 & 0.08 & 6.49 & 480 & 620 & 15.9 & 19.4 & 4 & 0 \\
\hline L11-1 & HR-10 & 9.0 & +157 & 0.08 & 6.17 & 487 & 599 & 2.3 & 3.8 & 62 & 0 \\
\hline L13-1 & HR-11 & 8.7 & +164 & 0.08 & 6.17 & 248 & 461 & 22.1 & 24.8 & 18 & 0 \\
\hline L20-1 & HR-12 & 8.4 & +174 & 0.07 & 6.20 & 454 & 552 & 2.9 & 5.1 & \multicolumn{2}{|c|}{ dendrite } \\
\hline C19-1 & HR-13 & 9.5 & +132 & 0.12 & 6.36 & 554 & 682 & 10.5 & 14.7 & 7 & 0 \\
\hline C9-1 & HR-14 & 8.0 & +192 & 0.11 & 6.30 & 522 & 607 & 13.4 & 14.6 & 24 & 0 \\
\hline C12-1 & HR-15 & 9.0 & +195 & 0.08 & 6.40 & 404 & 589 & 20.4 & 24.2 & 5 & 0 \\
\hline L8-1 & HR-16 & 9.0 & +215 & 0.08 & 6.60 & 411 & 571 & 15.6 & 17.9 & 64 & 0 \\
\hline
\end{tabular}

\subsection{Susceptibility to IGSCC}

Even at the low damage level of $\approx 0.4 \mathrm{dpa}$, heat-to-heat variations in susceptibility to IGSCC and TGSCC were significant among the steels tested and listed in Table 10. A high-purity Heat L22 of Type 316L SS, which contains very low concentrations of Si (0.024 wt.\%) and C (0.003 wt.\%), exhibited relatively low ductility and the highest susceptibility to IASCC (i.e., the highest percent IGSCC) among the 16 tested heats. The high-purity Heat L20 of Type 304L SS, which contains very low concentrations of Si (0.017 wt.\%) and C (0.002 wt.\%), also exhibited an indication of slight susceptibility to IGSCC. Susceptibility of all other heats to IGSCC was insignificant (see Fig. 7).

At this low fluence, the limited observation in Fig. 7 seems to indicate that very low concentrations of $\mathrm{Si}$ and $\mathrm{C}$ are deleterious from the standpoint of IASCC. The susceptible behavior of the two high-purity heats in the figure appears to be consistent with similar behavior of BWR neutron absorber tubes fabricated from 
high-purity 304L SSs which exhibited relatively higher susceptibility during SSRT tests performed after irradiation to $0.2 \times 10^{21} \mathrm{n} \cdot \mathrm{cm}^{-2}$ to $1.4 \times 10^{21} \mathrm{n} \cdot \mathrm{cm}^{-2}(\mathrm{E}>1 \mathrm{MeV}) \cdot{ }^{19}$ However, field failure by IASCC in a BWR usually occurs at higher fluence levels, e.g., $>1.5 \times 10^{21} \mathrm{n} \cdot \mathrm{cm}^{-2}(\mathrm{E}>1 \mathrm{MeV})$. Therefore, a comprehensive database at higher fluence levels is necessary to be able to evaluate the roles of $\mathrm{Si}, \mathrm{C}$, and other impurity elements.

Figure 8 shows that limited intergranular fracture surface morphology is surrounded by transgranular morphology in Heat L22, indicating that transgranular fracture made a transition to intergranular fracture. Heat L22 also exhibited relatively high susceptibility to IGSCC after irradiation to higher fluence (Section 7).

Table 10. Composition (wt.\%) of steels irradiated to $\approx 0.3 \times 10^{21} \mathrm{n} \cdot \mathrm{cm}^{-2}(\mathrm{E}>1 \mathrm{MeV})$ correlated with results of SSRT tests and SEM fractography.

\begin{tabular}{|c|c|c|c|c|c|c|c|c|c|c|c|c|c|c|c|}
\hline $\begin{array}{l}\text { Spec. } \\
\text { ID }\end{array}$ & $\mathrm{Ni}$ & $\mathrm{Si}$ & $P$ & $\mathrm{~S}$ & $\mathrm{Mn}$ & $\mathrm{C}$ & $\mathrm{N}$ & $\mathrm{Cr}$ & Others & $\begin{array}{c}\mathrm{YS} \\
(\mathrm{MPa}) \\
\end{array}$ & $\begin{array}{c}\text { UTS } \\
\text { (MPa) }\end{array}$ & $\begin{array}{l}\mathrm{UE} \\
(\%) \\
\end{array}$ & $\begin{array}{c}\mathrm{TE} \\
(\%) \\
\end{array}$ & $\begin{array}{l}\mathrm{TG} \\
(\%) \\
\end{array}$ & $\begin{array}{l}\text { IG } \\
(\%)\end{array}$ \\
\hline $\mathrm{C} 1-1$ & 8.12 & 0.50 & 0.038 & 0.002 & 1.00 & 0.060 & 0.060 & 18.11 & O 0.0102 & 490 & 680 & 13.4 & 16.6 & 4 & 0 \\
\hline $\mathrm{L} 5-1^{\mathrm{a}}$ & 9.66 & 0.90 & 0.113 & 0.028 & 0.47 & 0.006 & .033 & 21.00 & $\begin{array}{l}\text { O } 0.0068 \\
\approx 3 \% \delta^{\mathrm{a}}\end{array}$ & 413 & 539 & 29.5 & 32.7 & 2 & 2 \\
\hline L22-1 & 13.30 & 0.024 & 0.015 & 0.004 & 0.40 & 0.003 & 0.001 & 16.10 & $\begin{array}{l}\text { O } 0.0103 \\
\text { Mo } 2.04\end{array}$ & 360 & 596 & 6.6 & 9.4 & 50 & 15 \\
\hline C3-1 & 8.91 & 0.46 & 0.019 & 0.004 & 1.81 & 0.016 & 0.083 & 18.55 & - & 338 & 491 & 27.7 & 31.6 & 5 & 0 \\
\hline C16-1 & 12.90 & 0.38 & 0.014 & 0.002 & 1.66 & 0.020 & 0.011 & 16.92 & $\begin{array}{l}\text { O } 0.0157 \\
\text { Mo } 2.30\end{array}$ & 370 & 527 & 17.6 & 20.6 & 2 & 0 \\
\hline L4-1 & 10.20 & 0.94 & 0.031 & 0.010 & 1.75 & 0.110 & 0.002 & 15.80 & O 0.0037 & 367 & 542 & 19.7 & 22.3 & 46 & 0 \\
\hline L18-1 & 8.13 & 0.14 & 0.016 & 0.033 & 1.13 & 0.080 & 0.001 & 18.00 & O 0.0055 & 503 & 572 & 6.3 & 8.8 & 54 & 0 \\
\hline C10-1 & 8.13 & 0.55 & 0.033 & 0.002 & 1.00 & 0.060 & 0.086 & 18.19 & O 0.0074 & 523 & 640 & 17.4 & 18.9 & 6 & 0 \\
\hline C21-1 & 10.24 & 0.51 & 0.034 & 0.001 & 1.19 & 0.060 & 0.020 & 16.28 & $\begin{array}{l}\text { O } 0.0112 \\
\text { Mo } 2.08\end{array}$ & 480 & 620 & 15.9 & 19.4 & 4 & 0 \\
\hline L11-1 & 8.15 & 0.47 & 0.097 & 0.009 & 1.02 & 0.014 & 0.004 & 17.40 & O 0.0071 & 487 & 599 & 2.3 & 3.8 & 62 & 0 \\
\hline L13-1 & 8.18 & 1.18 & 0.027 & 0.022 & 0.36 & 0.026 & 0.001 & 17.40 & O 0.0042 & 248 & 461 & 22.1 & 24.8 & 18 & 0 \\
\hline L20-1 & 8.91 & 0.017 & 0.010 & 0.004 & 0.41 & 0.002 & 0.002 & 18.10 & O 0.0940 & 454 & 552 & 2.9 & 5.1 & \multicolumn{2}{|c|}{ dendrite } \\
\hline C19-1 & 8.08 & 0.45 & 0.031 & 0.003 & 0.99 & 0.060 & 0.070 & 18.21 & O 0.0200 & 554 & 682 & 10.5 & 14.7 & 7 & 0 \\
\hline C9-1 & 8.75 & 0.39 & 0.013 & 0.013 & 1.72 & 0.062 & 0.065 & 18.48 & O 0.0102 & 522 & 607 & 13.4 & 14.6 & 24 & 0 \\
\hline C12-1 & 8.23 & 0.47 & 0.018 & 0.002 & 1.00 & 0.060 & 0.070 & 18.43 & - & 404 & 589 & 20.4 & 24.2 & 5 & 0 \\
\hline L8-1 & 10.20 & 0.15 & 0.093 & 0.010 & 1.85 & 0.041 & 0.001 & 18.30 & O 0.0059 & 411 & 571 & 15.6 & 17.8 & 64 & 0 \\
\hline
\end{tabular}

${ }^{\text {a Heat }}$ L5 contains $\approx 3$ vol. $\%$ globular delta ferrite. 

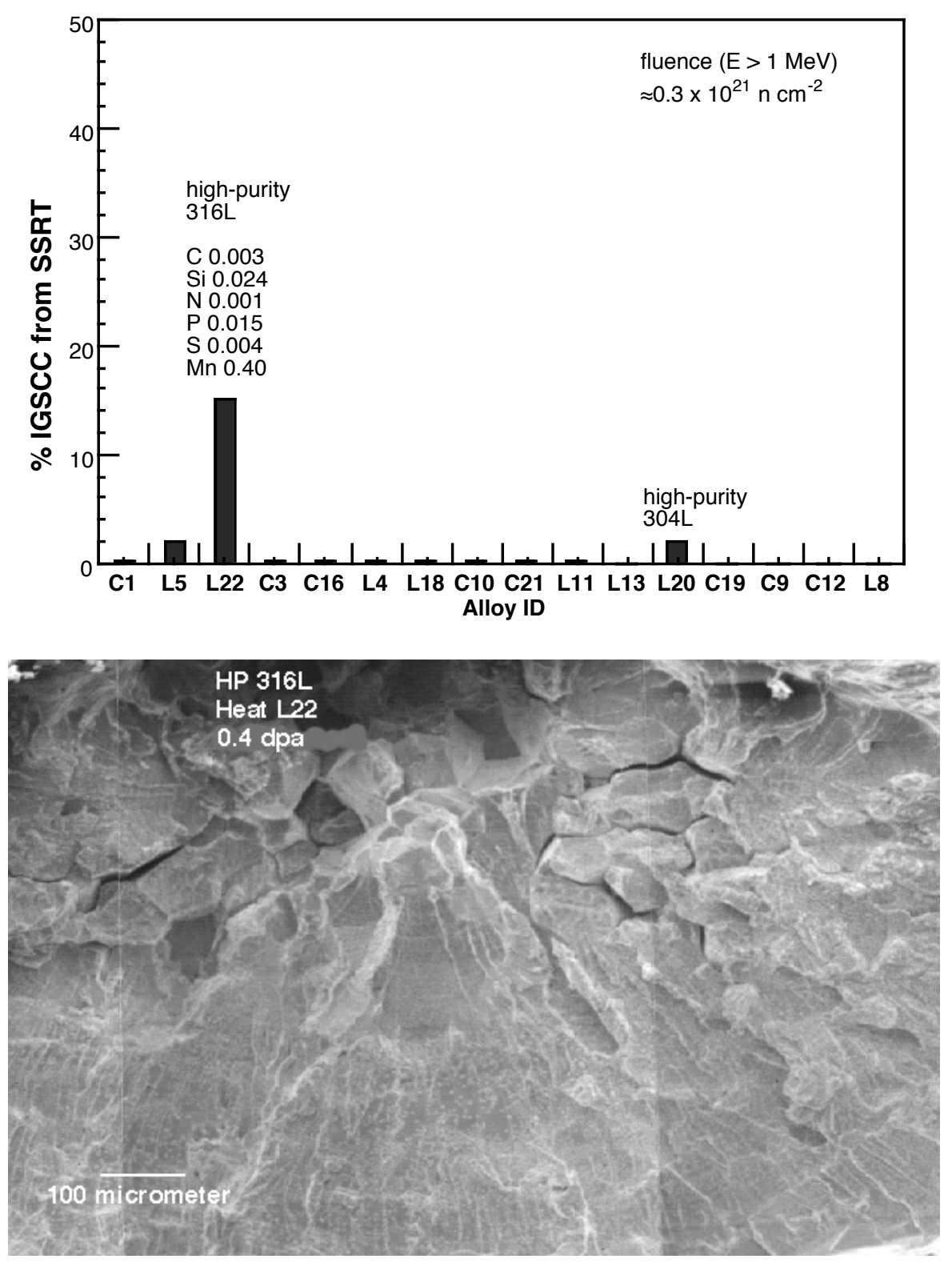

Figure 7.

Percent IGSCC of model SS alloys irradiated in $\mathrm{He}$ in the Halden reactor to fluence of $\approx 0.3 \times 10^{21}$ $\mathrm{n} \cdot \mathrm{cm}^{-2}(\mathrm{E}>1 \mathrm{MeV})$ and tested at $289^{\circ} \mathrm{C}$ in BWR-like water.
Figure 8.

Limited intergranular fracture surface surrounded by transgranular surface in 316L-like SS Heat L22 irradiated to $\approx 0.3 \times 10^{21} \mathrm{n} \cdot \mathrm{cm}^{-2}(\mathrm{E}$ $>1 \mathrm{MeV}, \approx 0.4 \mathrm{dpa}$ ) and tested at $289^{\circ} \mathrm{C}$ in BWR-like water.

\subsection{Effect of Si on Strength}

The relatively higher susceptibility of the high-purity heat of Type 316L SS (i.e., Heat L22) when compared with the commercial counterpart (Heat C21) is of particular interest. This behavior is similar to that observed for BWR neutron absorber tubes fabricated from high- and commercial-purity heats of Type $304 \mathrm{SS}^{23}$ In another investigation similar to that of the present study, Jenssen and Ljunberg irradiated Unotched rod specimens that had been fabricated from two heats of Type 316 SS, then conducted postirradiation SSRT tests in a BWR loop under conditions of normal oxidizing water chemistry. ${ }^{30}$ In their study, a commercial-purity heat of Type $316 \mathrm{SS}$ (Heat K) was resistant to IASCC, whereas a high-purity heat of Type 316L SS (Heat F) was susceptible. The two relatively more susceptible heats (i.e., Heats L22 and F) are characterized by an unusually low $\mathrm{Si}$ concentration of $<0.26 \mathrm{wt} . \%$, whereas the two relatively more resistant heats (i.e., Heats $\mathrm{C} 21$ and K) contain a higher Si concentration of $>0.5$ wt.\%. 
An interesting observation from Table 10 is the effect of Si content on the alloy strength that was measured in water before and after irradiation. Yield strength of unirradiated commercial heats of Types 304 and 304L SS, measured in water, was similar to that measured in air, ${ }^{1}$ i.e., $174-182 \mathrm{MPa}$ vs. 170-175 MPa, indicating that the effect of water is insignificant. The yield and maximum strengths (in water) are plotted in Fig. 9 as function of Si content for the unirradiated and low-fluence specimens. Before irradiation, 304- and 304L-type steels did not exhibit a systematic effect of Si content. However, after irradiation to $\approx 0.3 \times 10^{-}$ ${ }^{21} \mathrm{n} \cdot \mathrm{cm}^{-2}(\mathrm{E}>1 \mathrm{MeV})$, yield and maximum strengths decreased as Si content increased to 0.8-1.2 wt.\%.

The influence of Si content on the material strength indicates that, at high concentrations, Si atoms suppress formation of some types of irradiation-induced hardening centers and contribute to greater ductility, at least at low fluence levels. Tsukada et al. ${ }^{29}$ irradiated two SSRT specimens of high-purity Type 304L SS (C 0.003, Si 0.01, Mn 1.36, P 0.001, S 0.0014, and N 0.0014 wt. \%) in He at $\approx 240{ }^{\circ} \mathrm{C}$ in the JRR-3 reactor to a fluence of $\approx 0.67 \times 10^{21} \mathrm{n} \mathrm{cm}^{-2}(\mathrm{E}>1 \mathrm{MeV})$. One specimen had been doped with $\approx 0.69 \mathrm{wt} . \% \mathrm{Si}$ and the other had not been doped. After SSRT testing of the irradiated specimens at $\approx 300^{\circ} \mathrm{C}$ in high-purity water (DO $\approx 32 \mathrm{ppm}$ ), they observed that the Si-doped specimen exhibited significantly greater ductility than the undoped specimen. Silicone effect at $1.3 \mathrm{dpa}$ is discussed in Section 7.4.

\subsection{Correlation of S Content and Susceptibility to TGSCC of 304 and 304L SSs}

For the fluence level of $\approx 0.3 \times 10^{21} \mathrm{n} \cdot \mathrm{cm}^{-2}(\mathrm{E}>1 \mathrm{MeV})$, SSRT tests in $289^{\circ} \mathrm{C}$ water and fractographic analysis were performed for 11 heats of Type 304 or 304L SS, three heats of Type 316 or $316 \mathrm{~L} \mathrm{SS}$, and one heat of austenitic-ferritic duplex SS. Susceptibilities to TGSCC of the 11 heats of Type 304 or 304L SS varied strongly from heat to heat. However, it was found that bulk $\mathrm{S}$ content correlates reasonably well with percent TGSCC, as is shown in Fig. 10. Heats that contain $\geq 0.009$ wt. $\% \mathrm{~S}$ exhibited high susceptibility to TGSCC, whereas heats that contain $\leq 0.004$ wt.\% S exhibited low susceptibility to TGSCC.

For a given heat of all types of austenitic SSs at low fluence, significant susceptibility to TGSCC is often observed after an SSRT test, even though susceptibility to IGSCC is insignificant. As fluence level increases, the susceptibility to TGSCC peaks at a certain fluence specific to the heat, and at the same time, the susceptibility to IGSCC increases at the expense of TGSCC. Considering this trend, the good correlation observed between S content and percent TGSCC in Fig. 10 is considered an important indication that may provide useful insight into the susceptibility to IGSCC at higher fluence levels. 


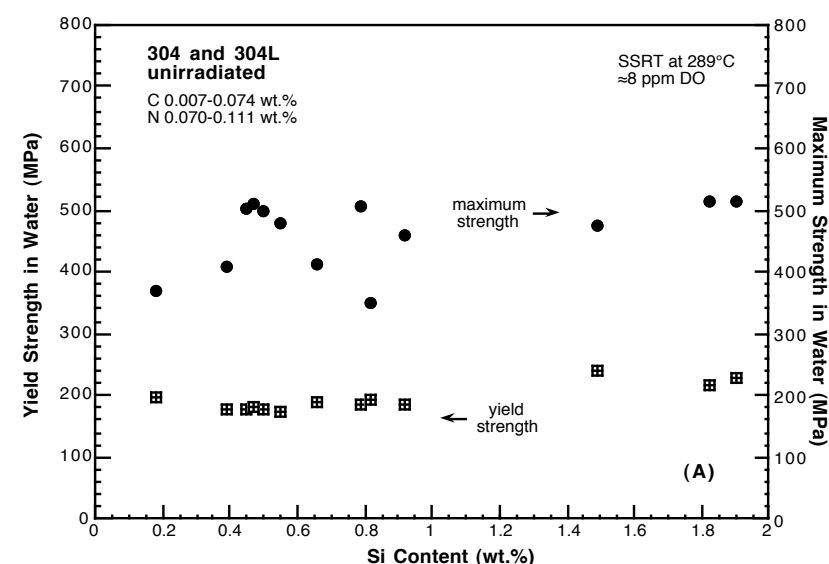

(a)

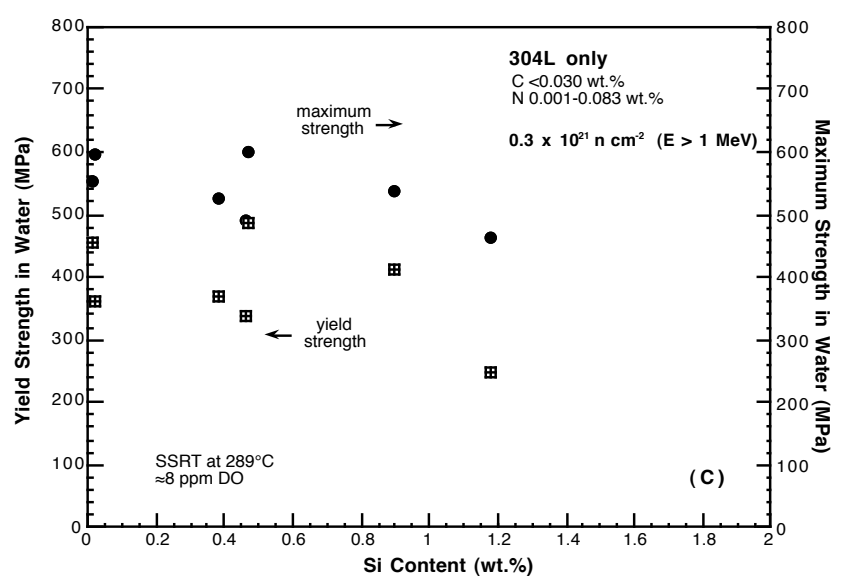

(c)

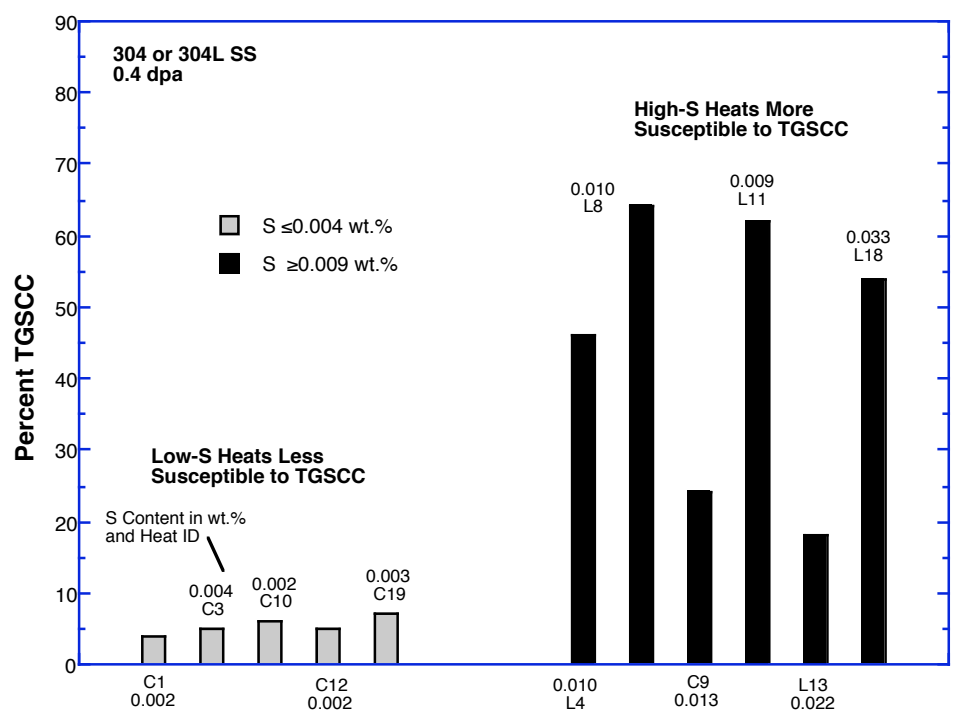

Figure 9.

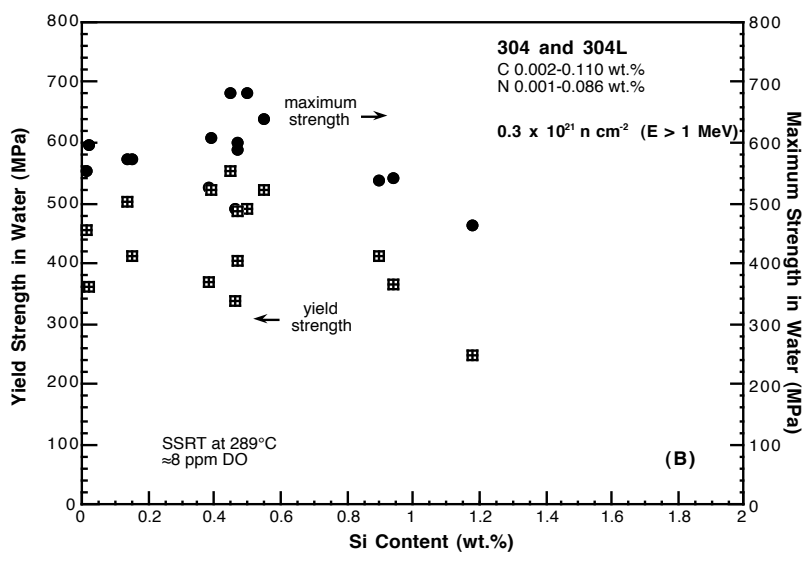

(b)

Effects of Si concentration on yield and maximum strength of: (a) unirradiated Types 304 and 304L SS; (b) Types 304 and $304 \mathrm{~L} \mathrm{SS}$, fluence $\approx 0.3 \times 10^{21} \mathrm{n} \cdot \mathrm{cm}^{-2}(\mathrm{E}$ $>1 \mathrm{MeV}$ ) and (c) Type 304L SS, fluence $\approx 0.3 \times 10^{21} \mathrm{n} \cdot \mathrm{cm}^{-2}$.

Figure 10.

Effect of $S$ content on the susceptibility to TGSCC of Type 304 or $304 \mathrm{~L}$ heats, irradiated to fluence of $\approx 0.3 \times 10^{21} \mathrm{n} \cdot \mathrm{cm}^{-2}(\mathrm{E}$ $>1 \mathrm{MeV})(\approx 0.4 \mathrm{dpa})$ and tested at $289^{\circ} \mathrm{C}$ in BWR-like water. 
This page is intentionally blank. 


\section{SSRT Test and SEM Fractography on Medium-Fluence Specimens ( $\approx 1.3 \mathrm{dpa})$}

\subsection{Tabulation of Test Results}

Slow-strain-rate tensile tests in $289^{\circ} \mathrm{C}$ BWR-like water and SEM fractographic analysis were performed on 26 medium-fluence specimens irradiated to $\approx 0.9 \times 10^{21} \mathrm{n} \cdot \mathrm{cm}^{-2}(\mathrm{E}>1 \mathrm{MeV})(\approx 1.3 \mathrm{dpa})$. Feedwater chemistry (i.e., DO, ECP, conductivity, and $\mathrm{pH}$ ) and results from SSRT testing (i.e., $0.2 \%$-offset yield strength, maximum strength, uniform plastic strain, and total plastic strain) are summarized in Table 11. Also shown in the table are results of SEM fractographic analysis of the failure mode (i.e., intergranular and transgranular fracture surface morphology) of the specimens. In Table 12, the results of SSRT and SEM fractographic analysis are correlated with compositional characteristics of the specimens.

For Heat L20, which contains an unusually high concentration of $\mathrm{O}(0.094 \mathrm{wt}$.) and a dendritic grain structure, fractographic analysis was not performed, although SSRT testing was conducted. This heat, which is not a prototypic austenitic SS, exhibited poor ductility when compared with other steels, and its behavior was excluded in the analyses of SCC test results.

\subsection{Heat-to-Heat Variations in Susceptibility to TGSCC and IGSCC}

As an example, effects of fluence and test environment on load-elongation behavior are shown for Type $304 \mathrm{SS}$ commercial Heat C19 in Fig. 11. As fluence increased from $\approx 0.3 \times 10^{21} \mathrm{n} \cdot \mathrm{cm}^{-2}$ to $\approx 0.9 \times 10^{21} \mathrm{n} \cdot \mathrm{cm}^{-}$

${ }^{2}$, maximum strength increased slightly (from $690 \mathrm{MPa}$ to $800 \mathrm{MPa}$ ). In contrast, total elongation decreased significantly (from $1.45 \%$ to $0.7 \%$ ).

Figures 12 and 13 show, respectively, heat-to-heat variations in percent TGSCC and IGSCC for the two tested fluence levels, i.e., $\approx 0.3 \times 10^{21} \mathrm{n} \cdot \mathrm{cm}^{-2}$ and $\approx 0.9 \times 10^{21} \mathrm{n} \cdot \mathrm{cm}^{-2}$. As fluence increased, percent TGSCC decreased significantly, and, at the same time, the percent IGSCC increased significantly for many heats, e.g., L22, L18, L11, and L8. The fact that the IGSCC fracture surfaces in these alloys were surrounded by TGSCC fracture surfaces indicates that an IGSCC fracture surface emerges from a portion of a TGSCC fracture surface. In addition, for many alloys, high susceptibility to TGSCC is a precursor to susceptibility to IGSCC at a higher fluence. However, the threshold fluence for the transition from TGSCC to IGSCC differed significantly from alloy to alloy. 
Table 11. Results of SSRT test and fractography for model austenitic stainless steels irradiated to $\approx 0.9 \times 10^{21} \mathrm{n} \cdot \mathrm{cm}^{-2}(\mathrm{E}>1 \mathrm{MeV})(\approx 1.3 \mathrm{dpa})$.

\begin{tabular}{|c|c|c|c|c|c|c|c|c|c|c|c|c|}
\hline $\begin{array}{l}\text { Speci. } \\
\text { ID }\end{array}$ & $\begin{array}{c}\text { SSRT } \\
\text { No. }\end{array}$ & $\begin{array}{c}\mathrm{DO} \\
(\mathrm{ppm})\end{array}$ & $\begin{array}{l}\text { ECP } \\
(\mathrm{mV} \\
\text { SHE) }\end{array}$ & $\begin{array}{c}\text { Cond. } \\
\text { at } 25^{\circ} \mathrm{C} \\
\left(\mu \mathrm{S} \mathrm{cm}^{-1}\right)\end{array}$ & $\begin{array}{c}\mathrm{pH} \\
\text { at } \\
25^{\circ} \mathrm{C}\end{array}$ & $\begin{array}{l}\text { Yield } \\
\text { Stress } \\
\text { (MPa) }\end{array}$ & $\begin{array}{l}\text { Max. } \\
\text { Stress } \\
\text { (MPa) }\end{array}$ & $\begin{array}{c}\text { Uniform } \\
\text { Elong. } \\
(\%)\end{array}$ & $\begin{array}{l}\text { Total } \\
\text { Elong. } \\
(\%)\end{array}$ & $\begin{array}{c}\text { TGSCC } \\
(\%)\end{array}$ & $\begin{array}{c}\text { IGSCC } \\
(\%)\end{array}$ & $\begin{array}{c}\text { TG+IG } \\
\text { SCC } \\
(\%)\end{array}$ \\
\hline L22-02 & HR-17 & 8.0 & +181 & 0.08 & 6.77 & 475 & 549 & 4.20 & 5.82 & 30 & 35 & 65 \\
\hline L11-02 & HR-18 & 8.0 & +191 & 0.08 & 6.55 & 820 & 856 & 0.43 & 1.65 & 50 & 14 & 64 \\
\hline L18-02 & HR-19 & 8.0 & +193 & 0.10 & 6.07 & 710 & 755 & 3.98 & 5.05 & 38 & 14 & 52 \\
\hline L20-02 & HR-28 & & test in & $289^{\circ} \mathrm{C}$ air & & 826 & 845 & 0.31 & 2.09 & dendritic & \multicolumn{2}{|c|}{ structure } \\
\hline L20-05 & HR-26 & 9.0 & +182 & 0.09 & 6.32 & 670 & 743 & 0.37 & 1.03 & dendritic & \multicolumn{2}{|c|}{ structure } \\
\hline L20-06 & HR-27 & 8.0 & +274 & 0.07 & 6.05 & 632 & 697 & 0.85 & 2.72 & 0 & 0 & 0 \\
\hline C9-02 & HR-21 & 8.0 & +240 & 0.07 & 6.47 & 651 & 679 & 1.42 & 2.50 & 62 & 22 & 84 \\
\hline L17-02 & HR-22 & 8.0 & +198 & 0.07 & 6.42 & 574 & 654 & 2.02 & 3.08 & 44 & 41 & 85 \\
\hline L7-02 & HR-23 & 8.0 & +215 & 0.07 & 6.03 & 553 & 561 & 0.24 & 2.44 & 38 & 54 & 92 \\
\hline $\mathrm{C} 10-02$ & HR-24 & 7.0 & +221 & 0.07 & 5.26 & 651 & 706 & 6.35 & 9.25 & 14 & 0 & 14 \\
\hline C3-02 & HR-25 & 8.0 & +240 & 0.07 & 6.34 & 632 & 668 & 16.72 & 19.74 & 9 & 4 & 13 \\
\hline C19-05 & HR-58 & & test in & $23^{\circ} \mathrm{C}$ air & & 1130 & 1260 & 15.50 & 15.70 & - & - & - \\
\hline C19-02 & HR-30 & & test in & $289^{\circ} \mathrm{C}$ air & & 888 & 894 & 6.41 & 10.21 & 1 & 0 & 1 \\
\hline C19-04 & HR-31 & 8.0 & +252 & 0.07 & 6.18 & 750 & 769 & 6.06 & 8.79 & 1 & 0 & 1 \\
\hline L6-02 & HR-32 & 8.0 & +250 & 0.07 & 6.40 & 493 & 546 & 2.45 & 3.77 & 8 & 27 & 35 \\
\hline L14-02 & HR-33 & 8.0 & +246 & 0.08 & 6.07 & 649 & 684 & 1.90 & 4.67 & 84 & 2 & 86 \\
\hline L13-02 & HR-34 & 7.0 & +222 & 0.09 & 6.85 & 602 & 624 & 1.67 & 4.95 & 55 & 12 & 67 \\
\hline L4-02 & HR-35 & 7.0 & +259 & 0.08 & 6.54 & 634 & 680 & 1.07 & 2.02 & 58 & 12 & 70 \\
\hline L5-02 & HR-36 & 7.0 & +243 & 0.07 & 6.85 & 665 & 725 & 3.07 & 4.57 & 3 & 5 & 8 \\
\hline C16-02 & HR-37 & 7.0 & +230 & 0.07 & 6.62 & 562 & 618 & 11.99 & 15.80 & 7 & 1 & 8 \\
\hline L8-02 & HR-38 & 8.0 & +242 & 0.07 & 6.57 & 838 & 838 & 0.12 & 3.12 & 15 & 22 & 37 \\
\hline C21-02 & HR-39 & 8.0 & +231 & 0.08 & 6.21 & 643 & 716 & 15.38 & 18.30 & 1 & 2 & 3 \\
\hline L2-02 & HR-40 & 7.0 & +239 & 0.07 & 7.11 & 839 & 849 & 0.88 & 1.56 & 31 & 11 & 42 \\
\hline L24-02 & HR-41 & 8.0 & +239 & 0.06 & 6.40 & 725 & 725 & 0.15 & 2.45 & 2 & 1 & 3 \\
\hline L23-02 & HR-42 & 7.0 & +237 & 0.08 & 6.60 & 787 & 818 & 0.38 & 1.24 & 3 & 24 & 27 \\
\hline $\mathrm{C} 12-02$ & HR-43 & 7.0 & +227 & 0.07 & 6.19 & 747 & 756 & 14.96 & 18.57 & 4 & 0 & 4 \\
\hline C1-02 & HR-44 & 8.0 & +229 & 0.07 & 6.30 & 707 & 763 & 13.36 & 17.04 & 2 & 0 & 2 \\
\hline
\end{tabular}

\subsection{Effect of Sulfur}

The information given in Tables 11 and 12 led us to carefully examine the relationship between fracture properties and compositional characteristics of the alloys in an effort to identify the alloying and impurity elements that strongly influence stress corrosion cracking behavior. Of the steel heats tested and listed in Table 12, 17 heats are Type 304 or 304L, three heats are Type 316 or $316 \mathrm{~L}$, two heats are Type 348 or $348 \mathrm{~L}$, and one heat is duplex steel that contains $\approx 3 \%$ delta ferrite.

Of the 17 heats of Types 304 or $316 \mathrm{SS}$, steels that contain low concentrations of S $(<0.004 \mathrm{wt} . \% \mathrm{~S})$ exhibited high resistance to IGSCC (see Fig. 14) and high uniform and total elongation (see Fig. 15), whereas steels that contain relatively higher concentrations of S ( $>0.005 \mathrm{wt} . \% \mathrm{~S})$ exhibited poor resistance to IGSCC and low uniform and total elongation.

The observations summarized in Figs. 14 and 15 indicate strongly that, for Types 304 and 304L SS, a high concentration of S ( $>0.005 \mathrm{wt} . \%)$ is significantly detrimental, and that a sufficiently low concentration of $\mathrm{S}$ (e.g., $<0.004$ wt. $\%$ ) is beneficial to render good resistance to IASCC at $\approx 1.3 \mathrm{dpa}$. 
Table 12. Composition (wt.\%) of stainless steels irradiated to $\approx 0.9 \times 10^{21} \mathrm{n} \cdot \mathrm{cm}^{-2}(\mathrm{E}>1 \mathrm{MeV})$ (1.3 dpa) correlated with results of SSRT test and fractography.

\begin{tabular}{|c|c|c|c|c|c|c|c|c|c|c|c|c|c|c|c|c|}
\hline $\begin{array}{c}\text { Spec. } \\
\text { ID }\end{array}$ & $\mathrm{Ni}$ & $\mathrm{Si}$ & $\mathrm{P}$ & $\mathrm{S}$ & $\mathrm{Mn}$ & $\mathrm{C}$ & $\mathrm{N}$ & $\mathrm{Cr}$ & $\mathrm{O}$ & Other & $\begin{array}{c}\mathrm{YS} \\
(\mathrm{MPa})\end{array}$ & $\begin{array}{c}\text { UTS } \\
\text { (MPa) }\end{array}$ & $\begin{array}{l}\text { UE } \\
(\%)\end{array}$ & $\begin{array}{l}\text { TE } \\
(\%)\end{array}$ & $\begin{array}{l}\text { TG } \\
(\%)\end{array}$ & $\begin{array}{l}\text { IG } \\
(\%)\end{array}$ \\
\hline L22-02 & 13.30 & 0.024 & 0.015 & 0.004 & 0.40 & 0.003 & 0.001 & 16.10 & 0.0102 & Mo 2.04 & 475 & 549 & 4.20 & 5.82 & 30 & 35 \\
\hline L11-02 & 8.15 & 0.47 & 0.097 & 0.009 & 1.02 & 0.014 & 0.004 & 17.40 & 0.0071 & - & 820 & 856 & 0.43 & 1.65 & 50 & 14 \\
\hline L18-02 & 8.13 & 0.14 & 0.016 & 0.033 & 1.13 & 0.080 & 0.001 & 18.00 & 0.0055 & - & 710 & 755 & 3.98 & 5.05 & 38 & 14 \\
\hline L20-05 & 8.91 & 0.017 & 0.010 & 0.004 & 0.41 & 0.002 & 0.002 & 18.10 & 0.0940 & - & 670 & 743 & 0.37 & 1.03 & \multicolumn{2}{|c|}{ dendrite } \\
\hline L20-06 & 8.91 & 0.017 & 0.010 & 0.004 & 0.41 & 0.002 & 0.002 & 18.10 & 0.0940 & - & 632 & 697 & 0.85 & 2.72 & \multicolumn{2}{|c|}{ dendrite } \\
\hline C9-02 & 8.75 & 0.39 & 0.013 & 0.013 & 1.72 & 0.062 & 0.065 & 18.48 & 0.0102 & - & 651 & 679 & 1.42 & 2.50 & 62 & 22 \\
\hline L17-02 & 8.00 & 0.66 & 0.090 & 0.009 & 0.48 & 0.061 & 0.078 & 15.30 & 0.0090 & - & 574 & 654 & 2.02 & 3.08 & 44 & 41 \\
\hline L7-02 & 10.60 & 0.18 & 0.040 & 0.038 & 1.02 & 0.007 & 0.111 & 15.40 & 0.0274 & - & 553 & 561 & 0.24 & 2.44 & 38 & 54 \\
\hline C10-02 & 8.13 & 0.55 & 0.033 & 0.002 & 1.00 & 0.060 & 0.086 & 18.19 & 0.0074 & - & 651 & 706 & 6.35 & 9.25 & 14 & 0 \\
\hline C3-02 & 8.91 & 0.46 & 0.019 & 0.004 & 1.81 & 0.016 & 0.083 & 18.55 & - & - & 632 & 668 & 16.72 & 19.74 & 9 & 4 \\
\hline C19-04 & 8.08 & 0.45 & 0.031 & 0.003 & 0.99 & 0.060 & 0.070 & 18.21 & 0.0200 & - & 750 & 769 & 6.06 & 8.79 & 1 & 0 \\
\hline L6-02 & 10.00 & 1.90 & 0.020 & 0.005 & 1.13 & 0.096 & 0.087 & 17.10 & 0.0058 & - & 493 & 546 & 2.45 & 3.77 & 8 & 27 \\
\hline L14-02 & 7.93 & 1.49 & 0.080 & 0.002 & 1.76 & 0.107 & 0.028 & 15.00 & 0.0045 & - & 649 & 684 & 1.90 & 4.67 & 84 & 2 \\
\hline L13-02 & 8.18 & 1.18 & 0.027 & & 0.36 & & & 17.40 & 0.0042 & - & 602 & 624 & 1.67 & 4.95 & 55 & 12 \\
\hline L4-02 & 10.20 & 0.94 & 0.031 & 0.010 & 1.75 & 0.110 & 0.002 & 15.80 & 0.0037 & - & 634 & 680 & 1.07 & 2.02 & 58 & 12 \\
\hline $\mathrm{L} 5-02^{\mathrm{a}}$ & 966 & 0.90 & 0.113 & 0.028 & 0.47 & 0.006 & 0.033 & 21.00 & 0.0068 & $a_{3} \% \delta$ & 665 & 725 & 3.07 & 4.57 & 3 & 5 \\
\hline C16-02 & 12.90 & 0.38 & 0.014 & 0.002 & 1.66 & 0 & & 16.92 & 0.0157 & Mo 2.30 & 562 & 618 & 11.99 & 15.80 & 7 & 1 \\
\hline L8-02 & 10.20 & 0.15 & 0.093 & 0.010 & 1.85 & 0.041 & 0.001 & 18.30 & 0.0059 & - & 838 & 838 & 0.12 & 3.12 & 15 & 22 \\
\hline C21-02 & 10.24 & 0.51 & 0.034 & 0.001 & 1.19 & 0.060 & 0.020 & 16.28 & 0.0112 & Mo 2.08 & 643 & 716 & 15.38 & 18.30 & 1 & 2 \\
\hline L2-02 & 10.50 & 0.82 & 0.080 & 0.034 & 1.58 & 0.074 & 0.102 & 17.02 & 0.0065 & - & 839 & 849 & 0.88 & 1.56 & 31 & 11 \\
\hline L24-02 & 12.30 & 0.03 & 0.007 & 0.005 & 0.48 & 0.031 & 0.002 & 16.90 & 0.0129 & $\mathrm{Nb} 1.72$ & 725 & 725 & 0.15 & 2.45 & 2 & 1 \\
\hline L23-02 & 12.04 & 0.68 & 0.030 & 0.047 & 0.96 & 0.043 & 0.092 & 17.30 & 0.0093 & $\mathrm{Nb} 1.06$ & 787 & 818 & 0.38 & 1.24 & 3 & 24 \\
\hline C12-02 & 8.23 & 0.47 & 0.018 & 0.002 & 1.00 & 0.060 & 0.070 & 18.43 & - & - & 747 & 756 & 14.96 & 18.57 & 4 & 0 \\
\hline $\mathrm{C} 1-02$ & 8.12 & 0.50 & 0.038 & 0.002 & 1.00 & 0.060 & 0.060 & 18.11 & 0.0102 & - & 707 & 763 & 13.36 & 17.04 & 2 & 0 \\
\hline
\end{tabular}

${ }^{\mathrm{a}} \mathrm{L} 5-02$ contains $\approx 3$ vol. $\%$ globular-shaped delta ferrite.

\subsection{Effect of Silicon}

The yield strength of the model steel alloys, measured in BWR-like water at $289^{\circ} \mathrm{C}(\mathrm{DO} \approx 8 \mathrm{ppm})$, was nearly constant at $\approx 200 \mathrm{MPa}$ in the unirradiated state and was more or less independent of Si concentration (see Fig. 16). However, as fluence was increased to $\approx 0.3 \times 10^{21} \mathrm{n} \cdot \mathrm{cm}^{-2}$ and $\approx 0.9 \times 10^{21} \mathrm{n} \cdot \mathrm{cm}^{-2}$, the degree of increase in yield strength was significantly lower for alloys that contain $>0.9 \mathrm{wt} \%$ Si than for alloys that contain $<0.8 \mathrm{wt} . \% \mathrm{Si}$. This behavior indicates that the nature of irradiation-induced hardening centers and the degree of irradiation hardening are influenced by Si. Silicon atoms in austenitic stainless steels occupy substitutional sites; therefore, they are likely to interact preferentially with irradiation-induced vacancy sites. This effect is likely to inhibit the formation of vacancy clusters or vacancy-impurity complexes, and is, therefore, conducive to a less significant degree of irradiation-induced hardening. An effect similar to that of Si was, however, not observed for $\mathrm{C}$ and $\mathrm{N}$. 

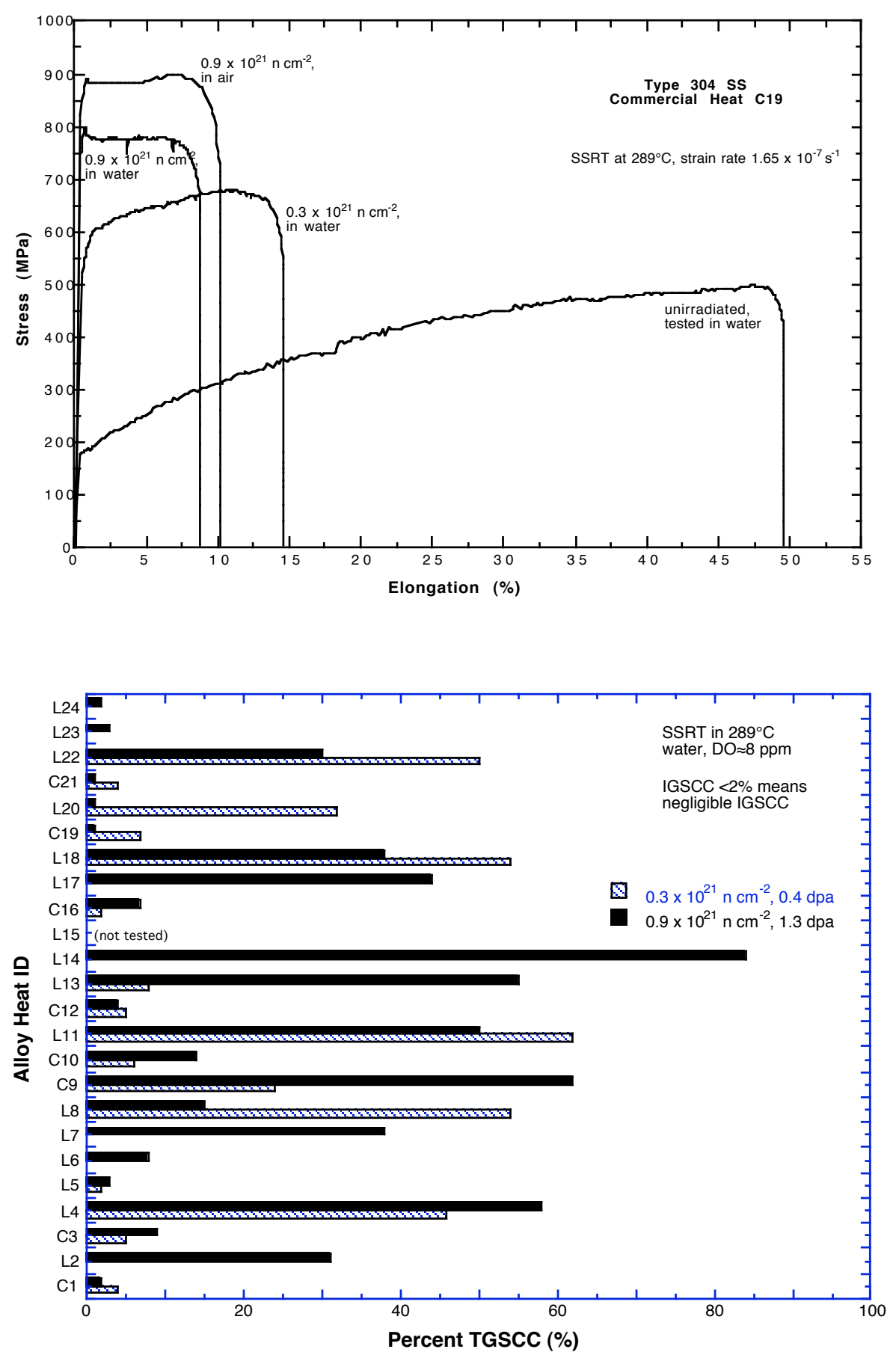

Figure 11.

Effects of fluence and test environment on load elongation behavior of Type 304 SS commercial heat $\mathrm{C} 19$.

Figure 12.

Effects of fluence on percent TGSCC measured in $289^{\circ} \mathrm{C}$ water containing $\approx 8 \mathrm{ppm} \mathrm{DO}$, 0.4 to $1.3 \mathrm{dpa}$. 


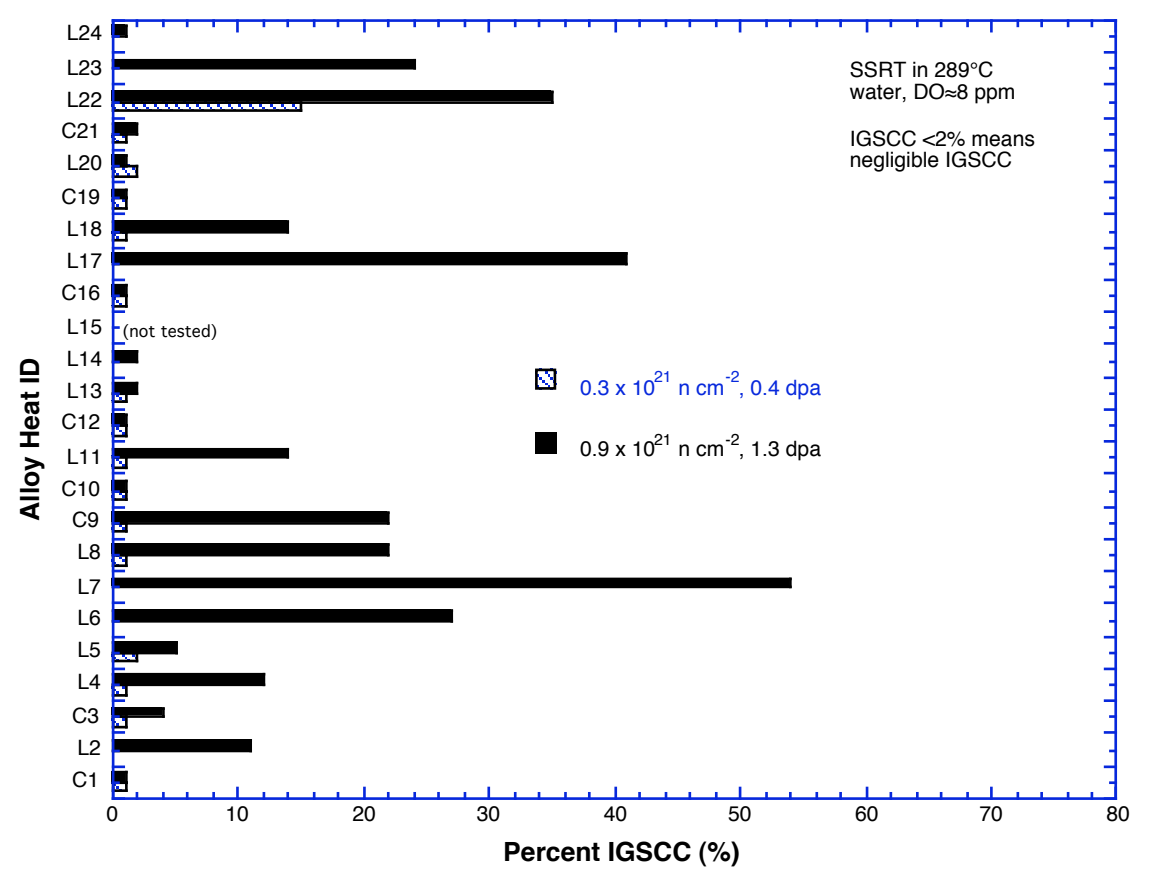

Figure 13.

Effects of fluence on percent IGSCC measured in $289^{\circ} \mathrm{C}$ water containing $\approx 8 \mathrm{ppm} \mathrm{DO}$, 0.4 and 1.3 dpa.

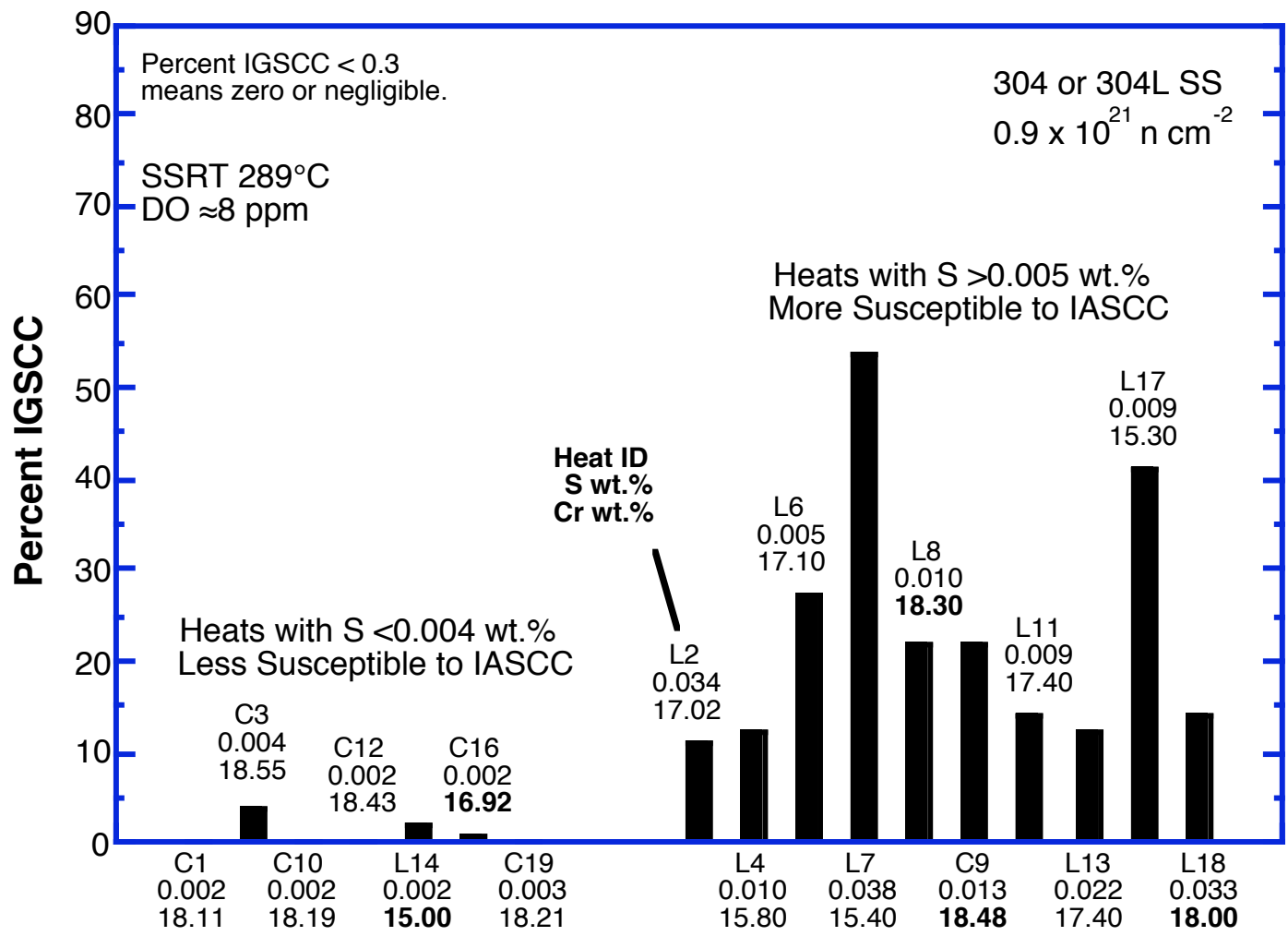

Figure 14. Effect of $S$ on susceptibility to IGSCC of Type 304 and 304L steels irradiated to $\approx 0.9 \times 10^{21} \mathrm{n} \cdot \mathrm{cm}^{-2}(\mathrm{E}>1 \mathrm{MeV})$; one group of steels contains $<0.004$ wt. $\% \mathrm{~S}$ and the other group contains $>0.005$ wt. $\% \mathrm{~S}$. 


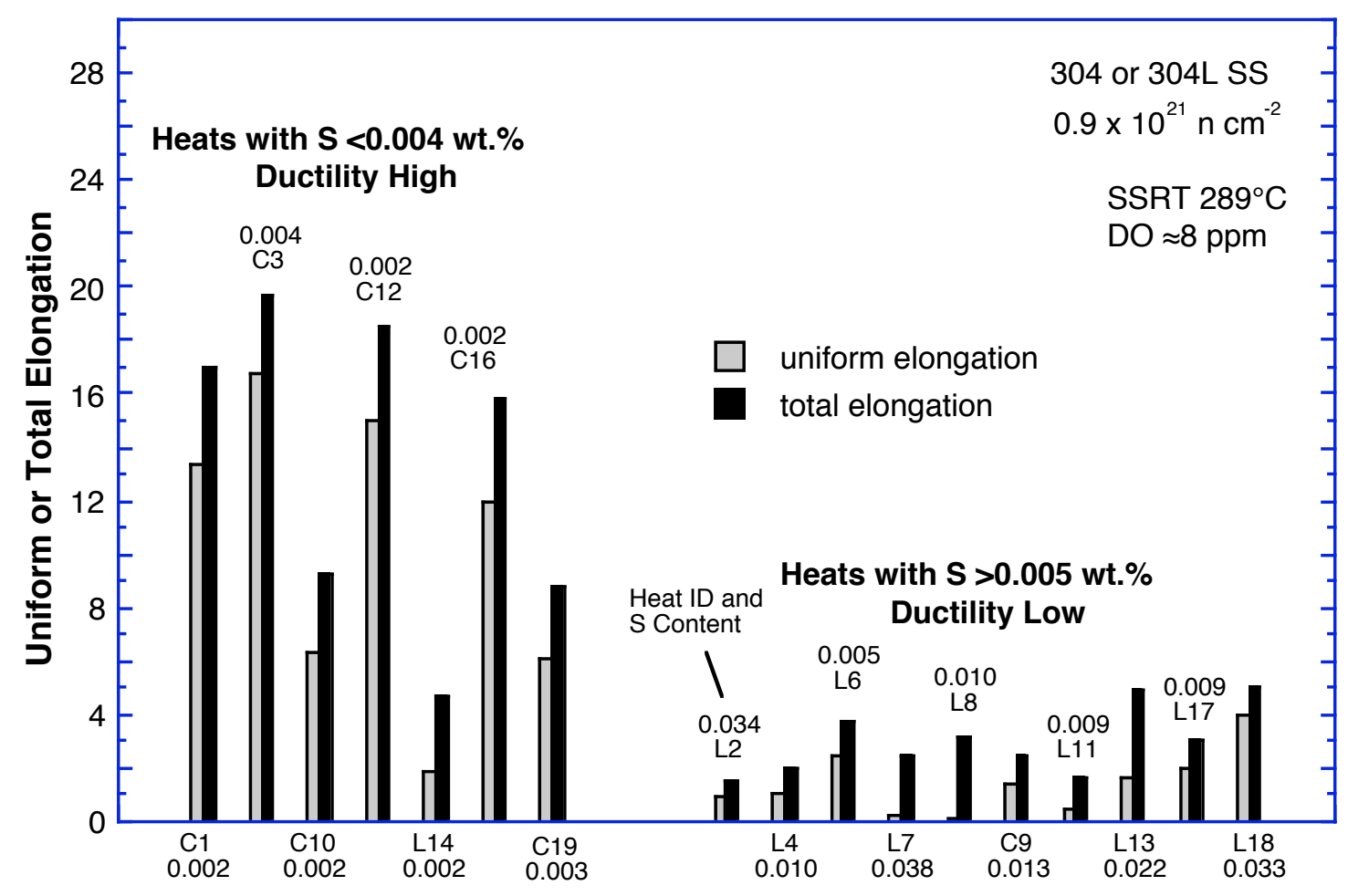

Figure 15. Effect of $S$ on uniform and total elongation of Type 304 and 304L steels irradiated to $\approx 0.9 \times 10^{21} \mathrm{n} \cdot \mathrm{cm}^{-2}(\mathrm{E}>1 \mathrm{MeV})$; one group of steels contains $<0.004$ wt. $\% \mathrm{~S}$ and the other group contains $>0.005 \mathrm{wt} . \% \mathrm{~S}$.

Among the laboratory-fabricated heats of Types 304 and 304L SS that contain relatively high concentrations of S (0.009-0.038 wt.\%), alloys that contain $\leq 0.66 \mathrm{wt} . \%$ Si exhibited significant susceptibility to IGSCC, whereas alloys with $\geq 0.82 \mathrm{wt} . \% \mathrm{Si}$ exhibited relatively lower susceptibility to IGSCC (see Fig. 17). However, Heat L6, which contains $\approx 1.9$ wt. $\% \mathrm{Si}$, exhibited susceptibility to IGSCC (percent IGSCC $\approx 27$ ). These observations indicate that $\mathrm{Si}$ concentration in the range of $\approx 0.8$ to $\approx 1.5 \mathrm{wt} . \%$ is beneficial in delaying the onset of or suppressing the susceptibility to IASCC, at least up to $1.3 \mathrm{dpa}$.

However, it is not clear if such a beneficial effect of $\mathrm{Si}$ (in the range of $\approx 0.8$ to $\approx 1.5$ wt. $\%$ ) is also significant at higher fluence levels. Considering the strongly deleterious effect of S shown in Figs. 14 and 15 , it is possible that, as fluence increases to higher levels, the deleterious effect of S more than offsets the beneficial effect of Si. As such, the effect of Si could be secondary, that is, manifested only at low fluence levels. 

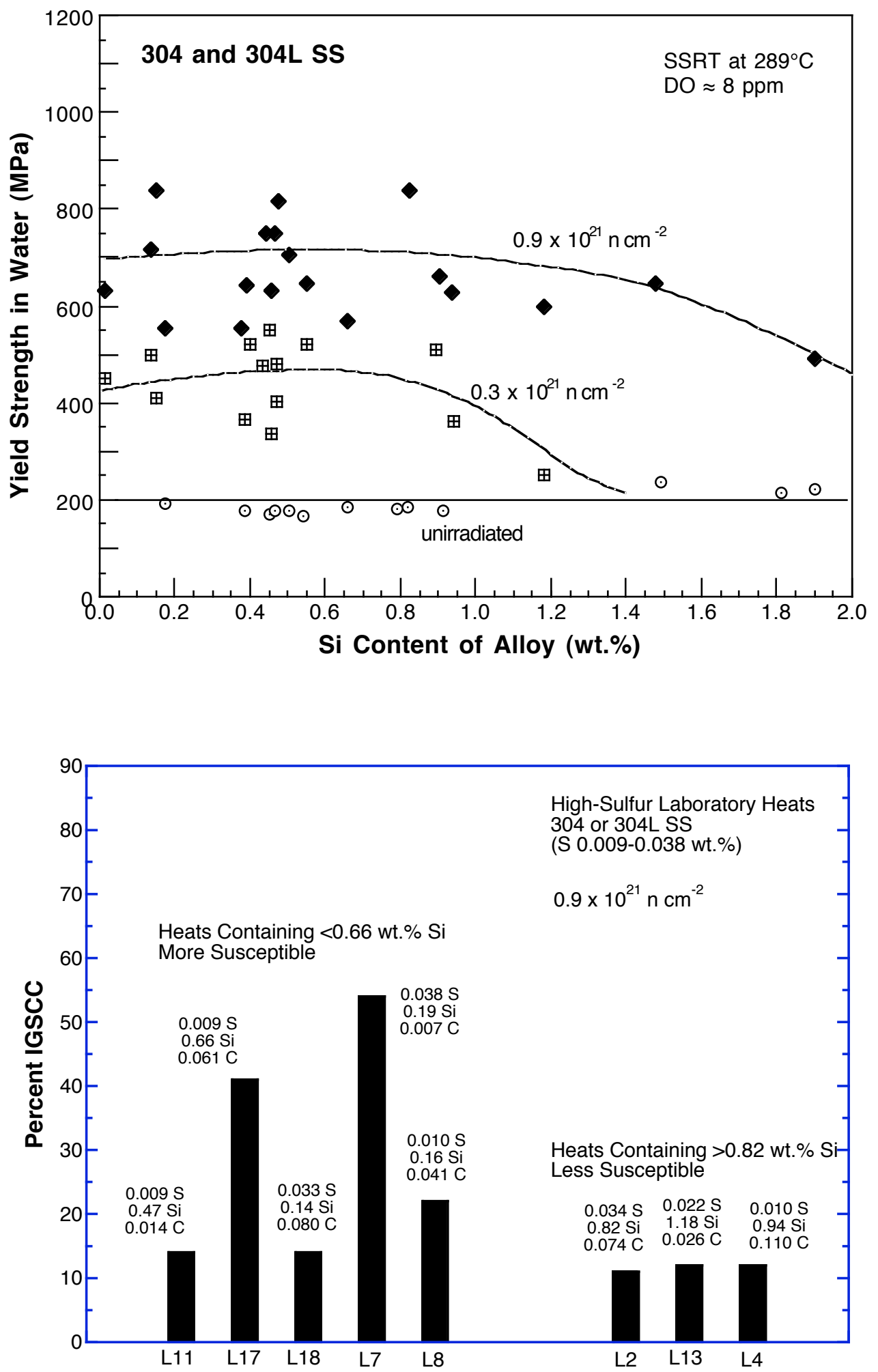

Figure 16.

Effect of Si concentration on yield strength of Types 304 and 304L steel measured in $289^{\circ} \mathrm{C}$ water before and after irradiation.
Figure 17.

Effect of Si on IGSCC of lab heats of Types 304 and 304L SS containing high concentrations of $S$ and irradiated to $\approx 1.3 \mathrm{dpa}$; susceptible heats contain lower concentrations of $\mathrm{Si}$; resistant heats contain higher concentrations of Si. 
This page is intentionally blank. 


\section{SSRT SCC Test and Fractography on High-Fluence Specimens ( $\approx 3.0 \mathrm{dpa})$}

\subsection{Tabulation of Test Results}

Twenty-four steel alloys were tested by the SSRT technique after irradiation to $\approx 2.0 \times 10^{21} \mathrm{n} \cdot \mathrm{cm}^{-2}(\mathrm{E}$ $>1 \mathrm{MeV})(\approx 3.0 \mathrm{dpa})$ in BWR-like oxidizing water at $289^{\circ} \mathrm{C}(\mathrm{DO} \approx 8 \mathrm{ppm})$. Of the 24 alloys, 18 were 304 - or 304L-type steels, 3 were 316- or 316L-type steels, 2 were 348- or 348L-type steels, and one alloy was austenitic-ferritic duplex steel (delta ferrite $\approx 3$ vol.\%). At this fluence, some of the specimens (Heats L13 and L8) were so brittle that they failed in $23^{\circ} \mathrm{C}$ air during assembly of the test train. Table 13 summarizes the test conditions and results of the SSRT testing and fractography. Table 14 summarizes correlation of the fracture characteristics with chemical composition of the steels.

Table 13. Results of SSRT tests and SEM fractography for model austenitic stainless steels irradiated to $\approx 2.0 \times 10^{21} \mathrm{n} \cdot \mathrm{cm}^{-2}(\mathrm{E}>1 \mathrm{MeV})(\approx 3.0 \mathrm{dpa})$

\begin{tabular}{|c|c|c|c|c|c|c|c|c|c|c|c|}
\hline $\begin{array}{c}\text { Test } \\
\text { Speci. } \\
\text { ID } \\
\end{array}$ & $\begin{array}{c}\text { SSRT } \\
\text { No. }\end{array}$ & $\begin{array}{c}\text { Oxygen } \\
\text { Conc. } \\
\text { (ppm) }\end{array}$ & $\begin{array}{c}\text { ECP } \\
(\mathrm{mV} \mathrm{SHE}) \\
\end{array}$ & $\begin{array}{c}\text { Cond. } \\
\left(\mu \mathrm{Scm}^{-1}\right)\end{array}$ & $\begin{array}{l}\mathrm{pH} \text { at } \\
25^{\circ} \mathrm{C}\end{array}$ & $\begin{array}{l}\text { Yield } \\
\text { Stress } \\
(\mathrm{MPa}) \\
\end{array}$ & $\begin{array}{l}\text { Max. } \\
\text { Stress } \\
(\mathrm{MPa}) \\
\end{array}$ & $\begin{array}{c}\text { Uniform } \\
\text { Elong. } \\
(\%) \\
\end{array}$ & $\begin{array}{c}\text { Total } \\
\text { Elong. } \\
(\%) \\
\end{array}$ & $\begin{array}{l}\text { TG } \\
(\%) \\
\end{array}$ & $\begin{array}{l}\text { IG } \\
(\%)\end{array}$ \\
\hline L4-03 & HR-45 & 9.0 & +198 & 0.09 & 6.5 & 876 & 1068 & 2.49 & 3.27 & 5 & 95 \\
\hline C12-03 & HR-46 & 8.0 & +208 & 0.09 & 6.5 & 922 & 996 & 1.28 & 2.73 & 8 & 2 \\
\hline C9-03 & HR-47 & 8.0 & +212 & 0.11 & 6.5 & \multicolumn{4}{|c|}{ early failure in $289^{\circ} \mathrm{C}$ water } & 6 & 94 \\
\hline L5-03 & HR-48 & 8.0 & +204 & 0.10 & 6.5 & 953 & 985 & 0.59 & 2.97 & 2 & 4 \\
\hline C19-08 & $\mathrm{Hr}-59$ & & test in & $289^{\circ} \mathrm{C}$ air & & 1001 & 1001 & 0.27 & 1.95 & - & - \\
\hline C19-09 & HR-60 & & test in & $325^{\circ} \mathrm{C}$ air & & 998 & 998 & 0.27 & 2.02 & - & - \\
\hline C19-03 & HR-49 & 8.0 & +171 & 0.11 & 6.5 & 787 & 801 & 0.89 & 3.32 & 2 & 62 \\
\hline C16-03 & HR-50 & 8.0 & +202 & 0.10 & 6.5 & 766 & 803 & 0.83 & 1.84 & 2 & 29 \\
\hline C10-03 & HR-51 & 8.0 & +167 & 0.11 & 6.5 & 1062 & 1065 & 3.15 & 4.51 & 3 & 0 \\
\hline L18-03 & HR-52 & 8.0 & +169 & 0.11 & 6.5 & 795 & 779 & 0.35 & 1.75 & 5 & 86 \\
\hline L13-03 & HR-53 & - & - & \multicolumn{5}{|c|}{ brittle fracture during test preparation in air } & - & - & - \\
\hline C1-03 & HR-54 & 8.0 & +161 & 0.10 & 6.5 & 802 & 833 & 3.38 & 5.27 & 2 & 0 \\
\hline C3-03 & HR-55 & 8.0 & +160 & 0.10 & 6.5 & 796 & 826 & 5.05 & 7.31 & 0 & 26 \\
\hline $\mathrm{C} 21-03$ & HR-56 & 8.0 & +156 & 0.10 & 6.5 & 893 & 924 & 1.89 & 4.85 & 2 & 1 \\
\hline L8-03 & HR-57 & - & \multicolumn{6}{|c|}{ brittle fracture during test preparation in air } & - & - & - \\
\hline L26-01 & HR-61 & 8.0 & +221 & 0.11 & 6.5 & 795 & 821 & 0.58 & 1.83 & 32 & 2 \\
\hline L25-01 & HR-62 & 8.0 & +220 & 0.09 & 6.5 & 867 & 867 & 0.05 & 0.48 & 8 & 43 \\
\hline L2-03 & HR-63 & 8.0 & +204 & 0.10 & 6.5 & 916 & 916 & 0.26 & 0.50 & 58 & 32 \\
\hline L7-03 & HR-64 & 8.0 & +196 & 0.11 & 6.5 & 889 & 889 & 0.02 & 0.05 & 10 & 52 \\
\hline L23-03 & HR-65 & 8.0 & +189 & 0.11 & 6.5 & 887 & 887 & 0.06 & 0.41 & 16 & 22 \\
\hline L17-03 & HR-66 & 8.0 & +188 & 0.11 & 6.5 & 1105 & 1116 & 0.23 & 0.28 & 56 & 20 \\
\hline L14-03 & HR-67 & 8.0 & +174 & 0.11 & 6.5 & 917 & 951 & 1.64 & 2.01 & 16 & 0 \\
\hline L27-01 & HR-68 & 8.0 & +175 & 0.11 & 6.5 & 776 & 808 & 0.73 & 1.02 & 12 & 2 \\
\hline L15-03 & HR-69 & 8.0 & +180 & 0.11 & 6.5 & 946 & 946 & 0.78 & 1.17 & 8 & 32 \\
\hline L6-03 & HR-70 & 8.0 & +171 & 0.11 & 6.5 & 794 & 805 & 2.02 & 2.44 & 12 & 36 \\
\hline L24-03 & HR-71 & 8.0 & +173 & 0.11 & 6.5 & 862 & 862 & 0.11 & 0.86 & 3 & 0 \\
\hline
\end{tabular}


Table 14. Composition (wt.\%) of stainless steels irradiated to $\approx 2.0 \times 10^{21} \mathrm{n} \cdot \mathrm{cm}^{-2}(\mathrm{E}>1 \mathrm{MeV})$ $(\approx 3.0 \mathrm{dpa})$ correlated with results of SSRT test and SEM fractography.

\begin{tabular}{|c|c|c|c|c|c|c|c|c|c|c|c|c|c|}
\hline $\begin{array}{c}\text { Test } \\
\text { Speci. } \\
\text { ID }\end{array}$ & $\mathrm{Ni}$ & $\mathrm{Si}$ & $\mathrm{P}$ & $\mathrm{S}$ & $\mathrm{Mn}$ & $\mathrm{C}$ & $\mathrm{N}$ & $\mathrm{Cr}$ & $\mathrm{O}$ & Other & $\begin{array}{c}\text { Unif. } \\
\text { Elong. } \\
(\%)\end{array}$ & $\begin{array}{c}\text { Total } \\
\text { Elong. } \\
(\%)\end{array}$ & $\begin{array}{l}\text { IG } \\
(\%)\end{array}$ \\
\hline L4-03 & 10.20 & 0.94 & 0.031 & 0.0100 & 1.75 & 0.110 & 0.002 & 15.80 & 0.0037 & - & 2.49 & 3.27 & 95 \\
\hline C12-03 & 8.23 & 0.47 & 0.018 & 0.0020 & 1.00 & 0.060 & 0.070 & 18.43 & - & - & 1.28 & 1.73 & 2 \\
\hline C9-03 & 8.75 & 0.39 & 0.013 & 0.0130 & 1.72 & 0.062 & 0.065 & 18.48 & 0.0102 & - & - & - & 94 \\
\hline $\mathrm{L} 5-03^{\mathrm{a}}$ & 9.66 & 0.90 & 0.113 & 0.0283 & 0.47 & 0.006 & 0.033 & 21.00 & 0.0068 & $\approx 3 \% \delta^{\mathrm{a}}$ & 0.59 & 2.97 & 4 \\
\hline C19-03 & 8.08 & 0.45 & 0.031 & 0.0030 & 0.99 & 0.060 & 0.070 & 18.21 & 0.0200 & - & 0.89 & 3.32 & 62 \\
\hline C16-03 & 12.90 & 0.38 & 0.014 & 0.0020 & 1.66 & 0.020 & 0.011 & 16.92 & 0.0150 & Mo 2.30 & 0.83 & 1.84 & 29 \\
\hline C10-03 & 8.13 & 0.55 & 0.033 & 0.0020 & 1.00 & 0.060 & 0.086 & 18.19 & 0.0074 & - & 3.15 & 4.51 & 0 \\
\hline L18-03 & 8.13 & 0.14 & 0.016 & 0.0326 & 1.13 & 0.080 & 0.001 & 18.00 & 0.0055 & - & 0.35 & 1.75 & 86 \\
\hline L13-03 & 8.18 & 1.18 & 0.027 & 0.0222 & 0.36 & 0.026 & 0.001 & 17.40 & 0.0042 & - & - & - & - \\
\hline $\mathrm{C} 1-03$ & 8.12 & 0.50 & 0.038 & 0.0020 & 1.00 & 0.060 & 0.060 & 18.11 & 0.0102 & - & 3.38 & 5.27 & 0 \\
\hline C3-03 & 8.91 & 0.46 & 0.019 & 0.0040 & 1.81 & 0.016 & 0.083 & 18.55 & - & - & 5.05 & 7.31 & 26 \\
\hline C21-03 & 10.24 & 0.51 & 0.034 & 0.0010 & 1.19 & 0.060 & 0.020 & 16.28 & 0.0112 & Mo 2.08 & 1.89 & 4.85 & 1 \\
\hline L8-03 & 10.20 & 0.15 & 0.093 & 0.0100 & 1.85 & 0.041 & 0.001 & 18.30 & 0.0059 & - & - & - & - \\
\hline L26-01 & 8.09 & 0.79 & 0.004 & 0.0022 & 0.91 & 0.070 & 0.089 & 17.20 & 0.0080 & - & 0.58 & 1.83 & 2 \\
\hline L25-01 & 8.93 & 0.92 & 0.020 & 0.0082 & 1.54 & 0.019 & 0.095 & 17.20 & 0.0085 & - & 0.05 & 0.48 & 43 \\
\hline L2-03 & 10.50 & 0.82 & 0.080 & 0.0345 & 1.58 & 0.074 & 0.102 & 17.02 & 0.0065 & - & 0.26 & 0.50 & 32 \\
\hline L7-03 & 10.60 & 0.18 & 0.040 & 0.0384 & 1.02 & 0.007 & 0.111 & 15.40 & 0.0274 & - & 0.02 & 0.05 & 52 \\
\hline L23-03 & 12.04 & 0.68 & 0.030 & 0.0475 & 0.96 & 0.043 & 0.092 & 17.30 & 0.0093 & $\mathrm{Nb} 1.06$ & 0.06 & 0.41 & 22 \\
\hline L17-03 & 8.00 & 0.66 & 0.090 & 0.0089 & 0.48 & 0.061 & 0.078 & 15.30 & 0.0090 & - & 0.23 & 0.28 & 20 \\
\hline L14-03 & 7.93 & 1.49 & 0.080 & 0.0023 & 1.76 & 0.107 & 0.028 & 15.00 & 0.0045 & - & 1.64 & 2.01 & 0 \\
\hline L27-01 & 10.30 & 0.96 & 0.040 & 0.0018 & 0.97 & 0.057 & 0.019 & 15.30 & 0.0058 & Mo 2.01 & 0.73 & 1.02 & 2 \\
\hline L15-03 & 8.00 & 1.82 & 0.010 & 0.0129 & 1.07 & 0.020 & 0.085 & 17.80 & 0.0110 & - & 0.78 & 1.17 & 32 \\
\hline L6-03 & 10.00 & 1.90 & 0.020 & 0.0051 & 1.13 & 0.096 & 0.087 & 17.10 & 0.0058 & - & 2.02 & 2.44 & 36 \\
\hline L24-03 & 12.30 & 0.03 & 0.007 & 0.0055 & 0.48 & 0.031 & 0.002 & 16.90 & 0.0129 & $\mathrm{Nb} 1.72$ & 0.11 & 0.86 & 0 \\
\hline
\end{tabular}

${ }^{\text {a }}$ 5-03 contains globular-shaped $\approx 3$ vol. $\%$ delta ferrite.

Examples of load-elongation behavior are shown in Fig. 18; they were obtained on SSRT specimens fabricated from a commercial heat of Type $304 \mathrm{SS}$ (Heat C19) and tested in water at $289^{\circ} \mathrm{C}$ and in air at 23 , 289 , and $325^{\circ} \mathrm{C}$. Effects of neutron damage levels of 0, 0.4, 1.3, and $3 \mathrm{dpa}$ are also shown in the figure. Several observations can be inferred from the results: (a) the increase in yield strength from 1.3 dpa to 3.0 dpa is small, indicating that irradiation hardening reaches near saturation at $\approx 2 \mathrm{dpa}$; (b) by the time the damage level reaches $\approx 3 \mathrm{dpa}$, work hardening capability of the steel is insignificant in water, and strain-softening occurs to some extent in air at $289-325^{\circ} \mathrm{C}$; (c) at $\approx 3 \mathrm{dpa}$, tensile behavior in $289^{\circ} \mathrm{C}$ and $325^{\circ} \mathrm{C}$ air is similar; (d) ductility, i.e., uniform and total elongations in 1.3-dpa specimens tested in air, is lower at $289^{\circ} \mathrm{C}$ than at $23^{\circ} \mathrm{C}$. The mechanism that leads to the last behavior is not known. However, the degree of strain aging or localized deformation via dislocation channeling or twinning could be more pronounced at the higher temperatures than at $23^{\circ} \mathrm{C}$.

\subsection{Correlation of Percent IGSCC with Elemental Composition}

From the results summarized in Table 14, percent IGSCC obtained on 304- and 316-type steels was plotted as a function of bulk concentration of $\mathrm{Cr}, \mathrm{Ni}, \mathrm{Mn}, \mathrm{Si}, \mathrm{P}, \mathrm{N}, \mathrm{O}, \mathrm{C}$, and $\mathrm{S}$ to see if a good correlation can be obtained with any of the elements. Such plots are shown in Figs. 19-27, respectively. In these plots, the results obtained on the 348-type steels (Alloys L23 and L24) and the austenitic-ferritic steel (i.e., Alloy L5 that contains $\approx 3$ vol. $\%$ delta ferrite) were not included. 


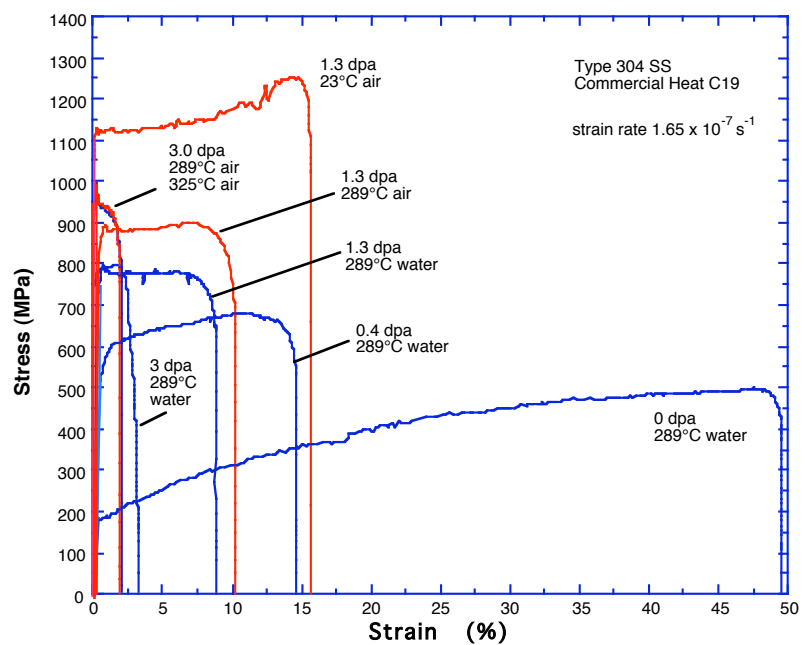

(a)

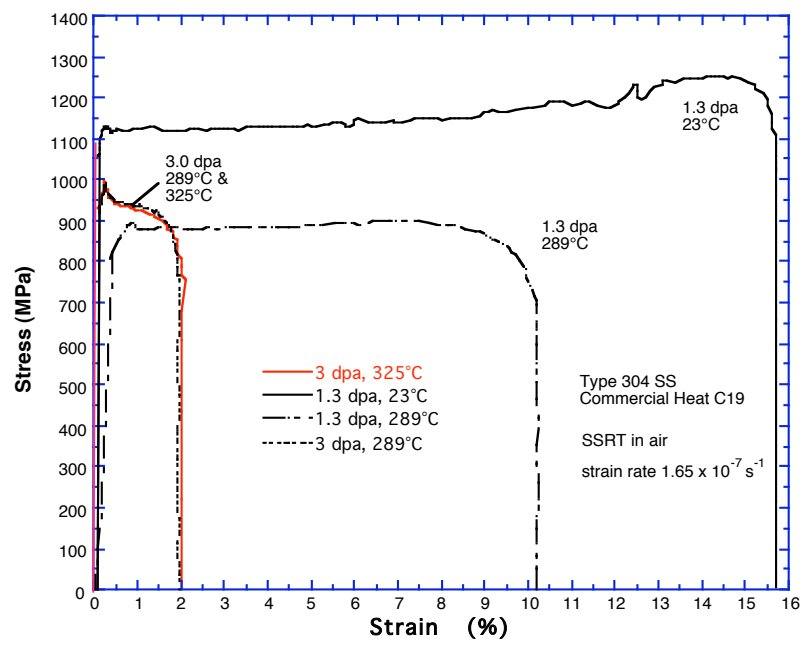

(c)

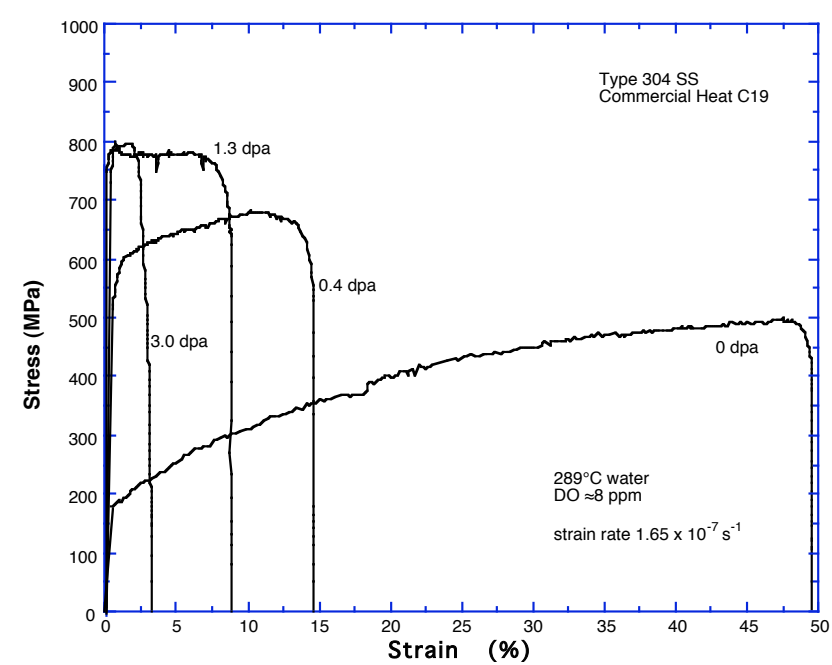

(b)

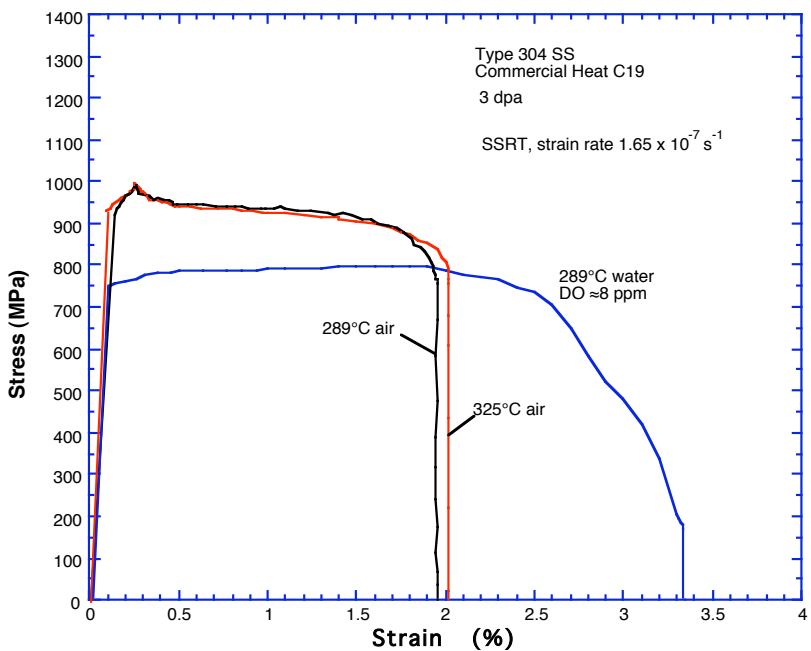

(d)

Figure 18. SSRT load-elongation behavior of Type 304 SS Heat C19: (a) overall data; (b) effect of damage level in $289^{\circ} \mathrm{C}$ water, $\mathrm{DO} \approx 8 \mathrm{ppm}$; (c) effects of damage level and temperature in air; and (d) behavior at $\approx 3 \mathrm{dpa}$ in $289^{\circ} \mathrm{C}$ water and $289-325^{\circ} \mathrm{C}$ air.

A careful examination of the data in Fig. 19 shows that relative IASCC susceptibility (i.e., percent IGSCC from the SSRT tests in this study) cannot be correlated well with bulk $\mathrm{Cr}$ concentration. That is, for a given $\mathrm{Cr}$ content between 15 and 19 wt.\%, percent IGSCC is independent of $\mathrm{Cr}$ content, although by the time the damage level reaches $3 \mathrm{dpa}$, grain-boundary $\mathrm{Cr}$ depletion should be significant in all the tested steels and should be near the saturated levels. Therefore, the results inFig. 19 do not support the premise that $\mathrm{Cr}$ atoms in bulk or on grain boundaries play a direct (primary) role in IASCC. In relation with this observation, it is interesting to note that the grain-boundary Cr-depletion mechanism is not supported by the results of postirradiation-annealing studies reported for BWR ${ }^{14-15}$ and PWR ${ }^{10,16}$ conditions. It has been shown in these studies that, during post-irradiation annealing at $400-550^{\circ} \mathrm{C}$, IASCC susceptibility becomes negligible long before grain-boundary $\mathrm{Cr}$ concentration begins to change from its level in the as-irradiated state. 
Similar examination of Figs. 20-26 strongly indicates that Ni, Mn, Si, P, N, O, or C do not play a primary role.

Of the 19 alloys analyzed in Figs. 19-27, of particular interest is the behavior of seven 304- or 316-type alloys that were found to be resistant to IASCC, i.e., Alloys C1, C10, C12, C21, L14, L26, and L27. Understanding why these heats are resistant is considered to hold an important clue to understanding the mechanism of IASCC. From Figs. 19-26, it is evident that IASCC susceptibilities (i.e., percent IGSCC) of the seven alloys are zero or insignificant, regardless of the concentrations of $\mathrm{Cr}, \mathrm{Ni}, \mathrm{Mn}, \mathrm{Si}, \mathrm{P}, \mathrm{N}, \mathrm{O}$, or C. The only exception is S (see Fig. 27).

The $\mathrm{S}$ and $\mathrm{C}$ content of the seven resistant heats is given in Figs. 19-26. The $\mathrm{S}$ and $\mathrm{C}$ content of C16, which is susceptible to IASCC, is also given. Sulfur content of all other heats not denoted in the figures is 0.003 wt. $\%$ or higher. It can be deduced from the figures that, whereas the IASCC-resistant behavior of the seven heats is independent of the concentration of the element of each figure, they possess a unique and common character. That is, $\mathrm{S}$ concentration is very low $(<0.002 \mathrm{wt} . \%)$ and, at the same time, $\mathrm{C}$ concentration is relatively high $(>0.05 \mathrm{wt} . \%)$.

Furthermore, Fig. 27 shows that all 304- or 316-type steels containing $>0.002$ wt. $\% \mathrm{~S}$ and tested in this investigation were susceptible, whereas steels containing $\leq 0.002 \mathrm{wt} . \% \mathrm{~S}$ were either susceptible or resistant. Therefore, the results in Figs. 19-27 strongly indicate that $\mathrm{S}$ concentration of $\leq 0.002 \mathrm{wt} . \%$ is a necessary but not a sufficient condition for a 304- or 316-type steel to be resistant to IASCC under BWR-like conditions. 


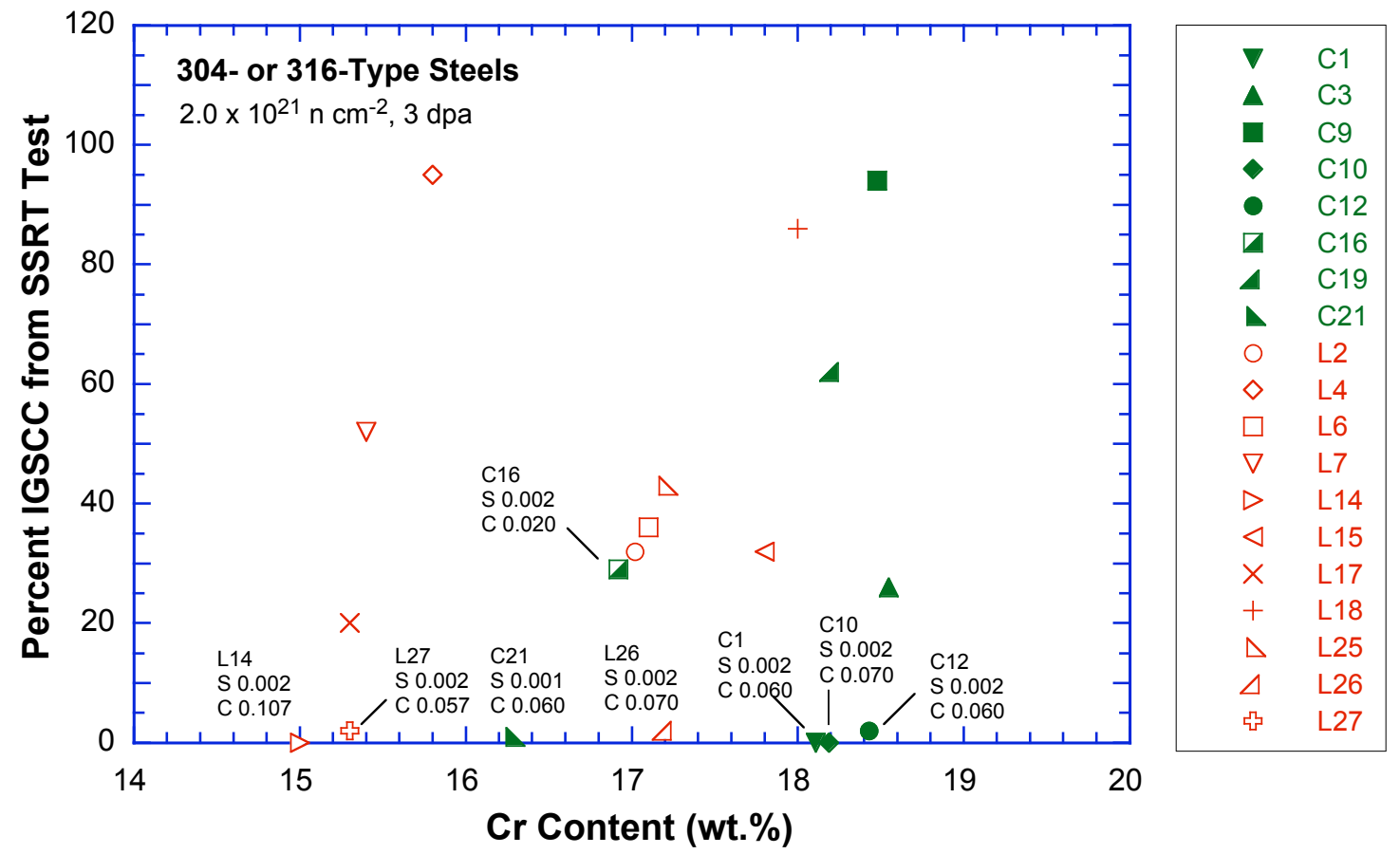

Figure 19. Percent IGSCC at $\approx 3$ dpa correlated with bulk $\mathrm{Cr}$ concentration, 304- and 316-type steels.

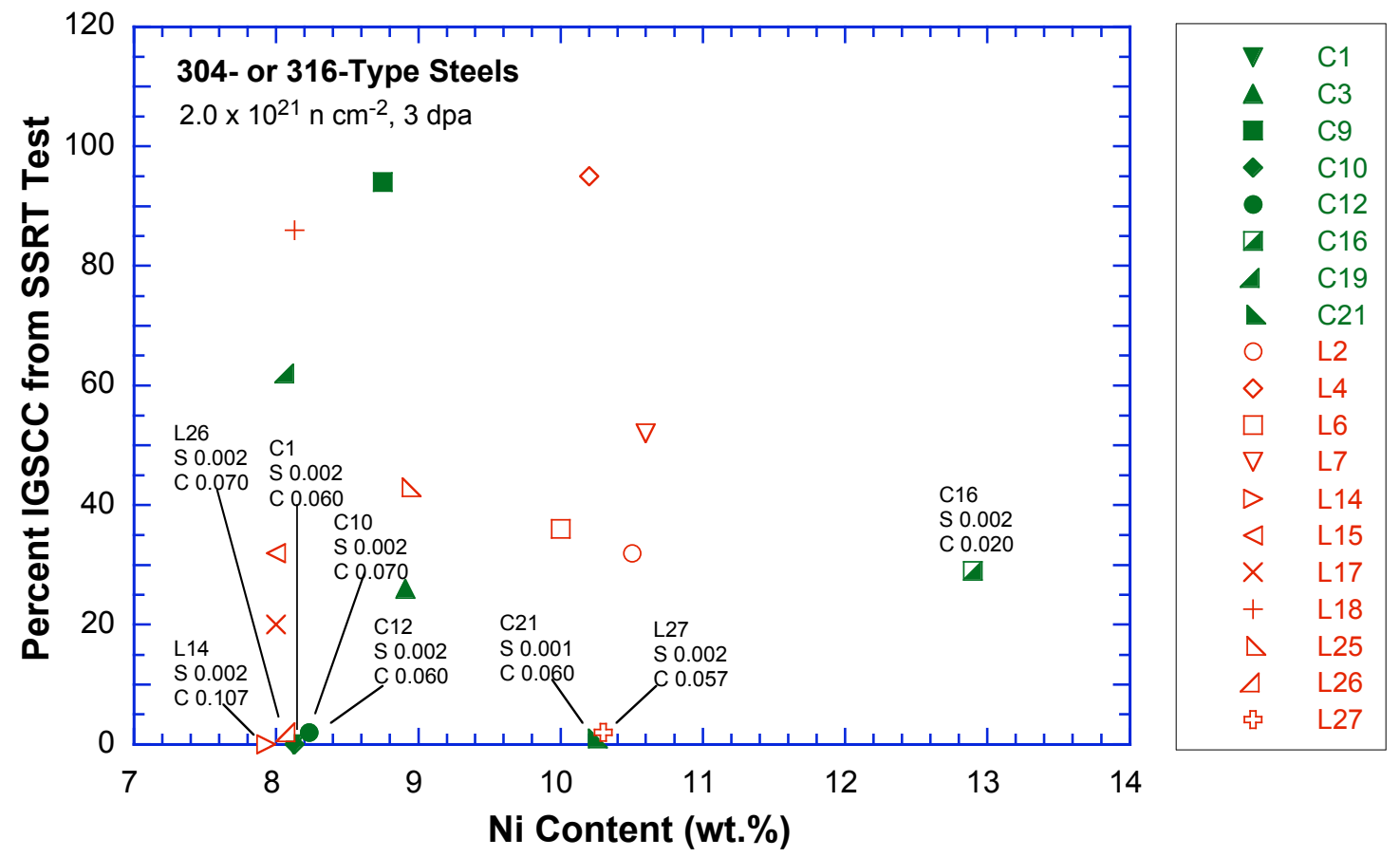

Figure 20. Percent IGSCC at $\approx 3$ dpa correlated with bulk Ni concentration, 304- and 316-type steels. 


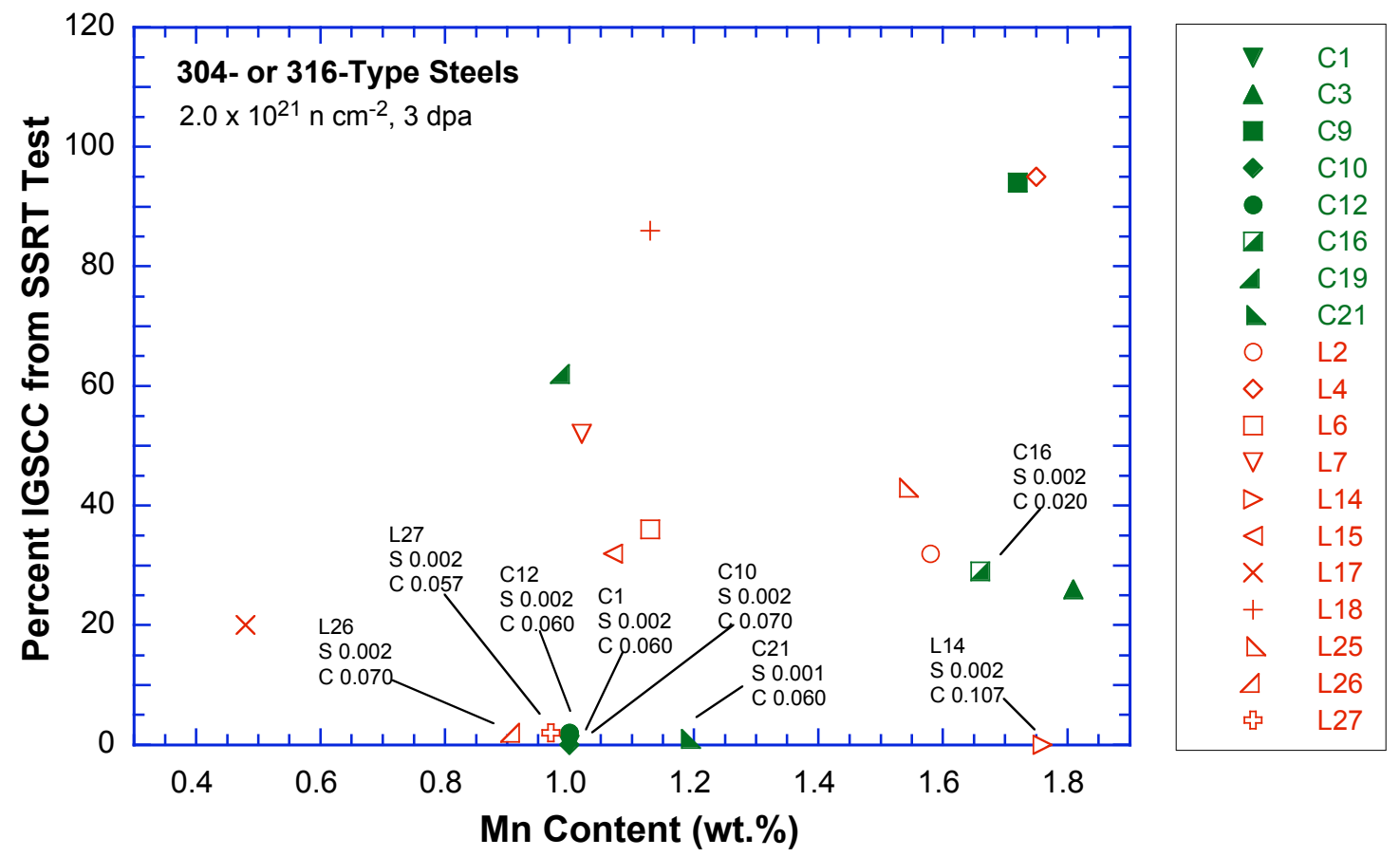

Figure 21. Percent IGSCC at $\approx 3$ dpa correlated with bulk Mn concentration, 304- and 316-type steels.
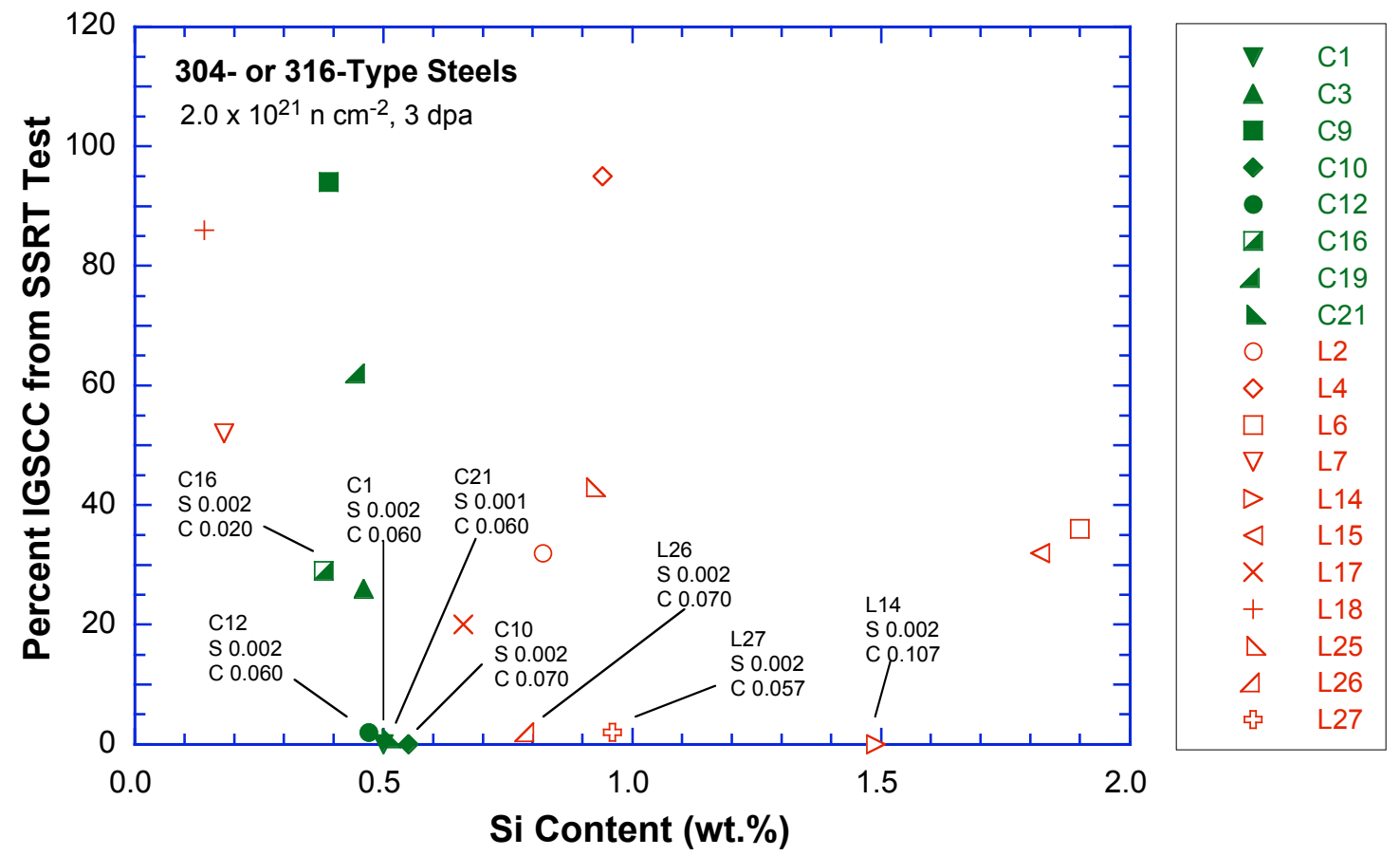

Figure 22. Percent IGSCC at $\approx 3$ dpa correlated with bulk Si concentration, 304- and 316-type steels. 


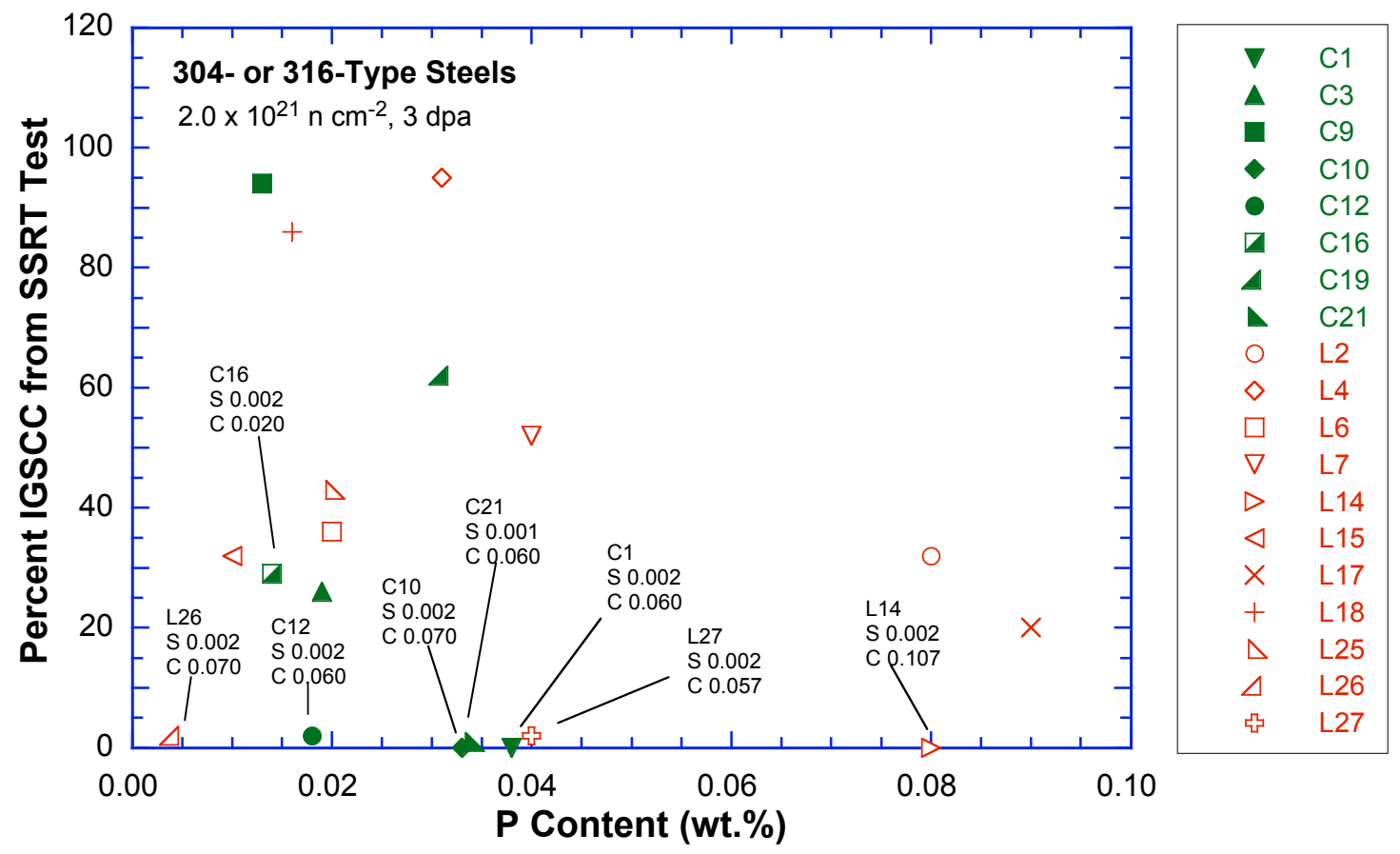

Figure 23. Percent IGSCC at $\approx 3$ dpa correlated with bulk $\mathrm{P}$ concentration, 304- and 316-type steels.

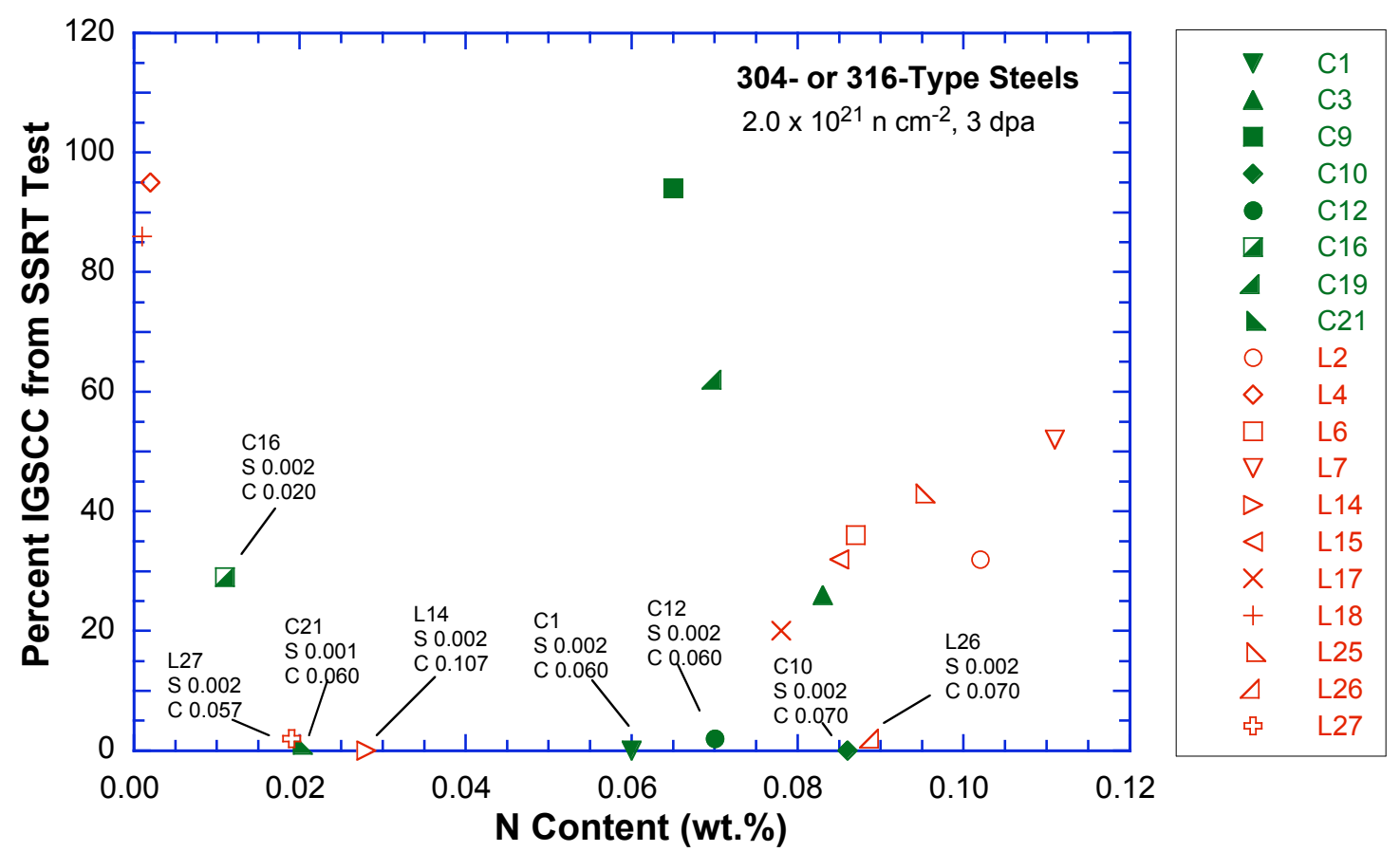

Figure 24. Percent IGSCC at $\approx 3$ dpa correlated with bulk $\mathrm{N}$ concentration, 304- and 316-type steels. 


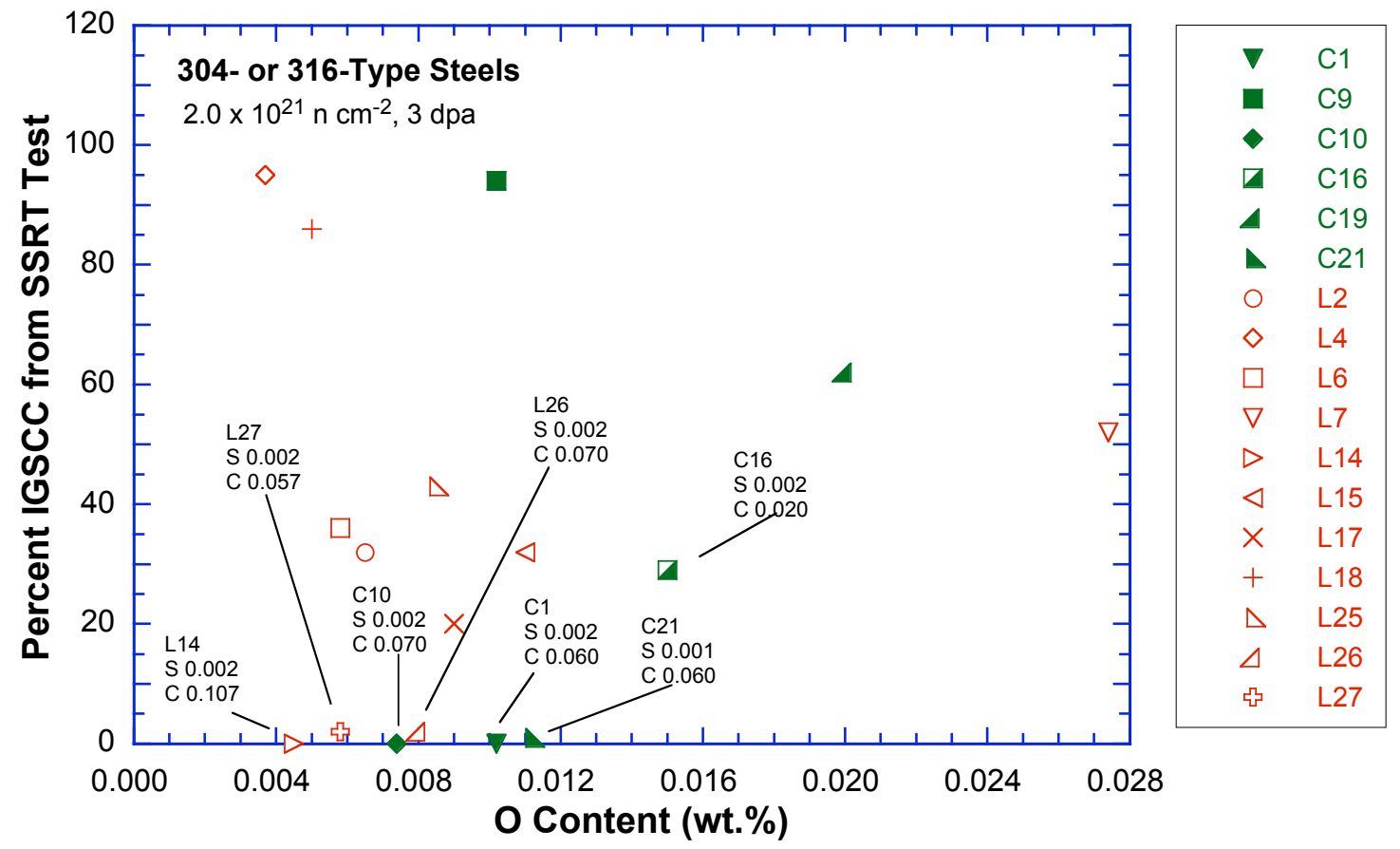

Figure 25. Percent IGSCC at $\approx 3$ dpa correlated with bulk $O$ concentration, 304- and 316-type steels.

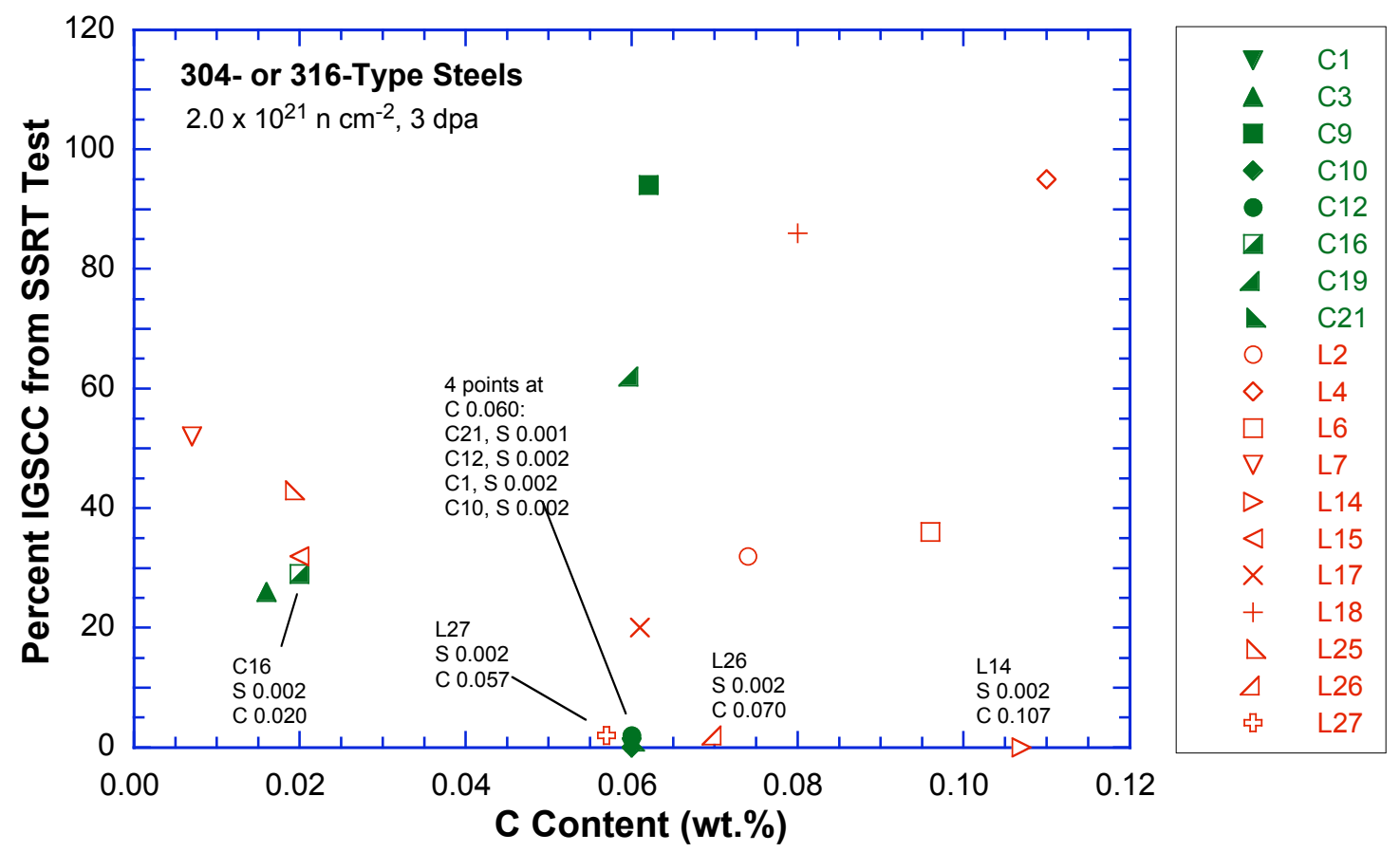

Figure 26. Percent IGSCC at $\approx 3$ dpa correlated with bulk $C$ concentration, 304- and 316-type steels. 


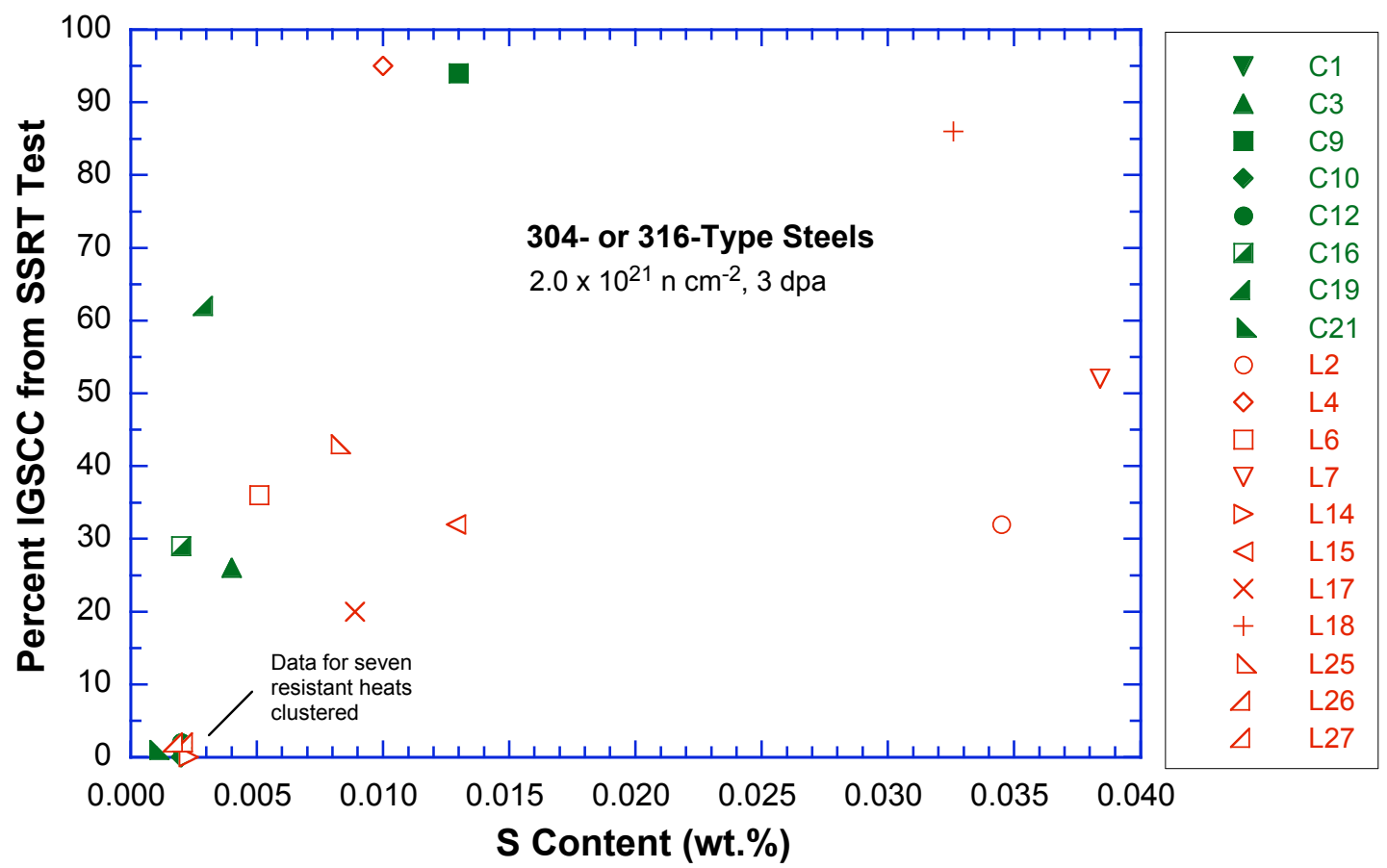

(a)

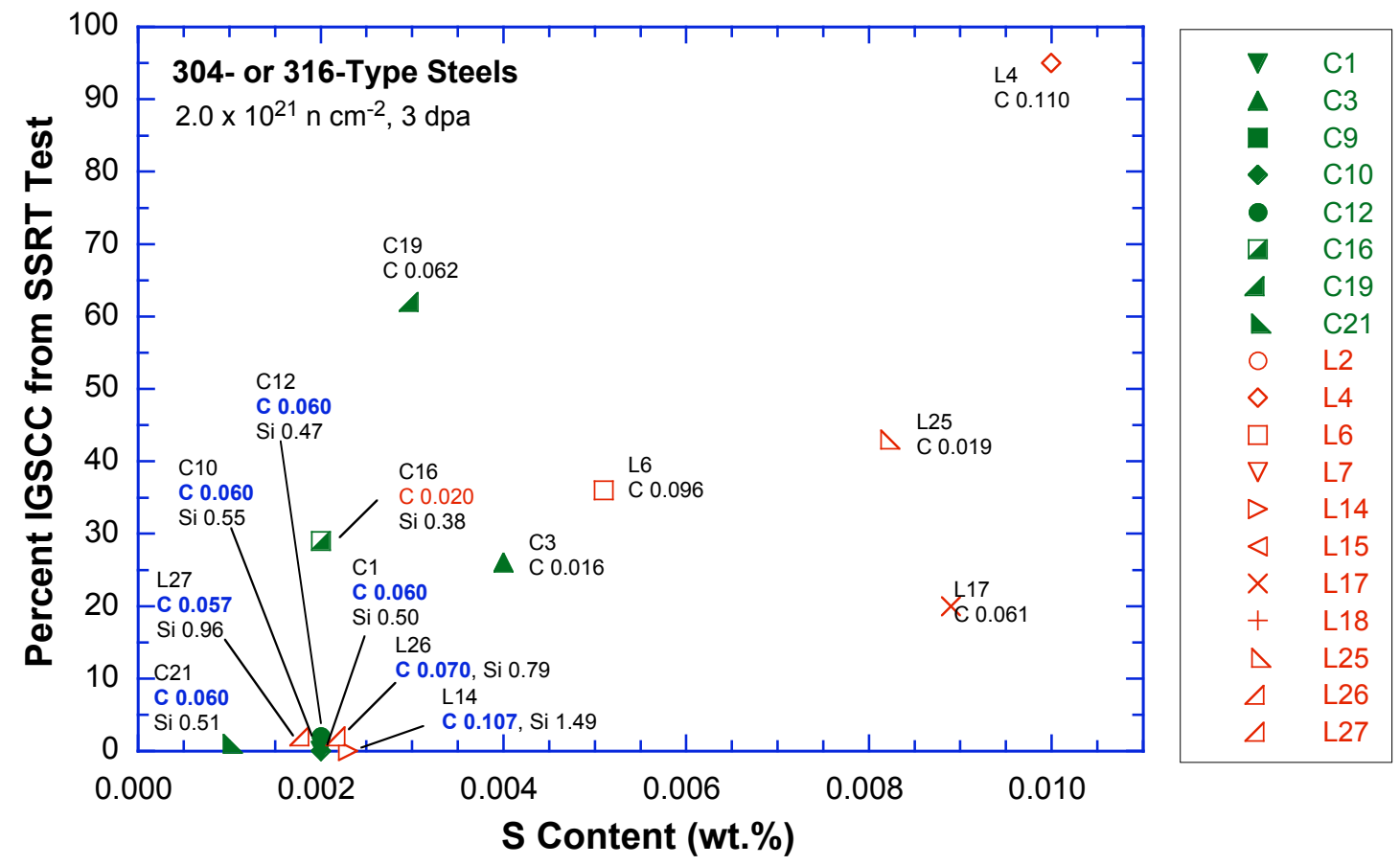

(b)

Figure 27. Percent IGSCC at $\approx 3 \mathrm{dpa}$ correlated with bulk $S$ concentration, 304- and 316-type steels: (a) all data at $S<0.004$ wt.\% and (b) expanded plot for $\mathrm{S}<0.01$ wt.\% showing details. 
In Fig. 26, the behavior of Heat C16, which contains a very low concentration of S (0.002 wt.\%) and a relatively low concentration of $\mathrm{C}(0.02 \mathrm{wt} . \%)$, is compared with the behavior of other similar heats that contain $\leq 0.002 \mathrm{wt} . \% \mathrm{~S}$ but higher concentrations of C. In spite of the very low concentration of S, the heat was susceptible. This finding indicates that $\mathrm{C}$ concentration higher than a threshold value (somewhere between 0.02 and $0.057 \mathrm{wt} . \%$ ) is also a necessary (but not a sufficient) condition for a 304- or 316-type steel to be resistant to IASCC.

However, a combined condition that $\mathrm{S}$ concentration be less than $\approx 0.002 \mathrm{wt} \%$ and, at the same time, that $\mathrm{C}$ concentration be higher than a threshold value (e.g., $>0.03 \mathrm{wt} . \%$ ) appears to be a sufficient condition for a 304- or 316-type steel to be resistant to IASCC. This observation strongly indicates that $\mathrm{S}$ is the primary contributor to IASCC susceptibility; therefore, the effect of $\mathrm{S}$ and relevant data were analyzed more systematically.

\subsection{Effect of Fluence}

Figure 28 shows the effect of fluence on the IASCC-resistant behavior of the seven heats of 304- or 316-type SSs that contain $\leq 0.002$ wt. $\% \mathrm{~S}$ and $>0.05$ wt. $\%$ C. For damage levels of $0.4,1.3$, and 3.0 dpa, no appreciable susceptibility to IASCC was observed in these heats in $289^{\circ} \mathrm{C} \mathrm{BWR}$-like high-purity water that contains $\approx 8 \mathrm{ppm} \mathrm{DO} \mathrm{(ECP} \approx 160-220 \mathrm{mV}$ SHE). The IASCC-resistant behavior of these heats is expected to be valid also in similar water that contains lower levels of DO and ECP.

In contrast, a strong effect of fluence was observed for two groups of 304- or 316-type steels that are susceptible to IASCC, i.e., heats that contain high $\mathrm{S}(\geq 0.003 \mathrm{wt} . \%)$ and heats that contain low $\mathrm{S}$ $(<0.002$ wt.\%) and low $\mathrm{C}(<0.03 \mathrm{wt} . \%)$. The effect of fluence for the 16 susceptible heats of 304 - or 316-type SSs tested in this study is shown in Fig. 29. The effect of fluence of the susceptible heats varied significantly from heat to heat. However, the root cause of the strong variation in fluence effect is not understood. Strong variation is evident for both laboratory and commercial heats.

\subsection{Role of S in IASCC at High Fluence}

In contrast to the laboratory-fabricated model SSs that have compositions outside of the AISI specifications, for all eight commercial heats of Type 304, 304L, 316, and 316L austenitic SSs investigated in this study, bulk S content provided a good monotonic correlation with percent IGSCC (see Fig. 30). Four commercial heats of Type 304 and 316 SS that contain very low concentrations of S $(\leq 0.002 \mathrm{wt} . \%)$ exhibited only negligible susceptibility to IGSCC. 


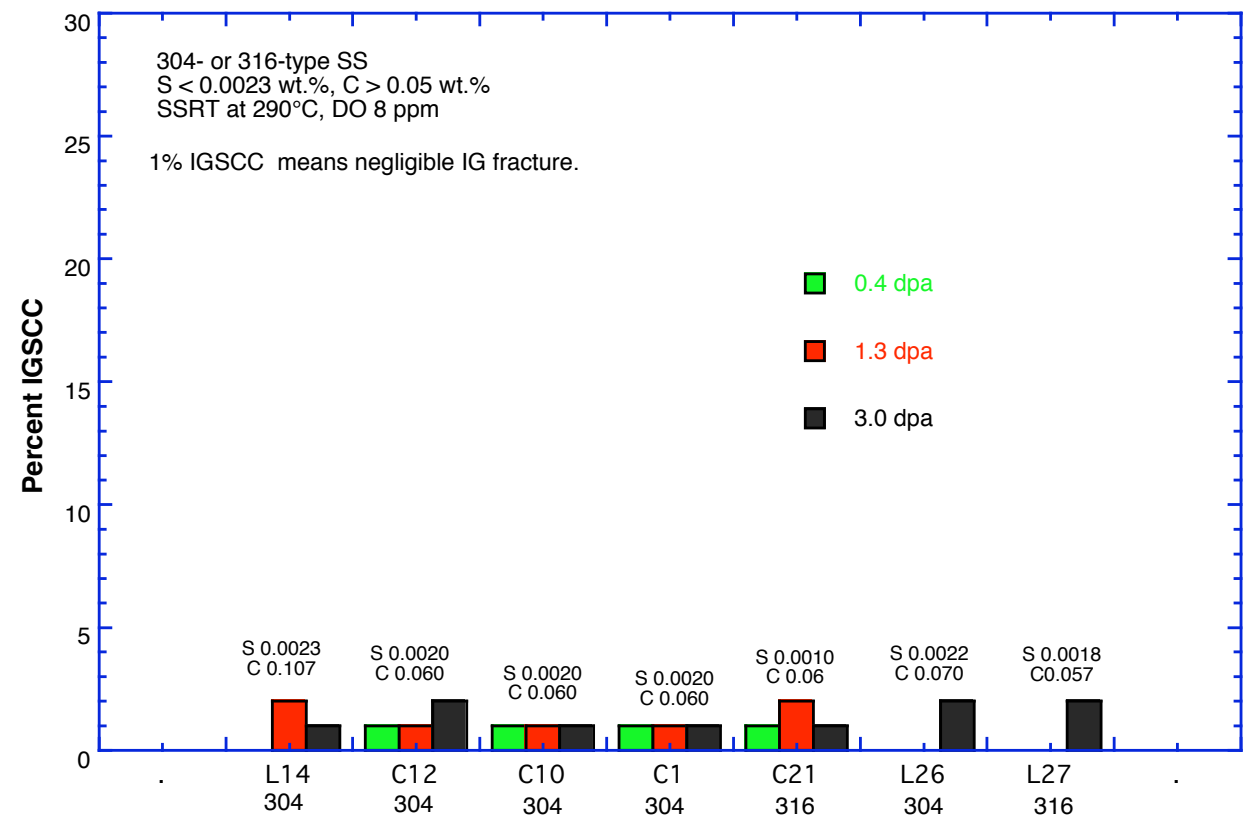

Figure 28. Effect of neutron damage on IASCC susceptibility (percent IGSCC) of Type 304 or 316 steels that contain low concentrations of $S$ and high concentrations of $C$ (i.e., $<0.0023$ wt.\% $S$ and $>0.05$ wt. $\% C$ ).

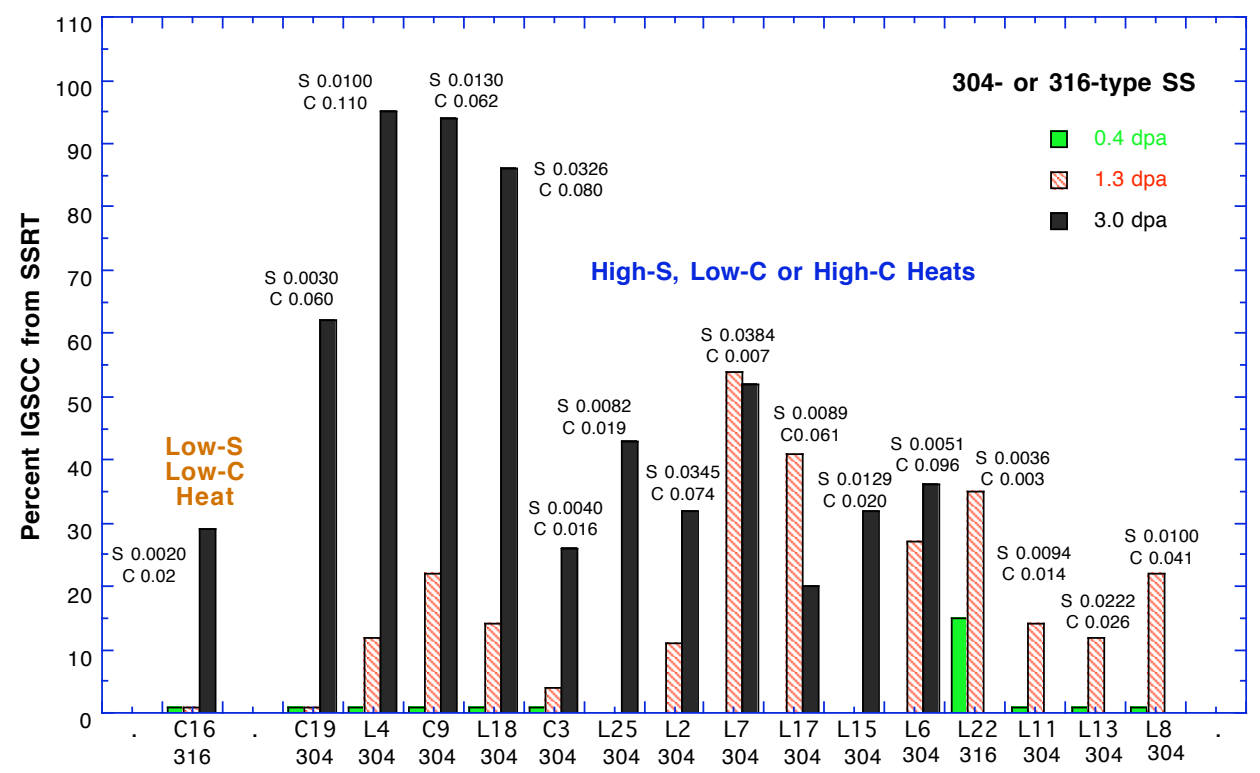

Figure 29. Effect of neutron damage on IASCC susceptibility (percent IGSCC) of Type 304 or 316 steels that contain low $S$ and low $C$ concentrations (i.e., $\leq 0.002$ wt. $\% \mathrm{~S}$ and $<0.03$ wt. $\% \mathrm{C}$ ), high $\mathrm{S}$ and high $\mathrm{C}$ concentrations (i.e., $>0.003$ wt. $\% \mathrm{~S}$ and $>0.05$ wt. $\% \mathrm{C}$ ), or high $\mathrm{S}$ and low $\mathrm{C}$ concentrations (i.e., $>0.003$ wt. $\% \mathrm{~S}$ and $<0.03$ wt. $\% \mathrm{C}$ ). 
However, as S content increased to $\geq 0.003$ wt. $\%$, susceptibility increased drastically. At an S content of $>0.005 \mathrm{wt} . \%$, the specimens from the commercial heats failed in virtually complete IG mode, just as in IASCC of field components. The steep increase of susceptibility at S levels $>0.003 \mathrm{wt} . \%$ indicates that an Srelated critical phenomenon plays an important role in IASCC.

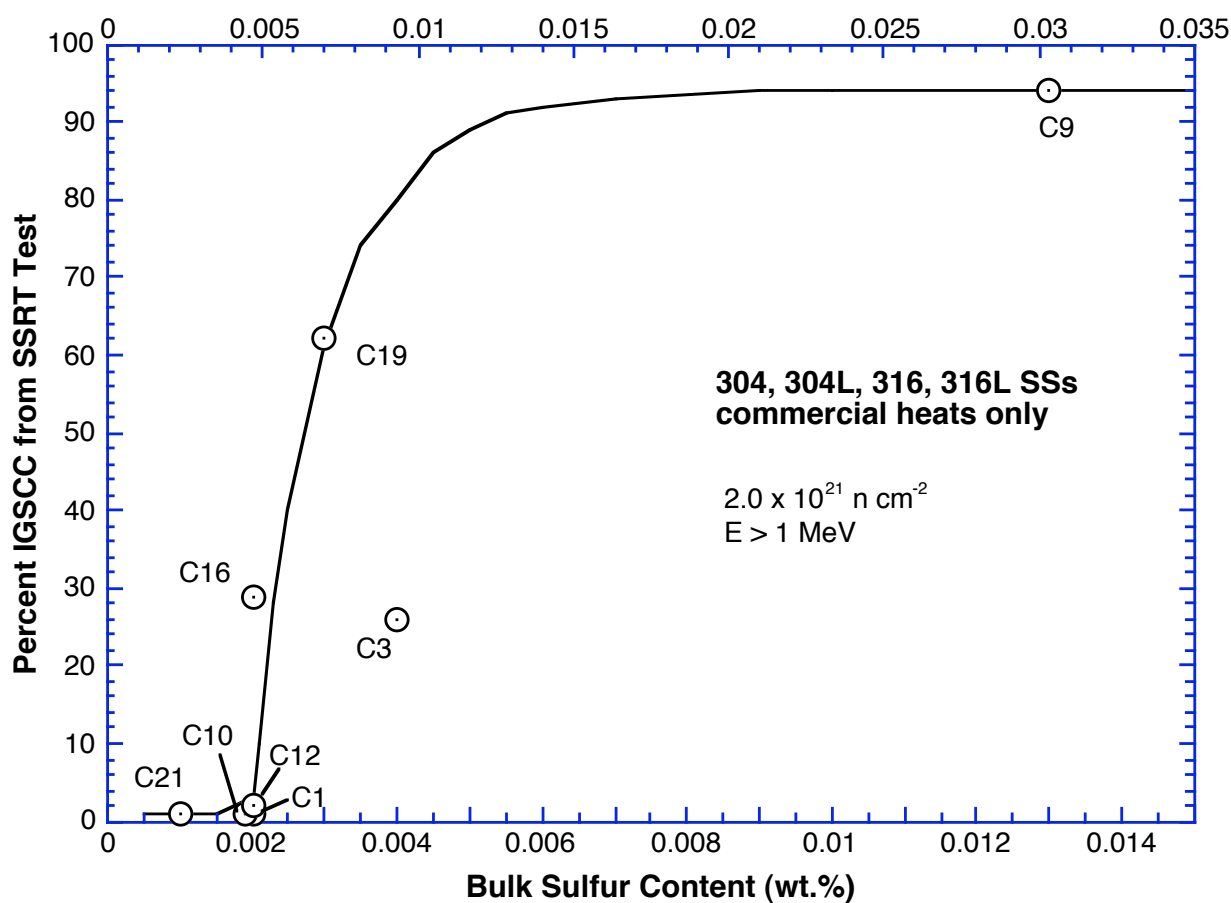

Figure 30. Effect of bulk S content on IASCC susceptibility (percent IGSCC) of commercial heats of Types 304, 304L, 316, and 316L steels.

The deleterious effect of S can be discerned more directly by comparing the IASCC susceptibilities of a pair of high- and low-S heats of the same grade that contain otherwise similar elemental compositions, e.g., Heat C12 (S 0.002 wt.\%) and Heat C9 (S 0.013 wt.\%). As fluence increased, the susceptibility of Heat C12 remained negligible, whereas the susceptibility of Heat C9 increased drastically (see Fig. 31).

The relative behavior of Heats $\mathrm{C} 9$ and $\mathrm{C} 12$ is consistent with the observation reported by Tsukada et al. on their HP and $\mathrm{HP}+\mathrm{S}$ heats. ${ }^{24,29}$ They reported that an HP heat that contained 0.0318 wt.\% S and 0.002 wt.\% C (Heat HP+S, see Fig. 32) was significantly more susceptible than an HP heat that contained 0.0014 wt. $\% \mathrm{~S}$ and $0.003 \mathrm{wt} . \% \mathrm{C}$ (Heat HP). They also reported that the latter heat was more susceptible than a C-doped HP heat that contains 0.0020 wt. $\% \mathrm{~S}$ and $0.098 \mathrm{wt} . \% \mathrm{C}$ (Heat $\mathrm{HP}+\mathrm{C}$ ). A deleterious effect of S is also indicated from the expanding-tube-test data reported by Kasahara et al., ${ }^{28}$ Jacobs et al., ${ }^{21}$ and Garzarolli et al. ${ }^{2}$ (see Figs. 33-35, respectively).

The tests used to obtain the data in Figs. 31 and 33-35 are based on the "binary-like" approach. In this approach, S content was varied high or low while the composition of other elements was kept similar to that of commercial steels used in reactor components. In contrast, the result in Fig. 32 is based on the "singleelement" approach in which high-purity heats are used. 

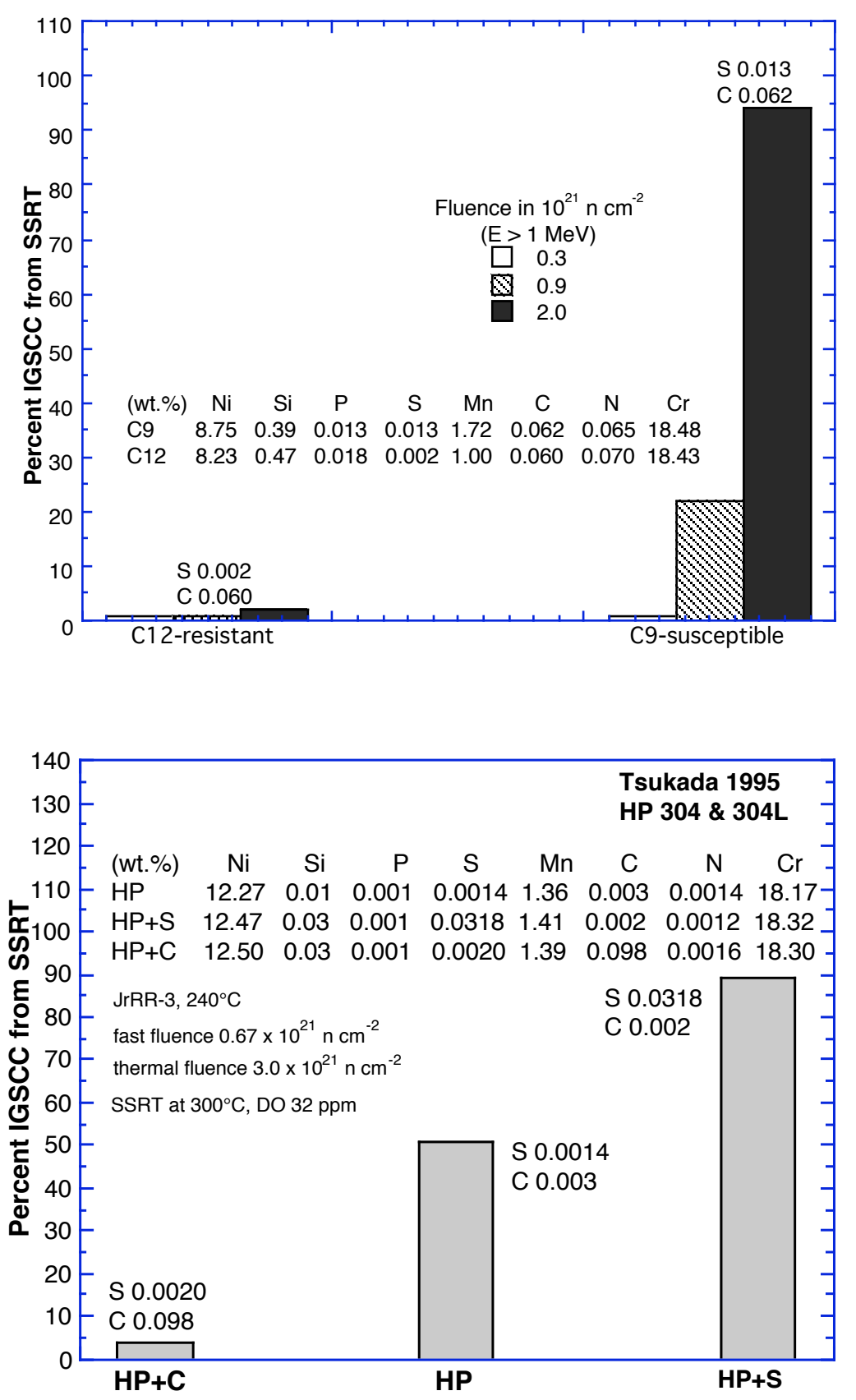

Figure 31.

IASCC susceptibility of low-S (Heat C12) and high-S (Heat C19) heats of comparable chemical composition; Type 304 SS.
Figure 32.

IASCC susceptibility of high-purity heats of Type 304L SS doped with $\mathrm{C}$ or $\mathrm{S}$, from Tsukada et al., Ref. 29. 

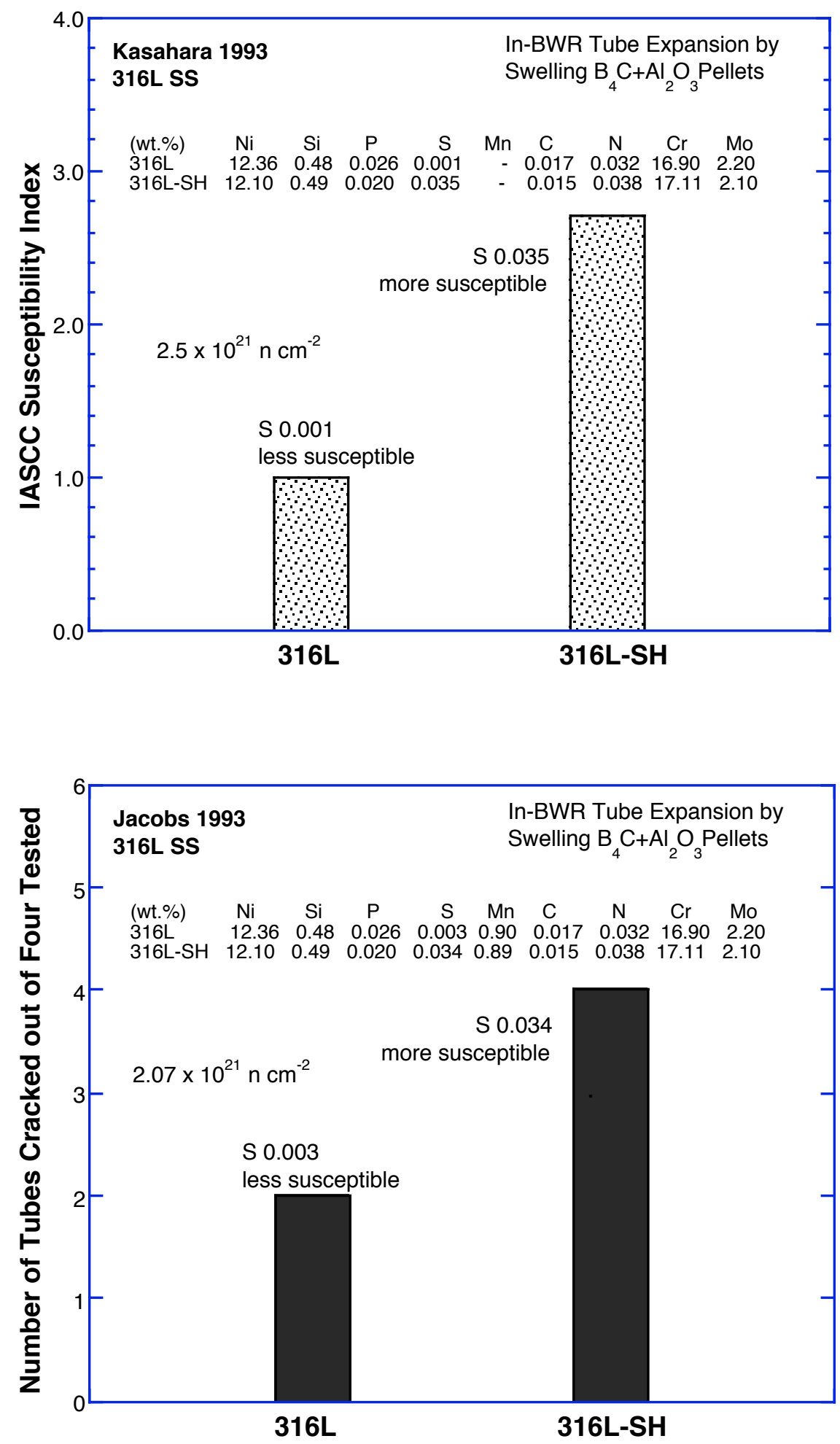

Figure 33.

IASCC susceptibility of low- and high-S heats of comparable composition, from Kasahara et al., Ref. 28.

Figure 34.

IASCC susceptibility of low- and high-S heats of comparable composition, from Jacobs et al., Ref. 21.

Although the latter approach is advantageous when used to isolate more clearly the effect of a single element, it is difficult to determine which element plays a dominant or secondary role and to determine if the 
effect of that particular element is influenced by other elements present in a steel similar to those used in a reactor. Therefore, a finding from such an approach must be confirmed for the type of steels used to fabricate actual field components. Tests on a sufficiently large number of commercial heats, such as those in Fig. 30, serve this purpose. Also, any potential effect of uncommon parameters, such as the presence of ferrite or dendrites, should be screened carefully. The deleterious effect of S indicated from the three approaches is consistent, i.e., the binary-like single-element approach with commercial steels (Figs. 31 and 33-35), the single-element approach with HP steels (Fig. 32), and the multiple-elements approach with commercial steels (Fig. 30).

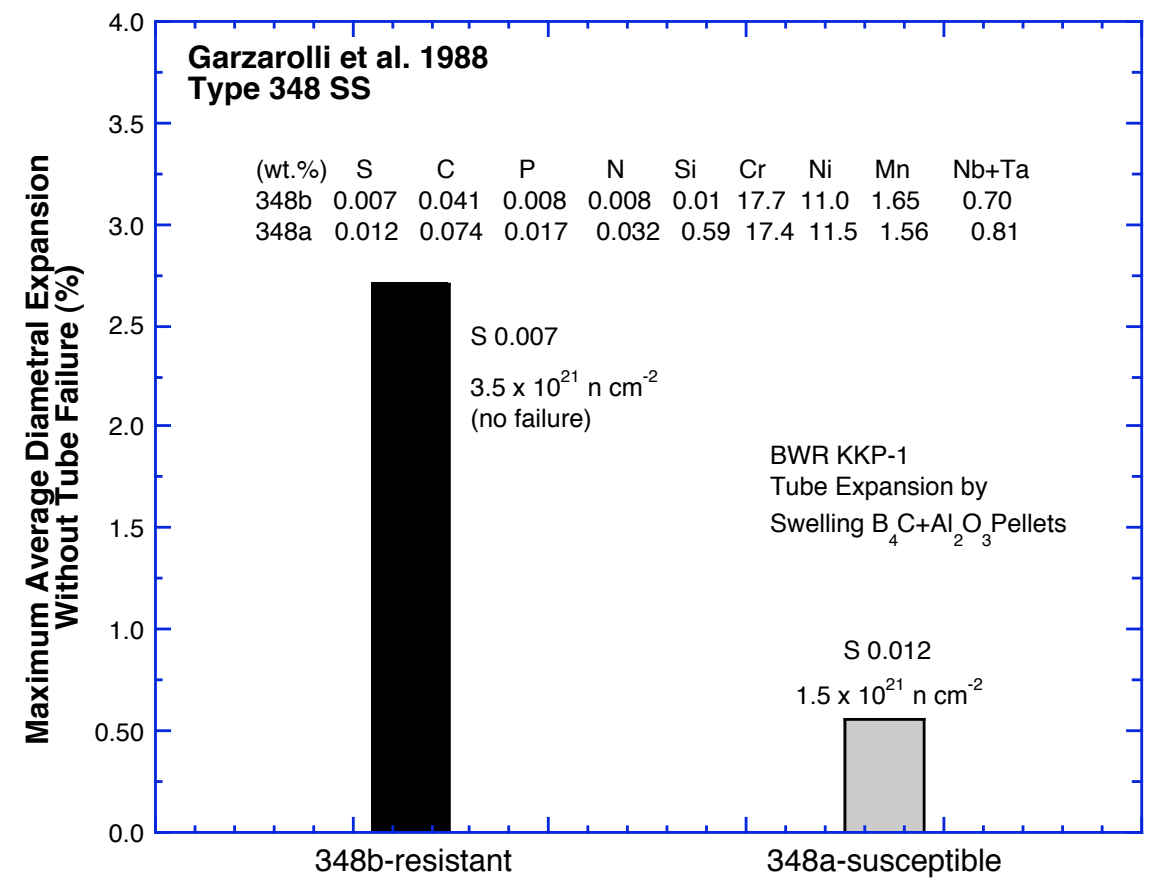

Figure 35. IASCC susceptibility of low- and high-S heats of comparable composition, from Garzarolli et al. Ref. 2.

\subsection{Effect of Carbon on Deleterious Role of Sulfur}

For high-carbon heats of Types 304 and 316 SS, it was shown in Fig. 28 that S content of $\leq 0.002$ wt.\% provides good resistance to IASCC. However, whether the same is true or not with low-carbon heats of Types 304L, 316L, or high-purity SSs needs careful examination.

In this investigation, Type $316 \mathrm{SS}$ Heat $\mathrm{C} 21$ that contains $0.001 \mathrm{wt} . \% \mathrm{~S}$ and $0.060 \mathrm{wt} . \% \mathrm{C}$ was resistant to IASCC. In contrast, a similar heat of Type 316L SS (Heat C16) that contains $0.002 \mathrm{wt} \% \mathrm{~S}$ and 0.020 wt. $\% \mathrm{C}$ was susceptible (Fig. 30). This behavior appears to be consistent with the data of Tsukada et al., ${ }^{29}$ i.e., the behavior of Heats HP+C vs. HP shown in Fig. 32. Tanaka and coworkers performed SSRT tests on 304L- and 316L-type SS heats that contained S in nominal concentrations between 0.000 and 0.003 wt.\% after irradiation in a BWR to $\approx 1.9$ to $2.1 \times 10^{21} \mathrm{n} \cdot \mathrm{cm}^{-2}(\mathrm{E}>1 \mathrm{MeV}) .{ }^{41}$ A 304-type heat that contained 0.002 wt. $\% \mathrm{~S}$ and $0.060 \mathrm{wt} . \% \mathrm{C}$ was resistant to IASCC at $1.3 \times 10^{21} \mathrm{n} \cdot \mathrm{cm}^{-2}(\mathrm{E}>1 \mathrm{MeV})$, whereas a 304Ltype heat that contained $0.002 \mathrm{wt} . \% \mathrm{~S}$ and $0.013 \mathrm{wt} . \% \mathrm{C}$ was susceptible to IASCC at $2.1 \times 10^{21} \mathrm{n} \cdot \mathrm{cm}^{-2}$. Of the nine 316L-type heats investigated by Tanaka et al., three exhibited negligible susceptibility to IASCC, whereas the other six exhibited susceptibility. Fukuya et al. reported similar results. ${ }^{20}$ 
Summarizing the results from the four investigations, Figs 36 and 37 show, respectively, relative IASCC susceptibilities (i.e., percent IGSCC from SSRT test) of low-S heats ( $\mathrm{S} \leq 0.002 \mathrm{wt} \%$ ) of high-C steels (i.e., Types 304 and $316 \mathrm{SS}$ ) and those of their low-C counterparts. The trend in the figures indicates that low-S heats ( $\mathrm{S} \leq 0.002 \mathrm{wt} . \%$ ) of 304- and 316-type SS are resistant to IASCC. However, all low-S heats of 304L- and 316L-type SS that contain $\leq 0.002 \mathrm{wt} . \% \mathrm{~S}$ are not necessarily resistant.

A similar trend is also evident for 348- and 348L-type SSs investigated by Garzarolli and coworkers by swelling-tube tests ${ }^{2,7,42}$ in a PWR (see Figs. 38 and 39). In their experiments, average diametral strain was measured for intact and cracked tubes from the same heat after irradiation to one to three fuel cycles. Sulfur concentration in the tubes ranged from 0.002 to $0.007 \mathrm{wt} \%$. Their one-cycle data in Fig. 38 show that, under the same irradiation conditions, high-C heats (C 0.027-0.043 wt.\%) could tolerate more diametral expansion without incurring a failure than low-C heats (C 0.003-0.015 wt.\%), in spite of the fact that the high-C heats contained somewhat higher levels of $\mathrm{S}$ than the latter (i.e., 0.005-0.007 wt.\% vs. 0.003-0.004 wt.\%). A similar trend is observed from the one-to-three cycle data shown in Fig. 39. That is, high-C heats (C 0.0270.048 wt.\%) could withstand more diametral expansion without a failure than low-C heats (C 0.003$0.007 \mathrm{wt} . \%$ ), in spite of the fact that the former heats contained higher levels of $\mathrm{S}$ than the latter and that fluence was higher in the former than in the latter.

The consistent behavior from the six investigations summarized in Figs. 36-39 shows that high C content suppresses the deleterious effect of S, if the S concentration is very low. In 304- or 316-type SSs, the beneficial effect of $\mathrm{C}$ (in concentrations $\geq 0.03 \mathrm{wt} . \%$ ) is manifested significantly if S concentration is less than $\approx 0.004$ wt.\%. In the absence of such a beneficial effect, 304L- or 316L-type steels seem to be inherently less resistant than their high-C counterparts; this seems to lead to significant susceptibility even in some low-S heats, e.g., those shown in Figs. 36 and 37. 


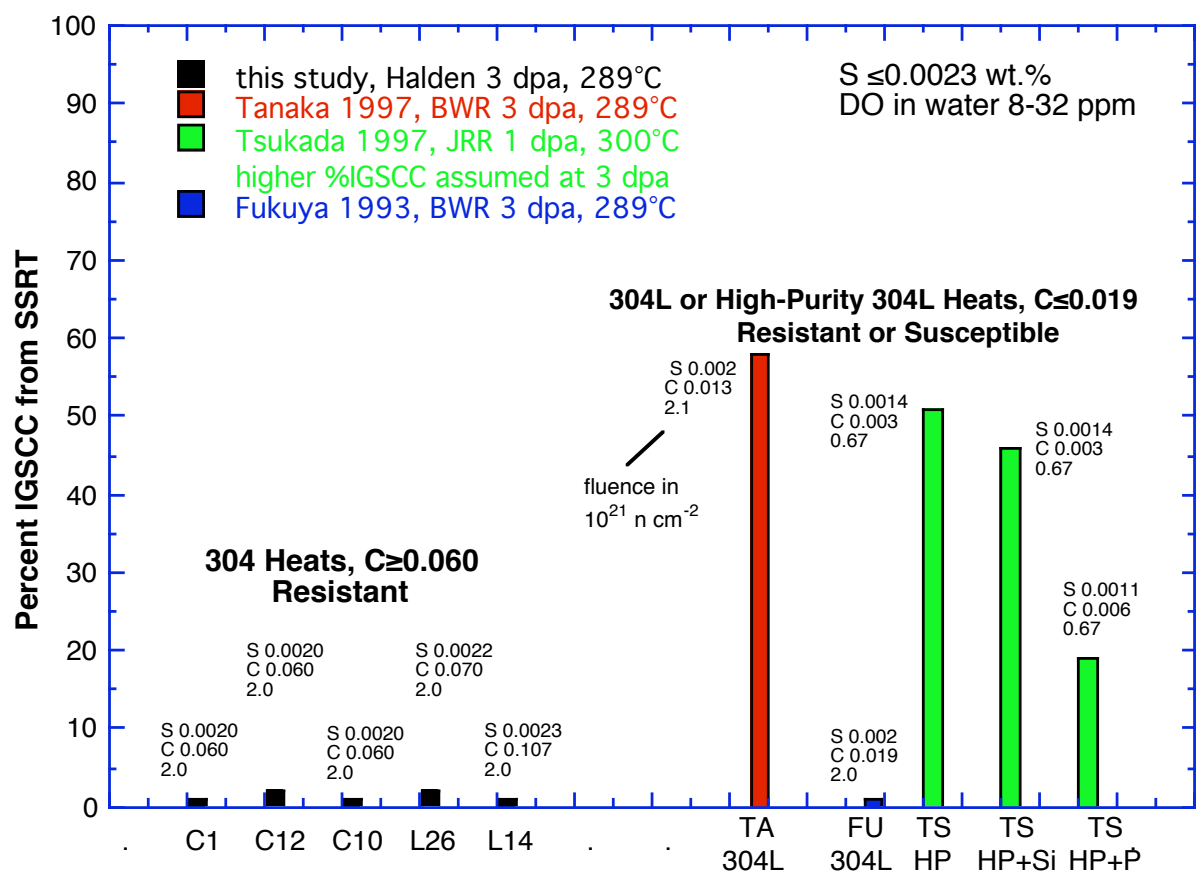

Figure 36. Percent IGSCC from SSRT tests of low-S high-C and low-S low-C heats of Type 304 or 304L SSs.

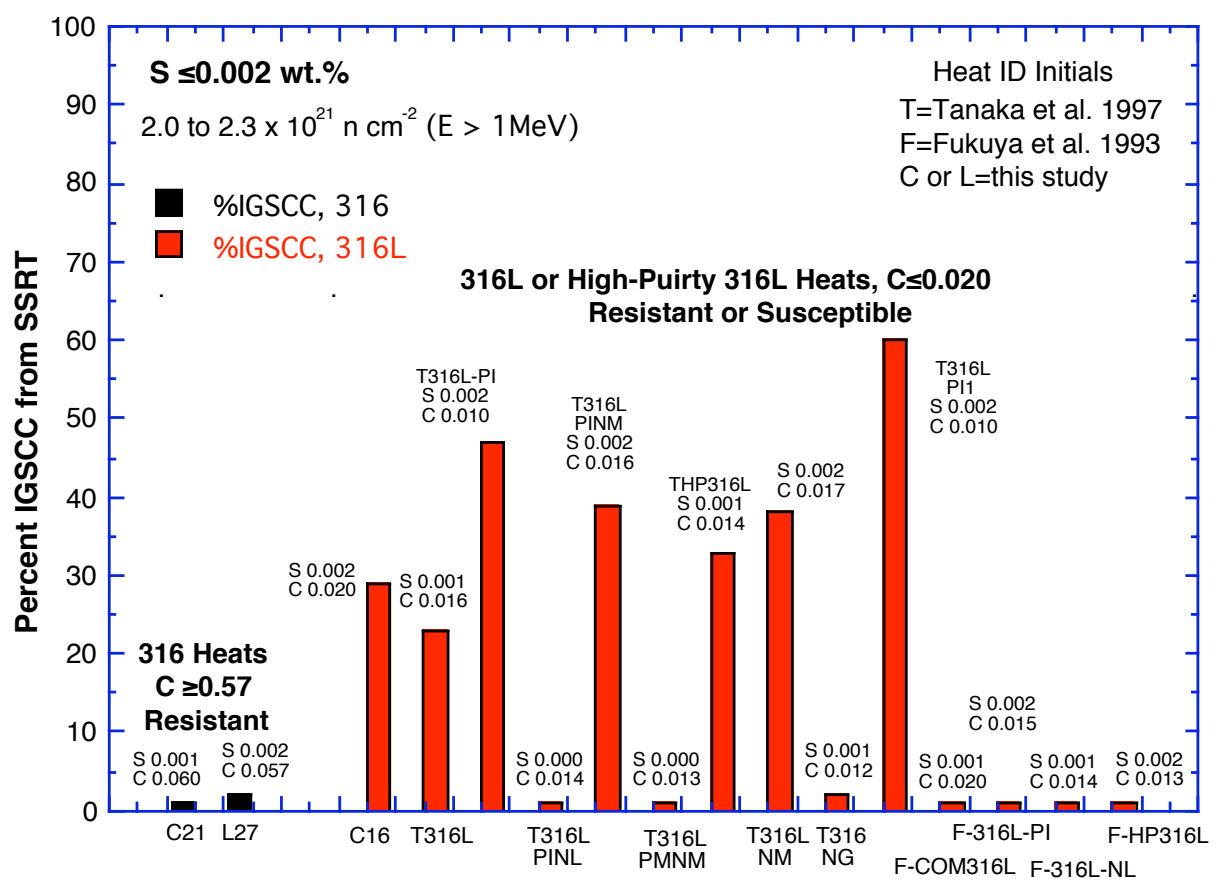

Figure 37. Percent IGSCC from SSRT test of low-S high-C and low-S low-C heats of Type 316 or $316 \mathrm{~L}$ SSs. 


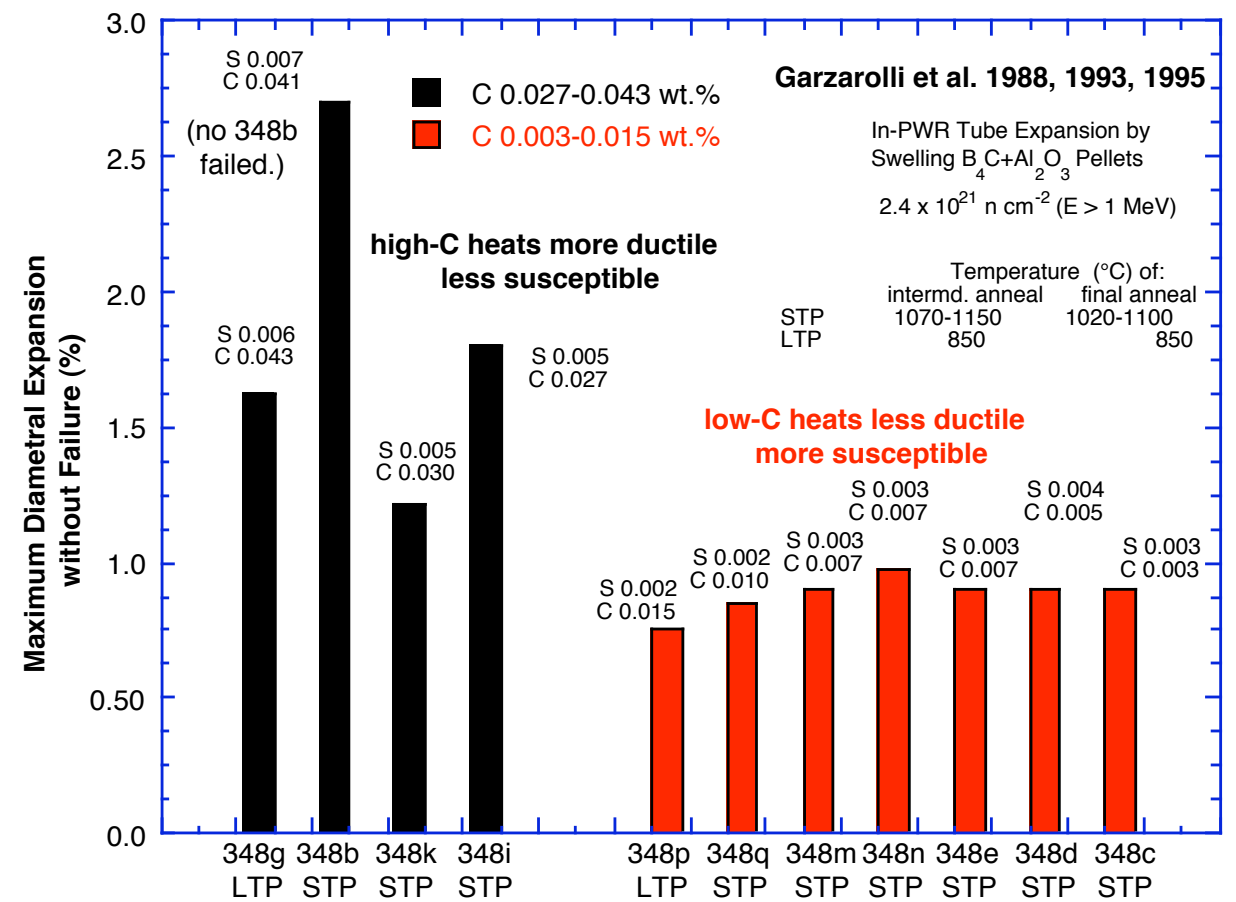

Figure 38. Diametral strain at failure for low-S high-C and low-S low-C heats of Type 348 SSs. Data from Garzarolli et al., Refs. 2, 7, and 42, one-cycle irradiation.

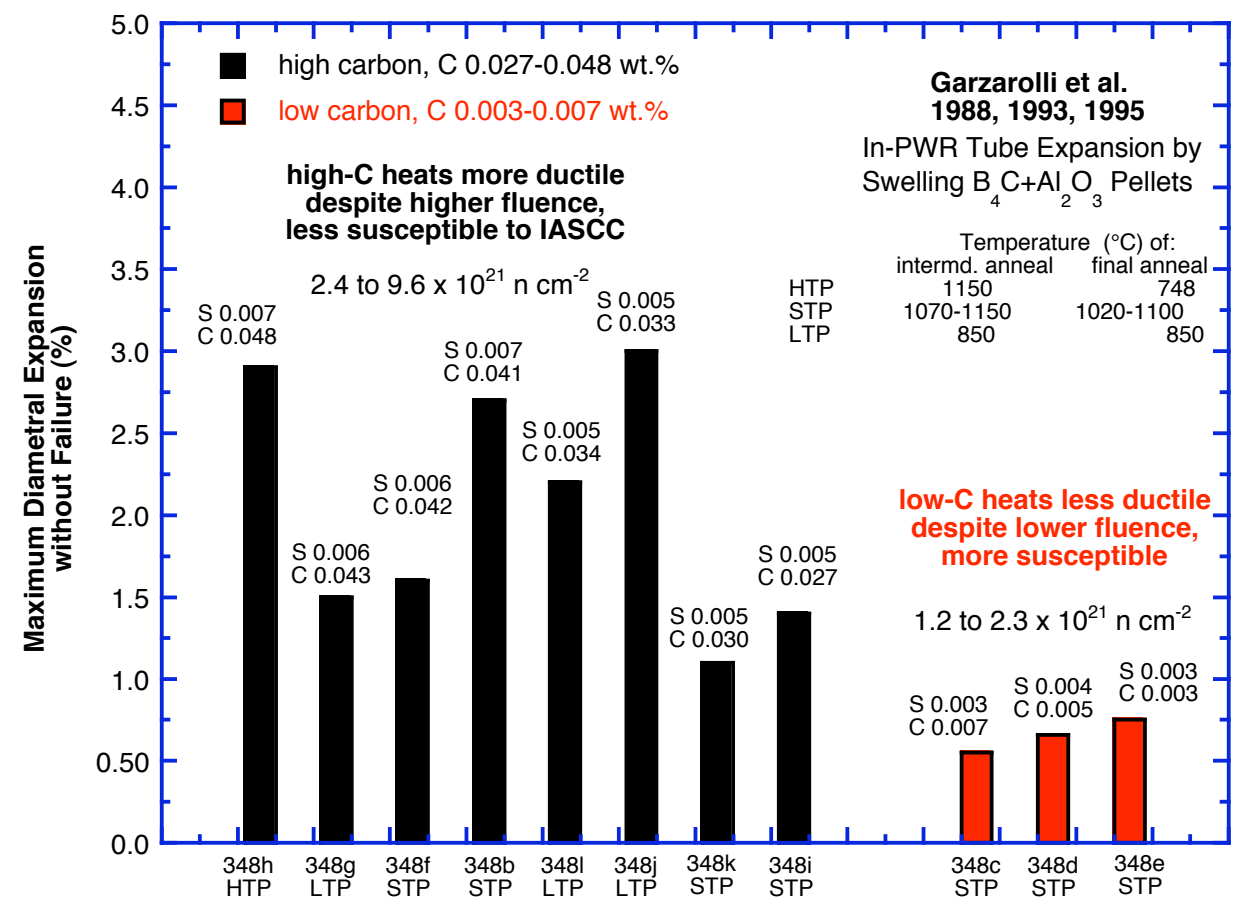

Figure 39. Diametral strain at failure for low-S high-C and low-S low-C heats of Type 348 SSs. Data from Garzarolli et al. Refs. 2, 7, and 42, one-to-three-cycle irradiation. 
When S concentration is high, e.g., $\geq 0.004$ wt. $\%$ in 304- or 316-type SSs and $\geq 0.01$ wt. $\%$ in 348-type $\mathrm{SSs}$, it appears that the deleterious effect of $\mathrm{S}$ is so dominant that the effect of $\mathrm{C}$ is negligible or insignificant, even at high concentrations of $\mathrm{C}$.

\subsection{Effect of Si at High Fluence}

As pointed out in Section 7, for a medium level of damage ( $\approx 1.3 \mathrm{dpa})$, the data in Fig. 17 indicate that $\mathrm{Si}$ in high concentrations either delays the onset of IGSCC or suppresses the susceptibility to IGSCC. However, by the time the damage level reaches $\approx 3 \mathrm{dpa}$, it appears that the deleterious effect of $\mathrm{S}$ is so dominant that the effect of $\mathrm{Si}$ is either insignificant or secondary at best. This conclusion can be deduced from Fig. 22, in which percent IGSCC is plotted as a function of Si content.

Three 304-type laboratory heats that contained unusually high concentrations of Si were tested in $289^{\circ} \mathrm{C}$ water in this investigation after irradiation to $\approx 3$ dpa, i.e., Heats L14 (Si 1.49 wt.\%), L15 (Si 1.82), and L6 (Si 1.90). These Si concentrations well exceed the AISI-specified limit of 1.0 wt.\%. As shown in Table 14 , the three heats exhibited relatively higher level of uniform elongation compared to other laboratory heats of 304- or 316-type SSs. However, in spite of this, the susceptibility of the three heats appeared to be determined largely by the concentrations of $S$ and $C$. This is shown in Fig. 40 . At $\approx 3$ dpa, there was no clear evidence that high Si content suppresses the susceptibility to IASCC of the steels investigated in this study.

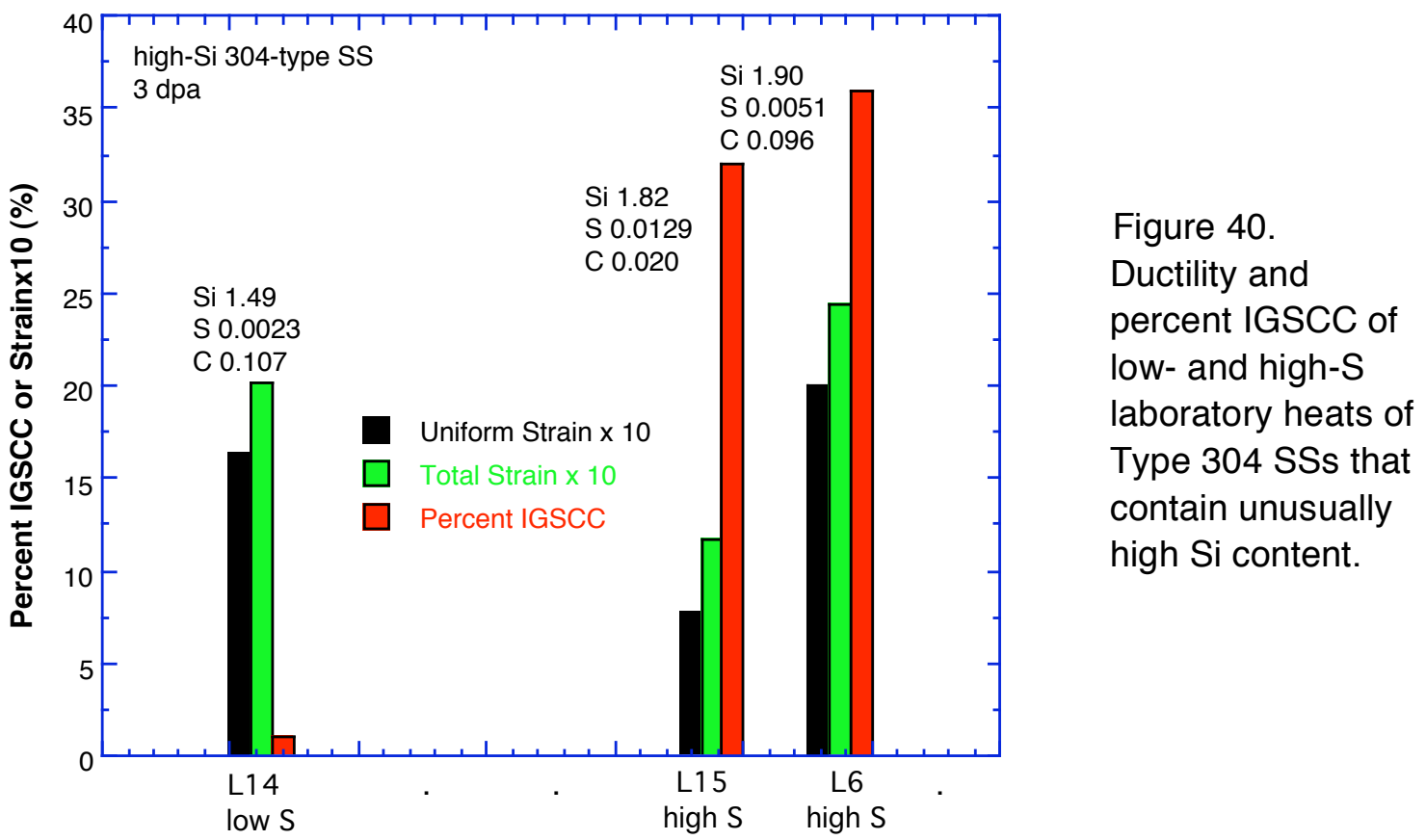

Some of the low-C, low-S heats of 316L-type SSs (damage level $\approx 3$ dpa), shown in Fig. 37, contain an unusually low Si concentration of $\leq 0.05 \mathrm{wt} . \% .{ }^{19,41}$ When compared with the other heats in the figure that contain higher levels of Si (0.38-0.59 wt.\%), the IASCC behavior of the high- and low-Si heats was similar; this is shown in Fig. 41.

As in the case of 304- and 316-type SSs, IASCC susceptibility of 348-type SS at high fluence $(\approx 3 \mathrm{dpa})$ seems to be determined largely by the concentrations of S and $\mathrm{C}$, and the effect of Si appears secondary. 


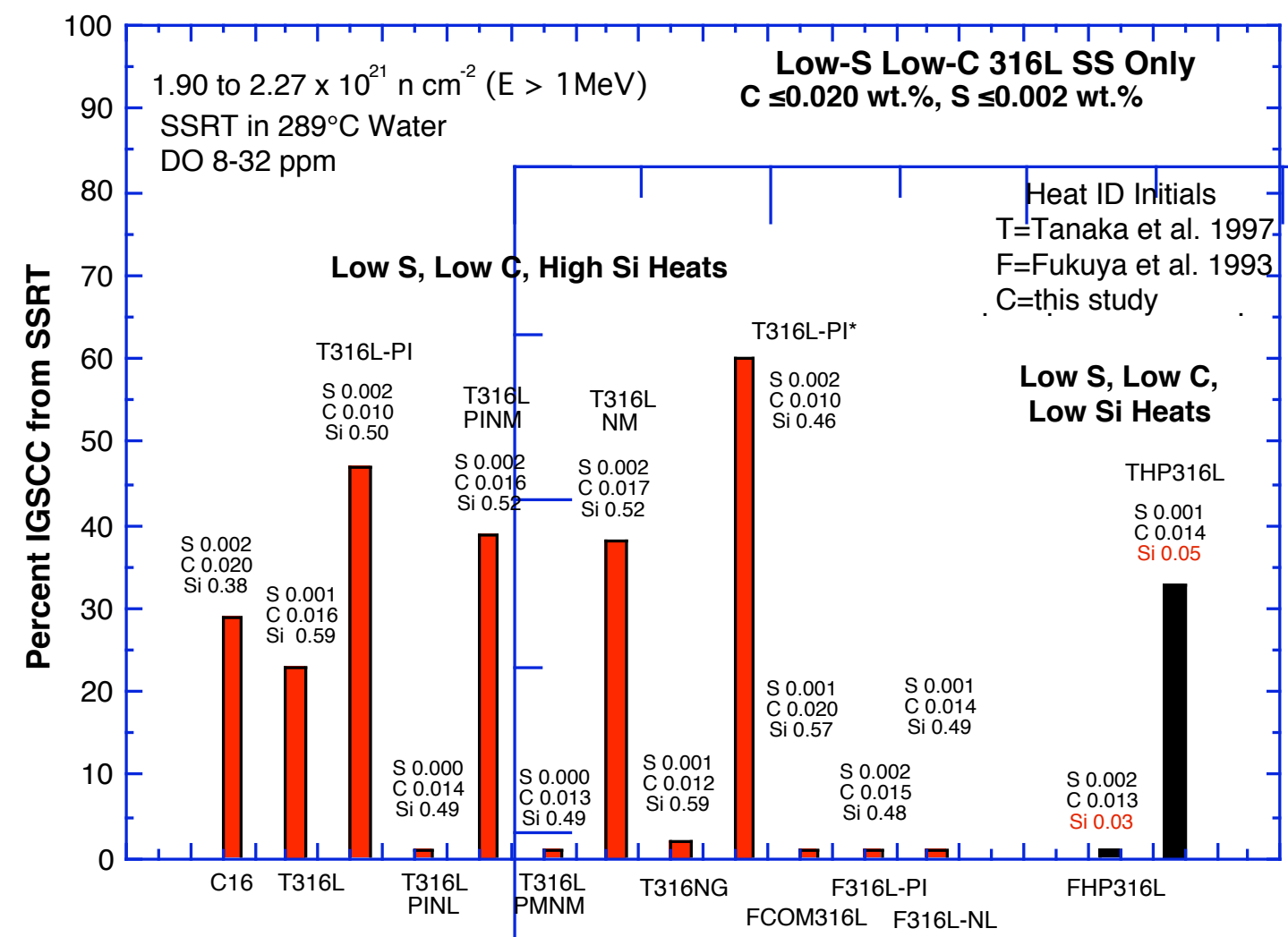

Figure 41. Comparison of failure diametral strain for high- and low-Si heats of Type 316L SSs that contain low-S and low-C concentrations. Data from Fukuya et al., Ref. 19 and Tanaka et al., Ref. 41. 


\section{Representation of IASCC-Resistant or-Susceptible Behavior of 304- and 316-Type Steels in Sulfur-Carbon Map}

Typical in-service cracking of BWR core internal components occurs at $>2 \mathrm{dpa}$ and is characterized by a virtually full intergranular fracture surface, sometimes accompanied by a small amount of transgranular fracture surface. In this respect, the IASCC behavior of SSs at $\approx 3 \mathrm{dpa}$ (Section 8 ) is more relevant than that at $\approx 1.3 \mathrm{dpa}$ (Section 7). As described in Section 8, IASCC-resistant or -susceptible behavior at $\approx 3$ dpa is largely determined by the bulk concentrations of S and C. Similar analysis was performed for data reported in the literature. Virtually all literature data have been reported after 1987. Figures 42 and 43 show a twodimensional map of bulk S and C contents to show the range in which 304- or 316-type steels are either resistant or susceptible to IASCC. The figure also includes similar data reported in the literature since 1987. The only data missing from the figure are those obtained for BWR internals for which S and C contents are not available, e.g., an IASCC-resistant 304 SS control blade sheath reported in Ref. 23 and an IASCCsusceptible 304L SS dry tube reported by Shen and Chang. ${ }^{43}$

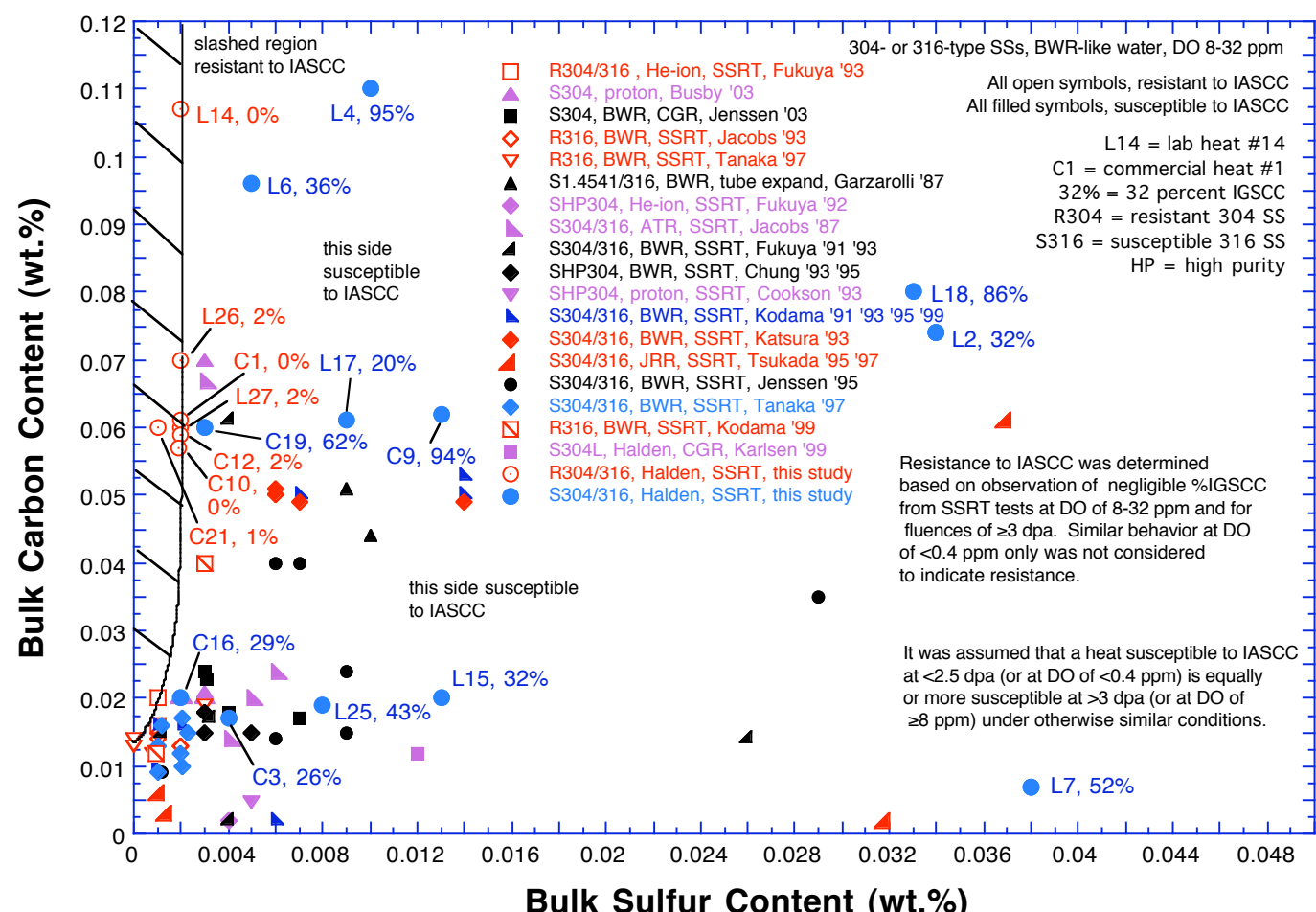

Figure 42. Range of bulk S and C contents in which Type 304 or 316 steels are resistant or susceptible to IASCC in BWR-like oxidizing water.

In constructing the maps in Figs. 42 or 43 , it was assumed that a heat susceptible at $<2.5$ dpa is equally or more susceptible at $\geq 3 \mathrm{dpa}$ under otherwise similar conditions. It was also assumed that a heat susceptible at a DO concentration of $<0.4 \mathrm{ppm}$ is more susceptible at a DO concentration of $\geq 8 \mathrm{ppm}$ under otherwise identical conditions. Note that, in the figure, the plotted ranges of $\mathrm{S}$ and $\mathrm{C}$ contents extend beyond the AISI limits specified for Types 304 and 316 SS, i.e., maximum S, $0.030 \mathrm{wt} . \%$ and maximum C, 0.08 wt.\%. 


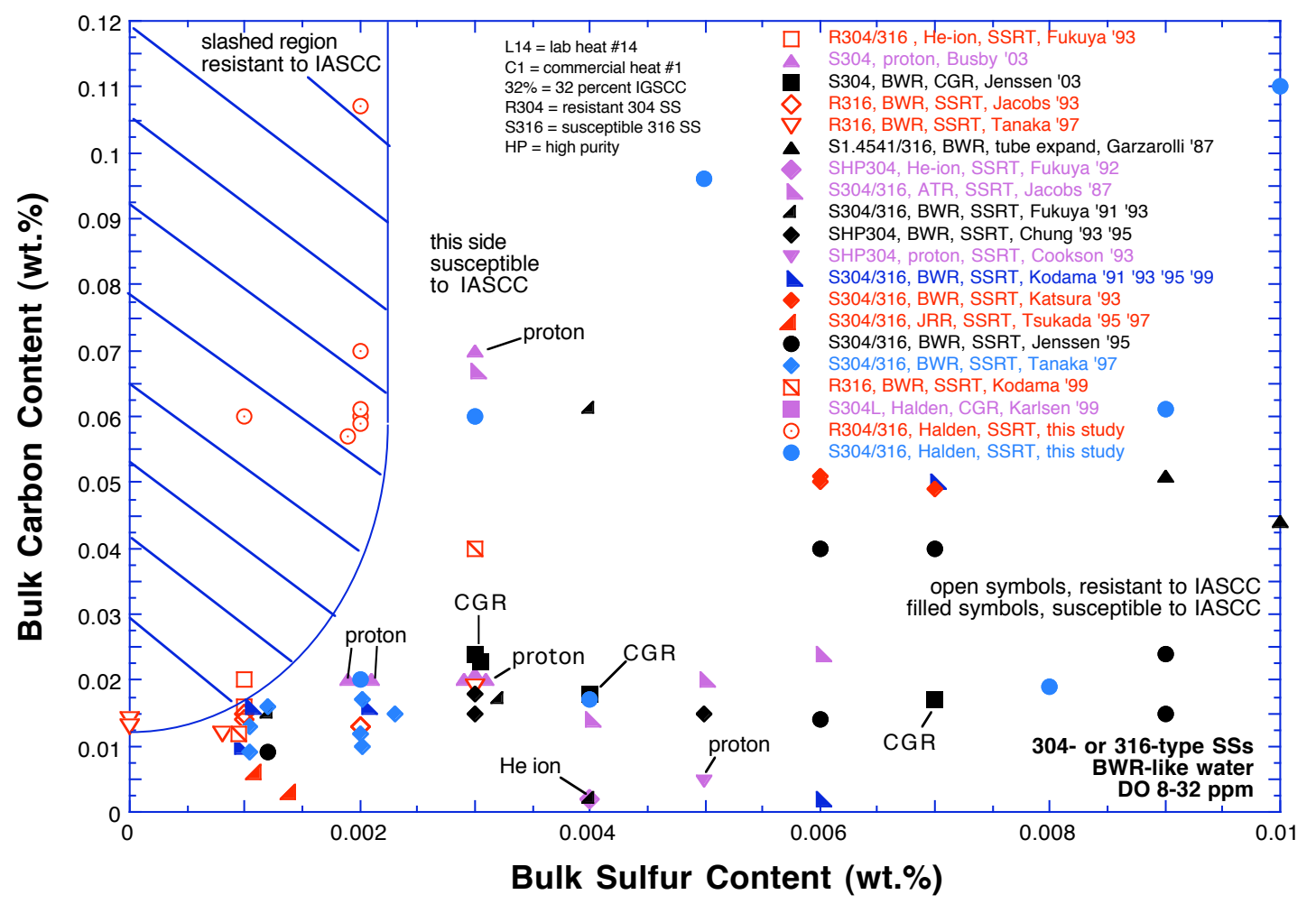

Figure 43. Expanded view of low-S portion of Fig. 42 showing data in detail.

In Figs. 42 and 43, data obtained on neutron-, ion-, or proton-irradiated steels from SSRT, crackgrowth-rate (CGR), or tube-expansion tests are shown for comparison with those obtained by SSRT in this investigation. As shown in Fig. 43, the results obtained on He-ion-irradiated steels (Fukuya et al. ${ }^{3}$ ) and proton-irradiated steels (Cookson et al. ${ }^{44}$ and Busby et al. ${ }^{45}$ ) are also consistent with the IASCC-susceptible range shown in the S-C map. The earlier efforts by the latter group of investigators focused on "ultra-highpurity" (UHP) heats. However, their "UHP" heats contained either insufficiently low concentrations of S, insufficiently high concentrations of $\mathrm{C}$, or both, to render the steel resistant to IASCC. Figure 43 also includes the results of CGR tests reported by Karlsen and Hauso ${ }^{46}$ and Jenssen et al., ${ }^{12}$ in which intergranular crack propagation was confirmed by SEM fractography.

In Fig. 44, which is similar to Fig. 42, data points for four susceptible heats tested after irradiation to 1.3 dpa (i.e., Heats L22, L11, L13, and L8; see Fig. 29) are also included. It was assumed that the four heats are also susceptible to IASCC at $3 \mathrm{dpa}$, although they were not tested at this damage level. 


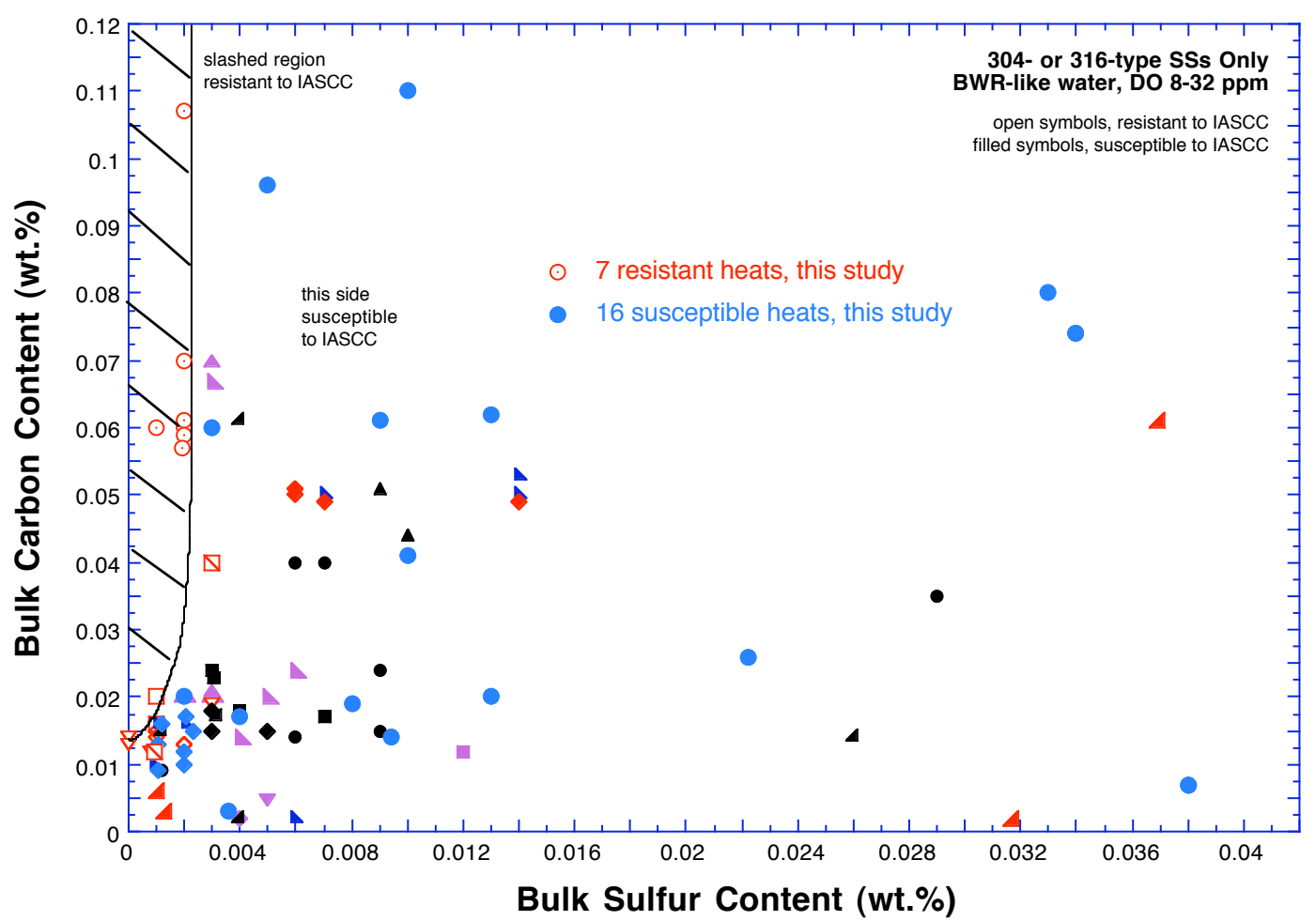

Figure 44. Range of bulk $S$ and $C$ contents in which Type 304 or 316 steels are resistant or susceptible to IASCC, including four susceptible heats tested at $1.3 \mathrm{dpa}$ in this study. 
This page is intentionally blank. 


\section{IASCC Behavior of Type 348 Steels}

Besides the 304- and 316-type steels, two heats of 348-type SS were tested in $289^{\circ} \mathrm{C}$ water in this investigation after irradiation to $\approx 1.3$ and $\approx 3 \mathrm{dpa}$. One heat (L23) contains a very high concentration of $\mathrm{S}$ (0.0475 wt.\%) and the other (L24), a low concentration of S (0.0055 wt.\%). Percent IGSCC of the two heats is compared in Fig. 45. The high-S heat was susceptible to IASCC, but the low-S heat was resistant at both levels of neutron damage. This behavior is consistent with the behavior of 304- or 316-type SSs described in Section 8 .

Similar to the correlation established for 304- and 316-type SSs in Fig. 42, the IASCC-resistant range of 348-type and an Nb-containing SS was plotted in a two-dimensional S-C map in Fig. 46. This map includes all such data in the literature that were obtained under BWR- and PWR-like conditions. As indicated in the figure, it appears that the IASCC-resistant range of 348-type and Nb-doped SSs in PWR- or BWR-like water can be described well in an S-C map that differs somewhat from S-C map of 304- and 316-type SSs. Behavior of the $\mathrm{Nb}$-doped 316-type steel was reported by Jacobs et al. for BWR conditions. ${ }^{21}$ Although the correlation in Fig. 46 should be considered only preliminary, it is qualitatively consistent with the correlation constructed for 304- and 316-type SS for BWR-like conditions. It appears that 348-type SSs exhibit higher tolerance to $\mathrm{S}$ than 304- or 316-type steels.

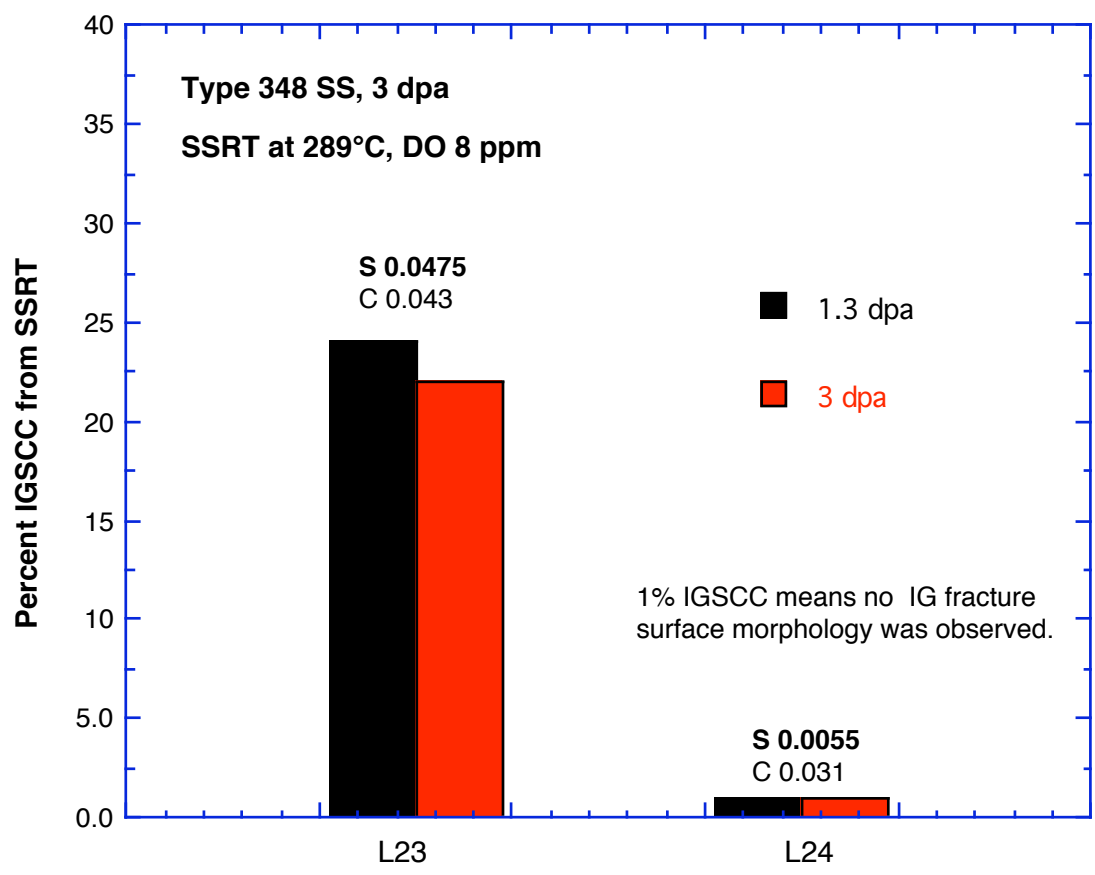

Figure 45.

Percent IGSCC of high- and low-sulfur laboratory heats of Type 348 SS after irradiation to 1.3 and 3 dpa, SSRT test in BWR-like water. 


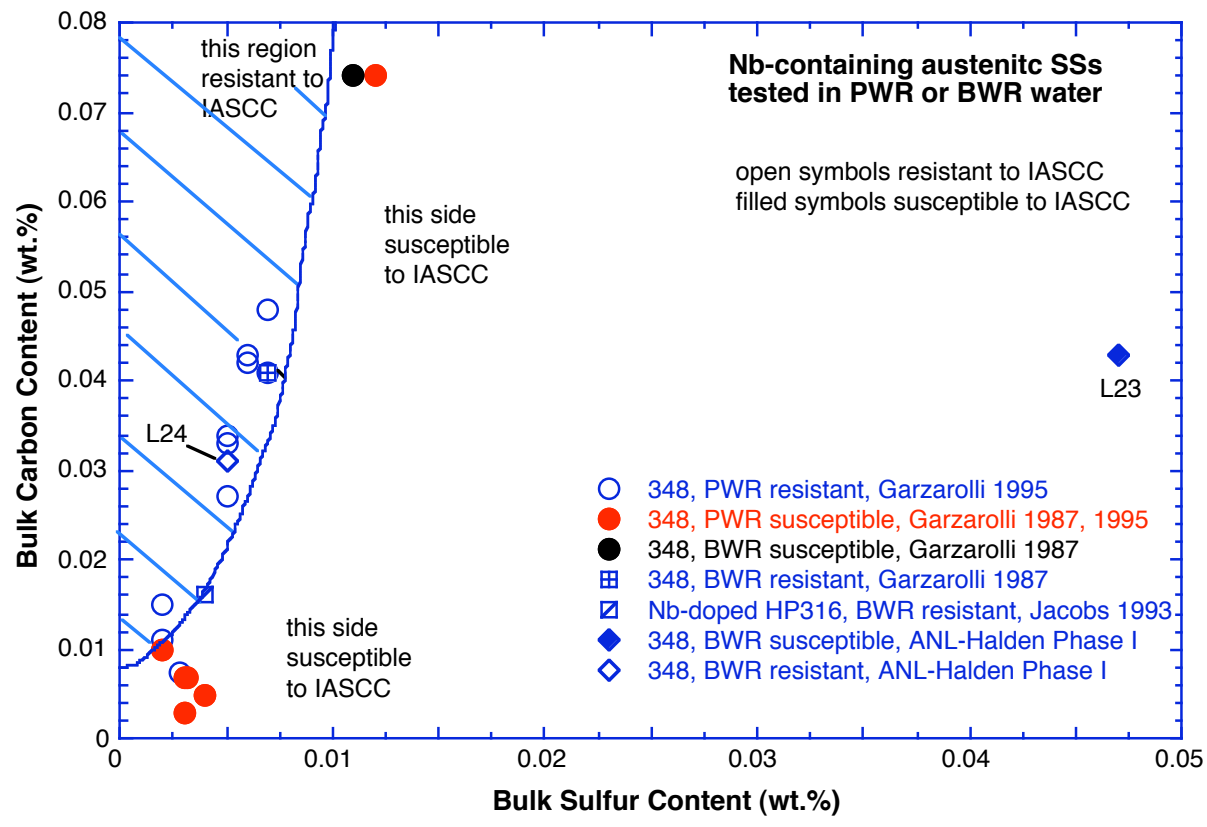

Figure 46.

Range of bulk $S$ and $C$ contents in which Type 348 stainless steels are resistant or susceptible to IASCC. 


\section{IASCC Behavior of Austenitic-Ferritic Steel}

In this investigation, one austenitic-ferritic duplex SS alloy was tested by SSRT in $289^{\circ} \mathrm{C}$ water after irradiation to $0.4,1.3$, and $3.0 \mathrm{dpa}$. The alloy (L5), which contains $21 \mathrm{wt} . \% \mathrm{Cr}$ and $\approx 3$ vol. $\%$ delta ferrite, was resistant to IASCC, even though its $\mathrm{S}$ content was very high (i.e., $0.028 \mathrm{wt} \%$ ). Figure 47 shows an insignificant level of percent IGSCC measured on the alloy at all the three damage levels.

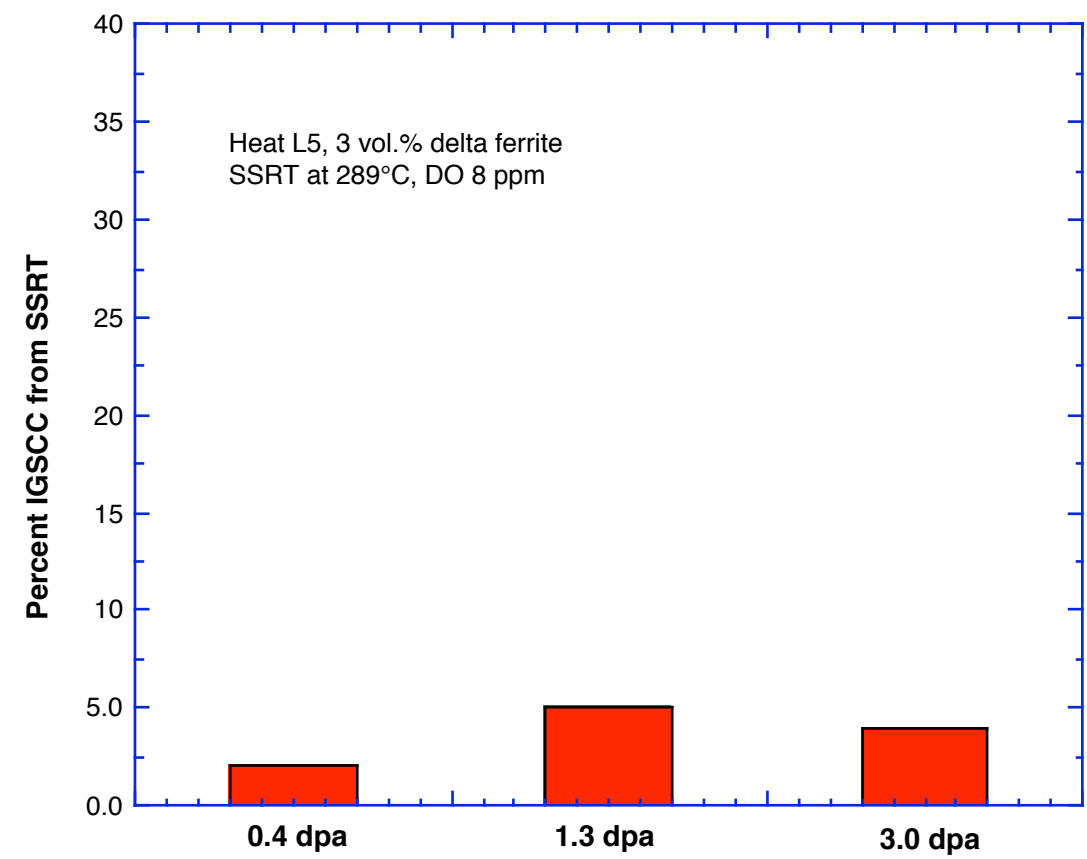

Figure 47.

Effect of neutron damage on percent IGSCC of austeniticferritic steel (Heat L5) that contains $\approx 3$ vol. $\%$ delta ferrite.

The morphology of the delta ferrite in the alloy was globular, as shown in Fig. 48. Annealing twins are also visible in the optical metallograph. The fracture surface of the alloy at 3 dpa showed small broken islands of delta ferrite surrounded by dominantly ductile regions (see Fig. 49).

The excellent resistance of this alloy to IASCC appears to be consistent with the behavior of cast austenitic SSs of Types CF-3 and CF-8, which, in the unirradiated state, are well known for their resistance to IGSCC. Most CF-3 and CF-8 duplex SSs contain a delta ferrite content of $>10$ vol.\%, usually in the form of acicular or elongated grains. If the volume fraction of delta ferrite is too high, or if the distribution of ferrite is continuous, significant embrittlement due to ferrite cleavage may lead to unacceptable degradation of fracture toughness after irradiation to high fluence. However, with a ferrite content of only $\approx 3 \%$, as in Alloy L5, small globular ferrite islands remain isolated, and overall material embrittlement due to ferrite cleavage appears insignificant. Supporting this premise, yield strength and total elongation of the alloy in $289^{\circ} \mathrm{C}$ water were significant even after irradiation.

It appears that the mechanism through which a small amount of delta ferrite may suppress the susceptibility to IASCC in Alloy L5 can be explained well by the effect of delta ferrite on S distribution in the steel. As shown in the equilibrium Fe-S diagram in Fig. 50, the solubility limit of $\mathrm{S}$ is several times higher in the $\delta$ ferrite phase than in the austenitic $(\gamma)$ phase. At $\approx 1365^{\circ} \mathrm{C}$, the solubility limits of $\mathrm{S}$ in delta ferrite and austenite are 0.18 and $0.05 \mathrm{wt} . \%$, respectively. Therefore, during ingot melting, solidification, and cooling of 
a material such as L5, S atoms are expected to migrate toward and be incorporated into the delta ferrite globules, which act as efficient trapping sites for $\mathrm{S}$ atoms. As a result, segregation of $\mathrm{S}$ atoms to austenite grain boundaries during fabrication or irradiation will be suppressed because of the presence of ferrite globules and the large austenite-ferrite phase boundaries.

Also, continuous austenite grain boundaries are rare in this type of steel, because ferrite grains intersect austenite grain boundaries. As a consequence, continuous crack propagation along austenite grain boundaries seems to be more difficult, and, as a consequence, IASCC susceptibility seems to be suppressed significantly.

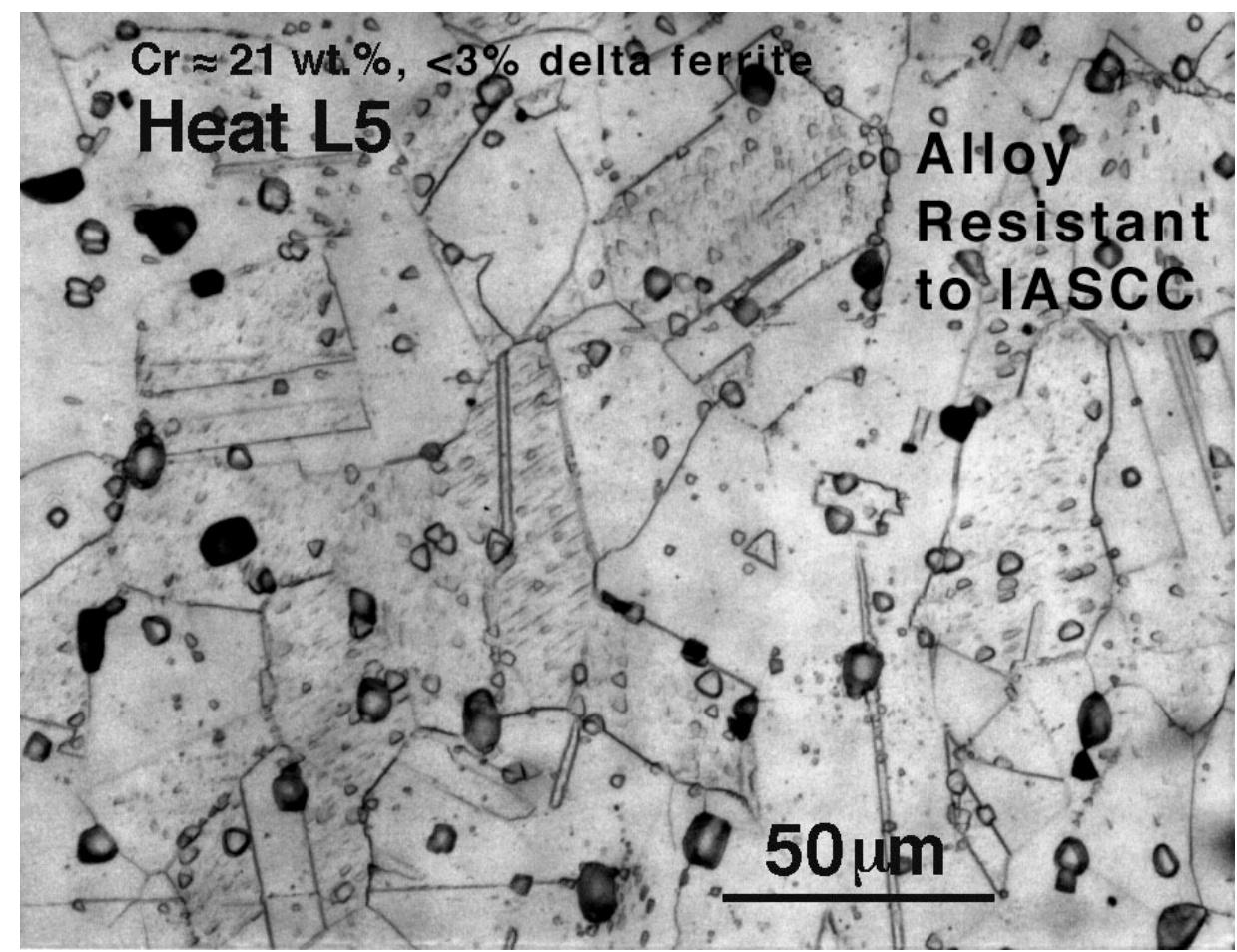

Figure 48.

Optical metallograph of IASCC-resistant Alloy L5 that contains $\approx 3$ vol. \% delta ferrite. 

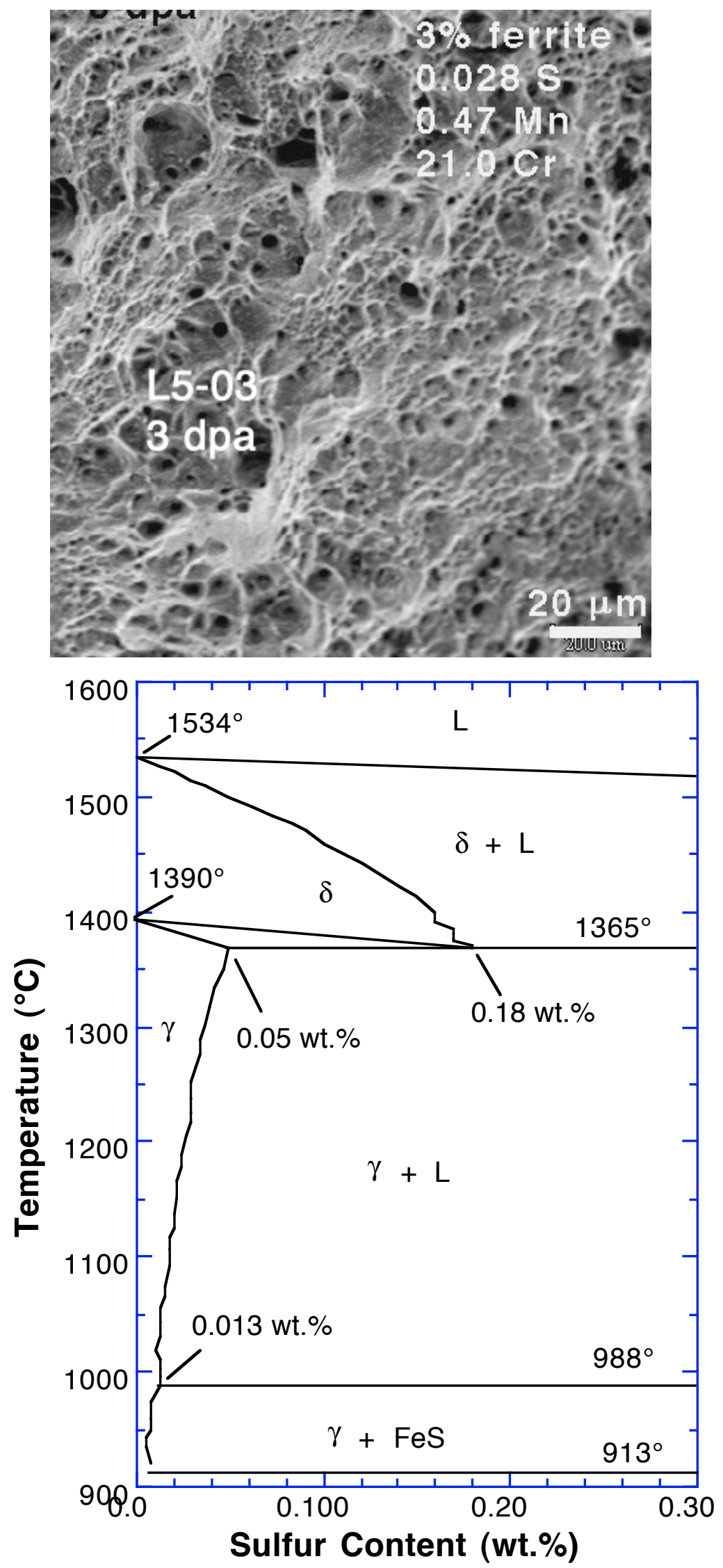

Figure 49.

Predominantly ductile fracture surface morphology of IASCCresistant Alloy L5 that contains $\approx 3$ vol. $\%$ delta ferrite, $3 \mathrm{dpa}$.

Figure 50.

Fe-rich side of Fe-S phase diagram; from Hansen, Ref. 47. 
This page is intentionally blank. 


\section{Fractographic Analysis}

Fractographs produced in $289^{\circ} \mathrm{C}$ water were obtained in a shielded SEM for all 3-dpa specimens listed in Table 14. Fractographs were also obtained for specimens that were irradiated to 0.4 and $1.3 \mathrm{dpa}$; some of these specimens exhibited significant susceptibility to IASCC. Typically, 10-15 fractographs were obtained for each specimen at various magnifications ranging from $20 \mathrm{X}$ to $800 \mathrm{X}$. For each specimen, a composite fractograph was then constructed for the whole fracture surface at a magnification ranging from $100 \mathrm{X}$ to 150X. This section summarizes results of the fractographic analysis for 3-dpa specimens.

\subsection{Fracture Surface Morphology of IASCC-Resistant Heats of 304, 316, and 348 Type Steels at 3 dpa}

Typical fracture surface morphologies of the IASCC-resistant seven heats of 304- or 316-type SSs (see Fig. 28) and one heat of 348 SS (see Fig. 45) are shown in Figs. 51-58. All of the eight heats, which were irradiated to $3 \mathrm{dpa}$, exhibited predominantly ductile fracture surface morphology, sometimes mixed with a limited amount of transgranular fracture. Percent intergranular fracture was negligible in the eight heats (i.e., $\leq 2 \%)$.

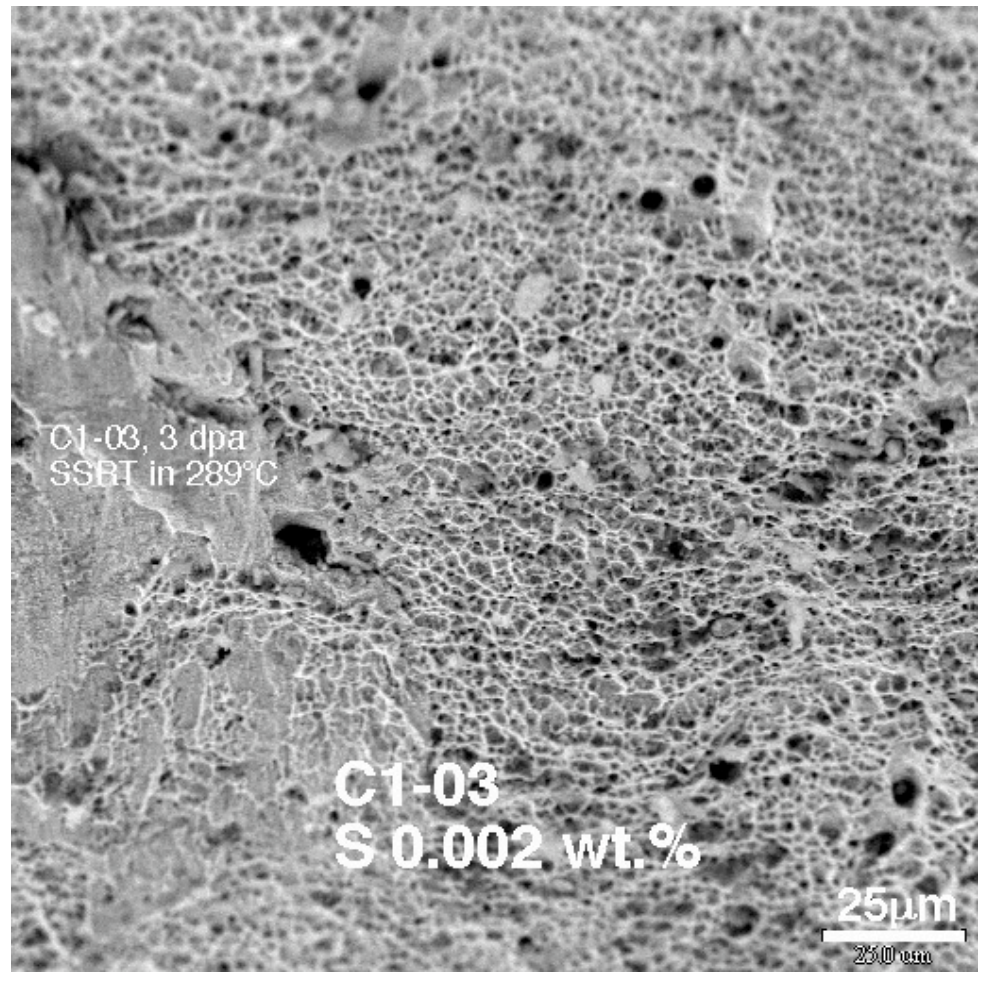

Figure 51.

Dominantly ductile fracture surface morphology of IASCCresistant Commercial Heat $\mathrm{C} 1$ of Type 304 SS; 3 dpa.

Transgranular fracture morphology was often observed near the specimen free surfaces, which were covered with thin oxide layers. In the IASCC-resistant heats, a transition from transgranular morphology to ductile morphology was often observed not far from the specimen free surface. Such examples are visible in Figs. 51, 56, and 57. The fracture surface morphology of Laboratory Heat L26 (Fig. 57) shows 
predominantly ductile morphology and a limited amount of transgranular morphology that surrounds an insignificant amount of intergranular morphology of $\approx 2 \%$.
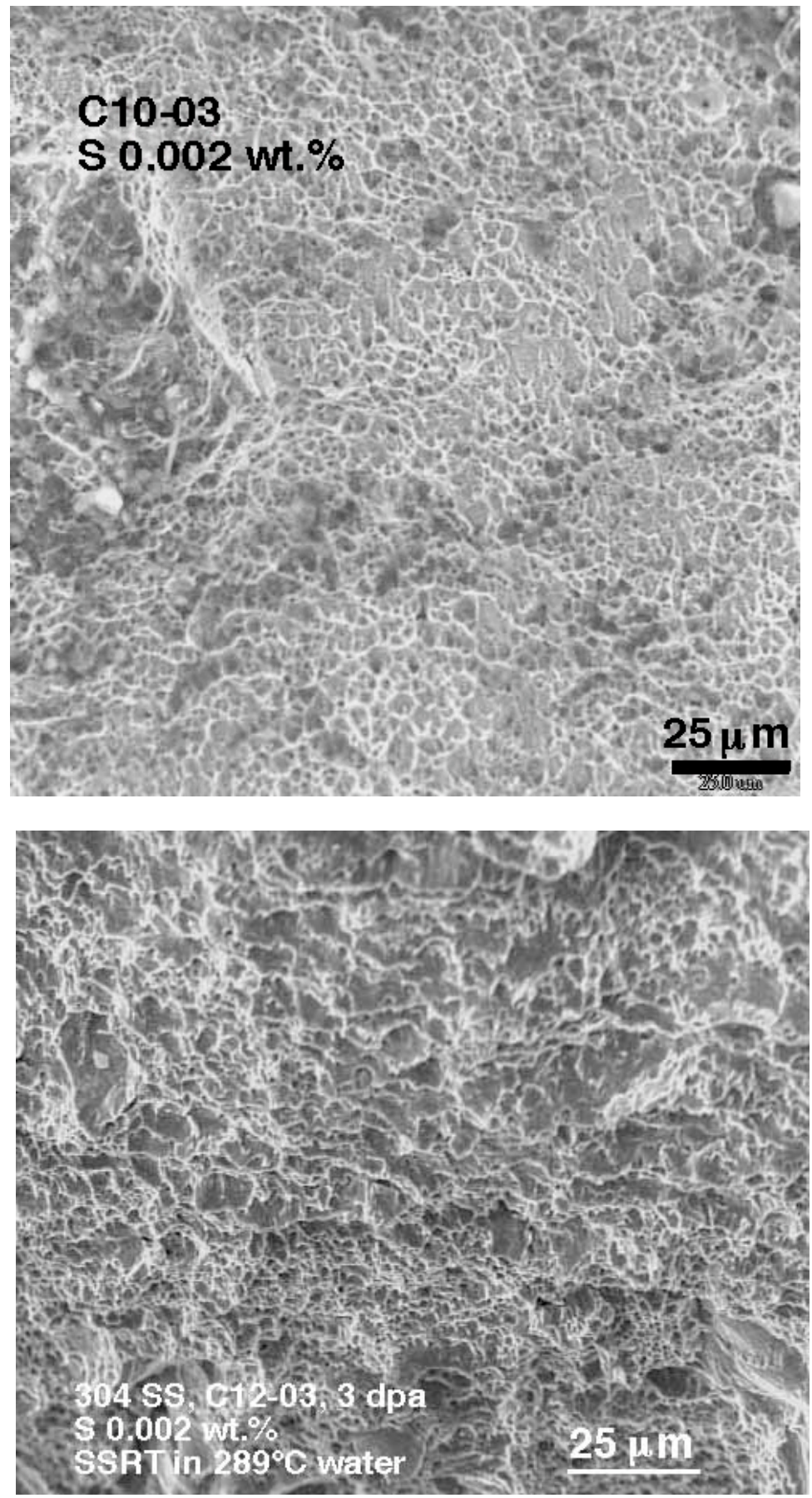

Figure 52.

Dominantly ductile fracture surface morphology of IASCCresistant Commercial Heat C10 of Type 304 SS; 3 dpa.
Figure 53.

Dominantly ductile fracture surface morphology of IASCC-resistant Commercial Heat C12 of Type 304 SS; 3 dpa. 


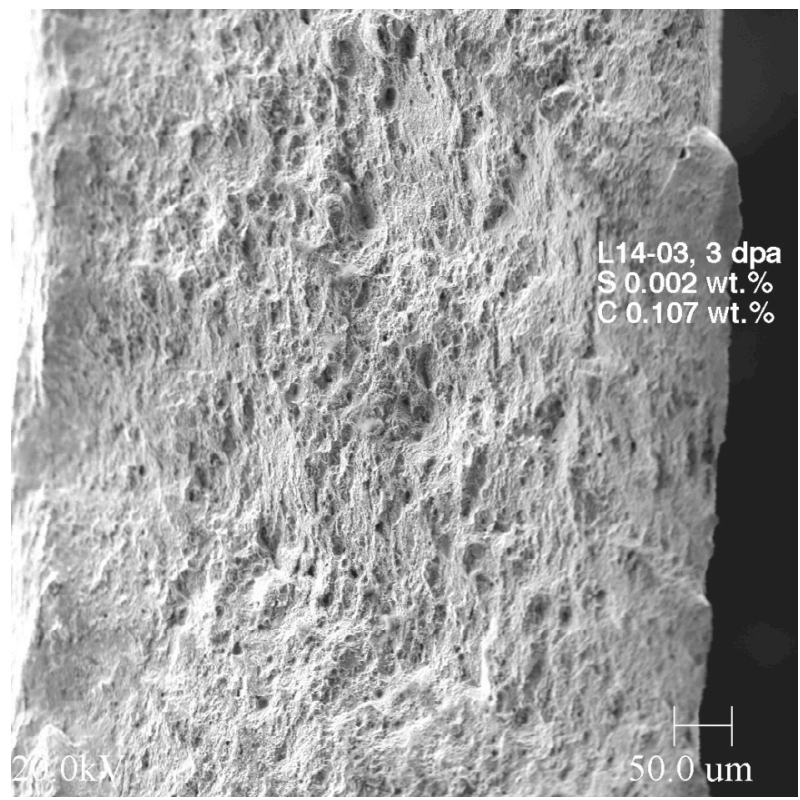

(a)

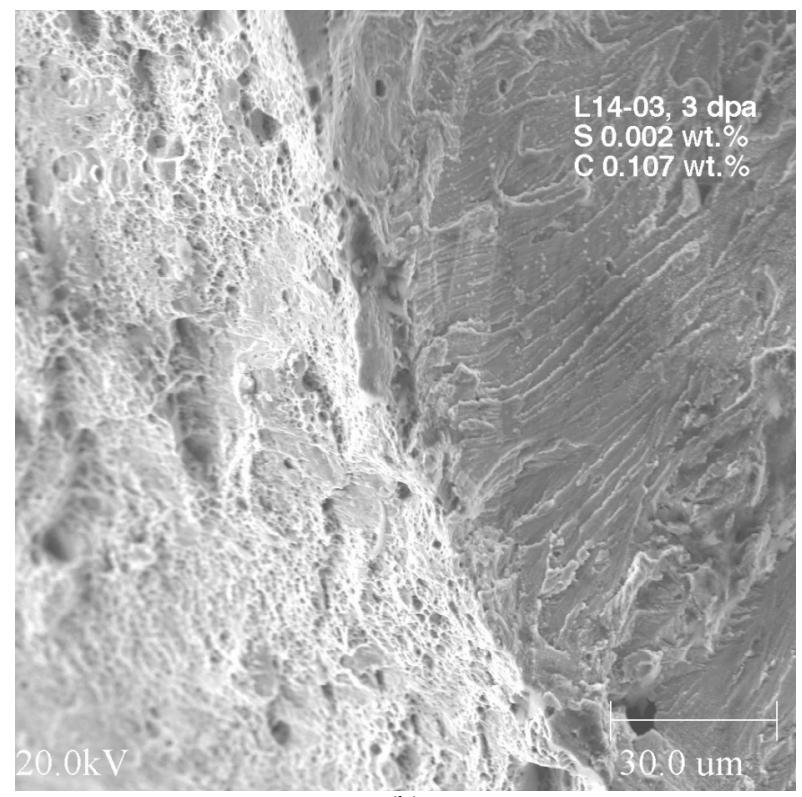

(b)

Figure 54. Fracture surface morphology of IASCC-resistant Laboratory Heat L14 of Type 304 SS (3 dpa), showing predominant ductile morphology (a) and limited transgranular morphology (b); intergranular morphology is negligible.

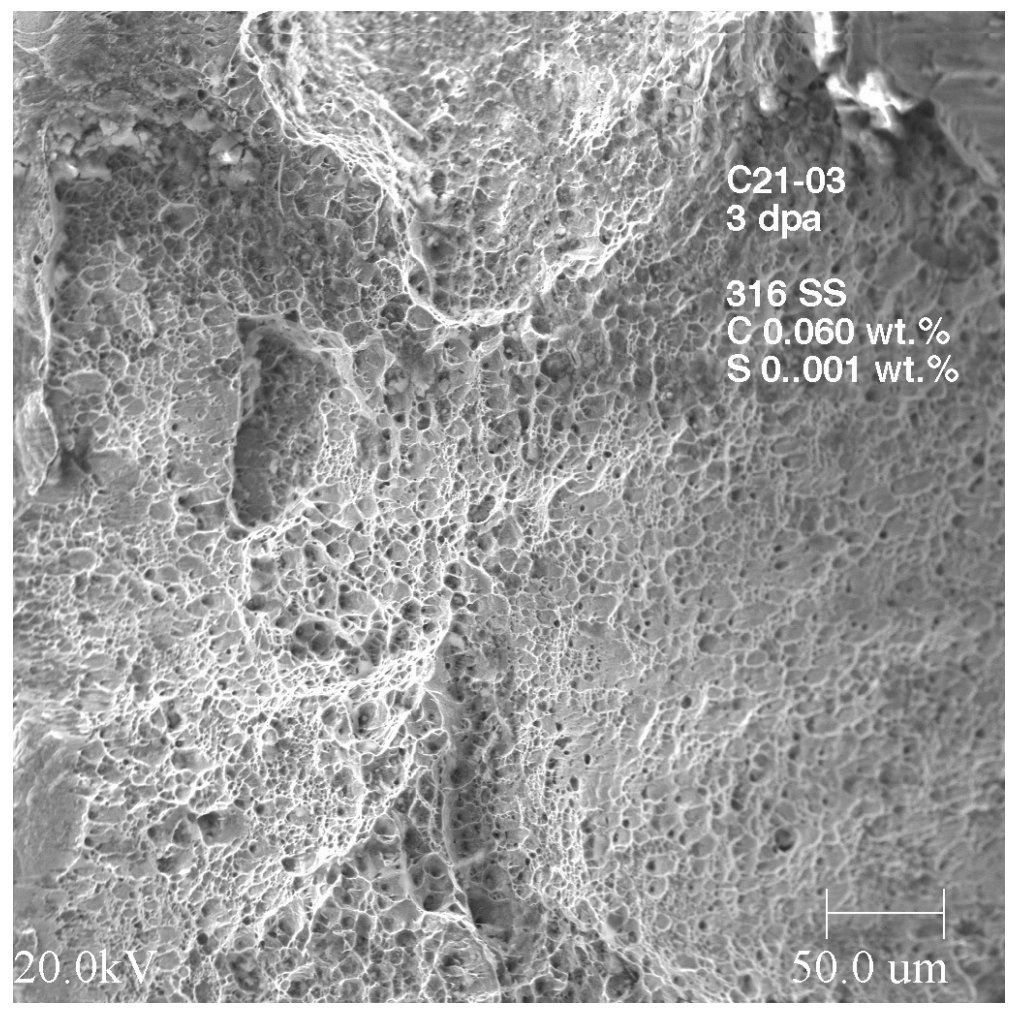

Figure 55.

Dominantly ductile fracture surface morphology of IASCC-resistant Commercial Heat C21 of Type 316 SS; 3 dpa. 


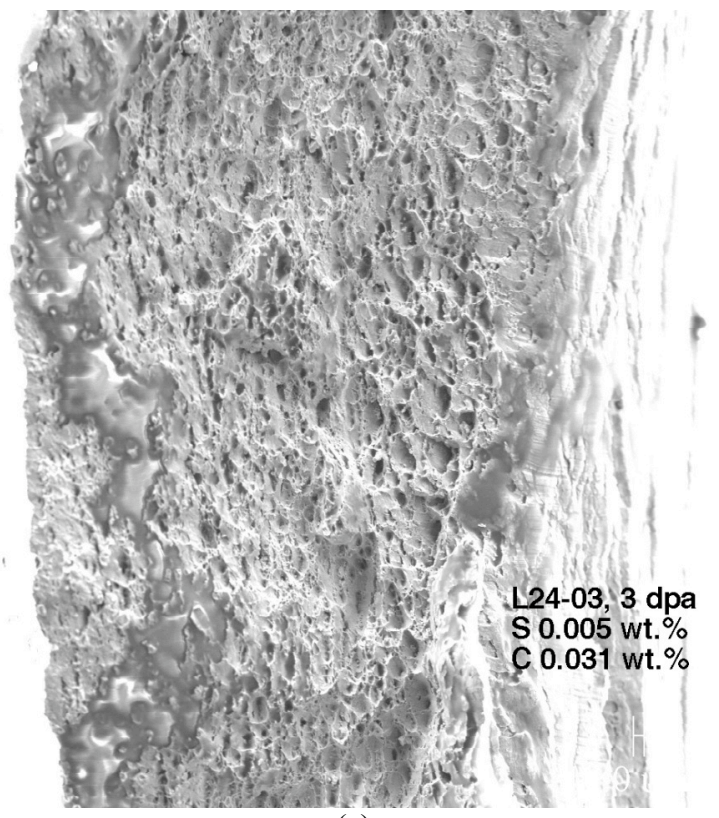

(a)

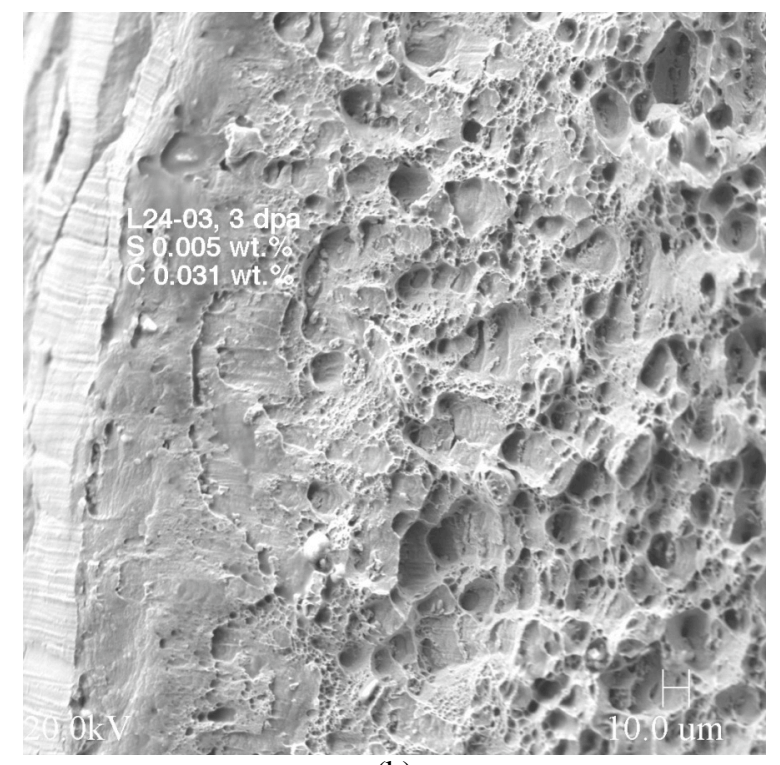

(b)

Figure 56. Fracture surface morphology of IASCC-resistant Laboratory Heat L24 of Type 348 SS ( $3 \mathrm{dpa})$; both low- (a) and high-magnification (b) images show that ductile morphology is dominant and intergranular morphology is negligible.

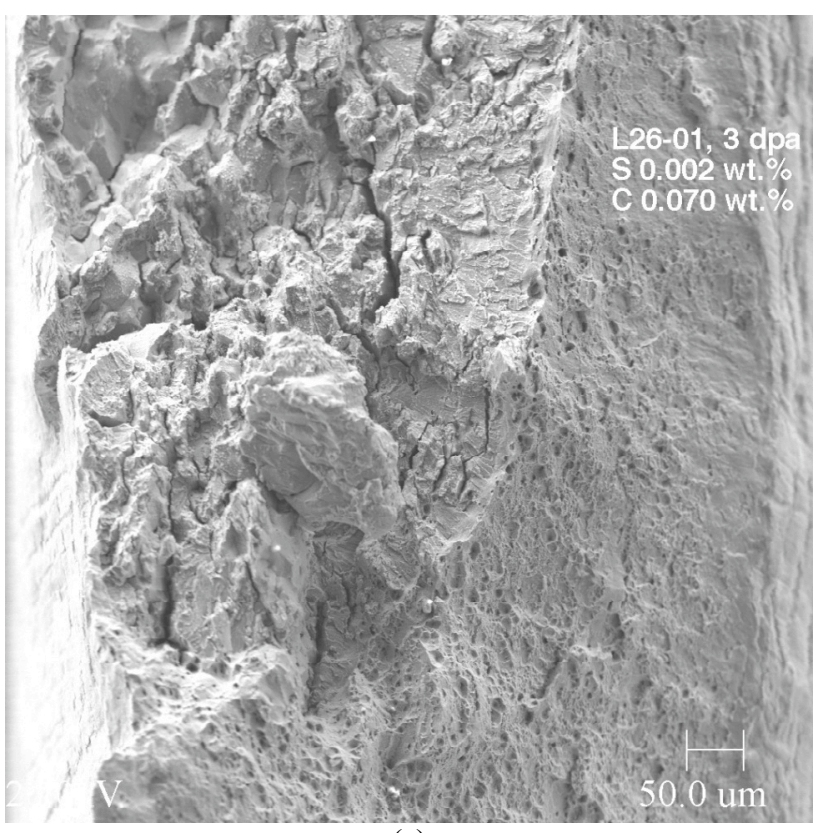

(a)

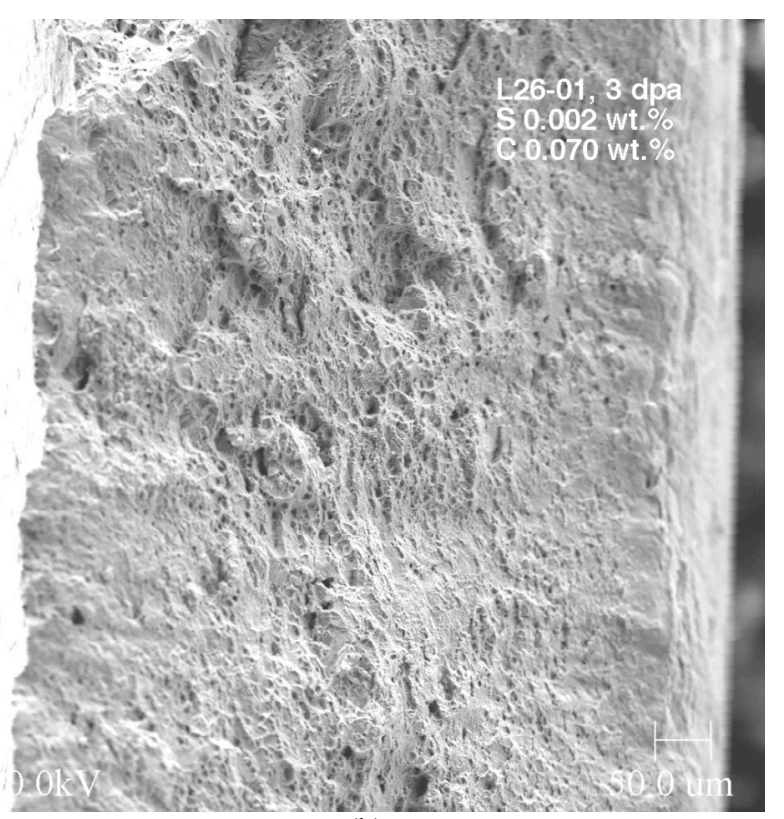

(b)

Figure 57. Fracture surface morphology of IASCC-resistant Laboratory Heat L26 of Type 304 SS (3 dpa), showing (a) limited amount of transgranular morphology that surrounds insignificant amount of intergranular morphology ( $\approx 2 \%$ IGSCC) and (b) dominantly ductile morphology. 


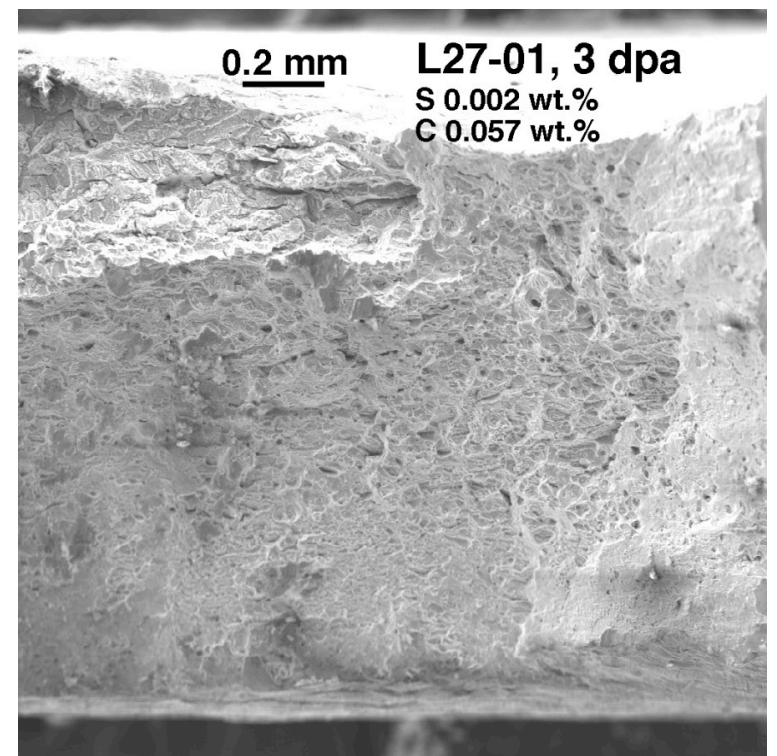

(a)

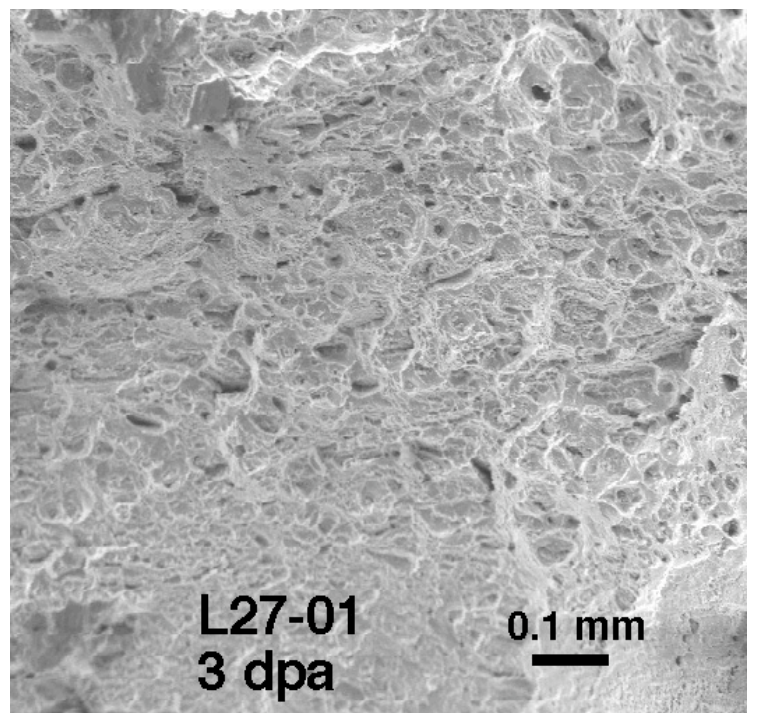

(b)

Figure 58. Ductile fracture morphology of IASCC-resistant Laboratory Heat L27 (Type 316 SS, 3 dpa); both low- (a) and high-magnification (b) images show that intergranular morphology is negligible.

\subsection{Fracture Surface Morphology of IASCC-Susceptible Heats of 304, 316, and 348 Type Steels at 3 dpa}

Typical fracture surface morphologies of the 12 IASCC-susceptible heats of 304- or 316-type SSs (3 dpa) are shown in Figs. 59-70. Similar morphology for one susceptible 348 SS heat is shown in Fig. 71. All of the 13 heats exhibited a significant amount of intergranular fracture surface morphology, sometimes close to $100 \%$. From the results of fractographic analysis, several characteristics were observed:

(1) Most of the intergranular fracture surfaces show numerous secondary cracks along the grain boundaries. These cracks branch at sharp angles from the plane of the main crack propagation.

(2) In some cases, virtually whole grains appear to be encircled by intergranular separation, e.g., Figs. 59, 60,63 , and 64 . This phenomenon has been commonly referred to as "grain encirclement" by some investigators. Sometimes, such a grain "drops out," like a grain of sand, during metallographic polishing.

(3) Intergranular fracture surfaces are often covered with an unknown type of corrosion debris, e.g., Figs. $59,60,62,63,66,67,68,70$, and 71 . The shape of the debris is mostly spherical, but in some case, it is tetrahedral, e.g., Fig. 62.

(4) Little corrosion debris is observed on ductile or transgranular fracture surfaces. 

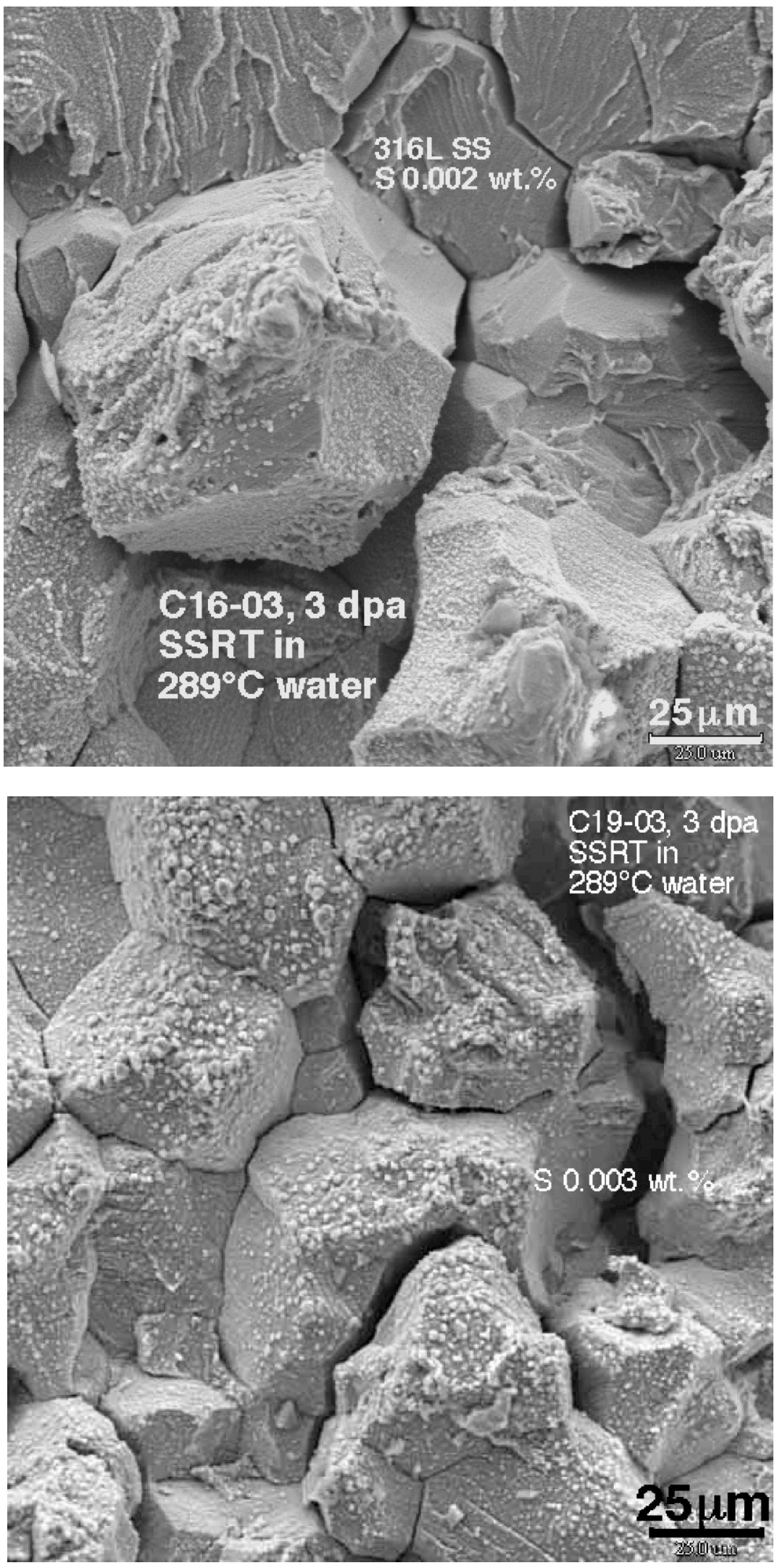

Figure 59.

Intergranular fracture surface morphology of IASCC-susceptible Heat C16 (316L SS, 3 dpa). Note secondary cracks along grain boundaries at high angles to plane of main crack propagation.
Figure 60.

Intergranular fracture surface morphology of IASCC-susceptible Heat C19 (304 SS, 3 dpa). Note corrosion debris and secondary cracks along grain boundaries at high angles to plane of main crack propagation. 

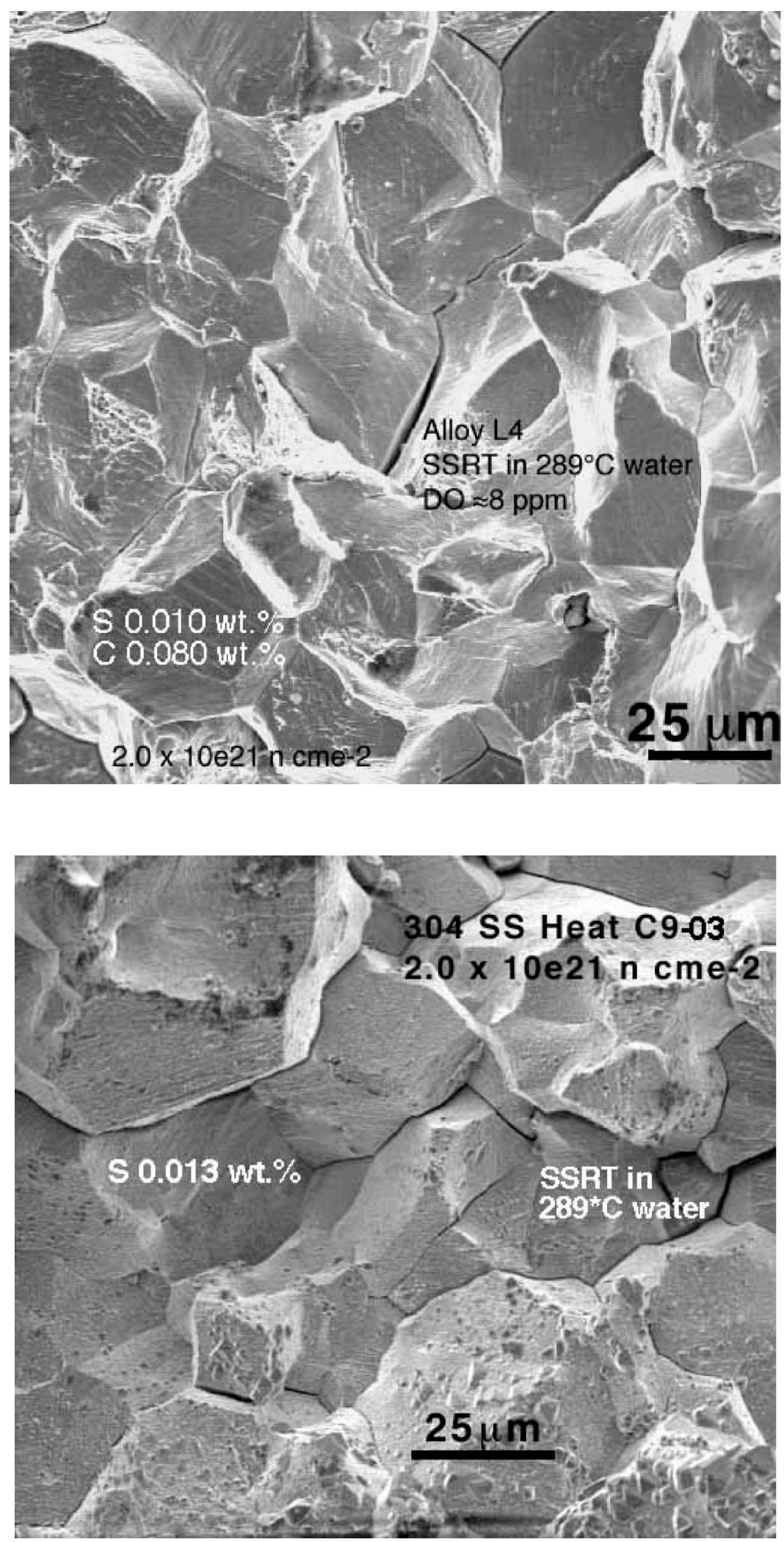

Figure 61.

Intergranular fracture surface morphology of IASCC-susceptible Heat L4 (304 SS, 3 dpa). Note secondary cracks along grain boundaries at high angles to plane of main crack propagation.
Figure 62.

Intergranular fracture surface morphology of IASCC-susceptible Heat C9 (304 SS, 3 dpa). Note corrosion debris and secondary cracks along grain boundaries at high angles to plane of main crack propagation. 


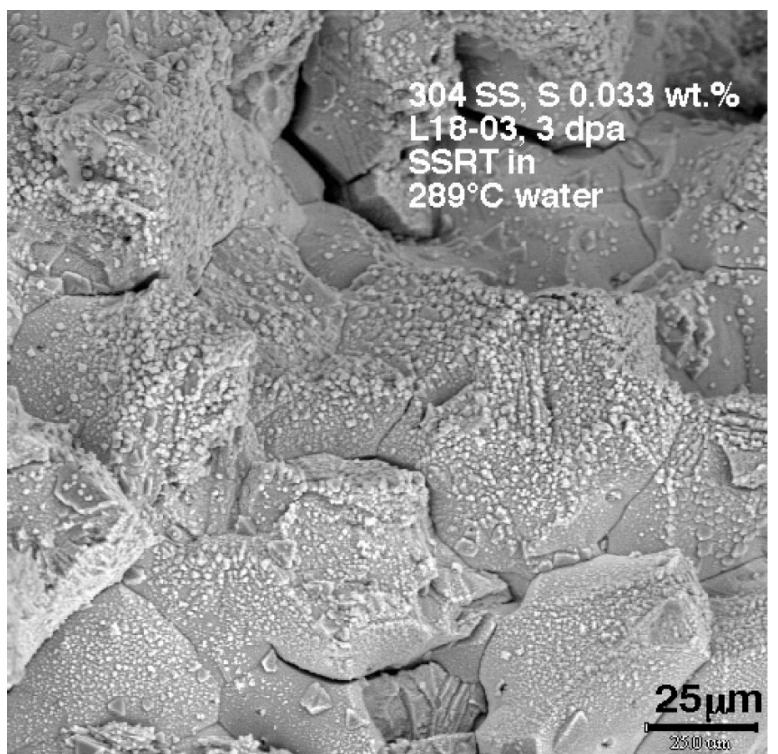

(a)

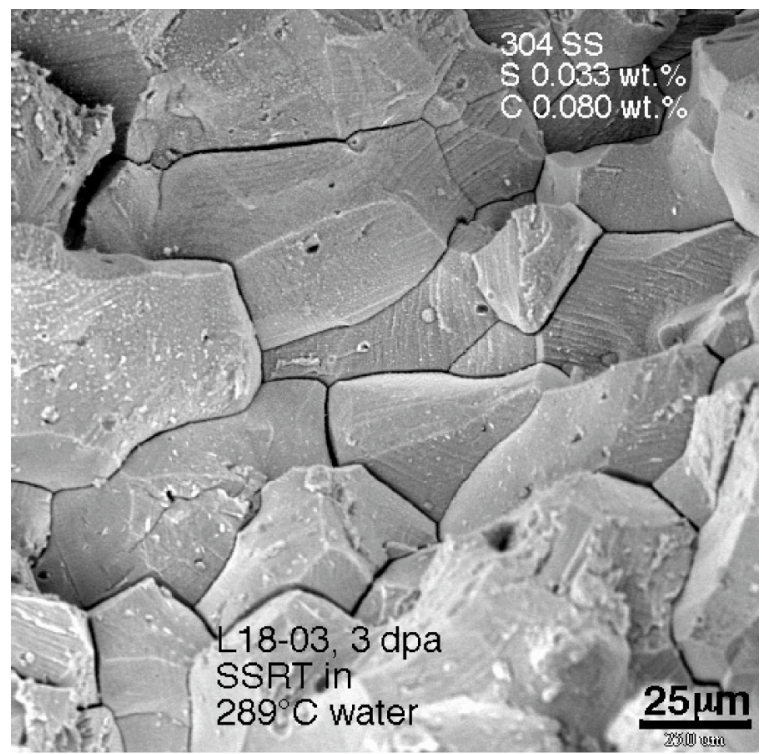

(b)

Figure 63. Intergranular fracture surface morphology of IASCC-susceptible Heat L18 (304 SS, $3 \mathrm{dpa}$ ). Note corrosion debris and secondary cracks along grain boundaries at high angles to plane of main crack propagation.

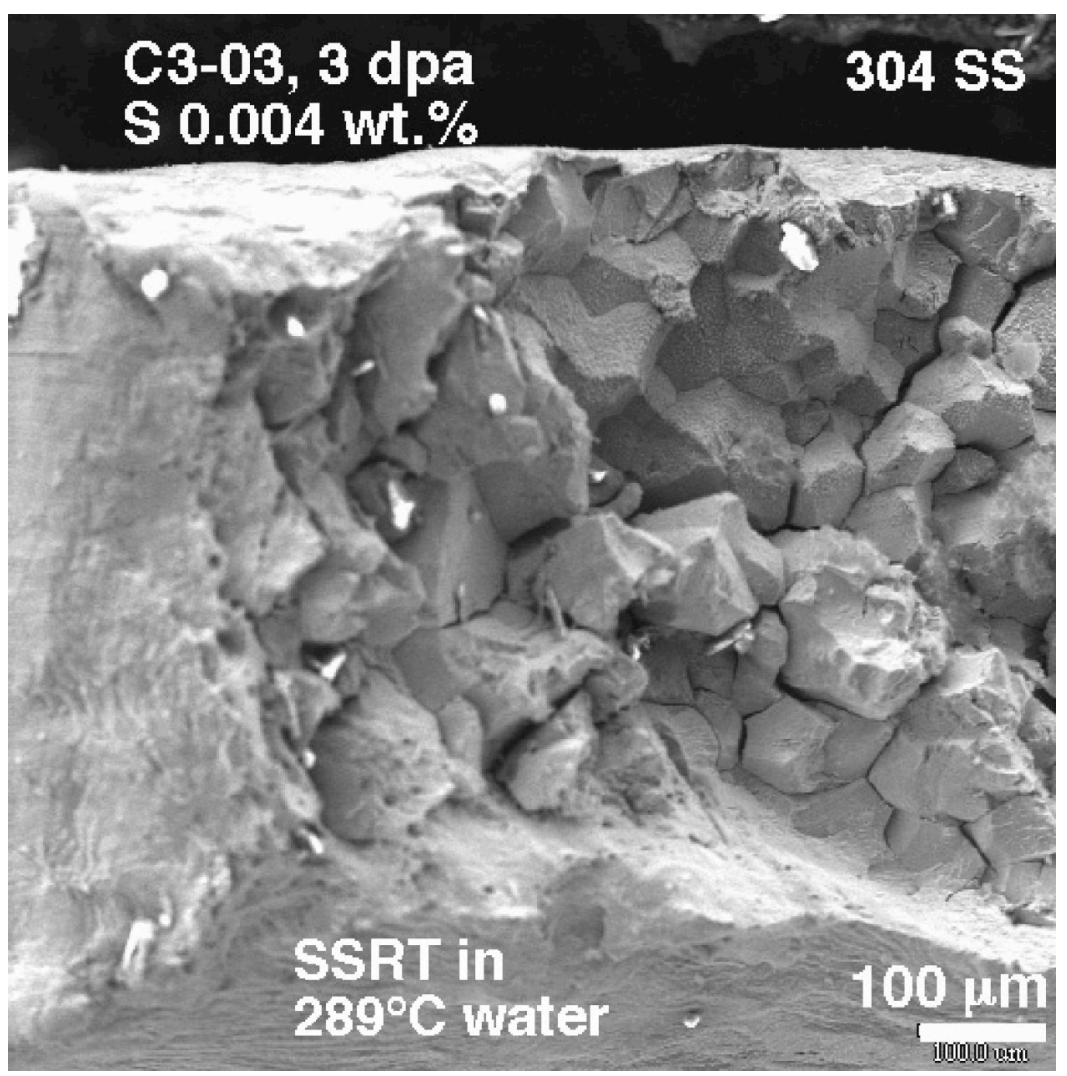

Figure 64.

Intergranular fracture surface morphology of IASCCsusceptible Heat C3 (304L SS, 3 dpa). Note secondary cracks along grain boundaries. 

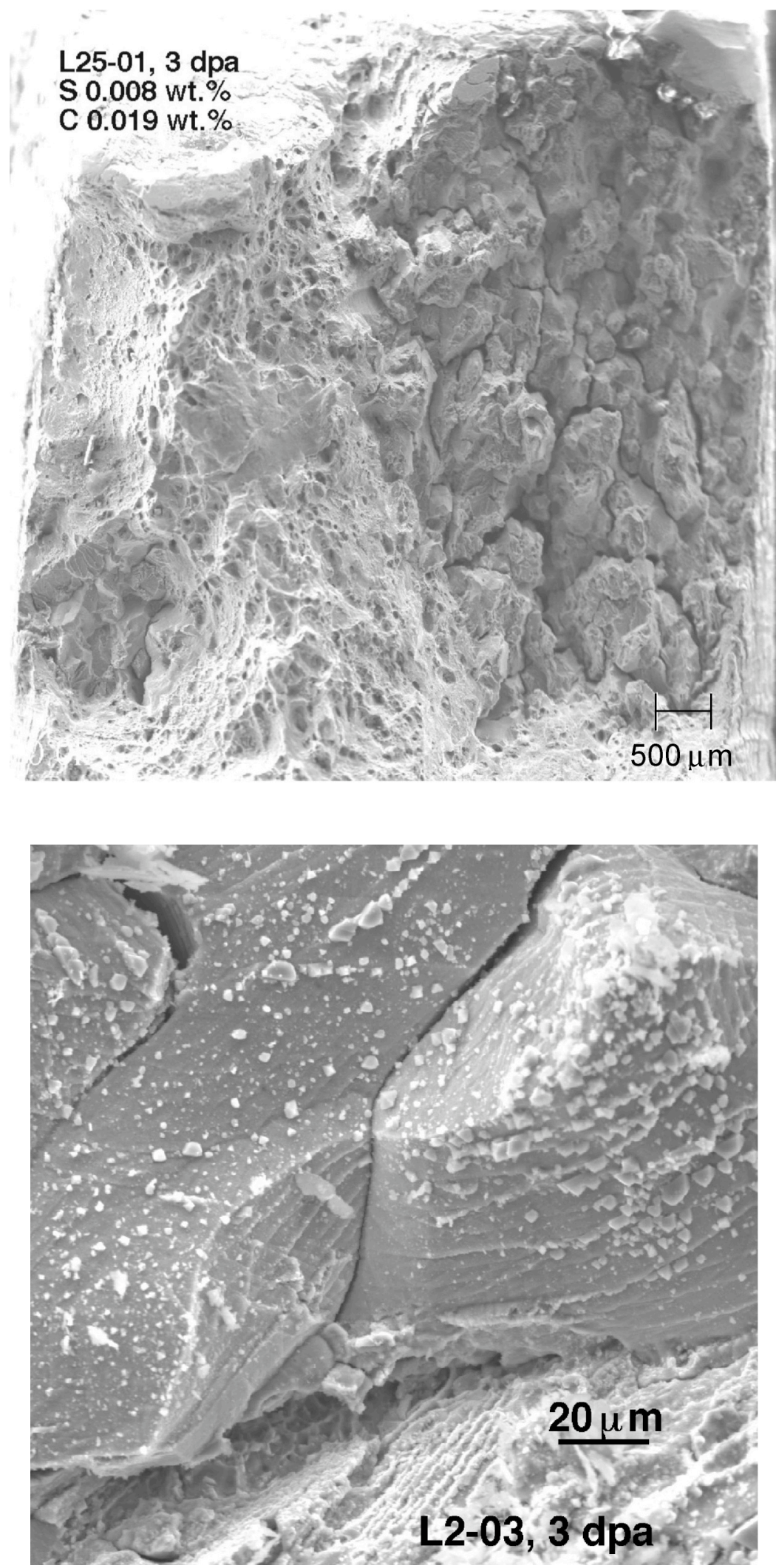

Figure 65.

Intergranular and ductile fracture surface morphologies of IASCC-susceptible Heat L25 (304L SS, 3 dpa). Note secondary cracks along grain boundaries.
Figure 66.

Intergranular fracture surface morphology of IASCC-susceptible Heat L2 (304 SS, 3 dpa). Note corrosion debris and deformation steps on grain boundaries. 

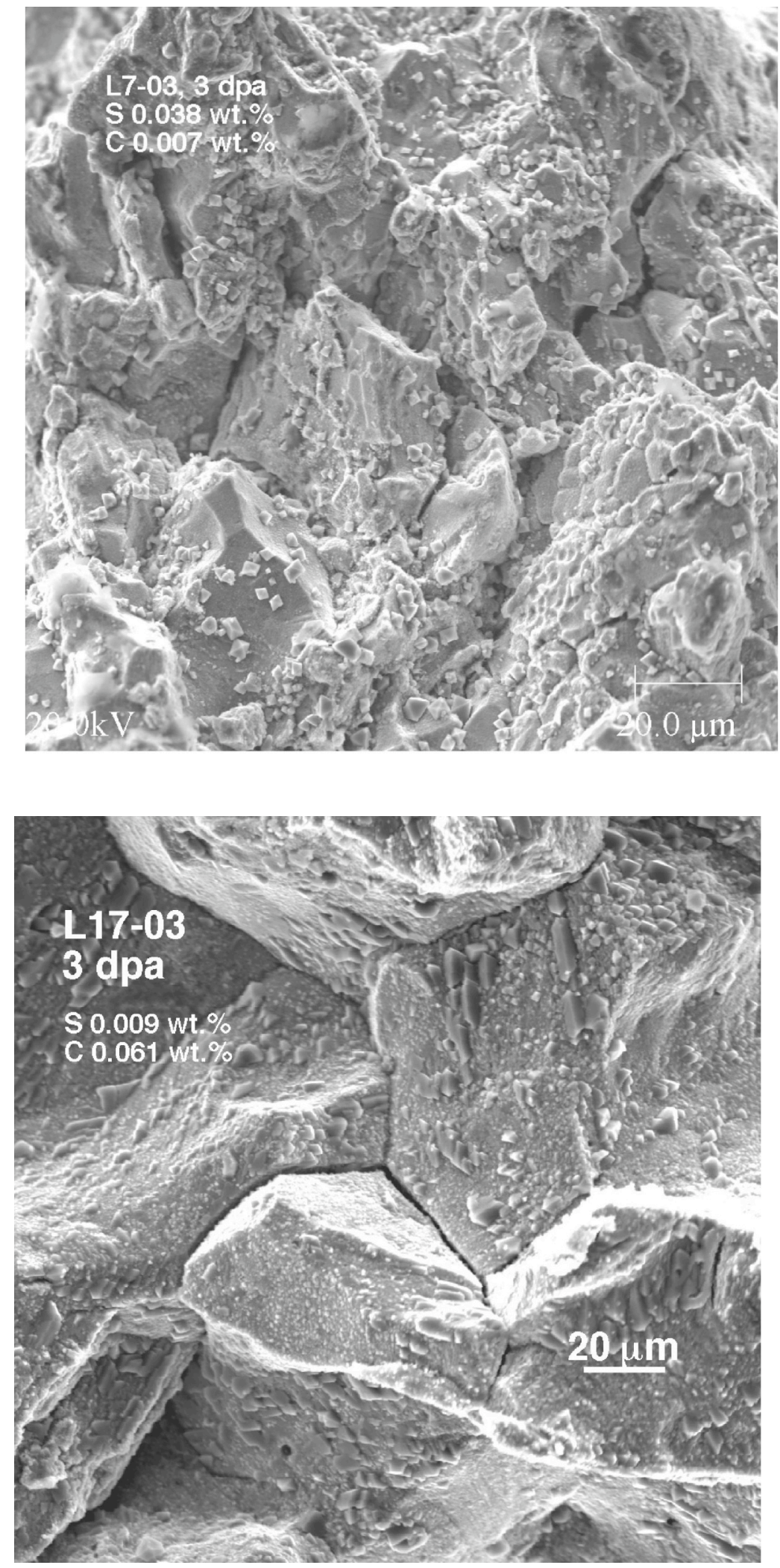

Figure 67.

Intergranular fracture surface morphology of IASCC-susceptible Heat L7 (304L SS, $3 \mathrm{dpa})$. Note corrosion debris and high-angle secondary cracks.
Figure 68.

Intergranular fracture surface morphology of IASCC-susceptible Heat L17 (304 SS, 3 dpa). Note corrosion debris and high-angle secondary cracks. 

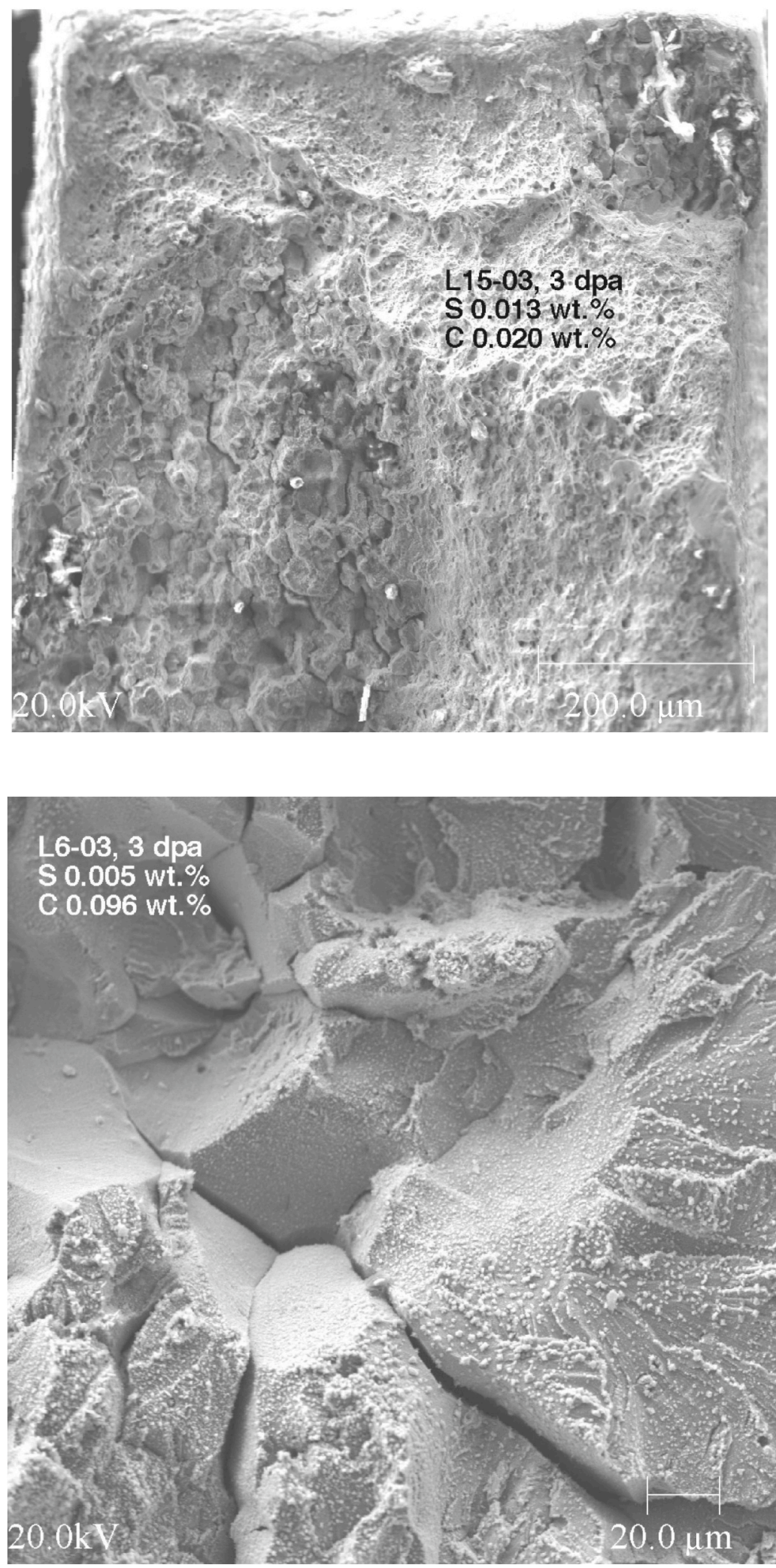

Figure 69. Intergranular and ductile fracture surface morphologies of IASCC-susceptible Heat L15 (304L SS, $3 \mathrm{dpa}$ ).
Figure 70.

Intergranular fracture surface morphology of IASCC-susceptible Heat L6 (304 SS, $3 \mathrm{dpa})$. Note corrosion debris and high-angle secondary cracks. 


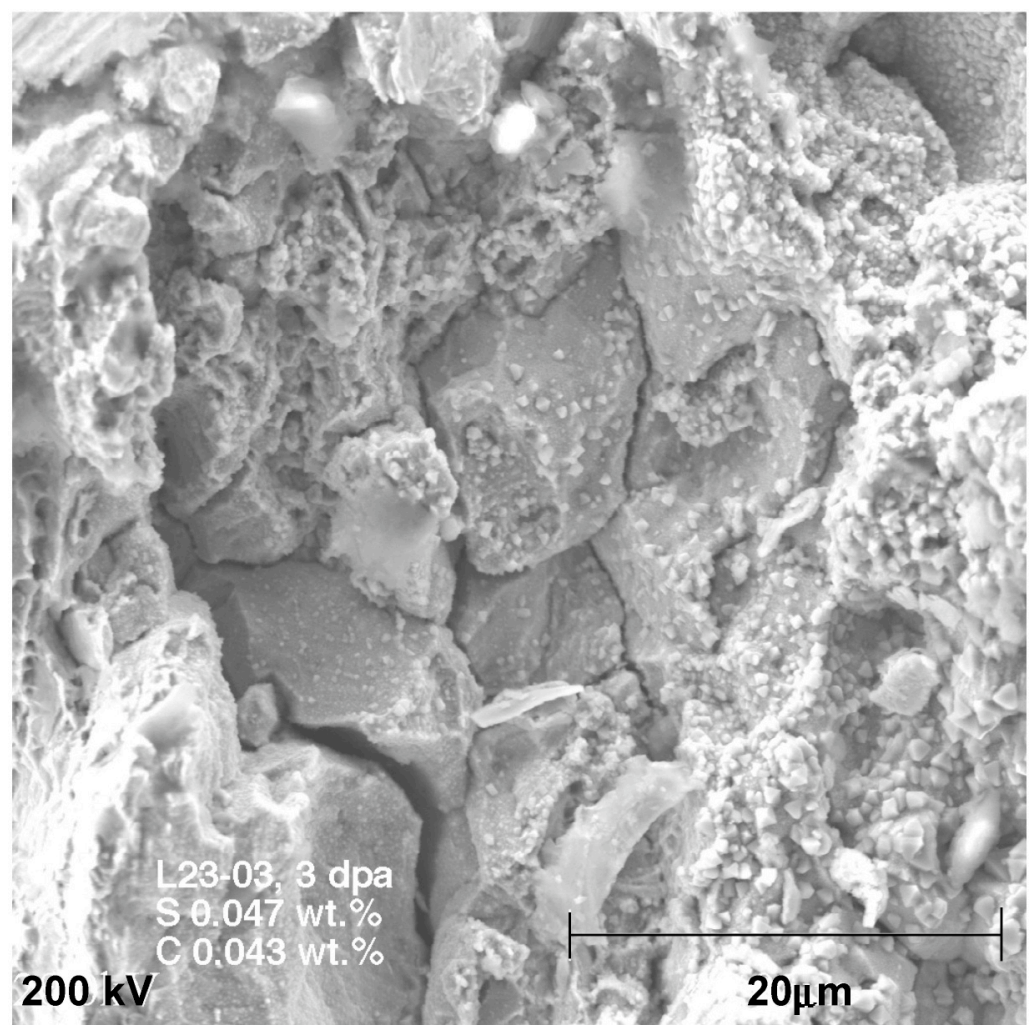

Figure 71.

Intergranular fracture surface morphology of IASCC-susceptible Heat L23 (348 SS, $3 \mathrm{dpa})$. Note corrosion debris and high-angle secondary cracks. 


\section{Analysis of Grain-Boundary Microchemistry by Auger Electron Spectroscopy}

In the consideration of the importance of the roles of S and C in IASCC described in Sections 7-9, the behavior of grain-boundary segregation of the two elements was characterized by Auger electron spectroscopy (AES). Similar analysis by advanced analytical electron microscopy (AAEM) is difficult or impractical for an ordinary grain boundary in an irradiated steel, although S-rich thin films on a crack-tip grain boundary can be detected. ${ }^{33,34}$ Auger electron spectroscopy is probably the only practical technique that can characterize well the profile and degree of grain-boundary segregation of S and $\mathrm{C}$ in an irradiated steel.

The materials selected for the AES analysis were taken from BWR neutron absorber tubes. The absorber tubes were fabricated from two commercial heats of Type 304 SS (Heats A and B) and were irradiated to $2.0 \times 10^{21} \mathrm{n} \mathrm{cm}^{-2}(\mathrm{E}>1 \mathrm{MeV})(\approx 3 \mathrm{dpa})$ during service in a BWR. The behavior of grainboundary segregation in such material was considered most relevant to BWR IASCC. The neutron absorber tubes were susceptible to field cracking. Unfortunately, neither documented chemical composition of the absorber tubes nor the archive, unirradiated ingots could be found.

Needle-like specimens were prepared from the selected BWR neutron absorber tubes. After cathodically charging with hydrogen at $\approx 50^{\circ} \mathrm{C}$ in a solution that contained $100-\mathrm{mg} / \mathrm{L} \mathrm{NaAsO} \mathrm{O}_{2}$ dissolved in $0.1-\mathrm{N} \mathrm{H}_{2} \mathrm{SO}_{4}$, the needle-like specimen was fractured in a $23^{\circ} \mathrm{C}$ vacuum in a scanning Auger electron microscope (SAM). In-situ analysis was performed in a JEOL JAMP-10 SAM equipped with automated Arsputtering and depth-profiling devices. Four to six ductile fracture surfaces and 12-15 intergranular (IG) fracture surface locations were selected for spot analysis in each specimen. Sulfur and C signals from the selected surfaces were then recorded and compared.

After each spot analysis, a depth-profile analysis was performed on a selected IG fracture surface. The procedure for automated depth-profiling analysis has been described elsewhere. ${ }^{18,19}$ Progressive sputtering of the intergranular surfaces with Ar ions and acquisition of the Auger electron signals in the ultra-high vacuum environment of the SAM were controlled by computer.

\subsection{Grain-Boundary Segregation of Sulfur and Carbon}

An example of an IG fracture surface, produced at $23^{\circ} \mathrm{C}$ in the $\mathrm{H}$-charged specimens from an absorber tube (304 SS Heat B), is shown in Fig. 72. The IG fracture surfaces reveal numerous deformation steps and a precipitate (diameter $\approx 15 \mu \mathrm{m}$ ) denoted with number " 6 ". Spots denoted with numbers " 5 " and " 20 " were the spots selected for acquisition of Auger electron signals. The results of spot analyses obtained for Tubes A-1 and B are shown in Figs. 73 and 74, respectively. In Fig. 73(a), the peak heights of Auger electrons of S obtained from four ductile fracture surfaces are presented with their counterparts from 12 IG fracture surfaces in Tube A-1. The S intensities from the IG fracture surfaces are significantly higher than their counterparts from ductile-fracture surfaces (i.e., spots not on a grain boundary). This behavior shows that $\mathrm{S}$ segregated significantly to grain boundaries (i.e., IG fracture surface) in Tube A-1. Similar results for C are also plotted in Fig. 73(b), which shows that $\mathrm{C}$ segregated significantly to grain boundaries in the same tube. Essentially the same behavior was observed for $\mathrm{S}$ and $\mathrm{C}$ segregation in Tube B; see Fig. 74. 
A careful examination of Figs. 73 and 74 reveals that some spots that contain high concentrations of S also contain high concentration of C, e.g., intergranular Spot 16, Tube A-1 and intergranular Spot 12, Tube B. However, whether $\mathrm{C}$ segregates preferentially to a grain-boundary region that contains a high concentration of $\mathrm{S}$, or vice versa is not conclusive. This behavior could not be conclusively determined by AES in this investigation; it needs further study by a more direct technique such as field-emission atom-probe technique.

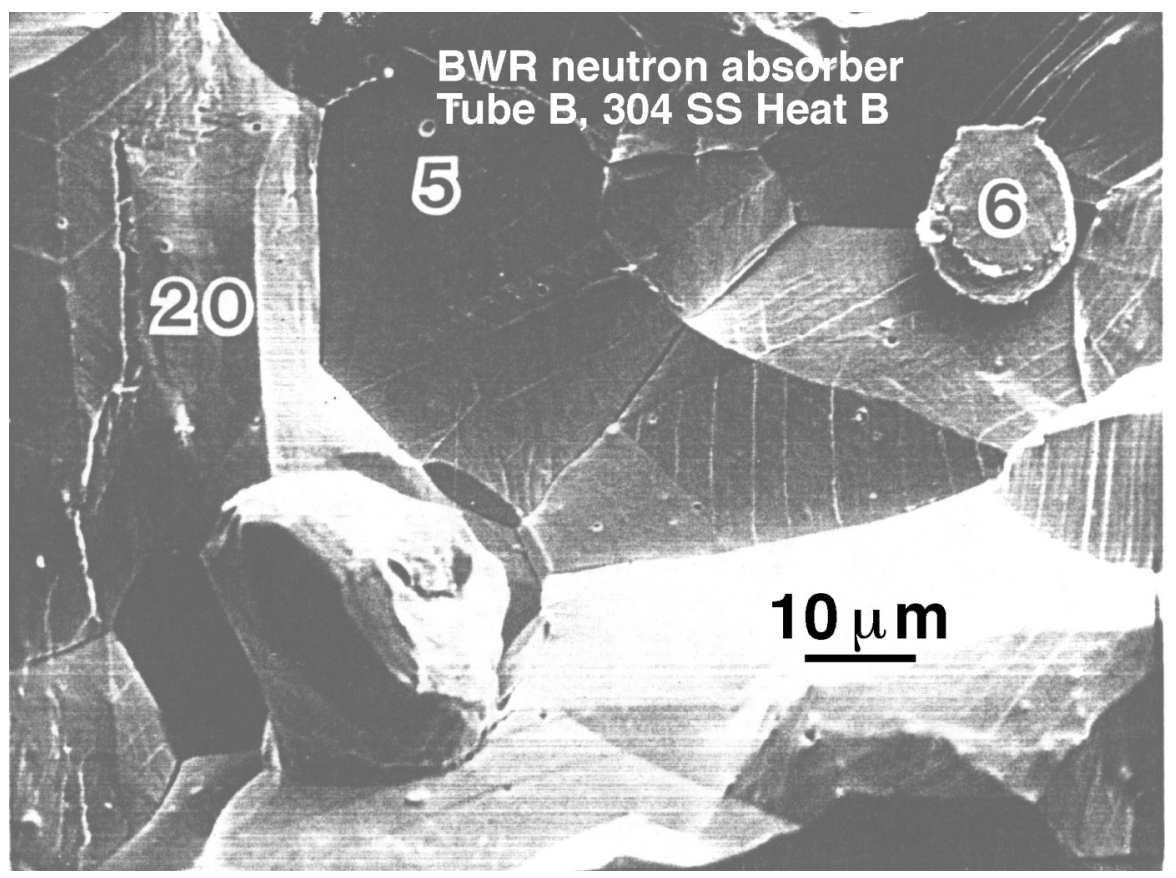

Figure 72.

High-magnification fractograph of $\mathrm{H}$ charged BWR neutron absorber tube, 304 SS, Heat B, $\approx 3 \mathrm{dpa}$; fracture was produced at $23^{\circ} \mathrm{C}$ in ultra-high vacuum environment in a scanning Auger electron microscope.

Figure 75 shows the results of depth-profile analysis for the two tubes fabricated from 304 SS Heats A1 and B. The figure confirms significant grain-boundary segregation of S in Tubes A-1 and B and C segregation in Tube B. 


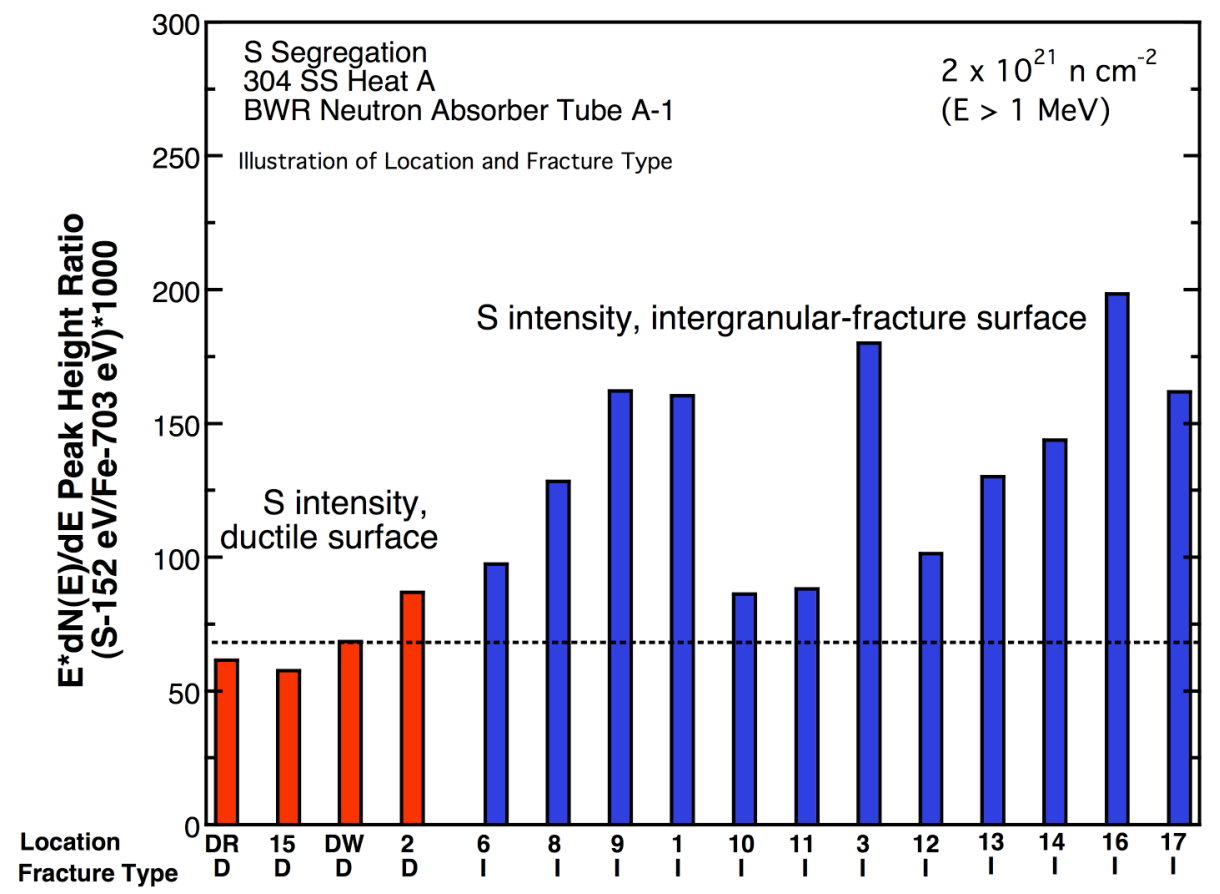

(a)

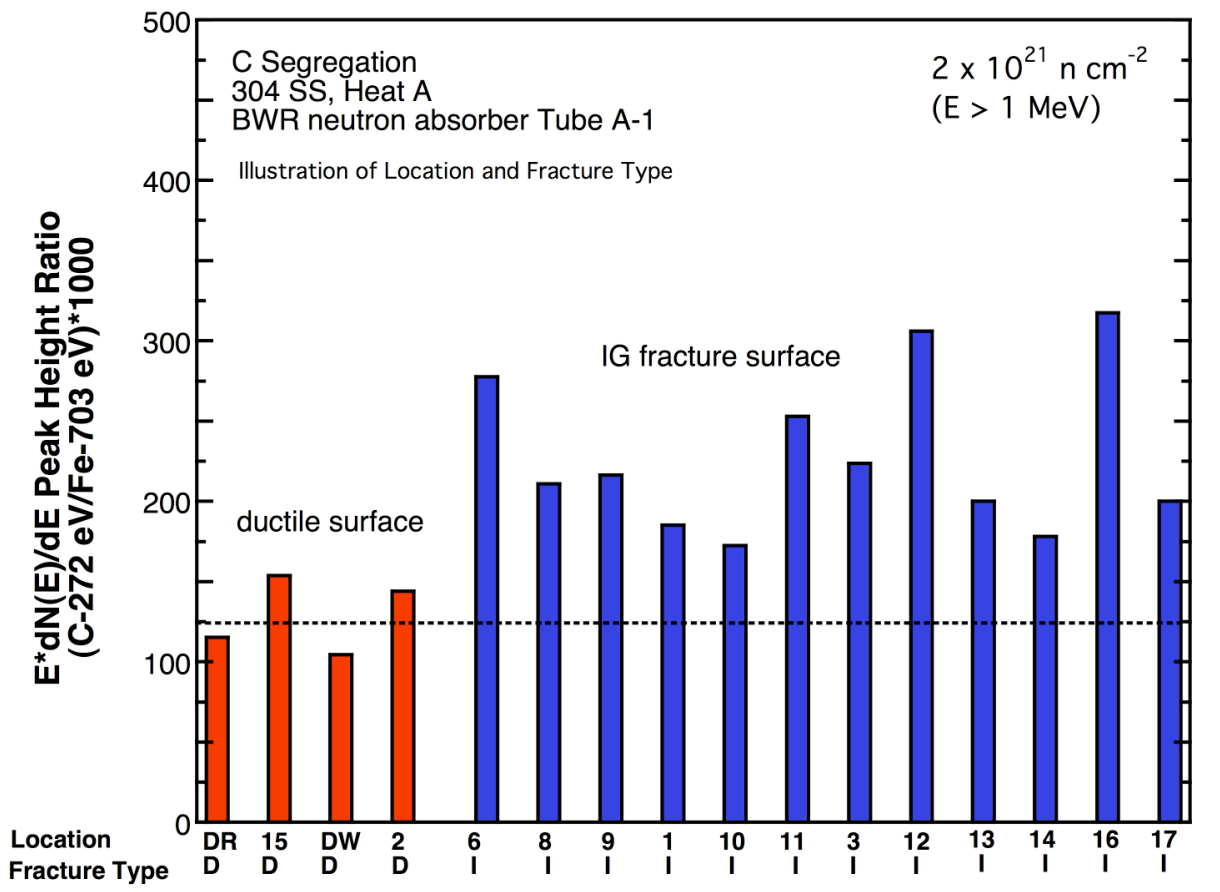

(b)

Figure 73. Summary of AES analysis of grain-boundary segregation of $S$ (a) and C (b) in BWR neutron absorber tube fabricated from Type 304 SS Heat A and irradiated to 3 dpa: S and C peak heights from ductile (denoted "D") and IG (denoted "I") fracture surfaces are compared. The horizontal line denotes the average signal strength on a ductile fracture surface. 


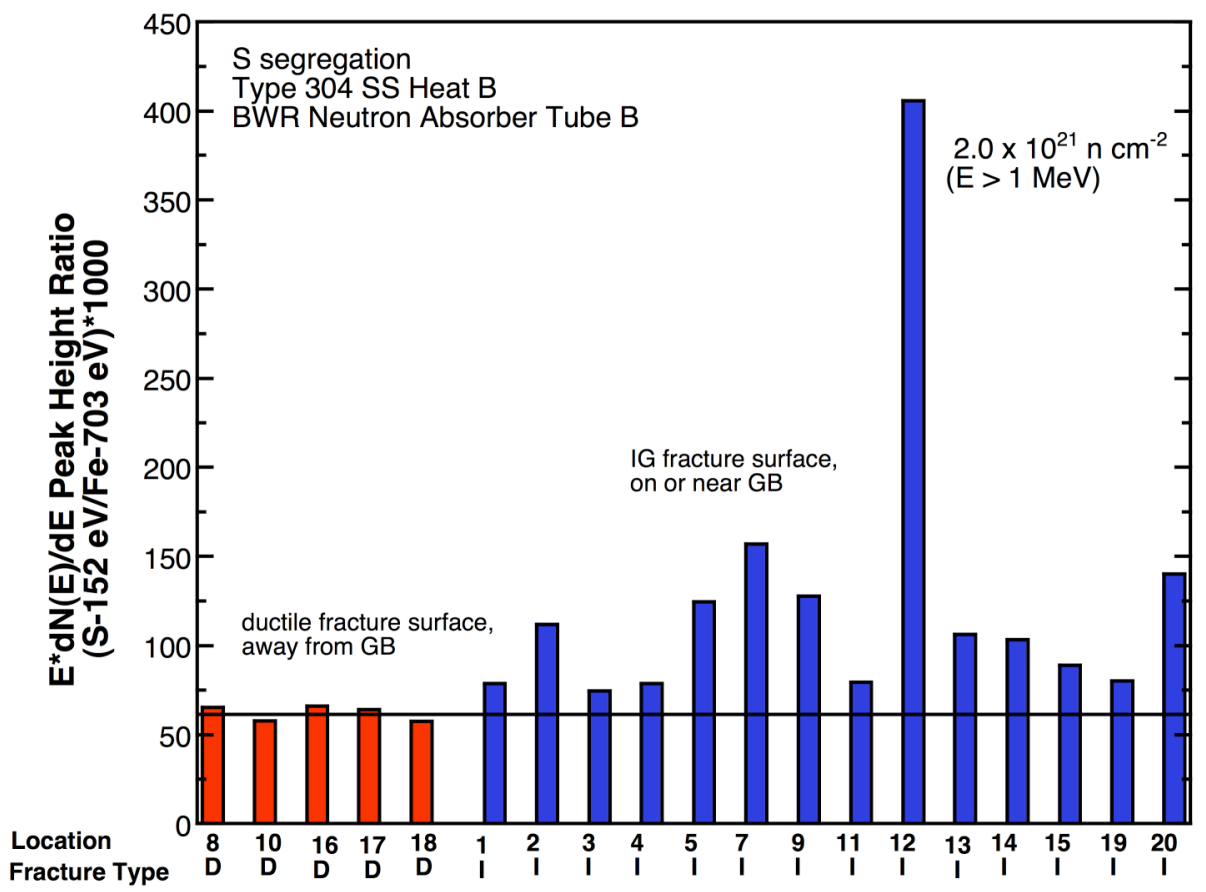

(a)

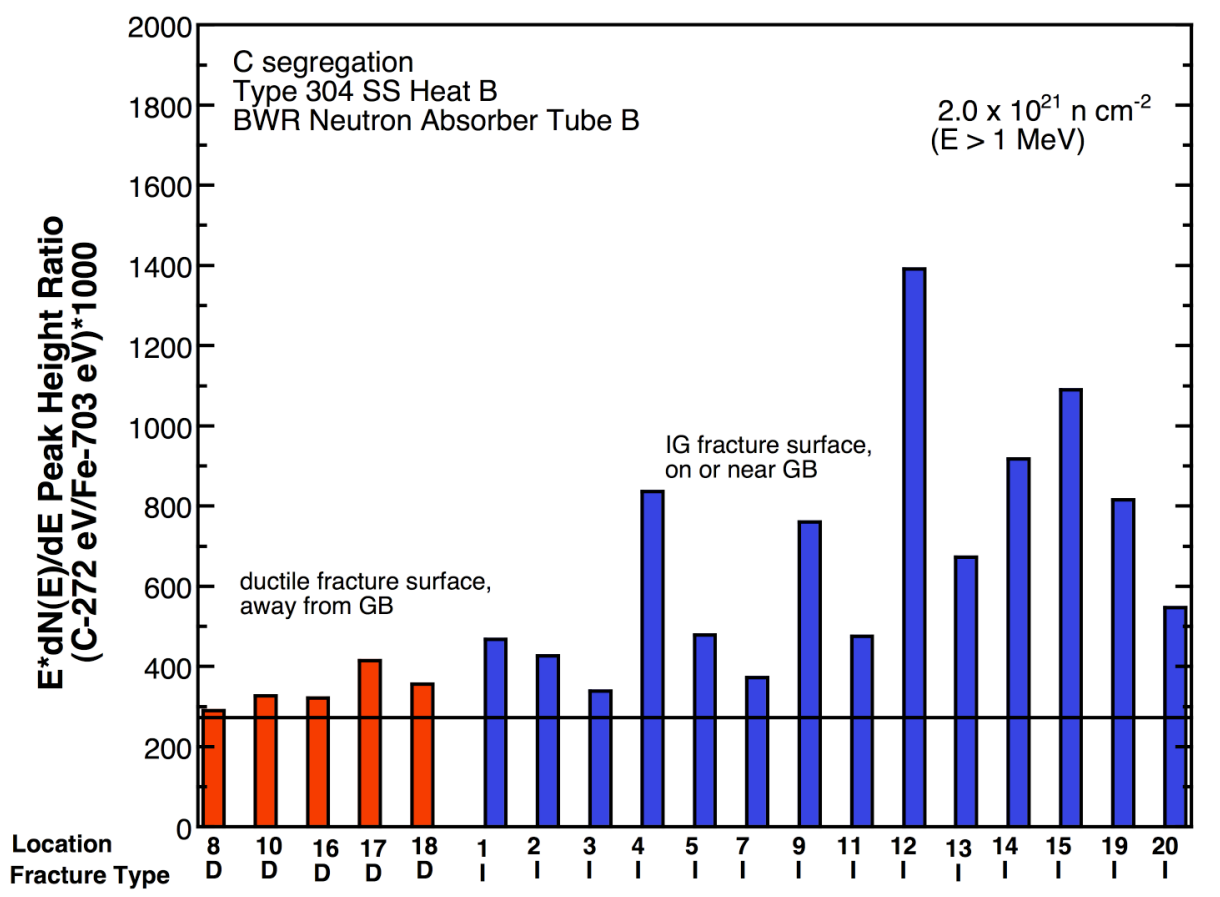

(b)

Figure 74. Summary of AES analysis of grain-boundary segregation of $S$ (a) and C (b) in BWR neutron absorber tube fabricated from Type 304 SS Heat B and irradiated to 3 dpa: S and C peak heights from ductile (denoted "D") and IG (denoted "I") fracture surfaces are compared. The horizontal line denotes the average signal strength on a ductile fracture surface. 


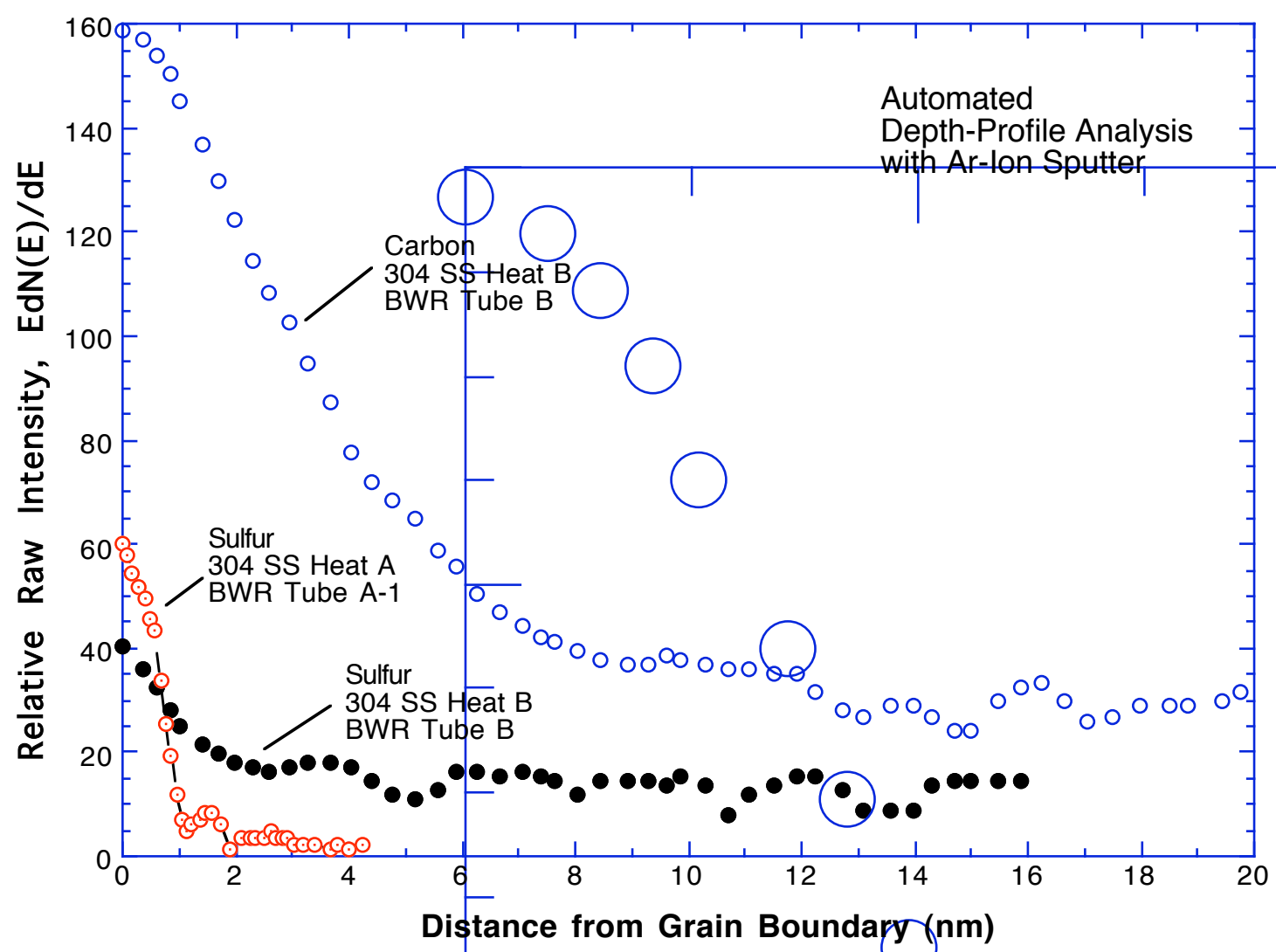

Figure 75. Result of AES depth-profiling analysis of grain-boundary segregation of $S$ and $C$ in BWR neutron absorber tubes fabricated from Type 304 SS Heats $A$ and $B$ and irradiated to $\approx 3 \mathrm{dpa}$.

The results in Figs. 73-75, however, do not clarify whether the grain-boundary segregation of S or C occurred via a thermal process (during fabrication), an irradiation-induced process, or both. The former type of segregation is expected to be significantly influenced by several steps during fabrication, e.g., ingot cooling, inter-rolling annealing and cooling, final annealing, and quenching. Thermal segregation is also influenced by plate thickness.

Results of AES analysis of grain-boundary segregation of S have been reported by Jacobs et al. ${ }^{48}$ for fuel-cladding-like tubes that were irradiated in a BWR. A tube fabricated from a commercial heat of Type $348 \mathrm{SS}$ was irradiated to $1.5 \times 1021 \mathrm{n} \cdot \mathrm{cm}^{-2}(\mathrm{E}>1 \mathrm{MeV})$, and a tube fabricated from a high-purity heat of Type 348 SS was irradiated to $3.4 \times 10^{21} \mathrm{n} \cdot \mathrm{cm}^{-2}(E>1 \mathrm{MeV})$. Results of spot analysis similar to that of Figs. 73 and 74 showed significant grain-boundary segregation of $S$ in both tubes. Depth-profiling analysis similar to that of Fig. 75 was, however, not reported from their investigation.

Thermal segregation of S to grain boundaries for unirradiated ultra-high-purity (UHP) austenitic SS doped with S has been reported by Andresen and Briant. ${ }^{49}$ They concluded that S plays an important role in producing the IG crack path in thermally sensitized non-irradiated steels. Because S atoms are thermally segregated on grain boundaries, more $\mathrm{S}$ ions are released into water from the grain boundary than from the grain matrix, and it was thought that an IG crack path is promoted in steels that contain high concentrations of S. Thus, the authors essentially viewed the role of $\mathrm{S}$ as accelerating corrosive attack (i.e., dissolution of grain 
boundary metal) of a Cr-depleted grain boundary, exacerbated by $\mathrm{S}$ ions released into the crack tip water. According to this model, as long as grain boundaries are significantly depleted of $\mathrm{Cr}$, the production of an IGSCC path is predicted, even in a steel free of S.

However, a similar model of the role of $\mathrm{S}$ does not appear to explain our results on IASCC susceptibility of irradiated steels. One difficulty is how to explain the observation that IASCC susceptibility becomes negligible when $\mathrm{S}$ concentration is very low even though $\mathrm{Cr}$ depletion is significant at $\approx 3 \mathrm{dpa}$ (see Figs. 28 and 43). Another difficulty is how to explain the trend that the $\mathrm{S}$ effect is strongly influenced by fluence at $>0.003$ wt.\% S, e.g., in 304- and 316-type steels (see Fig. 29).

\subsection{Analysis of Solubility of Carbon in Sulfides}

The results in Figs. 42-44 indicate that, when $\mathrm{S}$ concentration in a 304- or 316-type steel is $\leq 0.002 \mathrm{wt} . \%$, a high concentration of $\mathrm{C}(>0.03 \mathrm{wt} . \%)$ promotes a decrease of the susceptibility to IASCC. When S concentration exceeds $\approx 0.003$ wt. $\%$, such a "beneficial" effect of high C concentration appears to be insignificant or absent. This observation suggests that some kind of synergism occurs between $\mathrm{S}$ and $\mathrm{C}$ and that the effect of such synergism is significant only at sufficiently low concentrations of $\mathrm{S}(<0.002 \mathrm{wt} . \%)$.

With respect to the above observation, our attention was focused on the composition and properties of $\mathrm{Ni}$ - and S-rich thin films that were observed on grain boundaries under three situations: i.e., at crack-tip grain boundaries in an unirradiated thermally sensitized crack-growth specimen tested in sulfated BWR-like water (304 SS), reported by Dumbill; ${ }^{31}$ at crack-tip grain boundaries in a field-failed BWR top guide and a PWR baffle bolt (304 SS), reported by Thomas and Bruemmer; 33,34 and at ordinary grain boundaries of S-doped Ni specimens that failed during SSRT tests in air at $23^{\circ} \mathrm{C}$, reported by Heuer et al. ${ }^{50}$ The latter investigators showed that S-doped $\mathrm{Ni}$ specimens lose their tensile strength when the grain-boundary concentration of S exceeds $\approx 15$ at. $\%$, which causes an IG failure. Then, it was thought in our study that, if $\mathrm{C}$ is dissolved in a $\mathrm{Ni}_{\mathrm{X}} \mathrm{S}_{\mathrm{y}}$-type film in a significant amount, the mechanical properties of such a film are likely to be altered significantly. Accordingly, available information and data were evaluated to determine if $\mathrm{C}$ is soluble in sulfides.

The AES signal from the precipitate denoted with number "6" in Fig. 72 is shown in Fig. 76. The AES signal indicates that the precipitate is a CuS-type precipitate that contains a significant amount of C. Similar data are shown in Figs. 77 and 78 for two more CuS-type precipitates that were present in the same specimen. 


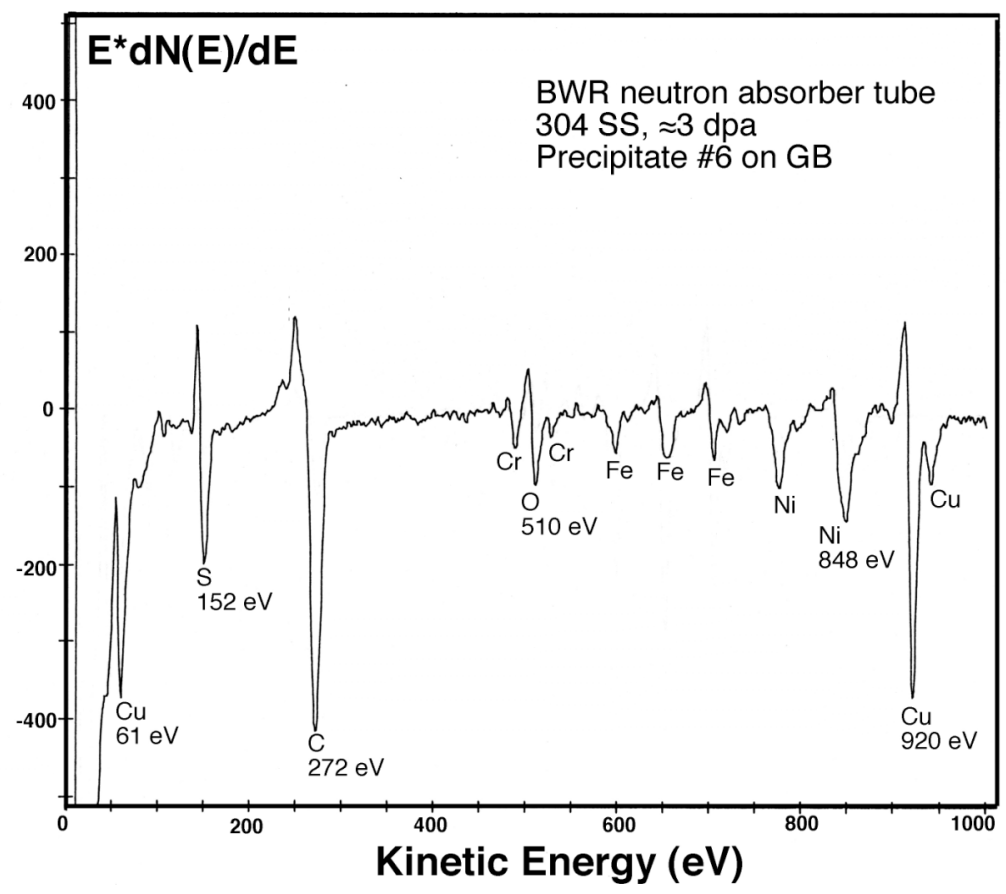

Figure 76.

AES signal showing high concentrations of $\mathrm{Cu}, \mathrm{S}$, and $\mathrm{C}$ in CuStype precipitate denoted with number "6" in

Fig. 72.

The only direct evidence of significant solubility of $\mathrm{C}$ in Ni sulfide could be observed from the data reported by Dumbill. ${ }^{31}$ The data (Fig. $6 \mathrm{c}$ in his report), obtained by field-emission-gun advanced analytical electron microscopy (FEG-AAEM), show X-ray intensities of $\mathrm{Ni}, \mathrm{S}$, and $\mathrm{C}$ contained in a $\mathrm{Ni}$ - and S-rich thin film that was observed at an intergranular crack in a thermally sensitized, unirradiated Type $304 \mathrm{SS}$. The FEG-AAEM X-ray spectra strongly indicate that $\mathrm{C}$ can be dissolved in significant amounts in Ni-and S-rich thin films at $\approx 290^{\circ} \mathrm{C}$. Unfortunately, similar data were not reported for the field-cracked (irradiated) steels examined by Thomas and Bruemmer. ${ }^{33,34}$ However, irradiation is not expected to significantly decrease the solubility of $\mathrm{C}$ in the Ni- and S-rich thin films or islands that they observed.

Based on the information described above, it is predicted that $\mathrm{C}$ atoms compete with $\mathrm{S}$ atoms to become incorporated in the unit cell of NiS-type sulfides under BWR conditions. The degree of such C incorporation, which replaces part of the $\mathrm{S}$ atoms in the sulfide, is predicted to be more pronounced for a higher concentration of $\mathrm{C}$ at the grain boundary, i.e., for a high $\mathrm{C}$ content in the steel and for a higher degree of grain-boundary segregation of $\mathrm{C}$. 


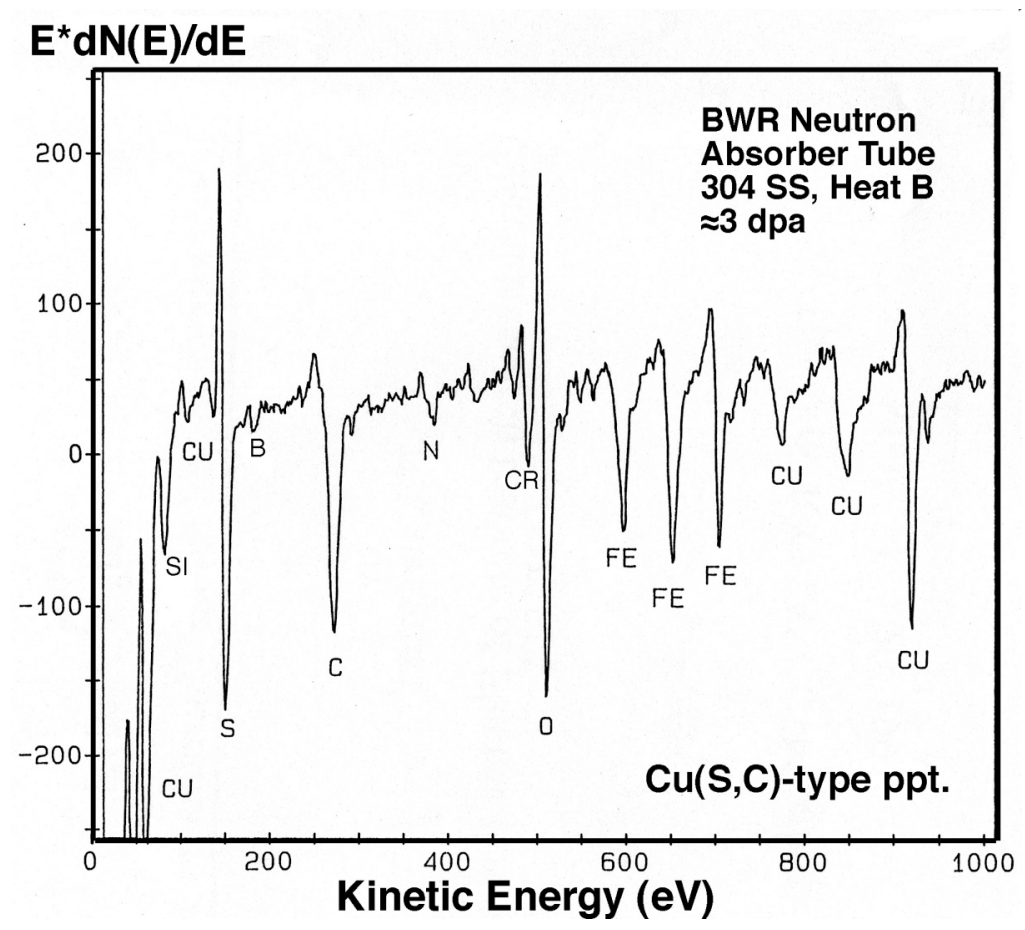

$E^{\star} d N(E) / d E$

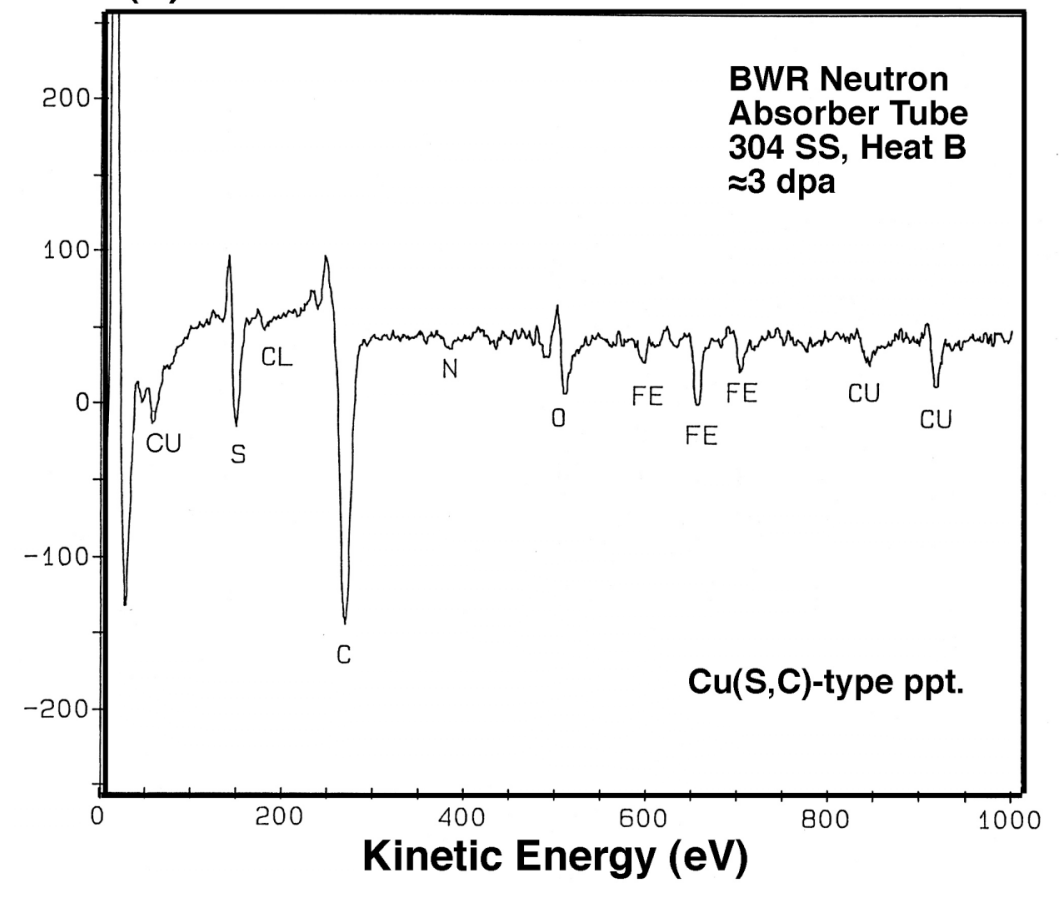

Figure 77.

AES signal showing a high concentration of $\mathrm{C}$ in CuS-type precipitate in BWR neutron absorber tube, 304 SS, Heat B, ₹3 dpa.

\section{Figure 78.}

AES signal showing a high concentration of $C$ in CuS-type precipitate in BWR neutron absorber tube, 304 SS, Heat B, $\approx 3$ dpa. 


\section{Discussion and Model Development}

\subsection{General Discussion}

The results of this investigation shows that, as neutron fluence increases to a high level (e.g., $2.0 \times 10^{21}$ $\mathrm{n} \mathrm{cm}^{-2}[\mathrm{E}>1 \mathrm{MeV}]$, or $3 \mathrm{dpa}$ ), the deleterious effect of S on IASCC susceptibility is dominant over the effects of other elements. The IG fracture surface morphology observed in commercial heats in this study was similar to that of field-cracked BWR core internals. This study also shows that a sufficiently low concentration of $\mathrm{S}(<0.002 \mathrm{wt} . \%)$ is the primary material factor necessary to ensure good resistance to IASCC. Even at slightly higher S concentrations of $>0.003$ wt.\%, Type 304, 304L, 316, and 316L steels were susceptible to IASCC at $3 \mathrm{dpa}$. This strong dependence on S concentration, shown in Fig. 30 as an example, suggests that some kind of threshold phenomenon related to $\mathrm{S}$ is involved in IASCC.

It is important to note that, for 304- and 316-type steels that contain a low concentration of $\mathrm{C}$ of $<0.03$ wt.\% (e.g., Types 304L, 316L, and their high-purity counterparts), an S concentration of $<0.002$ wt.\% is not a sufficient material condition to ensure good resistance to IASCC. This behavior is in distinct contrast to the behavior of 304- and 316-type steels that contain high $\mathrm{C}$ concentrations of $>0.03$ wt.\% (e.g., Types 304 and 316 steels) and $\mathrm{S}$ concentration of $<0.002 \mathrm{wt} . \%$. The latter class of steels exhibited good resistance to IASCC. This contrasting behavior indicates that, for $\mathrm{S}$ concentration $<0.002 \mathrm{wt} . \%$, a high concentration of $\mathrm{C}$ plays a beneficial role. However, when $\mathrm{S}$ concentration is high, i.e., $>0.002 \mathrm{wt} . \%$, it seems that the deleterious effect of $\mathrm{S}$ is so pronounced that the effect of a high concentration of $\mathrm{C}$ is largely obscured.

At lower damage levels (i.e., $<1$ dpa), a beneficial effect of a high concentration of Si (i.e., 0.81.5 wt.\%) was observed. At higher damage levels, however, such effect appears to be obscured by the deleterious effect of S. Therefore, from the standpoint of BWR IASCC, which usually occurs at damage levels $>2.5$ dpa, we believe that the typical variation in Si concentration in Types 304 and 316 SS (i.e., 0.4 to $1.0 \mathrm{wt} . \%$ ) is not an important factor. It is not clear if, in addition to a sufficiently low concentration of S (i.e., $<0.002$ wt.\%) and a sufficiently high concentration of C (i.e., $>0.03 \mathrm{wt} . \%$ ), an unusually high concentration of $\mathrm{Si}$ (e.g., $>1.5$ wt.\%) provides an extra benefit when fluence is high (e.g., $>2.5 \mathrm{dpa}$ ). The two heats that belong in this category, i.e., 304 SS Heat L14 (S $\approx 0.002$ wt.\%, C 0.107 wt.\%, and Si 0.96 wt.\%) and 316 SS heat L27 ( $\mathrm{S} \approx 0.002$ wt.\%, C 0.057 wt.\%, and Si 1.82 wt.\%) exhibited good resistance at 3 dpa. On the other hand, 304 SS Heat $\mathrm{C} 19$, which contains a slightly higher $\mathrm{S}$ concentration (i.e., 0.003 wt.\%) and a relatively low concentration of $\mathrm{Si}$ (i.e., $0.45 \mathrm{wt} . \%$ ), exhibited a significant susceptibility at 3 dpa despite a high concentration of C (i.e., 0.06 wt.\%) (see Table 14). Also, 304 SS Heat L6, which contains 0.005 wt. \% S and 0.096 wt.\% C, exhibited a significant susceptibility at 3 dpa despite a high concentration of Si (i.e., 1.90 wt.\%).

Most field-cracked LWR core internals and steels used in SSRT tests or to evaluate crack-growth behavior in the IASCC community contain S concentrations $>0.002 \mathrm{wt} . \%$. Therefore, it is not surprising to see that most of them were susceptible to IASCC in one way or another. For S concentrations $>0.002$ wt. $\%$, the degree of IASCC susceptibility in this study varied significantly from heat to heat, and it was difficult to predict the degree quantitatively. This behavior, consistent with literature data, is not unexpected when one considers the fact that, for a given fluence level, several factors can influence the degree of S segregation to grain boundaries, e.g., annealing and cooling history during fabrication, Mn content, precipitation of sulfides such as $\mathrm{MnS}$ and $\mathrm{CuS}$, and solubility of the sulfides in BWR-like water. 
The observation that steels that contain a very low or negligible amount of S are resistant to IASCC provides an important clue to the mechanism of IASCC. To understand the mechanism, we believe it is important to consider the following:

(1) The strong dependence of IASCC susceptibility on fluence

(2) The strong dependence of IASCC susceptibility on S concentration and an indication that some kind of critical phenomenon involving S occurs

(3) A high concentration of C ( $>0.03$ wt.\%) suppresses IASCC susceptibility at sufficiently low S concentrations $(<0.002 \mathrm{wt} . \%)$ but not at $\mathrm{S}$ concentrations $>0.003 \mathrm{wt} . \%$.

(4) Very low solubility of $\mathrm{S}$ in an austenitic SS at $\approx 300^{\circ} \mathrm{C}$

(5) Segregation of S to grain boundary

(6) Parallel grain-boundary $\mathrm{Cr}$ depletion and Ni segregation

(7) Strong influence of water chemistry on BWR IASCC

(8) Strong effect of strain rate on percent IGSCC from SSRT tests

Considering the finding that the $\mathrm{S}$ effect is dominant at high fluence and the fact that grain-boundary $\mathrm{Cr}$ depletion is in some respect a mirror image of grain-boundary Ni segregation, we believe it is important to understand the peculiar properties of Ni-S thin film reported by Heuer et al., who investigated the effect of ion-implanted $\mathrm{S}$ on disorder-induced amorphization of $\mathrm{Ni}^{50}$ Those authors also investigated the effect of thermal segregation of $\mathrm{S}$ on grain boundaries on the mechanical properties of unirradiated binary Ni-S. In the latter investigation, they found that, as the grain boundary concentration of $\mathrm{S}$ exceeds $\approx 10$ at. $\%(\approx 5.6 \mathrm{wt} . \%)$, the mechanical properties of S-segregated Ni start to degrade drastically in $23^{\circ} \mathrm{C}$ air, i.e., there is a precipitous decrease in total elongation, tensile strength, modulus of toughness, reduction-in-area, and a sharp increase in percent intergranular cracking (IGC). This means that, at a sufficiently high level of S segregation, a grain boundary in the Ni-S system loses metallic strength and behaves more like a clay. Okamoto and his coworkers also showed that the volume fraction of amorphization of S-ion-implanted specimens starts to increase drastically when the bulk $\mathrm{S}$ concentration exceeds $\approx 5.6 \mathrm{wt} . \% .{ }^{50,51}$ Based on these observations, they concluded that $\mathrm{S}$-induced intergranular fracture in binary Ni-S is explained well by disorder-induced melting of a Ni-S-rich thin film that formed on grain boundaries. They proposed that this process is strongly influenced by $\mathrm{S}$ and $\mathrm{H}$ concentrations, stress, temperature, and irradiation damage. We believe that the results of Okamoto and his coworkers constitute a very useful framework that can shed light on the mechanistic understanding of IASCC.

Similar to the observation of Heuer et al., ${ }^{50}$ predominantly IG fracture was observed in one of our highstrain-rate bending tests in $23^{\circ} \mathrm{C}$ air, specifically, a Type $304 \mathrm{SS}$ Heat L13, which contained an unusually high concentration of S (0.022 wt.\%) and an unusually low concentration of Mn (0.36 wt.\%). The specimen was neither exposed to water nor charged with hydrogen before the bending test. Therefore, the intergranular fracture in the specimen cannot be explained on the basis of $\mathrm{H}$-induced embrittlement of grain boundaries. The high-magnification intergranular fractograph of the specimen, shown in Fig. 79, is characterized by a 
smooth grain boundary separation, a virtual absence of deformation steps, and an indication of significant grain encirclement. These features are similar to those of IASCC failures produced in $289^{\circ} \mathrm{C}$ water. Because the specimen was irradiated in high-purity helium, it is also difficult to explain the intergranular fracture by grain boundary oxidation or $\mathrm{O}$ segregation. The fracture behavior seems to differ from limited amount of near-surface intergranular separation reported by Onchi and his coworker ${ }^{52,53}$ for thermally sensitized and irradiated $304 \mathrm{SSs}$ that were tested in inert gas at $\approx 290^{\circ} \mathrm{C}$. Nevertheless, the experiment of Fig. 79 shows that purely mechanical intergranular failure similar to that reported in the unirradiated Ni-S system can occur in a highly irradiated austenitic SS that contains an unusually high concentration of S.

Considering the observations discussed above, we believe that it is important to better understand the structure and properties of $\mathrm{Ni}$ - and S-rich thin films and islands that have been reported by Thomas and Bruemmer $^{32-34}$ and Dumbill. ${ }^{31}$ The former investigators conducted extensive studies on crack-tip microstructure and microchemistry of field-cracked BWR and PWR core internal components. ${ }^{33,34}$ Similar studies were also performed by Dumbill ${ }^{31}$ and Bruemmer and Thomas ${ }^{32}$ on unirradiated, thermally sensitized $304^{31}$ and $316^{32} \mathrm{SSs}$ that were tested in sulfated ${ }^{31}$ or deoxygenated ${ }^{32}$ BWR-like water at $289^{\circ} \mathrm{C}$.

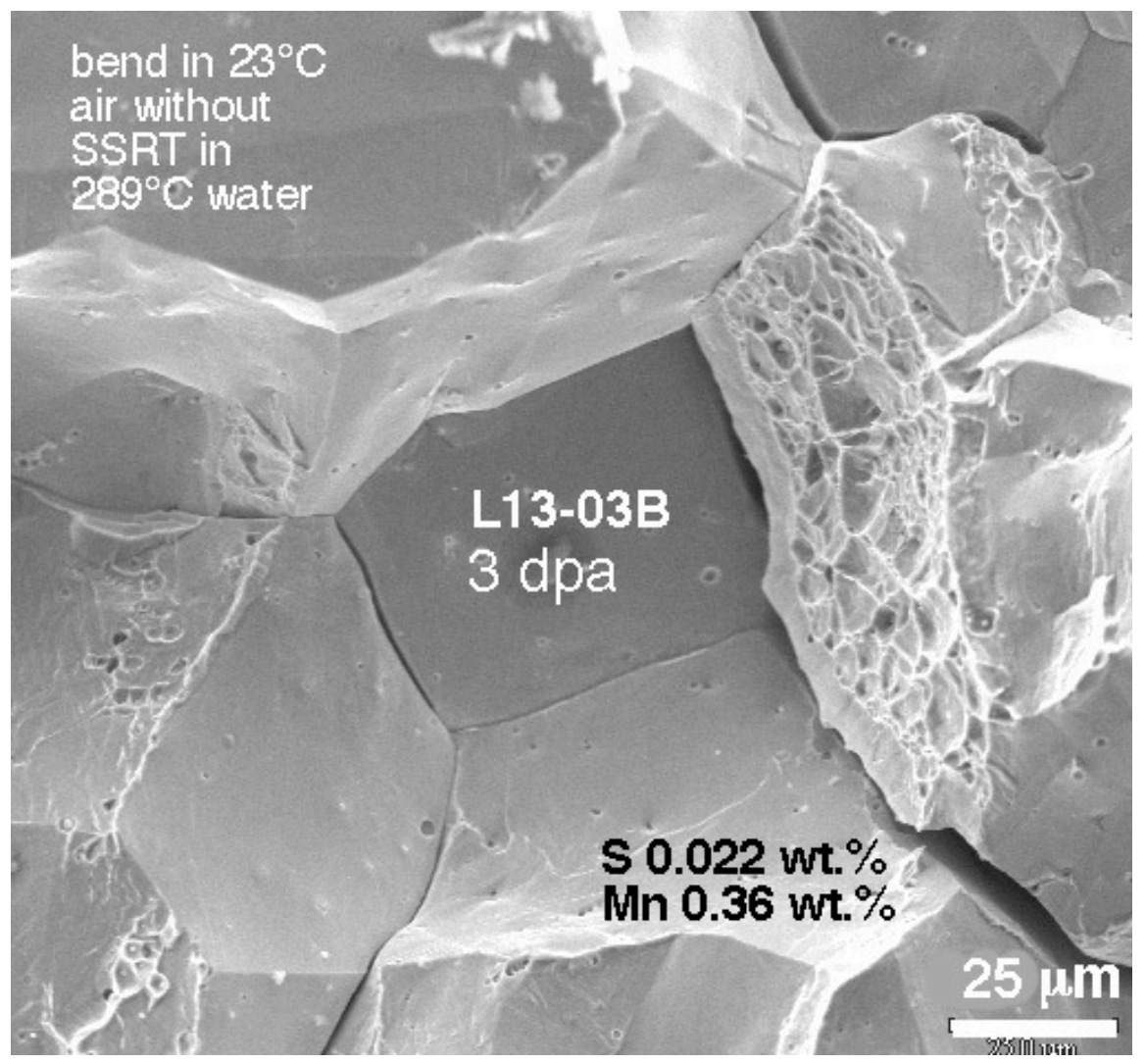

Figure 79. Fracture surface morphology of high-S, low-Mn Type 304 SS Specimen L13-03B (S, 0.022 wt.\%; Mn, 0.36 wt.\%; ₹3 dpa in helium at $289^{\circ} \mathrm{C}$ ) produced during bending in $23^{\circ} \mathrm{C}$ air without previous exposure to water or $\mathrm{H}$ charging.

In Ref. 33, Thomas and Bruemmer report extensively on the crack-tip grain boundary microstructural characteristics of a PWR baffle bolt and a BWR top guide, both of which cracked during service. A layer of 
Cr-Fe-type spinel oxide sandwiched between the two adjacent grain matrices was always observed ahead of an open crack tip. Such an oxide was fine-grained and contained tiny pores (diameter 2-10 nm). In the case of the BWR top guide, numerous irregularly shaped microcavities, as large as $\approx 100 \mathrm{~nm}$ in length and $\approx 50 \mathrm{~nm}$ in width, were observed, usually at the metal/oxide boundary and near the tip of the spinel oxide.

Direct evidence of $\mathrm{Ni}_{\mathrm{x}} \mathrm{S}_{\mathrm{y}}$-type thin films produced between such a spinel oxide and the metal matrix is observed in several photomicrographs, e.g., Figs. 3-10 and 3-13 in Ref. 33 for the PWR baffle bolt. Small islands of $\mathrm{Ni}$ or $\mathrm{Ni}_{\mathrm{x}} \mathrm{S}_{\mathrm{y}}$-type phase are also observed. The width of such $\mathrm{Ni}_{\mathrm{x}} \mathrm{S}_{\mathrm{y}}$-type thin film is extremely small, i.e., $<7 \mathrm{~nm}$, based on data from energy-dispersive spectroscopy (EDS) and $<3 \mathrm{~nm}$ based on bright-field image. In the case of the BWR top guide, a similar type of thin film (thickness $\approx 3 \mathrm{~nm}$ ), which exhibits the same imaging contrast is observed at the boundary between the metal matrix and the spinel oxide, e.g., Figs. 4-11, 4-12, 4-14, 4-17, and 4-20 of Ref. 33.

Results of analysis by energy dispersive spectroscopy on the top guide indicate that such film contains a high concentration of Ni. However, data for S distribution near the film were not reported. The distance between EDS spots in the analysis was 5-25 nm, significantly larger than the width of such a thin film. Under such conditions, one can easily miss probing a spot correctly placed in the middle of a thin film that is only $<3$ $\mathrm{nm}$ wide. Therefore, it is not easy to measure the distribution of $\mathrm{S}$ near such a film. However, microstructural features such as spinel oxide, voids, cavities, the position and shape of an open crack, and $\mathrm{Ni}_{\mathrm{X}} \mathrm{S}_{\mathrm{y}}$-type thin film can be detected readily through bright-field imaging and tilting. A dark-field image of a $<3$-nm-wide $\mathrm{Ni}_{\mathrm{X}} \mathrm{S}_{\mathrm{y}}$-type thin film, which is a more valuable piece of information, would be very difficult to obtain in an irradiated core internal. Dumbill reported results of X-ray mapping that show a matching distribution of $\mathrm{Ni}$ and $\mathrm{S}$ for a crack tip in his unirradiated sensitized $304 \mathrm{SS}$ specimen. ${ }^{31}$ The Ni- and S-rich thin film in his specimen was relatively thicker (i.e., width $\approx 100 \mathrm{~nm}$ ), and a continuous EDS line scan and matching elemental mapping that clearly showed the nature of such film could be obtained.

Thomas and Bruemmer provided a comprehensive interpretation of the crack-tip microstructures observed in their studies. ${ }^{33,34}$ They suggested that $\mathrm{Cr}$ - and Fe-rich spinel oxide, observed ahead of an open crack tip, was produced as a corrosion byproduct that filled the crack opening after the crack had advanced along the grain boundary. Thus, the spinel oxide tip was interpreted to be the same as the crack tip. Formation of Ni-rich thin films and islands was attributed to a mechanism of selective dissolution in which $\mathrm{Cr}$ and $\mathrm{Fe}$ atoms are dissolved preferentially over $\mathrm{Ni}$ atoms in the crack-tip water.

Nevertheless, photomicrographs and EDS data given in the reports of Thomas and Bruemmer ${ }^{32-34}$ or Dumbill ${ }^{31}$ shed light on several new clues that are helpful to the understanding of the metallurgical processes that occur near a crack tip. Thus, we thought that a more detailed integrated evaluation is timely. Several important observations in the following discussion suggest a mechanism in which spinel oxide and Ni and $\mathrm{Ni}_{\mathrm{X}} \mathrm{S}_{\mathrm{y}}$ thin films and islands visible near the crack tip were produced, not after the crack advanced to the position of the spinel oxide tip, but, instead, before the crack advanced in association with internal grainboundary oxidation which occurred ahead of the crack tip.

The first observation is that a crack tip is often visible adjacent to a grain boundary rather than in line with the grain boundary. The offset distance between the line of crack advance and the grain boundary (imaged edge on) was $\approx 20 \mathrm{~nm}$ in the field-cracked BWR top guide; see Figs. 4-19 and 4-21 in Ref. 33. In the case of unirradiated thermally sensitized 304 and 316 SSs tested in deoxygenated BWR-like water, the offset distance was $\approx 90 \mathrm{~nm}$ and $\approx 15 \mathrm{~nm}$, respectively, (Ref. 32). This observation is difficult to explain on the basis 
of preferential dissolution of the grain-boundary metal; it is equally difficult to explain on the basis of a premise that the grain boundary itself shifts continuously ahead of an advancing crack tip. The offset distance is, in fact, the same as the distance between the grain boundary and the metal/spinel boundary, in which a $\mathrm{Ni}_{\mathrm{x}} \mathrm{S}_{\mathrm{y}}$-type thin film and islands are present, often accompanied by high-density voids and cavities. More voids and cavities tend to appear in regions where thin films or islands of $\mathrm{Ni}_{\mathrm{X}} \mathrm{S}_{\mathrm{y}}$-type or $\mathrm{Ni}$-rich phases occur. This observation suggests that the voids and cavities were products of localized melting of Ni- and S-rich films or islands. This view is essentially consistent with the results of experiments and the theory advanced by Okamoto and his coworkers on the behavior of S-rich thin film in the Ni-S binary system. ${ }^{50,51}$

The second observation is dark-field morphology of spinel oxide present ahead of an open crack tip. Such a dark-field image was reported in Ref. 32 for a crack tip in an unirradiated, thermally sensitized 316 SS. In the image, extremely small particles of spinel oxide (diameter $\approx 5 \mathrm{~nm}$ ) are observed decorating the grain boundary $\approx 290$ to $\approx 450 \mathrm{~nm}$ ahead of the open crack tip, and twin boundaries $\approx 350 \mathrm{~nm}$ ahead of the crack tip. This observation provides direct evidence of internal oxidation on grain boundaries and twin boundaries in a BWR-like environment, and it is reasonable to expect a similar phenomenon in a BWR core internal. For ordinary grain boundaries (i.e., grain boundaries that are not involved in crack-tip advancement), evidence of grain-boundary internal oxidation has been reported only for the heat-affected zone (HAZ) in BWR core shroud welds that were prepared by shielded-metal-arc or submerged-arc procedure. ${ }^{26,54}$ Oxygen contamination in such a HAZ is pronounced, and because $\mathrm{O}$ solubility in the grain matrices is extremely low near room temperature, $\mathrm{O}$ atoms segregate to grain boundaries during cooling of the HAZ. Internal oxide particles produced by this process have been characterized by Auger electron spectroscopy in Refs. 26 and 54 by transmission electron microscopy in Ref. 26.

The third observation is pores and voids that decorate previous twin boundaries located within a spinel oxide ahead of an open crack tip. Such a feature, visible in a top guide crack tip in Figs. 4-9 and 4-10 of Ref. 33, cannot be explained on the basis of a premise that the spinel oxide filled the crack opening up to the tip of the spinel oxide. Such a feature is, however, explained well based on a premise that a grain boundary region that contains a twin was oxidized internally before the crack advanced to that particular location.

The fourth observation notes the tendency that more cavities are observed near the tip of the spinel oxide layer than near the metal/spinel boundary, e.g., the top guide crack-tip structure shown in Figs. 4-20 to 4-25 of Ref. 33. Also, more $\mathrm{Ni}$ and Ni-sulfide islands tend to be present near the tip of a spinel oxide, e.g., Figs. 3-14 (baffle bolt) and 4-18 (top guide) in Ref. 33. This behavior is not explained well based on a premise that the spinel oxide filled the crack opening but is explained well based on a premise that the spinel oxide extended its length via internal oxidation of the grain-boundary. In the latter process, $\mathrm{Cr}$ and $\mathrm{Fe}$ atoms are expected to be selectively oxidized by the oxygen atoms that diffuse down the grain boundary, thereby gradually enriching the metal near the tip of the oxide with $\mathrm{Ni}$. At the same time, $\mathrm{S}$ atoms are predicted to remain in the metal ahead of the spinel tip rather than being incorporated in the spinel oxide in which their solubility is lower (than in the metal).

The above observations lend strong support to a mechanism in which a spinel oxide layer and $\mathrm{Ni}$ - and S-rich thin films and islands are produced ahead of an advancing crack tip, and localized melting of the Niand S-rich films and islands plays a primary role in crack propagation. The result of such melting is the production of voids and cavities at the metal/spinel boundary and near the tip of the spinel layer. 


\subsection{An IASCC Model}

On the basis of several key observations in this study and elsewhere, and on the basis of the discussions above, we propose a new IASCC mechanism for irradiated austenitic SS. The model, initially reported in Ref. 55 and schematically illustrated in Fig. 80, is based on the following steps, some postulated and some supported by observations in this study or other investigations:

(1) Many incipient cracks are nucleated in the brittle surface oxide layer that is in contact with water.

(2) When one such incipient crack encounters a grain boundary, the metal in front of the crack tip is oxidized preferentially along the grain boundary, because stress and defects (crystallographic and irradiation-induced defects) are higher at the grain boundary. A grain boundary is a preferential path for faster diffusion of $\mathrm{O}$ from the water, especially in a highly irradiated steel.

(3) The rate of $\mathrm{O}$ transport from water to grain-boundary metal is strongly influenced by the thickness and morphology of the $\mathrm{Cr}$ oxide layer that covers the crack-tip grain boundary. When grain boundary $\mathrm{Cr}$ depletion is significant, the $\mathrm{Cr}$ oxide layer is thinner and less protective, which allows a faster permeation and transport of $\mathrm{O}$. If the $\mathrm{Cr}$ oxide layer that covers the crack-tip grain boundary is ruptured by twinning or dislocation channeling, $\mathrm{O}$ transport to the grain-boundary metal is facilitated.

(4) The metal at the crack-tip grain boundary is gradually converted to $\mathrm{Cr}$-Fe-type spinel oxide, because $\mathrm{Cr}$ and $\mathrm{Fe}$ atoms are preferentially (or selectively) oxidized over $\mathrm{Ni}$ atoms by the $\mathrm{O}$ atoms that diffused down the grain boundary. Nickel atoms are significantly more difficult to oxidize than Fe and $\mathrm{Cr}$. The free energies of oxidation at $\approx 300^{\circ} \mathrm{C}$ of $\mathrm{Ni}, \mathrm{Fe}$, and $\mathrm{Cr}$ are, respectively, $-92,-111$, and $-155 \mathrm{kcal} / \mathrm{mole}$ of $\mathrm{O}_{2}$. Thus, most $\mathrm{Ni}$ atoms remain unoxidized in the metal matrix. The result is that, $\mathrm{Ni}$ atoms, excluded from the growing $\mathrm{Cr}-\mathrm{Fe}$ spinel oxide layer on the grain boundary, accumulate near the metal/spinel boundary and at the tip of the spinel oxide.

(5) At the same time, $\mathrm{S}$ atoms segregated on the grain boundary are also pushed out of the spinel oxide, because the solubility of $\mathrm{S}$ is lower in the oxide than in the metal.

(6) Eventually, Ni- and S-rich thin films or islands form at the metal/spinel boundary and at the tip of the growing spinel oxide layer. The $\mathrm{Ni}$ - and $\mathrm{S}$-rich region can be in the shape of a continuous or discontinuous film or a small isolated island. Nickel and S atoms accumulate more at the tip of the long spinel oxide layer than at the metal/spinel boundary, because less oxidation occurs in the latter direction.

(7) Some $\mathrm{S}$ ions accumulate in the crack tip water because of dissolution of soluble sulfides. ${ }^{56}$ Some $\mathrm{S}$ atoms are released into the metal due to irradiation-induced instability of $\mathrm{MnS}^{57}$ and subsequently diffuse to the thin region of metal that is in contact with the Ni- and S-rich film under the influence of high tensile stress.

(8) When the concentration of S in the Ni- and S-rich thin film or island exceeds a threshold level, the film or island melts or is amorphized, thereby losing its metallic strength. When the thin film or island melts, voids and cavities are formed near the metal/spinel boundary and at the tip of the spinel layer. 
(9) The crack tip then advances along the weakened metal/oxide boundary, i.e., along the thin region in which the Ni- and S-rich thin film and islands melt or are amorphized, thereby producing voids and cavities.

(10) Voids and cavities tend to be produced more ahead of the spinel tip than at the metal/spinel boundary because of the factor described in Step 6. When a large cavity(ies) form at the spinel tip, crack advance halts until a new spinel layer forms ahead of such a cavity(ies). At this time the line of crack advance can switch.

(11) Once the Ni- and S-rich thin films or islands melt or are amorphized, they lose their crystalline structure. The polyhedral crystal structure of the phase, such as the cage structure described by Ashby and Spaegen, ${ }^{58}$ is broken. Then, the $\mathrm{S}$ atoms incorporated in the polyhedral cages diffuse away into the metal matrix.

(12) Depending on postcracking thermal history, the degree of such back-diffusion of S atoms varies. Then, the S-to-Ni ratio and the distribution of S and Ni near voids and cavities observed in a postcracking examination may vary significantly.

\subsection{Role of Carbon}

The role of carbon that tends to suppress IASCC susceptibility at very low concentrations of S $(\leq 0.002 \mathrm{wt} . \%)$ is not well understood at this time. However, an attractive model that can explain the beneficial effect is based on a postulation that $\mathrm{C}$ atoms are dissolved in significant amounts in the Ni- and $\mathrm{S}$ rich thin film. As shown by Heuer et al. a Ni- and S-rich thin film loses metallic strength when the S content

in the film exceeds a threshold level. ${ }^{50}$ Such a loss of metallic strength is attributed to severe localization of free electrons by $\mathrm{S}$ atoms incorporated in the Ni-S-type film, i.e., trapping of free electrons by $\mathrm{S}$. When deprived of free electrons, the film no longer exhibits metallic behavior or metallic strength. A simple consideration suggests that $\mathrm{C}$ atoms can easily occupy the same octahedral sites in the unit cell of Ni sulfide that would be normally occupied by $\mathrm{S}$ atoms. Thus, when $\mathrm{C}$ concentration is high near the Ni- and S-rich thin film that is formed at the crack-tip grain boundary, $\mathrm{S}$ and $\mathrm{C}$ atoms compete to occupy the same octahedral sites. Under such a situation, $\mathrm{C}$ dissolved in the film is expected to promote a strong covalent bonding with $\mathrm{Ni}$, in effect suppressing the effect of trapping free electrons by S. The limited information described in Section 13.2 indicates that the solubility of $\mathrm{C}$ in a CuS- and NiS-type thin film is significant, which is consistent with, but does not prove, the model outlined above. A further investigation is desirable to provide a better mechanistic understanding of the role of $\mathrm{C}$ atoms on BWR IASCC. 


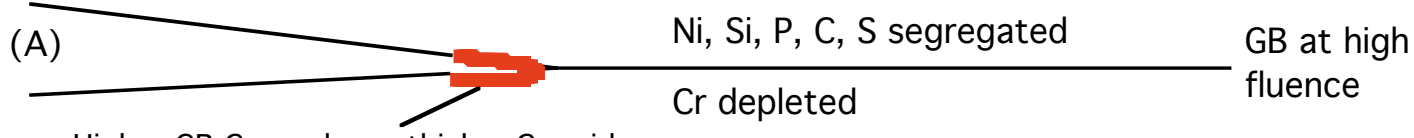

Higher GB Cr produces thicker $\mathrm{Cr}$ oxide, which slows $\mathrm{O}$ permeation and diffusion along GB. More $\mathrm{O}$ atoms diffuse when $\mathrm{Cr}$ oxide is broken by twins.

(B)

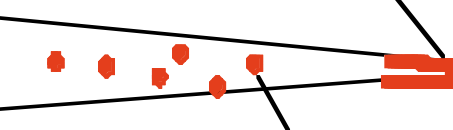

$S$ ions released into water

$\mathrm{O}$ diffuses fast along GB under stress and irradiation. Cr-Fe spinel oxide grows along GB. metal/spinel boundary.

(C)

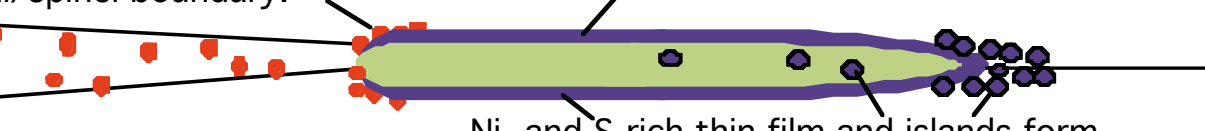

$\mathrm{Ni}$ - and S-rich thin film and islands form.

At high $\mathrm{S}$ concentration, $\mathrm{Ni}$ - and $\mathrm{S}$-rich film and islands melt or is amorphized under the influence of irradiation and stress. Voids and cavities form, preferentially near metal/spinel boundary and spinel tip.

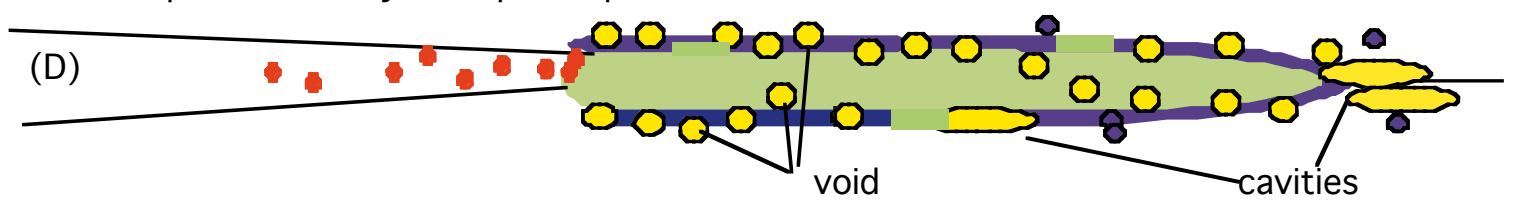

When voids, cavities, and molten film are in significant amounts, the metal/spinel boundary loses strength, and crack tip advances along the boundary.

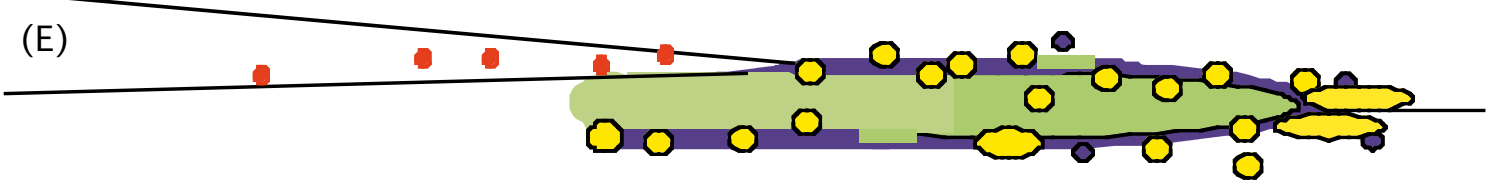

(F) When S-rich Ni film and islands are amorphized or melt, Ni-S polyhedral cage is destroyed, $\mathrm{S}$ is freed from the cage and diffuses back into metal matrix. Altered distribution of $\mathrm{S}$ is observed when the tip is examined after discharge or test.

Figure 80. Schematic illustration of an IASCC model 


\section{Conclusions}

Slow-strain-rate tensile tests in BWR-like water (dissolved oxygen $\approx 8 \mathrm{ppm}$ ) and fractographic analysis were conducted on commercial and laboratory-fabricated model heats of austenitic stainless steels irradiated at $289^{\circ} \mathrm{C}$ in helium to $\approx 0.3 \times 10^{21} \mathrm{n} \mathrm{cm}^{-2}, \approx 0.9 \times 10^{21} \mathrm{n} \mathrm{cm}^{-2}$, and $\approx 2.0 \times 10^{21} \mathrm{n} \mathrm{cm}^{-2}(\mathrm{E}>1 \mathrm{MeV})(\approx 0.4,1.4$, and $\approx 3 \mathrm{dpa}$ ). Susceptibility of the steels to irradiation-assisted stress corrosion cracking (IASCC) was determined on the basis of the degree of intergranular fracture surface morphology. The investigation has led to the following conclusions.

(1) At $\approx 0.4 \mathrm{dpa}$, IASCC susceptibility was negligible for all tested heats, with the exception of a 316L-like high-purity alloy that contained $0.003 \mathrm{wt} . \% \mathrm{C}$ and $0.004 \mathrm{wt} \% \mathrm{~S}$. At 0.4 and $1.4 \mathrm{dpa}$, significant transgranular fracture was mixed with intergranular fracture. At $3 \mathrm{dpa}$, the tendency to transgranular stress corrosion cracking was negligible, and fracture surface morphology was either dominantly intergranular, as in field-cracked core internal components, or dominantly ductile or mixed. This behavior indicates that percent IGSCC determined at $\approx 3 \mathrm{dpa}$ is a good measure of IASCC susceptibility.

(2) At $1.4 \mathrm{dpa}$, a beneficial effect of a high concentration of Si (0.8-1.5 wt.\%) was observed. At 3 dpa, however, such effect was obscured by a strongly deleterious effect of S. From the standpoint of BWR IASCC, which usually occurs at $>2.5 \mathrm{dpa}$, typical variation in Si concentration in the range of 0.4$1.1 \mathrm{wt} . \%$ in Types 304, 316, and 348 steel is, therefore, not an important factor.

(3) Excellent resistance to IASCC was observed up to $\approx 3$ dpa for seven heats of Types 304 and 316 steel that contain very low $\mathrm{S}$ concentrations of $\leq 0.002 \mathrm{wt} . \%$ and for one heat of Type 348 steel that contains 0.005 wt. $\%$ S. Susceptibility of Types 304 and 316 steel that contain $>0.003$ wt.\% S increased drastically. These observations indicate that a sulfur-related critical phenomenon plays an important role in IASCC. A sufficiently low concentration of S (i.e., $<0.002 \mathrm{wt} . \%$ ) is the primary material factor necessary to ensure good resistance to IASCC.

(4) For Types 304L and 316L steel and their high-purity counterparts that contain $<0.025 \mathrm{wt} . \% \mathrm{C}$, a sulfur concentration of $<0.002 \mathrm{wt} . \%$ alone is not a sufficient material condition to ensure good resistance to IASCC. This is in distinct contrast to the behavior of the high-C counterparts (i.e., Types 304 and 316 steel that contain $<0.002 \mathrm{wt} . \% \mathrm{~S}$ and $>0.03 \mathrm{wt} . \% \mathrm{C}$ ), which exhibit good resistance to IASCC. The contrasting behavior indicates that, at sufficiently low concentrations of $\mathrm{S}$, a high concentration of $\mathrm{C}$ is beneficial. However, at S concentrations $>0.003$ wt. $\%$, the deleterious effect of $\mathrm{S}$ is so dominant that a high concentration of $\mathrm{C}$ is not an important factor.

(5) A two-dimensional map was developed in which susceptibility or resistance to IASCC is shown as a function of bulk concentrations of S and C. Data reported in the literature are consistent with the map. The map is helpful to predict relative IASCC susceptibility of Types 304 and 316 steel. A similar map is helpful to predict IASCC behavior of Type 348 steel.

(6) At S concentrations $>0.003$ wt. $\%$, IASCC susceptibility is thought to be influenced significantly by various material-related factors, such as the degree of $\mathrm{S}$ segregation to grain boundaries, annealing and cooling during fabrication, component thickness, presence of delta ferrite, Mn content, precipitation of 
sulfides, solubility of sulfides in the crack-tip water, and the thickness and morphology of the Cr oxide on the crack-tip grain boundary, which controls oxygen permeation and diffusion along the grain boundary.

(7) A model alloy that contains $\approx 3$ vol.\% globular-shaped delta ferrite and $\approx 21 \mathrm{wt} . \%$ Cr exhibited excellent resistance to IASCC, despite the fact that it contained a very high S concentration of $0.028 \mathrm{wt} \%$. The excellent resistance is attributed to the effect of delta ferrite, which traps $\mathrm{S}$ atoms, and the effect of a high concentration of $\mathrm{Cr}$, which forms $\mathrm{Cr}$ oxide and helps to block oxygen permeation and diffusion along the austenite grain boundary.

(8) Grain-boundary segregation of S was observed for BWR neutron absorber tubes. It is not clear, however, whether the S segregation occurred via a thermal process, an irradiation-induced process, or both.

(9) Based on the results of this study, an IASCC model has been developed. The model is based on several key steps known or postulated to occur at the crack-tip grain boundary, i.e., grain-boundary segregation of $\mathrm{Ni}$ and $\mathrm{S}$, preferential oxidation of $\mathrm{Cr}$ and $\mathrm{Fe}$ atoms over $\mathrm{Ni}$ atoms by oxygen that diffuses along the grain boundary, formation of a $\mathrm{Cr}$-Fe spinel oxide ahead of the crack tip, formation of Ni- and S-rich thin films and islands at the metal/spinel boundary, and melting or amorphization of the Ni-and S-rich thin films and islands. The model also predicts that the thickness and morphology of the Croxide that covers the crack-tip grain boundary strongly influence the rate of oxygen permeation and diffusion along the grain boundary. 


\section{References}

1. A. J. Jacobs, G. P. Wozadlo, K. Nakata, T. Yoshida, and I. Masaoka, "Radiation Effects on the Stress Corrosion and Other Selected Properties of Type-304 and Type-316 Stainless Steels," in Proc. 3rd Intl. Symp. Environmental Degradation of Materials in Nuclear Power Systems - Water Reactors, August 30-September 3, 1987, Traverse City, MI, G. J. Theus and J. R. Weeks, eds., The Metallurgical Society, Warrendale, PA, 1988, pp. 673-680.

2. F. Garzarolli, D. Alter, P. Dewes, and J. L. Nelson, "Deformability of Austenitic Stainless Steels and Ni-Base Alloys in the Core of a Boiling and a Pressurized Reactor," in Proc. 3rd Intl. Symp. Environmental Degradation of Materials in Nuclear Power Systems - Water Reactors, August 30September 3, 1987, Traverse City, MI, G. J. Theus and J. R. Weeks, eds., The Metallurgical Society, Warrendale, PA, 1988, pp. 657-664.

3. K. Fukuya, K. Nakata, and A. Horie, "An IASCC Study Using High Energy Ion Irradiation," in Proc. 5th Intl. Symp. on Environmental Degradation of Materials in Nuclear Power Systems - Water Reactors, August 25-29, 1991, Monterey, CA, D. Cubicciotti, E. P. Simonen, and R. Gold, eds., American Nuclear Society, La Grange Park, IL, 1992, 814-820.

4. M. E. Indig, J. L. Nelson, and G. P. Wozadlo, "Investigation of Protection Potential against IASCC," in Proc. 5th Intl. Symp. on Environmental Degradation of Materials in Nuclear Power Systems - Water Reactors, August 25-29, 1991, Monterey, CA, D. Cubicciotti, E. P. Simonen, and R. Gold, eds., American Nuclear Society, La Grange Park, IL, 1992, pp. 941-947.

5. M. Kodama, S. Nishimura, J. Morisawa, S. Shima, S. Suzuki, and M. Yamamoto, "Effects of Fluence and Dissolved Oxygen on IASCC in Austenitic Stainless Steels," in Proc. 5th Intl. Symp. on Environmental Degradation of Materials in Nuclear Power Systems - Water Reactors, August 25-29, 1991, Monterey, CA, D. Cubicciotti, E. P. Simonen, and R. Gold, eds., American Nuclear Society, La Grange Park, IL, 1992, pp. 948-954.

6. H. M. Chung, W. E. Ruther, J. E. Sanecki, A. G. Hins, and T. F. Kassner, "Effects of Water Chemistry on Intergranular Cracking of Irradiated Austenitic Stainless Steels," in Proc. 7th Int. Symp. on Environmental Degradation of Materials in Nuclear Power Systems - Water Reactors, August 7-10, 1995, Breckenridge, CO, G. Airey et al., eds., NACE International, Houston, 1995, pp. 1133-1143.

7. F. Garzarolli, P. Dewes, R. Hahn, and J. L. Nelson, "Deformability of High-Purity Stainless Steels and Ni-Base Alloys in the Core of a PWR," in Proc. 6th Intl. Symp. on Environmental Degradation of Materials in Nuclear Power Systems - Water Reactors, August 1-5, 1993, San Diego, CA, R. E. Gold and E. P. Simonen, eds., The Minerals, Metals, and Materials Society, Warrendale, PA, 1993, pp. 607613.

8. I. Suzuki, M. Koyama, H. Kanasaki, M. Akiyama, T. Okubo, Y. Mishima, and T. R. Mager, "Stress Corrosion Cracking of Irradiated Stainless Steels in Simulated PWR Primary Water," in Proc. 4th Intl. Conf. on Nuclear Engineering, 1996, Vol. 5, p. 205, American Society of Mechanical Engineers, New York. 
9. H. Kanasaki, T. Okubo, I. Satoh, M. Koyama, T. R. Mager, and R. G. Lott, "Fatigue and Stress Corrosion Cracking Behavior of Irradiated Stainless Steels in PWR Primary Water," in Proc. 5th Intl. Conf. on Nuclear Engineering, March 26-30, 1997, Nice, France.

10. J. Coneman, R. P. Shogan, D. R. Forsyth, I. L. W. Wilson, and H.-T. Tang, "Characterization of Baffle Former Bolts Removed from Service in US PWRs," in CD, Proc. 10th Intl. Conf. on Environmental Degradation of Materials in Nuclear Power Systems - Water Reactors, Aug. 5-9, 2001, Lake Tahoe, Nevada.

11. R. P. Shogan and T. R. Mager, "Susceptibility of Type 316 Stainless Steel to Irradiation-Assisted Stress Corrosion Cracking in a PWR Environment,“ in CD, Proc. 10th Intl. Conf. on Environmental Degradation of Materials in Nuclear Power Systems - Water Reactors, Aug. 5-9, 2001, Lake Tahoe, Nevada.

12. A. Jenssen, P. Efsing, K. Gott, and P.-O. Andersson, "Crack Growth Behavior of Irradiated Type 304L Stainless Steel in Simulated BWR Environment," in CD, Proc. 11th Intl. Conf. on Environmental Degradation of Materials in Nuclear Power Systems - Water Reactors, Stevenson, WA, Aug. 10-14, 2003, pp. 1015-1026.

13. A. J. Jacobs, G. P. Wozadlo, and G. M. Gordon, "Low Temperature Annealing - A Process to Mitigate IASCC," Corrosion 95, March 26-31, 1995, Orlando, Florida, NACE International, Houston, Texas.

14. A. J. Jacobs and S. Dumbill, "Effects of Low Temperature Annealing on the Microstructure and GrainBoundary Chemistry of Irradiated 304 SS and Correlation with IASCC," in Proc. 7th Int. Symp. on Environmental Degradation of Materials in Nuclear Power Systems - Water Reactors, August 7-10, 1995, Breckenridge, CO, G. Airey et al., eds., NACE International, Houston, 1995, pp. 1021-1031.

15. S. Katsura, Y. Ishiyama, N. Yokota, T. Kato, K. Nakata, K. Fukuya, H. Sakamoto, and K. Asano, "Post-Irradiation Annealing Effects of Austenitic SS in IASCC," Corrosion 98, NACE International, Houston, TX, 1998, Paper \#0132.

16. K. Fukuya, M. Nakano, K. Fujii, M. Kodama, T. Torimaru," Effects of Post-Irradiation Annealing on Radiation-Induced Material Changes and IASCC Susceptibility in PWR-Irradiated Stainless Steels," in CD-ROM Proc. 11th Intl. Conf. on Environmental Degradation of Materials in Nuclear Power Systems - Water Reactors, Stevenson, WA, Aug. 10-14, 2003, pp. 1153-1163.

17. J. T. Busby, G. S. Was, and E. A. Kenik, "Isolation of the Role of Radiation-Induced Segregation in Irradiation-Assisted Stress Corrosion Cracking of Proton-Irradiated Austenitic Stainless Steels," in CDROM Proc. 10th Intl. Conf. on Environmental Degradation of Materials in Nuclear Power Systems Water Reactors, Aug. 5-9, 2001, Lake Tahoe, Nevada.

18. H. M. Chung, W. E. Ruther, J. E. Sanecki, A. G. Hins, and T. F. Kassner, "Stress Corrosion Cracking Susceptibility of Irradiated Type 304 Stainless Steels," in Effects of Radiation on Materials: 16th Int. Symp., ASTM STP 1175, June 23-25, 1992, Aurora, CO, A. S. Kumar, D. S. Gelles, R. K. Nanstad, and T. A. Little, eds., American Society for Testing and Materials, Philadelphia, 1993, pp. 851-869. 
19. H. M. Chung, W. E. Ruther, J. E. Sanecki, and T. F. Kassner, "Grain-Boundary Microchemistry and Intergranular Cracking of Irradiated Austenitic Stainless Steels," in Proc. 6th Intl. Symp. on Environmental Degradation of Materials in Nuclear Power Systems - Water Reactors, August 1-5, 1993, San Diego, CA, R. E. Gold and E. P. Simonen, eds., The Minerals, Metals, and Materials Society, Warrendale, PA, 1993, pp. 511-519.

20. K. Fukuya, S. Shima, K. Nakata, S. Kasahara, A. J. Jacobs, G. P. Wozadlo, S. Suzuki and M. Kitamura, "Mechanical Properties and IASCC Susceptibility in Irradiated Stainless Steel," in Proc. 6th Intl. Symp. on Environmental Degradation of Materials in Nuclear Power Systems - Water Reactors, August 1-5, 1993, San Diego, CA, R. E. Gold and E. P. Simonen, eds., The Minerals, Metals, and Materials Society, Warrendale, PA, 1993,,pp. 565-572.

21. A. J. Jacobs, G. P. Wozadlo, T. Okada, S. Kawano, K. Nakata, S. Kasahara, and S. Suzuki, "The Correlation of Grain Boundary Composition in Irradiated Steel with IASCC Resistance," in Proc. 6th Intl. Symp. on Environmental Degradation of Materials in Nuclear Power Systems - Water Reactors, August 1-5, 1993, San Diego, CA, R. E. Gold and E. P. Simonen, eds., The Minerals, Metals, and Materials Society, Warrendale, PA, 1993, pp. 597-604.

22. M. Kodama, J. Morisawa, S. Nishimura, K. Asano, S. Shima, and K. Nakata, "Stress Corrosion Cracking and Intergranular Corrosion of Austenitic Stainless Steels Irradiated at $323 \mathrm{~K}$," J. Nucl. Mater. 212-215 (1994) 1509.

23. H. M. Chung, W. E. Ruther, J. E. Sanecki, A. G. Hins, N. J. Zaluzec, and T. F. Kassner, "IrradiationAssisted Stress Corrosion Cracking of Austenitic Stainless Steels: Recent Progress and New Approaches," J. Nucl. Mater. 239 (1996) 61.

24. T. Tsukada, Y. Miwa, H. Nakajima, and T. Kondo, "Effects of Minor Elements on IASCC of Type 316 Model Stainless Steels," in Proc. 8th Int. Symp. on Environmental Degradation of Materials in Nuclear Power Systems - Water Reactors, Aug. 10-14, 1997, Amelia Island, FL, S. M. Bruemmer, ed., American Nuclear Society, La Grange Park, IL, 1997, pp. 795-802.

25. J. M. Cookson, G. S. Was, and P. L. Andresen, "Oxide-Induced Initiation of Stress Corrosion Cracking in Irradiated Stainless Steels," Corrosion 54 (1998) 299.

26. H. M. Chung, J.-H. Park, J. E. Sanecki, N. J. Zaluzec, M. S. Yu, and T. T. Yang, "Cracking Mechanism of Type 304L Stainless Steel Core Shroud Welds," in Proc. 9th Intl. Symp. on Environmental Degradation of Materials in Nuclear Power Systems - Water Reactors, August 1-5, 1999, Newport Beach, CA, S. Bruemmer, P. Ford, and G. Was, eds., The Metallurgical Society, Warrendale, PA, 1999, pp. 973-985.

27. H. M. Chung, "Formation of Microcavities in BWR Core Shroud Welds," in CD-ROM Proc. 10th Intnl. Conf. on Environmental Degradation of Materials in Nuclear Power Systems - Water Reactors, August 5-9, 2001, Lake Tahoe, Nevada. 
28. S. Kasahara, K. Nakata, K. Fukuya, S. Shima, A. J. Jacobs, G. P. Wozadlo, and S. Suzuki, "The Effects of Minor Elements on IASCC Susceptibility in Austenitic Stainless Steels Irradiated with Neutrons," in Proc. 6th Intl. Symp. on Environmental Degradation of Materials in Nuclear Power Systems - Water Reactors, August 1-5, 1993, San Diego, CA, R. E. Gold and E. P. Simonen, eds., The Minerals, Metals, and Materials Society, Warrendale, PA, 1993, pp. 615-623.

29. T. Tsukada and Y. Miwa, "Stress Corrosion Cracking of Neutron Irradiated Stainless Steels," in Proc. 7th Int. Symp. on Environmental Degradation of Materials in Nuclear Power Systems - Water Reactors, August 7-10, 1995, Breckenridge, CO, G. Airey et al., eds., NACE International, Houston, 1995, pp. $1009-1018$.

30. A. Jenssen and L. G. Ljungberg, "Irradiation Assisted Stress Corrosion Cracking - Postirradiation CERT Tests of Stainless Steels in a BWR Test Loop," in Proc. 7th Int. Symp. on Environmental Degradation of Materials in Nuclear Power Systems - Water Reactors, August 7-10, 1995, Breckenridge, CO, G. Airey et al., eds., NACE International, Houston, 1995, pp. 1043-1052.

31. S. Dumbill, "Examination of Stress Corrosion Crack Tip Microstructures in Stainless Steel," SKI Report 01:35, Swedish Nuclear Power Inspectorate, September 2001.

32. S. Bruemmer and L. Thomas, "Stress Corrosion Crack-Tip Characteristics in Austenitic Stainless Steels Exposed to High-Temperature Water Environments," Handout presented at the International Cooperative Group on Environmentally Assisted Cracking, Kyungju, South Korea, April 2001.

33. L. Thomas and S. Bruemmer, "Analytical Transmission Microscopy (ATEM) Characterization of Stress Corrosion Cracks in LWR-Irradiated Austenitic Stainless Steel Components," EPRI-1003422, Electric Power Research Institute, Palo Alto, CA, May 2002.

34. L. Thomas and S. Bruemmer, "Analytical Transmission Microscopy (ATEM) Characterization of Stress Corrosion Cracks in LWR-Irradiated Austenitic Stainless Steel Components," in CD-ROM Proc. 11th Intl. Conf. on Environmental Degradation of Materials in Nuclear Power Systems - Water Reactors, Stevenson, WA, Aug. 10-14, 2003, pp. 1049-1061.

35. G. Taguchi, in "Quality Engineering Using Robust Design," M. S. Phadke, ed., Prentice Hall, Englewood Cliffs, NJ, 1989.

36. H. M. Chung, R. V. Strain, and W. J. Shack, "Irradiation-Assisted Stress Corrosion Cracking of Model Austenitic Stainless Steels," in Proc. 9th Intl. Symp. on Environmental Degradation of Materials in Nuclear Power Systems - Water Reactors, August 1-5, 1999, Newport Beach, CA, S. Bruemmer, P. Ford, and G. Was, eds., The Metallurgical Society, Warrendale, PA, 1999, pp. 931-939.

37. H. M. Chung, W. E. Ruther, and R. V. Strain, "Irradiation-Assisted Stress Corrosion Cracking of Model Austenitic Stainless Steels Irradiated in the Halden Reactor," NUREG/CR-5608, ANL-98/25, Argonne National Laboratory, March 1999. 
38. H. M. Chung, R. V. Strain, and W. J. Shack, "Irradiation-Assisted Stress Corrosion Cracking of Model Austenitic Stainless Steel Alloys," in CD-ROM Proc. 10th Intl. Conf. on Environmental Degradation of Materials in Nuclear Power Systems - Water Reactors, Aug. 5-9, 2001, Lake Tahoe, Nevada.

39. H. M. Chung, W. E. Ruther, R. V. Strain, and W. J. Shack, "Irradiation-Assisted Stress Corrosion Cracking of Model Austenitic Stainless Steel Alloys," NUREG/CR-6687, ANL-00/21, Argonne National Laboratory, October 2000.

40. H. M. Chung, R. V. Strain, D. L. Perry, and W. J. Shack, "Irradiation-Assisted Cracking of Austenitic Stainless Steels in Water and in Inert Environment," in CD-ROM Proc. 11th Intl. Conf. on Environmental Degradation of Materials in Nuclear Power Systems - Water Reactors, Stevenson, WA, Aug. 10-14, 2003, pp. 1164-1175.

41. Y. Tanaka, S. Suzuki, K. Fukuya, H. Sakamoto, M. Kodama, S. Nishimura, K. Nakata, and T. Kato, "IASCC Susceptibility of Type 304, 304L and 316 Stainless Steels," in Proc. 8th Int. Symp. on Environmental Degradation of Materials in Nuclear Power Systems - Water Reactors, , Aug. 10-14, 1997, Amelia Island, FL, S. M. Bruemmer, ed., American Nuclear Society, La Grange Park, IL, 1997, pp. 803-811.

42. F. Garzarolli, P. Dewes, R. Hahn, and J. L. Nelson, "In-Reactor Testing of IASCC Resistant Steels," in Proc. 7th Int. Symp. on Environmental Degradation of Materials in Nuclear Power Systems - Water Reactors, August 7-10, 1995, Breckenridge, CO, G. Airey et al., eds., NACE International, Houston, 1995, pp. 1055-1065.

43. A.-T. Shen and C. S. Chang, "IASCC Behavior of 304L Stainless Steel," in CD-ROM Proc. 11th Intl. Conf. on Environmental Degradation of Materials in Nuclear Power Systems - Water Reactors, Stevenson, WA, Aug. 10-14, 2003, pp. 986-994.

44. J. M. Cookson, D. L. Damcott, G. S. Was, and P. L. Anderson, "The Role of Microchemical and Microstructural Effects in the IASCC of High-Purity Austenitic Stainless Steels," in Proc. 6th Intl. Symp. on Environmental Degradation of Materials in Nuclear Power Systems - Water Reactors, August 1-5, 1993, San Diego, CA, R. E. Gold and E. P. Simonen, eds., The Minerals, Metals, and Materials Society, Warrendale, PA, 1993, pp. 573-580.

45. J. T. Busby and G. S. Was, "Irradiation-Assisted Stress Corrosion Cracking in Model Austenitic Alloys with Solute Additions," in CD-ROM Proc. 11th Intl. Conf. on Environmental Degradation of Materials in Nuclear Power Systems - Water Reactors, Stevenson, WA, Aug. 10-14, 2003, pp. 995-1014.

46. T. M. Karlsen and E. Hauso, "Qualification and Application of Instrumented Specimens for In-Core Studies on Cracking Behavior of Austenitic Stainless Steels," in Proc. 9th Intl. Symp. on Environmental Degradation of Materials in Nuclear Power Systems - Water Reactors, August 1-5, 1999, Newport Beach, CA, S. Bruemmer, P. Ford, and G. Was, eds., The Metallurgical Society, Warrendale, PA, 1999, pp. 951-961.

47. M. Hansen, "Constitution of Binary Alloys," McGraw Hill, New York, 1958, pp. 704-707. 
48. A. J. Jacobs, R. E. Clausing, M. K. Miller, and C. Shepherd, "Influence of Grain Boundary Composition on the IASCC Susceptibility of Type 348 Stainless Steel," in Proc. 4th Intl. Conf. on Environmental Degradation of Materials in Nuclear Power Systems - Water Reactors, Stevenson, WA, Aug. 10-14, 2003, pp. 14-21 to 14-44.

49. P. L. Andresen and C. L. Briant, "Role of S, P, and N Segregation on Intergranular Environmental Cracking of Stainless Steels in High Temperature Water," in Proc. 3rd Intl. Symp. on Environmental Degradation of Materials in Nuclear Power Systems - Water Reactors, August 30-September 3, 1987, Traverse City, MI, G. J. Theus and J. R. Weeks, eds., The Metallurgical Society, Warrendale, PA, 1988, pp. 371-381.

50. J. K. Heuer, P. R. Okamoto, N. Q. Lam, J. F. Stubbins, "Disorder-Induced Melting in Nickel: Implication to Intergranular Sulfur Embrittlement," J. Nucl. Mater. 301 (2002) 129-141.

51. P. R. Okamoto, J. K. Heuer, and N. Q. Lam, "Is Segregation-Induced Grain Boundary Embrittlement a Polymorphous Melting Process?" in CD-ROM Proc. 2003 TMS Spring Meeting, March 2-6, 2003, San Diego, California, NACE International, Houston, Texas.

52. K. Hide, T. Onchi, M. Mayazumi, and S. Dumbill, "Correlation of Microstructure and IGSCC Behavior for Irradiated Thermally Sensitized Type 304 Stainless Steels, “ in CD-ROM Proc. 10th Intl. Conf. on Environmental Degradation of Materials in Nuclear Power Systems - Water Reactors, Aug. 5-9, 2001, Lake Tahoe, Nevada.

53. T. Onchi, K. Dohi, and N. Soneda, "Neutron Fluence Dependent Intergranular Cracking of Thermally Sensitized Type 304 Stainless Steel at $290^{\circ} \mathrm{C}$ in Inert Gas and in Water," in CD-ROM Proc. 11th Intl. Conf. on Environmental Degradation of Materials in Nuclear Power Systems - Water Reactors, Stevenson, WA, Aug. 10-14, 2003, pp. 1111-1120.

54. H. M. Chung, J.-H. Park, W. E. Ruther, J. E. Sanecki, R. V. Strain, and N. J. Zaluzec, "Stress Corrosion Cracking Of Austenitic Stainless Steel Core Internal Welds," Corrosion '99, April 25-30, 1999, San Antonio; Paper No. 443.

55. H. M. Chung, D. L. Perry, and W. J. Shack, "Sulfur in Austenitic Stainless Steel and IrradiationAssisted Stress Corrosion Cracking," Corrosion 2003, March 16-20, San Diego, CA, Paper \#3662.

56. Proc. Intl. Symposium on: "Sulfide Inclusions in Steel," November 7-8, 1974, Port Chester, New York, J. J. de Barbadillo and E. Snape, eds., American Society of Metals, Warrendale, Pennsylvania.

57. H. M. Chung, J. E. Sanecki, and F. A. Garner, "Radiation-Induced Instability of MnS Precipitates and Its Possible Consequences on Irradiation-Induced Stress Corrosion Cracking of Austenitic Stainless Steels," in Effects of Radiation on Materials: 18th Intl. Symp., June 23-25, 1996, Hyannis, MA, ASTM STP 1325, R. K. Nanstad, M. L. Hamilton, A. S. Kumar, and F. A. Garner, eds., American Society for Testing and Material, 1999, pp. 647-658.

58. M. F. Ashby and F. Spaegen, "A New Model for the Structure of Grain Boundaries: Packing of Polyhedra," Scripta Met. 12 (1978) 193. 


\begin{tabular}{|c|c|c|}
\hline 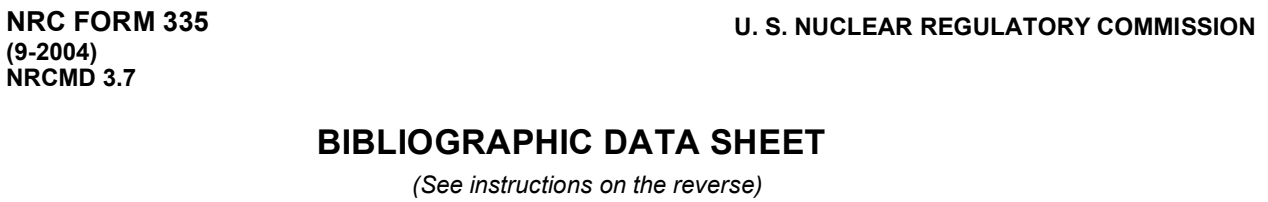 & \multicolumn{2}{|c|}{$\begin{array}{l}\text { 1. REPORT NUMBER } \\
\text { (Assigned by NRC. Add Vol., Supp., Rev., } \\
\text { and Addendum Numbers, if any.) }\end{array}$} \\
\hline \multirow{3}{*}{$\begin{array}{l}\text { 2. TITLE AND SUBTITLE } \\
\text { Irradiation-Assisted Stress Corrosion Cracking Behavior of Austenitic Stainless Steels } \\
\text { Applicable to LWR Core Internals }\end{array}$} & \multicolumn{2}{|c|}{ 3. DATE REPORT PUBLISHED } \\
\hline & $\begin{array}{l}\text { MONTH } \\
\text { March }\end{array}$ & $2005^{\text {YEAR }}$ \\
\hline & \multicolumn{2}{|c|}{$\begin{array}{l}\text { 4. FIN OR GRANT NUMBER } \\
\text { Y6388 }\end{array}$} \\
\hline \multirow[b]{2}{*}{ H. M. Chung and W. J. Shack } & \multicolumn{2}{|c|}{$\begin{array}{l}\text { 6. TYPE OF REPORT } \\
\text { Technical; Topical }\end{array}$} \\
\hline & \multicolumn{2}{|c|}{ 7. PERIOD COVERED (Inclusive Dates) } \\
\hline
\end{tabular}

Argonne National Laboratory

9700 South Cass Avenue

Argonne, IL 60439

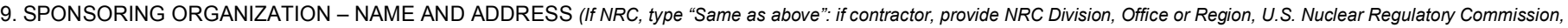
and mailing address.)

Division of Engineering Technology

Office of Nuclear Regulatory Research

U.S. Nuclear Regulatory Commission

Washington, DC 20555-0001

10. SUPPLEMENTARY NOTES

William H. Cullen, Jr., NRC Project Manager

11. ABSTRACT (200 words or less)

As LWRs age and neutron fluence increases, core internals become susceptible to irradiation-assisted stress corrosion cracking (IASCC). To better understand the mechanism of this type of degradation, austenitic stainless steels were irradiated in the Halden reactor under BWR conditions, and slow-strain-rate tensile tests were conducted in BWR-like water on 27 commercial and model laboratory heats. Fractographic and microchemical analyses were performed to characterize grain-boundary segregation of alloying and impurity elements. As neutron damage increases to $\approx 3 \mathrm{dpa}$, sulfur atoms play a dominant role in causing IASCC. To provide good resistance to IASCC in Types 304 or 316 steel, it is necessary to ensure a sulfur content of $<0.002 \mathrm{wt} . \%$ and a carbon content of $>0.03 \mathrm{wt} . \%$. A two-dimensional map was developed in which IASCC susceptibility or resistance of Types 304 or 316 is shown as a function of bulk concentrations of S and C. A similar map is applicable to Type 348 steel. Nine heats of Types 304, 316, and 348 steel were identified to be resistant to IASCC under BWR conditions. On the basis of the results of the stress-corrosion-cracking tests and the microstructural characterization, a mechanistic IASCC model was developed.

12. KEY WORDS/DESCRIPTORS (List words or phrases that will assist researchers in locating this report.)

Irradiation-induced degradation

Stress corrosion cracking

BWR core internals

Grain boundary segregation
13. AVAILABILITY STATEMENT unlimited

\begin{tabular}{l} 
14. SECURITY CLASSIFICATION \\
(This Page) \\
unclassified \\
\hline (This Report) \\
unclassified \\
15. NUMBER OF PAGES \\
101 \\
16.PRICE
\end{tabular}

PRINTED ON RECYCLED PAPER 